Otávio Beruski

Simulação e Modelagem de Células a

Combustível de Membrana de Troca Protônica

São Carlos 

Otávio Beruski

\section{Simulação e Modelagem de Células a Combustível de Membrana de Troca Protônica}

Tese apresentada ao Instituto de Química de São Carlos da Universidade de São Paulo como requisito parcial para a obtenção do título de doutor em ciências.

Área de Concentração: FísicoQuímica

Orientador: Prof. Dr. Joelma Perez 



\section{RESUMO}

Foram estudados dois sistemas referentes à células a combustível de membrana de troca protônica através de modelos computacionais. Um protótipo de célula foi utilizado para o estudo da dinâmica de fluidos, tendo sido utilizados resultados cedidos para a validação da formulação do escoamento e posterior quantificação da contribuição do mesmo no transporte de espécies nos meios porosos. Este mesmo sistema foi explorado quanto à geometria dos canais de escoamento, sendo possível estabelecer uma hierarquia de perda por sobrepotencial de concentração em função da estequiometria do reagente. Obteve-se que, para as estequiometrias recomendadas em uma célula real, os melhores desempenhos seriam atingidos por geometrias de serpentina simples e serpentina dupla, ou tripla, para o ânodo e cátodo, respectivamente. Uma célula completa também fora estudada, sendo comparada a resultados experimentais obtidos localmente. Foi observado que o modelo utilizado apresenta boa concordância com os aspectos globais do dispositivo real, enquanto que os aspectos locais são largamente mal representados pelo modelo computacional. Este modelo também fora utilizado para quantificar a contribuição do transporte convectivo na distribuição de reagentes, corroborando e estendendo os estudos realizados com o protótipo de célula. Em suma, são sugeridas as possibilidades e desafios de se utilizar modelos computacionais para células a combustível e sistemas similares, neste caso estabelecendo a conexão entre um protótipo e um dispositivo real.

Palavras-chave: célula a combustível, modelagem, simulação, convecção, transporte em meio poroso. 



\section{ABSTRACT}

Two systems related to proton-exchange membrane fuel cells were studied through computational models. A cell prototype was used to study fluid dynamics, where the fluid flow formulation was validated against provided experimental results, being later used to quantify its contribution to species transport in the porous media. This same systems was explored regarding its flow channel geometry, where it was possible to establish a hierarchy relative to the concentration overpotential loss as a function of the reactant stoichiometry. It was obtained that, for the recommended stoichiometries for a real cell, the best performance would be attained by a single serpentine and a double, or triple, serpentine geometries for the anode and cathode, respectively. A full cell was also studied, being compared against experimental results obtained locally. It was observed that the model shows good agreement with the global aspects of the real device, while the local aspects are widely misrepresented. This model was also used to quantify the contribution of convection to reactant distribution, corroborating and extending the studies performed with the cell prototype. In all, the possibilities and challenges concerning the use of computational models with fuel cells and similar systems are suggested, particularly by establishing the connection between a prototype and a real device.

Keywords: fuel cell, modeling, simulation, convection, transport in porous media. 

For the love of god, for the glory of satan. 



\section{AGRADECIMENTOS}

Agradeço a todos que de alguma maneira contribuíram ao meu trabalho e formação, através de exemplos positivos e/ou negativos.

Em particular, agradeço à Guan'Chuma por literalmente tudo, apesar da falta de reconhecimento por parte desta.

Agradeço a supervisão e orientação dadas pela Prof. Dr. Joelma Perez. Aos meus pais pelo apoio financeiro, e minha família de modo geral pelo apoio moral.

Agradeço à Mariana pelo apoio e companherismo nos momentos finais do projeto.

Agradeço aos amigos e amigas, de diversas nacionalidades e culturas, pela disposição em ouvir e compartilhar e pelo apoio moral. Em especial, agradeço Alana, Bruno, Carlos, Eduardo, Flávio, Guilherme, Henrique, Igor, Jéssica, João, Julia, Manuel, Marcelo, Murilo, Pietro, Rafael, Rafael (2), Régis e Salimeh.

Reconheço o auxílio do Grupo de Eletroquímica, do Instituto de Química de São Carlos e da Universidade de São Paulo ao providenciar a estrutura física para a elaboração do projeto de Doutorado. Reconheço a Fundação de Amparo à Pesquisa do Estado de São Paulo pelo concessão da bolsa de Doutorado Direto, projeto \#2013/11316-9. 

"Who do we think we are?"

J. S. Bell 



\section{LISTA DE ILUSTRAÇÕES}

Figura 1 - Esquema simplificado de uma célula a combustível, em particular uma PEMFC operando com $\mathrm{H}_{2}$ e $\mathrm{O}_{2}$, indicando as componentes usualmente utilizadoa: placas bipolares (BP), canais de escoamento (FC), membrana de troca protônica (PEM) e as camadas porosas de transporte (PTL), compostas do substrato macroporoso (MPS), camada microporosa (MPL) e camada catalítica (CL).

Figura 2 - Exemplos de a) curva de polarização e b) curva de potência para uma PEMFC típica, apontando as principais contribuições para a perda de desempenho: sobrepotencial de ativação $\eta_{\mathrm{ct}}$, sobrepotencial de queda ôhmica $\eta_{R}$, e sobrepotencial de transferência de massa $\eta_{\mathrm{mt}}$. As linhas tracejadas indicam um desempenho perfeito, dado pelo potencial termodinâmico $E^{0}$.

Figura 3 - Exemplo de aplicação do método de Euler para integração de uma função $f^{\prime}(x)$ conhecida sobre um intervalo $0 \leq x \leq 10$ : a) discretização utilizada $\delta x=1(\circ)$, condição inicial $f(x=0)=f_{i=1}=10$ e a função $f(x)$ a ser obtida (linha tracejada); b) integrações realizadas utilizando diferenças progressivas $(\circ)$, diferenças centrais $(\circ)$, e com diferenças progressivas porém com $\delta x=0.5(\circ)$. A linha sólida preta indica o $y=0$.

Figura 4 - Esquema da célula a combustível utilizada. a) Ordem de montagem dos componentes: i) placa externa, ii) isolante, iii) coletor de corrente, iv) auxílio para contato, v) placa de distribuição de corrente, vi) placa monopolar, vii) espaçador e viii) MEA, composto de dois eletrodos e a membrana polimérica. b) Detalhes da geometria de canal utilizado nas placas monopolares.

Figura 5 - Geometria utilizada no modelo Alfa: a) visão superior, mostrando a superfície que acompanha o meio do canal de escoamento; b) visão inferior, indicando a entrada e saída de gases; e c) parte da seção transversal, no plano $y z$, explicitando os domínios.

Figura 6 - Malha utilizada no modelo Alfa: a) visão superior, b) visão inferior, e c) visão lateral.

Figura 7 - Geometrias do FC adicionais utilizadas com o modelo Alfa: a) serpentina2 , b) serpentina-3, c) interdigital, e d) paralela.

Figura 8 - Geometria utilizada no modelo FC mkII: a) visão completa, b) geometria dos canais de escoamento utilizada, c) detalhes da geometria dos canais de escoamento, e d) detalhes da composição interna do modelo ao longo da espessura. . . . . . . . . . . . . . . . . 
Figura 9 - Malha utilizada no modelo FC mkII: a) visão completa, b) detalhe dos domínios internos, c) detalhe dos domínios de meios porosos. . . . . . 85

Figura 10 - Curvas de polarização experimentais obtidas com MEA \#1 (×) e \#2 $(+)$, para os conjuntos definidos na Tab. 1: I (azul), II (vermelho), III (preto) e IV (verde). a) Conjunto completo de dados, e b) conjuntos individuais. As barras de erro representam um desvio em relação à média.

Figura 11 - Superfícies de corrente experimentais médias, obtidas para os conjuntos I, para os MEAs \#1 (linha superior) e \#2 (linha inferior). Em cada coluna é indicado o valor de $I_{R}$ aplicado no dispositivo. As entradas de gases se dão pelo canto inferior esquerdo e direito para o cátodo e ânodo, respectivamente. As saídas se dão no canto superior direito e esquerdo, para o cátodo e ânodo respectivamente. . . . . . . . . . . . . 9

Figura 12 - Superfícies de corrente experimentais médias, obtidas para os conjuntos IV, para os MEAs \#1 (linha superior) e \#2 (linha inferior). Em cada coluna é indicado o valor de $I_{R}$ aplicado no dispositivo. As entradas de gases se dão pelo canto inferior esquerdo e direito para o cátodo e ânodo, respectivamente. As saídas se dão no canto superior direito e esquerdo, para o cátodo e ânodo respectivamente.

Figura 13 - Valores médios de $I_{i j}$ do MEA\#2 em função do MEA \#1, para valores representativos de $I_{R}$ : conjunto I (linha superior) e IV (linha inferior). As barras de erro representam um desvio em relação à média. As linhas vermelhas representam correlação linear perfeita.

Figura 14 - Distribuições de temperatura experimentais médias obtidas para o conjunto I, para os MEAs \#1 (linha superior) e \#2 (linha inferior): ab) e d-e) superfícies de temperatura para $I_{R}=0,1$ e 1 , respectivamente; e c) f) distribuições linearizadas para $I_{R}=0,1(\times), 0,5(\times)$ e $1(\times)$. Barras de erro representam um desvio em relação à média.

Figura 15 - Distribuições de temperatura experimentais médias obtidas para o conjunto IV, para os MEAs \#1 (linha superior) e \#2 (linha inferior): ab) e d-e) superfícies de temperatura para $I_{R}=0,1$ e 1 , respectivamente; e c) f) distribuições linearizadas para $I_{R}=0,1(\times), 0,5(\times)$ e $1(\times)$. Barras de erro representam um desvio em relação à média.

Figura 16 - Valores médios de $T_{i j}$ do MEA\#2 em função do MEA \#1, para valores representativos de $I_{R}$ : conjunto I (linha superior) e IV (linha inferior). As barras de erro representam um desvio em relação à média. As linhas vermelhas representam correlação linear perfeita. 
Figura 17 - Superfícies de pressão parcial de $\mathrm{O}_{3}$ para $Q=250$ (linha superior) e $450 \mathrm{~cm}^{3} \mathrm{~min}^{-1}$ (linha inferior): a) e e) resultados experimentais; b) e f) formulação SD; c) e g) formulação DB; e d) e h) formulação SB. . 100

Figura 18 - Variáveis globais em função de $Q$, simuladas com a formulação SD ( $\square$ ), $\mathrm{DB}(\triangle), \mathrm{SB}(\diamond)$, comparadas aos resultados experimentais (०): a) perda de carga, com barras de erro representando a incerteza das medidas; e b) consumo de $\mathrm{O}_{3}$, com barras de erro representando um desvio padrão nas medidas. . . . . . . . . . . . . . . . . . . . . . 101

Figura 19 - Perfil de pressão parcial normalizada de $\mathrm{O}_{3}$ ao longo do caminho do FC, para $Q=350 \mathrm{~cm}^{3} \mathrm{~min}^{-1}$ : dados simulados com as fomulações SD (azul), DB (preto) e SB (verde); e dados experimentais (vermelho). . . 103

Figura 20 - Superfícies de pressão parcial simuladas: a)-c) formulação SD; d)-f) formulação DB; e g)-i) formulação SB. Os valores de $Q$ e $k$ utilizados foram 200 e 50 (coluna esquerda), 350 e 100 (coluna central), e $450 \mathrm{~cm}^{3} \mathrm{~min}^{-1}$ e $500 \mathrm{~s}^{-1}$ (coluna direta) respectivamente. . . . . . . . 104

Figura 21 - Consumo ozônio em função da vazão, simulado com as formulações $\mathrm{SD}(\square)$, DB $(\triangle)$ e SB $(\diamond)$. Valores de $k$ utilizados: 50 (azul), 100 (verde), 250 (preto), e $500 \mathrm{~s}^{-1}$ (amarelo). Valores experimentais (o) foram incluídos como referência.

Figura 22 - Pressão parcial normalizada de $\mathrm{O}_{3}$ no domínio da CL ao longo do FC, para $Q=350$ (linha superior) e $Q=450 \mathrm{~cm}^{3} \mathrm{~min}^{-1}$ (linha inferior), usando as formulações SD (coluna esquerda), DB (coluna central) e SB (coluna direita). Os valores de $k$ contemplados são: 50 (azul), 100 (verde), 250 (preto) e $500 \mathrm{~s}^{-1}$ (amarelo). A normalização é feita em relação ao maior valor da respectiva superfície de pressão.

Figura 23 - Perfil da componente $x$ da velocidade de escoamento ao longo do eixo $z$, para $Q=350 \mathrm{~cm}^{3} \mathrm{~min}^{-1}$, obtido no meio da primeira seção horizontal do canal de escoamento: formulação SD (azul), DB (preto) e SB (verde). As linhas vermelhas tracejadas indicam a interface entre domínios. . . 109

Figura 24 - Sobrepotencial de concentração médio em função da corrente total equivalente, definidos nas Eqs. 4.18 e 4.20 respectivamente, para as formulações $\mathrm{SD}(\square)$, DB $(\triangle)$ e SB $(\diamond)$. Valores de $Q$ usados: 250 (azul), 350 (vermelho) e $450 \mathrm{~cm}^{3} \mathrm{~min}^{-1}$ (preto). 
Figura 25 - Campo de velocidades do escoamento na terceira volta do FC, para $Q=350 \mathrm{~cm}^{3} \mathrm{~min}^{-1}(\operatorname{Re} \approx 457)$. ’̀ esquerda, seção transversal à meia altura no plano $x y$, onde a superfície mapeia a componente $z$ de $\mathbf{u}$, enquanto as linhas de corrente mapeiam as componentes $x$ e $y$. À direita, seção transversal, no meio da volta, no plano $x z$, onde a superfície mapeia a componente $y$ de $\mathbf{u}$, enquanto as linhas de corrente mapeiam as componentes $x$ e $z$. . . . . . . . . . . . 112

Figura 26 - Superfícies de pressão parcial de $\mathrm{O}_{3}$ usando o modelo Alfa-mod: a) $Q=250$, b) 350 e c) $450 \mathrm{~cm}^{3} \mathrm{~min}^{-1}$.

Figura 27 - Diferença normalizada da pressão parcial entre os modelos Alfa-mod e Alfa, dada pela Eq. 4.22, para $Q=350 \mathrm{~cm}^{3} \min ^{-1}(\operatorname{Re} \approx 457)$. Ciano representa subestimativa, vermelho superestimativa, em relação ao modelo Alfa. A linha cinza representa a projeção do centro do FC.

Figura 28 - Transporte molar de ozônio, dado pela Eq. 4.23, para os modelos Alfa (preto) e Alfa-mod (vermelho): transporte total $(\diamond)$, convectivo $(\triangle)$ e difusivo $(\square) . \ldots \ldots \ldots$. . . . . . . . . . . . . . . . 114

Figura 29 - Sobrepotencial de concentração médio em função da corrente total equivalente, definidos nas Eqs. 4.18 e 4.20 respectivamente, para o modelo Alfa $(\triangle)$ e Alfa-mod $(\square)$. Valores de $Q$ usados: 250 (azul), 350 (vermelho) e $450 \mathrm{~cm}^{3} \mathrm{~min}^{-1}$ (preto).

Figura 30 - Razão volumétrica (Eq. 4.38) após a deformação do MPS, para as modificações a) III.a (IV.a) e b) III.b (IV.b). As superfícies foram obtidas no plano $x y$ imediatamente acima do domínio do FC. O contorno observado representa a projeção do domínio do FC. . . . . . . . . . . 116

Figura 31 - Superfícies de pressão parcial de $\mathrm{O}_{3}$ para $Q=350 \mathrm{~cm}^{3} \mathrm{~min}^{-1}$ para as diversas modificações descritas na Tab. 4. O resultado sem modificações (g) foi incluído a título de comparação.

Figura 32 - a) Perda de carga e b) consumo total de $\mathrm{O}_{3}$ em função de $Q$ para as diversas modificações descritas na Tab. 4: I ( $\square)$, III.a $(\diamond)$ e IV.a $(\triangle)$, com símbolos cheios; e II, III.b e IV.b com os mesmos respectivos símbolos porém vazios. Os resultados experimentais (o) e do modelo Alfa não modificado $(\bullet)$ foram incluídos a título de comparação. As barras de erro nos resultados experimentais representam a incerteza das medidas, no caso de $Q$ e $\Delta P$ e um desvio no caso de $\Delta \mathrm{O}_{3}$. Pode haver superposição de símbolos devido às escalas utilizadas.

Figura 33 - Desvios no consumo total de $\mathrm{O}_{3}$ em relação aos resultados experimentais, em função de $Q$ : modificação II $(\square)$ e IV.a $(\triangle$ ), para $k=256$ (azul) e $257 \mathrm{~s}^{-1}$ (preto). Os limites estabelecidos pelo desvios experimentais são dados por $(+) \ldots \ldots \ldots \ldots \ldots \ldots$ 
Figura 34 - Superfícies de pressão parcial de $\mathrm{O}_{3}$ para $Q=250$ (linha superior) e $450 \mathrm{~cm}^{3} \mathrm{~min}^{-1}$ (linha inferior), para as diferentes geometrias de canais usando o modelo Beta: a e e) serpentina-2, b e f) serpentina-3, c g) interdigital e $\mathbf{d}$ e $\mathbf{h}$ ) paralela. . . . . . . . . . . . . . . 122

Figura 35 - a) Perda de carga e b) consumo total de $\mathrm{O}_{3}$ em função da vazão para as geometrias de canal de escoamento avaliadas: serpentina-2 (०), serpentina-3 $(\square)$, interdigital $(\triangle)$ e paralela $(\diamond)$. São apresentados resultados para os modelos Alfa (símbolos vazios) e Beta (símbolos cheios).

Figura 36 - Diferença relativa das variáveis globais: a) perda de carga e b) consumo de $\mathrm{O}_{3}$; entre os modelos Beta e Alfa, dada pelas Eqs. 6.1 e 6.2, respectivamente. As geometrias avaliadas foram: serpentina-2 (०), serpentina-3 $(\square)$, interdigital $(\triangle)$ e paralela $(\diamond)$. As linhas sólidas indicam o limite de convergência das simulações, de $10^{-3}$.

Figura 37 - Trajetórias de $P_{\mathrm{O}_{3}}$ relativa entre canais de uma seção horizontal ao canal mais distante da entrada de gases para a mesma seção horizontal, para as geometrias a) serpentina-2, b) serpentina-3, c) interdigital e d) paralela. Os valores de vazão contemplados foram $Q=250$ (linhas sólidas), 350 (linhas tracejadas) e $450 \mathrm{~cm}^{3} \mathrm{~min}^{-1}$ (linhas pontilhadas). A distância ao canal de referência, em número de terraças, é dado como -4 (azul), -3 (vermelho), -2 (preto) e -1 (verde).

Figura 38 - a) Consumo de $\mathrm{O}_{3}$ para os modelos Beta (símbolos vazios) e Beta-mod (símbolos cheios), e b) diferença relativa de $\Delta \mathrm{O}_{3}$ entre os modelos (Eq. 6.3, em função da vazão $Q$. As geometrias são codificadas como: serpentina-2(०), serpentina-3 $(\square)$, interdigital $(\triangle)$ e paralela $(\diamond) . \quad$. . . 13

Figura 39 - Superfícies de $\boldsymbol{\Delta} \mathbf{P}_{\mathrm{O}_{3}}$, dada pela Eq. 78 para os modelos Beta-mod e Beta, com $Q=350 \mathrm{~cm}^{3} \mathrm{~min}^{-1}$ e a seguintes geometrias de FC: a) serpentina-2, b) serpentina-3, c) interdigital e d) paralela. $\mathrm{Na}$ codificação atual, ciano representa subestimativa, enquanto vermelho representa superestimativa de pressão parcial de $\mathrm{O}_{3}$ em relação ao modelo Beta. . . . . . . . . . . . . . . . . . 131

Figura 40 - Sobrepotencial de concentração médio em função da corrente total equivalente, definidos nas Eqs. 4.18 e 4.20 respectivamente: a) comparação entre as geometrias utilizadas com o modelo Beta, e b) comparação individual entre os modelos Beta (símbolos vazios) e Beta-mod (símbolos cheios): serpentina-2 (०), serpentina-3 $(\square)$, interdigital $(\triangle)$ e paralela $(\diamond)$. Os valores de $Q$ contemplados foram 250,350 e $450 \mathrm{~cm}^{3} \mathrm{~min}^{-1}$, com a tendência indicada pela seta em a). 
Figura 41 - a) Perda de potência $\eta_{C} \times I_{\mathrm{O}_{3}}$ em função de $I_{\mathrm{O}_{3}}$ e b) $\eta_{C}$ em função de $\lambda_{\mathrm{O}_{3}}$ (Eq. 6.4), para as geometrias estudadas com o modelo Beta: serpentina$2(\circ)$, serpentina-3 $(\square)$, interdigital $(\triangle)$ e paralela $(\diamond)$, com adição da geometria serpentina-1 $(\times)$. Foi utilizado o valor de $k=256,5 \mathrm{~s}^{-1}$ para o cálculo das curvas. . . . . . . . . . . . . . . . . . . . . . 135

Figura 42 - a) Curvas de polarização simuladas com o modelo FC mkII, para os conjuntos de vazão descritos na Tab. 1: I (o), II ( $\square)$, III $(\triangle)$ e IV $(\diamond)$. b) Comparação individual dos resultados simulados com resultados experimentais $(x)$. O conjunto de vazões é indicado no título de cada subgráfico. As barras de erro nos resultados experimentais representam um desvio em relação à média.

Figura 43 - Resíduo relativo entre curvas de polarização simuladas pelo modelo FC mkII e experimentais. Conjunto de vazão são indicados no título de cada subgráfico: I $(\times)$, II $(\times)$, III $(\times)$ e IV $(\times)$. A linha sólida preta indica $\Delta_{\text {res }} E=0$, enquanto as linhas tracejadas indicam o limite relativo de convergência do modelo, $10^{-2}$. As barras de erro são os desvios experimentais em relação à média, normalizados pelos respectivos valores simulados.

Figura 44 - Superfícies de corrente experimentais (linha superior) e simuladas (linha inferior) para valores representativos de $I_{R}$ dos conjuntos I, II e III, indicados em cada coluna. As entradas de gases se dão pelo canto inferior esquerdo e direito para o cátodo e ânodo, respectivamente. As saídas se são no canto superior direito e esquerdo, para o cátodo e ânodo, respectivamente. . . . . . . . . . . . . . . . . . . . . . . . 141

Figura 45 - Distribuições de corrente linearizadas, para o conjunto de vazões II, experimentais $(\times)$ e computacionais $(\square)$, para as correntes a) $I=1, \mathbf{b}$ ) 5 e c) $10 \mathrm{~A}$. As barras de erro nos resultados experimentais representam um desvio em relação à média. A entrada de gases catódica se dá em altos valores da abscissa, enquanto a saída se dá para baixos valores. . 142

Figura 46 - a) Erro médio (ME, símbolos vazios) e erro absoluto médio (MEA, símbolos cheios) e b) coeficiente de correlação de Pearson (R), em função da corrente total aplicada, entre as distribuições linearizadas de corrente computacionais e experimentais: conjunto I (o), II ( $\square)$, III $(\triangle)$, e IV $(\diamond)$. A linha sólida preta em a) representa erro nulo. 
Figura 47 - Resíduo relativo entre as distribuições de corrente linearizadas simuladas pelo modelo FC mkII e experimentais, usando o conjunto de vazões II: a) $I=1$, b) 5 e c) 10 A. A linha sólida preta indica $\Delta_{\text {res }} I=0$, enquanto as linhas tracejadas indicam o limite relativo de convergência do modelo, $10^{-2}$. As barras de erro são os desvios experimentais em relação à média, normalizados pelos respectivos valores simulados. . . 144

Figura 48 - a) Distribuições de corrente linearizada simulada com o modelo FC $\operatorname{mkII}(\triangle)$ e experimentais $(\times)$, e b) resíduo relativo entre as curvas de a). Conjunto de vazões III e corrente total $I=20 \mathrm{~A}$. As barras de erro em a) representam um desvio em relação à média, enquanto as barras de erro em b) são os desvios experimentais normalizados pelos respectivos valores simulados. A linha sólida preta indica $\Delta_{\text {res }} I=0$, enquanto as linhas tracejadas indicam o limite relativo de convergência do modelo, $10^{-2}$. As barras de erro são os desvios experimentais em relação à média, normalizados pelos respectivos valores simulados.

Figura 49 - a) Curvas de temperatura do compartimento anódico obtidas ao longo da curva de polarização, computacionais e experimentais $(\times)$, para os conjuntos de vazão I (o), II $(\square)$, III $(\triangle)$, e IV $(\diamond$. b) Comparação individual dos resultados simulados aos experimentais. O conjunto de vazões é indicado no título de cada subgráfico. As barras de erro nos resultados experimentais representam um desvio em relação à média. . 146

Figura 50 - a) Curvas de temperatura do compartimento catódico obtidas ao longo da curva de polarização, computacionais e experimentais $(\times)$, para os conjuntos de vazão I (o), II $(\square)$, III $(\triangle)$, e IV ( . b) Comparação individual dos resultados simulados aos experimentais. O conjunto de vazões é indicado no título de cada subgráfico. As barras de erro nos resultados experimentais representam um desvio em relação à média. . 147

Figura 51 - Resíduo relativo entre curvas de temperaturas a) anódicas e b) catódicas, simuladas pelo modelo FC mkII e experimentais. Conjunto de vazão são indicados no título de cada subgráfico: I $(\times)$, II $(\times)$, III $(\times)$ e IV $(\times)$. A linha sólida preta indica $\Delta_{\text {res }} T=0$. As barras de erro são os desvios experimentais em relação à média, normalizados pelos respectivos valores simulados. . . . . . . . . . . . . . . . . . 148

Figura 52 - Superfícies de desvios de temperatura experimentais (linha superior) e simuladas (linha inferior) para valores representativos de $I_{R}$ dos conjuntos I, II e III, conforme indicado em cada superfície. As entradas de gases se dão pelo canto inferior esquerdo e direito para o cátodo e ânodo, respectivamente. As saída se dão no canto superior direito e esquerdo, para o cátodo e ânodo, respectivamente. . . . . . . . . . 150 
Figura 53 - Distribuições de desvios de temperatura linearizadas, para o conjunto de vazões II, experimentais $(\times)$ e computacionais $(\square)$, para as correntes a) $I=1$, b) 5, d) 10 A. As barras de erro nos resultados experimentais representam um desvio em relação à média. A entrada de gases catódica se dá em altos valores da abcissa, enquanto a saída se dá para baixos valores.

Figura 54 - a) Erro médio (ME, símbolos vazios) e erro absoluto médio (MEA, símbolos cheios) e b) coeficiente de correlação de Pearson (R), em função da corrente total aplicada, entre as distribuições linearizadas de desvio de temperatura computacionais e experimentais: conjunto I (o), II $(\square)$, III $(\triangle)$, e IV $(\diamond)$. A linha sólida preta indica erro nulo. . . . . 152

Figura 55 - Curvas de polarização simuladas com o modelo FC mkII, usando as formulações DB (símbolos vazios) e SD (símbolos cheios), para os conjuntos de vazão a) I (o) e II ( $\square)$, e b) III $(\triangle)$ e IV $(\diamond)$, conforme indicados no título de cada subgráfico. Os resultados experimentais (×) são incluídos como referência. As barras de erro nos resultados experimentais representam um desvio em relação à média. . . . . . . . 158

Figura 56 - Distribuições de corrente linearizadas simuladas com o modelo FC mkII, com as formulações DB (símbolos vazios) e SD (símbolos cheios), para os conjuntos de vazões a) I (o), b) II $(\square)$, c) III $(\triangle)$ e d) IV $(\diamond)$. Resultados experimentais $(\times \mathrm{e} \times)$ são incluídos como referência. As barras de erro nos resultados experimentais representam um desvio em relação à média. . . . . . . . . . . . . . . . . . . . . . . . . . . . . . . 160

Figura 57 - Curvas de temperatura dos compartimentos a) anódico e b) catódico, obtidas ao longo da curva de polarização, para as formulações DB (símbolos vazios) e SD (símbolos cheios). Os conjuntos de vazão são indicados no título de cada subgráfico: I ( ○), II $(\square)$, III $(\triangle)$, e IV ( . Os resultados experimentais são incluídos como referência. As barras de erro nos resultados experimentais representam um desvio em relação à média.

Figura 58 - Distribuições de calor linearizadas simuladas com o modelo FC mkII, com as formulações DB (símbolos vazios) e SD (símbolos cheios), para os conjuntos de vazões a) I (o), b) II $(\square)$, c) III $(\triangle)$ e d) IV $(\diamond) . \quad$. . 162

Figura 59 - Sobrepotenciais médios a) anódico e b) catódico para as formulações DB (símbolos vazios) e SD (símbolos cheios). Os conjuntos de vazões são indicados no título de cada subgráfico: I (o), II ( $\square)$, III $(\triangle)$ e IV $(\diamond) .164$ 
Figura 60 - Curvas de polarização simuladas com o modelos FC mkII (símbolos vazios) e mkII-mod (símbolos cheios), para os conjuntos de vazão a) I (o) e II $(\square)$, e b) III $(\triangle)$ e IV $(\diamond)$, conforme indicados no título de cada subgráfico. Os resultados experimentais $(\times)$ são incluídos como referência. As barras de erro nos resultados experimentais representam um desvio em relação à média. . . . . . . . . . . . . . . . . . . . . 164

Figura 61 - Distribuições de corrente linearizadas simuladas com o modelos FC mkII (símbolos vazios) e mkII-mod (símbolos cheios), para os conjuntos de vazões a) I (o), b) II $(\square)$, c) III $(\triangle)$ e d) IV $(\diamond)$. Resultados experimentais $(\times \mathrm{e} \times)$ são incluídos como referência. As barras de erro nos resultados experimentais representam um desvio em relação à média. 166

Figura 62 - Sobrepotenciais médios a) anódico e b) catódico para os modelos FC mkII (símbolos vazios) e mkII-mod (símbolos cheios). Os conjuntos de vazões são indicados no título de cada subgráfico: I (o), II ( $\square)$, III $(\triangle)$

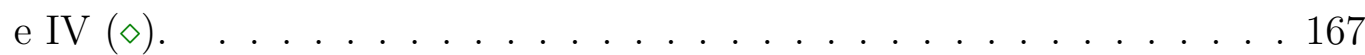

Figura 63 - Curvas de temperatura dos compartimentos a) anódico e b) catódico, obtidas ao longo da curva de polarização, para os modelos FC mkII (símbolos vazios) e mkII-mod (símbolos cheios). Os conjuntos de vazão são indicados no título de cada subgráfico: I (o), II $(\square)$, III $(\triangle)$, e IV $(\diamond)$. Os resultados experimentais são incluídos como referência. As barras de erro nos resultados experimentais representam um desvio em relação à média.

Figura 64 - Distribuições de calor linearizadas simuladas com os modelos FC mkII (símbolos vazios) e mkII-mod (símbolos cheios), para os conjuntos de vazões a) I (o), b) II ( $\square)$, c) III $(\triangle)$ e d) IV $(\diamond)$.

Figura 65 - Exemplo de geometria utilizada na simulação do experimento de descarga, sendo indicados a entrada e saída de fluido. 189

Figura 66 - Vista lateral da geometria do modelo Alfa, evidenciando as diferentes malhas descritas na Tab. 21: a) I, b) II, c) III e d) IV. . . . . . . . . 200

Figura 67 - a) Perda de carga em função da vazão de entrada para as diferentes malhas utilizadas com o modelo Alfa: I ( $\square$ ), II ( $\square$ ), III ( $\square$ ), e IV $(\square)$. Os valores experimentais (o) foram incluídos como referência. b) Perda de carga relativa em função da vazão de entrada: II - I ( $\square$ ), III - II ( $\square)$, IV - III ( $\square$ ). A diferença é relativa à malha anterior. Os resultados experimentais ( $\circ$ ) representam a incerteza das medidas relativas à magnitude. . . . . . . . . . . . . . . . . . . . 201 
Figura 68 - a) Consumo de ozônio em função da vazão de entrada para as diferentes malhas utilizadas com o modelo Alfa: I ( $\square$ ), II ( $\square$ ), III ( $\square$ ), e IV $(\square)$. Os valores experimentais (o) foram incluídos como referência. b) Consumo de ozônio relativo, absoluto, em função da vazão de entrada: II - I ( $\square)$, III - II ( $\square)$, IV - III ( $\square)$. A diferença é relativa à malha anterior. Os resultados experimentais (o) representam o desvio padrão das medidas relativas à magnitude.

Figura 69 - Histogramas da diferença relativa de pressão parcial de ozônio entre pares de malhas: a) II - I; b) III - II; e c) IV - III. As linhas tracejadas representam o erro médio (ME), erro máximo (MAE), erro médio absoluto (MEA) e um intervalo de desvio padrão (STD). Os histograma foram criados a partir de matrizes $536 \times 500$, sendo os valores organizados em 100 colunas.

Figura 70 - Perfis da magnitude da velocidade de escoamento ao longo dos eixos a) $x$ e b) $z$, na região de entrada do domínio do canal de escoamento, para as condições CV e MF. A linha tracejada em b) indica a interface entre as seções cílindrica e retangular do canal de escoamento. . . . . 206

Figura 71 - a) Perda de carga em função da vazão, para as condições de entrada MF $(\triangle)$ e $\mathrm{CV}(\square)$, usando diferentes malhas no modelo Alfa: I $(\triangle)$, II $(\triangle)$, III $(\triangle)$, e IV $(\triangle)$. Os valores experimentais (o) foram incluídos como referência. b) Perda de carga relativa em função da vazão. Diferença relativa entre condições MF e CV, para as malhas: I ( $\square)$, II ( $\square)$, III $(\square)$, e IV $(\square)$. Diferença relativa entre pares de malhas para a condição MF: II - I $(\triangle)$, III - II $(\triangle)$, IV - III $(\triangle)$. A diferença é relativa à malha anterior. Os resultados experimentais (०) representam a incerteza das medidas relativas à magnitude.

Figura 72 - a) Consumo de ozônio em função da vazão, para as condições de entrada $\operatorname{MF}(\triangle)$ e $\mathrm{CV}(\square)$, usando diferentes malhas no modelo Alfa: I $(\triangle)$, II $(\triangle)$, III $(\triangle)$, e IV $(\triangle)$. Os valores experimentais (o) foram incluídos como referência. b) Consumo de ozônio relativo em função da vazão. Diferença relativa entre condições MF e CV, para as malhas: I ( $\square$ ), II $(\square)$, III ( $\square)$, e IV $(\square)$. Diferença relativa entre pares de malhas para a condição MF: II - I $(\triangle)$, III - II $(\triangle)$, IV - III $(\triangle)$. A diferença é relativa à malha anterior. Os resultados experimentais (o) representam a incerteza das medidas relativas à magnitude. . . . . . . . . . . . . 208 
Figura 73 - Histogramas da diferença relativa de pressão parcial de ozônio entre condições de entrada MF e CV, para as malhas: a) I, b) II, c) III, e d) IV. As linhas representam o erro médio (ME), erro máximo (MAE), erro médio absoluto (MEA) e um intervalo de desvio padrão (STD). Os histograma foram criados a partir de matrizes $536 \times 500$, sendo os valores organizados em 100 colunas. . . . . . . . . . . . . . . 209

Figura 74 - Desvio de temperatura catódica em relação à $T_{0}(\times)$ em função do fluxo total de calor simulado (coluna esquerda), usando os modelos: Eq. E.3

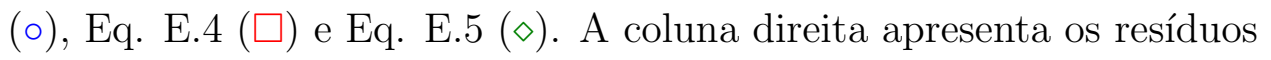
dos respectivos modelos, sendo que a linha sólida preta indica resíduo igual a zero. As barras de erro representam um desvio em relação à média experimental. . . . . . . . . . . . . . . . . 213

Figura 75 - Desvio de temperatura catódica em relação à $T_{0}(\times)$ em função do fluxo total de calor simulado (coluna esquerda), usando os modelos: Eq.

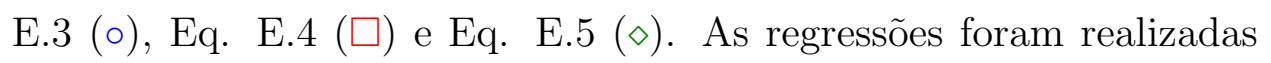
desconsiderando os valores de $\Delta T_{\text {cat }}$ do conjunto de vazões I. A coluna direita apresenta os resíduos dos respectivos modelos, sendo que a linha sólida preta indica resíduo igual a zero. As barras de erro representam um desvio em relação à média experimental.

Figura 76 - Distribuições de corrente linearizadas computacionais, para os conjunto de vazões I $(\circ)$, II $(\square)$, III $(\triangle)$ e IV $(\diamond)$; e os respectivos valores experimentais $(\times \mathrm{e} \times)$. Os valores de corrente relativa são dados no título de cada gráfico. As barras de erro nos resultados experimentais representam um desvio em relação à média. . . . . . . . . . . . . . . 218

Figura 77 - Resíduo normalizado para distribuições de corrente, para os conjunto de vazões I $(\times)$, II $(\times)$, III $(x)$ e IV $(x)$. Os valores de corrente relativa são dados no título de cada gráfico. As barras de erro representam um desvio experimental, normalizados pelo respectivo valor simulado. A linha contínua preta indica $\Delta_{\text {res }} I=0$, enquanto as linhas tracejadas indicam o limite relativo de convergência do modelo, $10^{-2}$. . . . . . . 219

Figura 78 - Distribuições de desvios de temperatura linearizadas computacionais, para os conjunto de vazões I (०), II $(\square)$, III $(\triangle)$ e IV $(\diamond)$; e os respectivos valores experimentais $(\times \mathrm{e} \times)$. Os valores de corrente relativa são dados no título de cada gráfico. As barras de erro nos resultados experimentais representam um desvio em relação à média. . . . . . . . . . . . . . . 222 



\section{LISTA DE TABELAS}

Tabela 1 - Parametrização adotada para curvas de polarização . . . . . . . . . . . 51

Tabela 2 - Dimensões utilizadas na geometria do modelo Alfa durante a validação. 56

Tabela 3 - Parâmetros utilizados no modelo Alfa durante a validação. . . . . . . . 58

Tabela 4 - Modificações utilizadas no modelo Alfa para a compressão dos meios porosos. . . . . . . . . . . . . . . . 6 6 . . . .

Tabela 5 - Parâmetros utilizados para o cálculo de deformação mecânica. . . . . . 65

Tabela 6 - Dimensões utilizadas na geometria do modelo FC mkII. . . . . . . . . . 70

Tabela 7 - Parâmetros necessários ao transporte de momento no modelo FC mkII. 71

Tabela 8 - Parâmetros necessários ao transporte de calor no modelo FC mkII. . . 74

Tabela 9 - Parâmetros necessários ao transporte de carga no modelo FC mkII. . . 76

Tabela 10 - Especificações para tamanhos de elementos pré-estabelecidos para a geração da malha do modelo FC mkII. . . . . . . . . . . . . . . . . . . 84

Tabela 11 - Temperaturas médias registradas durante a coleta de dados experimentais. 89

Tabela 12 - Valores médios para o potencial de equilíbrio e polarização por queda ôhmica para os conjuntos de dados experimentais. . . . . . . . . . . 90

Tabela 13 - Coeficientes de Pearson (R) entre distribuições de corrente dos MEAs \#1 e \#2, para valores representativos de $I$. . . . . . . . . . . . . . . . 93

Tabela 14 - Coeficientes de Pearson $(\mathrm{R})$ entre distribuições de temperatura dos MEAs \#1 e \#2, para valores representativos de $I$. . . . . . . . . . . . 97

Tabela 15 - Descritores estatísticos utilizados na comparação entre as formulações SD e DB em relação aos dados de $\Delta \mathrm{O}_{3}(Q)$ apresentados Fig. 18b. . . 102

Tabela 16 - Descritores estatísticos de $\mathbf{P}_{\mathrm{O}_{3}}$ para as diferentes geometrias avaliadas, utilizando os modelos Alfa e Beta e valores selecionados de vazão. . . 124

Tabela 17 - Grandezas analisadas para avaliação do desempenho do modelo FC mk2 em relação às curvas de polarização. . . . . . . . . . . . . . . . 139

Tabela 18 - Grandezas analisadas para avaliação do desempenho do modelo FC mk2 em relação às curvas de temperaturas anódica e catódica. . . . . 147

Tabela 19 - Grandezas analisadas para comparação entre as formulações de transporte de momento usadas no modelo $\mathrm{FC}$ mk2, em relação às curvas de polarização. . . . . . . . . . . . . . . . . . . . 159

Tabela 20 - Razão entre os sobrepotenciais médios, anódico e catódico, dos modelos mkII e mkII-mod. . . . . . . . . . . . . . . . . . . . . 167

Tabela 21 - Parâmetros utilizados nas malhas analisadas para o modelo Alfa. . . . 199

Tabela 22 - Coeficientes e resultados estatísticos das regressões não-lineares da variação da temperatura catódica experimental em função do fluxo total de calor simulado. . . . . . . . . . . . . . . . . . . . . 214 



\section{LISTA DE ABREVIATURAS E SIGLAS}

PEMFC Célula a combustível de membrana de troca protônica

PEFC Célula a combustível de eletrólito polimérico

BP Placa bipolar

FC Canal de escoamento

PEM Membrana de troca protônica

MPS Substrato macroporoso

MPL Camada microporosa

CL Camada catalítica

MEA Conjunto membrana-eletrodos

CFD Dinâmica de fluidos computacional

DB Darcy-Brinkman

SD Stokes-Darcy

SB Stokes-Brinkman

MAE Erro médio absoluto

MaxE $\quad$ Erro máximo

ME $\quad$ Erro médio

STD Desvio padrão 



\section{SUMÁRIO}

INTRODUÇÃO $\ldots \ldots \ldots \ldots \ldots \ldots \ldots \ldots$

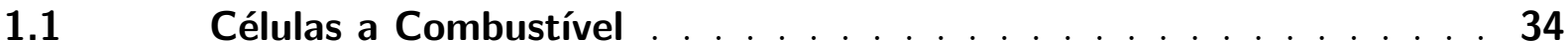

$1.2 \quad$ Simulação de Processos Físicos . . . . . . . . . . . . . . 38

2 OBJETIVOS .................45

3 METODOLOGIAS EXPERIMENTAIS . . . . . . . . . . 47

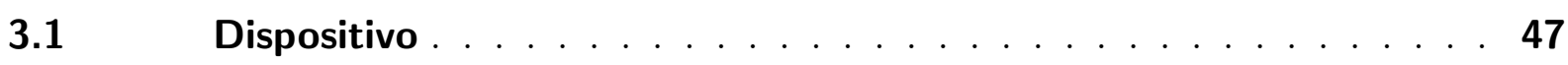

$3.2 \quad$ Break-in . . . . . . . . . . . . . . . . . . 49

3.3 Aquisição de Dados . . . . . . . . . . . . . . . . . . . 50

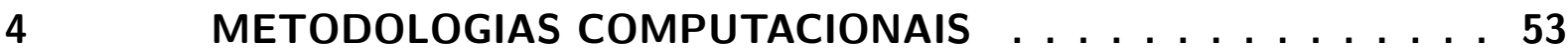

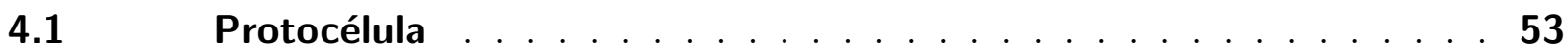

$4.1 .1 \quad$ Formulação Matemática . . . . . . . . . . . . . . . . . . . . . . . 54

4.1 .2 Validação . . . . . . . . . . . . . . . . . 56

4.1.3 Estudo do Transporte Convectivo . . . . . . . . . . . . . . . . . . . 59

4.1.4 Estudo da Compressão do Substrato Macroporoso . . . . . . . . . . . . . 61

4.1.4.1 Deformação mecânica do MPS . . . . . . . . . . . . . . . . . . . . . 63

4.1.5 Estudo da Geometria dos Canais . . . . . . . . . . . . . . . . . 66

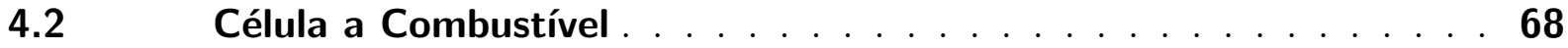

4.2.1 Geometria e Parametrização . . . . . . . . . . . . . . . . . 68

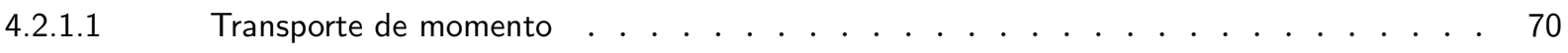

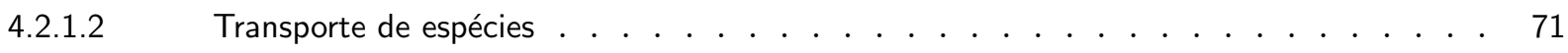

4.2.1.3 Transporte de calor . . . . . . . . . . . . . . . . . . 73

4.2.1.4 Transporte de carga _ . . . . . . . . . . . . . . . . . . . 75

4.2.2 Formulação Matemática . . . . . . . . . . . . . . . . . 76

4.2.2.1 Transporte de momento . . . . . . . . . . . . . . . . . 76

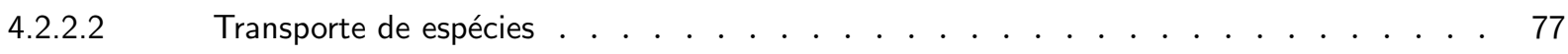

4.2.2.3 Transporte de calor . . . . . . . . . . . . . . . . . . . 80

4.2.2.4 Transporte de carga $\ldots \ldots \ldots$. . . . . . . . . . . . . . 81

4.2 .2 .5 Malha e solver . . . . . . . . . . . . . . . . . . . . . 83

4.2.2.6 Comparação aos resultados experimentais . . . . . . . . . . . . . . . 86

4.2.3 Estudo do Transporte Convectivo . . . . . . . . . . . . . . 87

5 RESULTADOS EXPERIMENTAIS . . . . . . . . . . 89

5.1 Curvas de Polarização . . . . . . . . . . . . . . . 89

$5.2 \quad$ Distribuição de Corrente . . . . . . . . . . . . . . 91 
$5.3 \quad$ Distribuição de Temperatura . . . . . . . . . . . . . . . . . . . 94

$5.4 \quad$ Discussão . . . . . . . . . . . . . . . . . . . . . . 96

6 RESULTADOS COMPUTACIONAIS . . . . . . . . . . 99

$6.1 \quad$ Protocélula . . . . . . . . . . . . . . . 99

$6.1 .1 \quad$ Validação . . . . . . . . . . . . . . . . . 99

6.1.1.1 Comparação aos resultados experimentais . . . . . . . . . . . . . . 99

6.1.1.2 Avaliação da constante de velocidade . . . . . . . . . . . . . . . 102

6.1.1.3 Comparação entre formulações matemáticas . . . . . . . . . . . . . . . . 106

6.1.2 Estudo do Transporte Convectivo . . . . . . . . . . . . . . . . . . . 110

6.1.2.1 Implicações para uma célula a combustível . . . . . . . . . . . . . . . . 110

6.1.2.2 Transporte de espécies na "camada difusora de gases" . . . . . . . . . . . . . . . 110

6.1.3 Estudo da Compressão do Substrato Macroporoso . . . . . . . . . . . . . 116

6.1.3.1 Avaliação da deformação do MPS . . . . . . . . . . . . . . . 116

6.1.3.2 Comparação entre modificações . . . . . . . . . . . . . . . . . . . 117

6.1.3.3 Discussões . . . . . . . . . . . . . . . . . . . . . . . . . . 119

$6.1 .4 \quad$ Estudo da Geometria dos Canais . . . . . . . . . . . . . . . . 122

6.1.4.1 Efeitos da geometria de interesse experimental . . . . . . . . . . . . . . . 122

6.1.4.2 Comparação entre modelos . . . . . . . . . . . . . . . . . . . . . . . 124

6.1.4.3 Comparação entre geometrias . . . . . . . . . . . . . . . . 126

6.2 Célula a Combustível . . . . . . . . . . . . . . . . . . . . 137

6.2.1 Comparação aos Resultados Experimentais . . . . . . . . . . . . . 137

6.2.1.1 Aspectos elétricos . . . . . . . . . . . . . . . . . . 137

6.2.1.2 Aspectos térmicos . . . . . . . . . . . . . . . . . . 144

6.2.1.3 Discussões . . . . . . . . . . . . . . . . . . . . 152

6.2.2 Estudo do Transporte Convectivo . . . . . . . . . . . . . . 157

6.2.2.1 Efeitos da formulação do transporte de momento . . . . . . . . . . . . . . . . 157

6.2.2.2 Contribuição do transporte convectivo . . . . . . . . . . . . . . . . . . 163

6.2.2.3 Discussões . . . . . . . . . . . . . . . . . . . . . . . 169

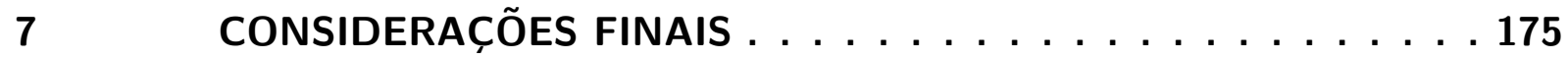

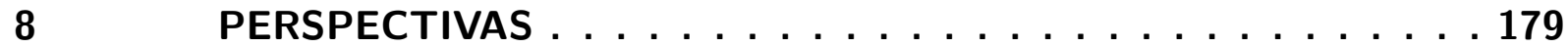

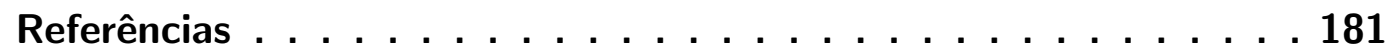

APÊNDICE A - PROPRIEDADES DE TRANSPORTE DA CL NO MODELO ALFA . . . . . . . . 189

A.1 Metodologia computacional . . . . . . . . . . . . 190 
APÊNDICE B - CÓDIGO PARA DISTRIBUIÇÃO ALEATÓRIA DE

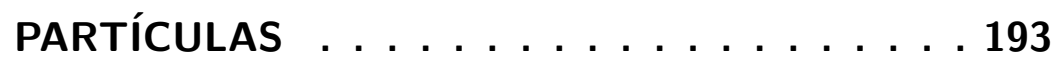

APÊNDICE C - ANÁLISE DA QUALIDADE DE MALHA USADA NO MODELO ALFA . . . . . . . . . 199

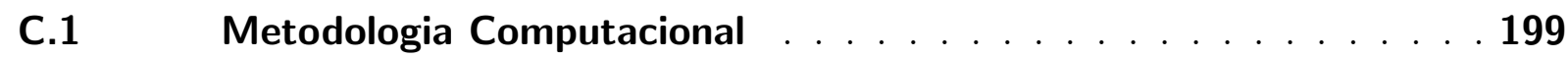

C.2 Resultados . . . . . . . . . . . . . . . . . . 200

APÊNDICE D - ANÁLISE DA CONDIÇÃO DE ENTRADA USADA NO MODELO ALFA . . . . . . . . . 205

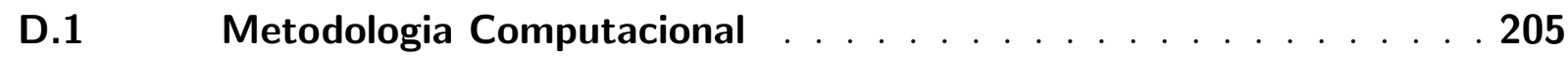

D.2 Resultados . . . . . . . . . . . . . . . . . . . . . 205

APÊNDICE E - DETERMINAÇÃO DA ESCALA DO FLUXO DE

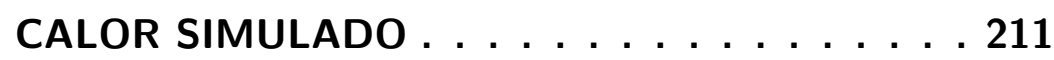

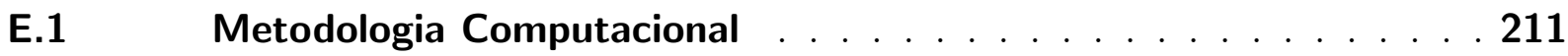

E.2 Resultados . . . . . . . . . . . . . . . . . . . . . . 212

ANEXO A - DISTRIBUIÇÕES DE CORRENTE LINEARIZADAS . 217

ANEXO B - DISTRIBUIÇÕES DE TEMPERATURA LINEARIZA-

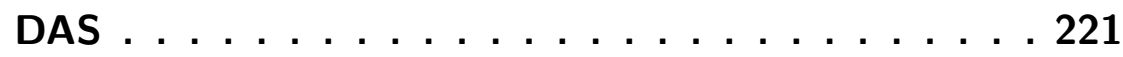





\section{INTRODUÇÃO}

A construção do conhecimento, conforme estabelecida pelo método científico, está baseada na observação da natureza; formulação de uma hipótese que explique tal observação, e na subsequente busca contínua de evidências para demonstrar falhas na hipótese original. A repetição deste método levou à percepção clássica da Ciência como sendo sustentada por dois robustos pilares: teoria e experimento. No entanto, no século XX foi estabelecido, silenciosamente, um novo pilar, resultante do aumento da complexidade e muitas vezes indisponibilidade dos objetos de interesse sendo observados, e dos recursos disponibilizados pelo avanço da tecnologia. Tal pilar pode ser resumido como "computação", e inclui diversas ferramentas e práticas, sendo utilizada em virtualmente todas as áreas do conhecimento humano: desde o estudo de partículas fundamentais e suas interações nos limites microscópicos(1); interações sociais, sejam entre humanos(2), entidades virtuais(3), ou entre $\operatorname{ambos}(4)$; fenômenos climáticos em escala global(5, 6, 7); e na evolução de sistemas estelares $(8,9)$, galáxias $(10,11)$, e até mesmo do próprio universo(12).

Entre as diversas ferramentas e abordagens permitidas pelo uso de recursos computacionais, a simulação de processos físicos, descrito na Seção 1.2, tem papel fundamental na busca da compreensão de fenômenos naturais, dado que possibilita a obtenção de informações muitas vezes inacessíveis através de experimentos. Uma simulação pode ser descrita como o processo de se aplicar e resolver um modelo matemático referente a um dado processo natural, na tentativa de reproduzir o comportamento observado experimentalmente. Quando bem sucedida, além de informações referentes sobre o(s) processo(s) físico(s) sob estudo, simulações oferecem vislumbres de processos semelhantes e novos e diferenciados pontos de vista sobre tópicos considerados consolidados. De particular importância, é a possibilidade de prever o comportamento do sistema em estudo frente à diferentes condições, levando assim a um maior entendimento do mesmo. Isto também se reflete no interesse comercial de estudos computacionais, ou in silico, que é a possibilidade de buscar condições ótimas para um dado sistema de maneira rápida e extensiva, muitas vezes poupando tempo e dinheiro.

Como mencionado acima, virtualmente todas as áreas do conhecimento humano se beneficiam de estudos computacionais. Em relação a simulações, áreas que se beneficiam de tal abordagem usualmente envolvem várias disciplinas e sistemas altamente acoplados. O uso de recursos computacionais em simulações facilita o emprego de técnicas numéricas para a resolução de sistemas de equações que não possuem soluções em forma fechada ou mesmo analíticas, ou seja, soluções que possam ser descritas com operações bem definidas e passíveis de serem resolvidas usando um número finito de operações. Notoriamente inclusos em tal classe estão sistemas de equações diferenciais parciais, usualmente apresentando dependências temporal e/ou espaciais, e sistemas de várias variáveis contendo interdependência, aqui sendo chamados de acoplados. O sistema em estudo neste trabalho, 
células a combustível, possui ambas características exemplificadas (ver, por exemplo, $(13,14,15,16,17))$ sendo também particularmente sensível a condições operacionais e de difícil caracterização experimental (por exemplo (18, 19, 20, 21, 22, 23, 24, 17)).

Células a combustível, como melhor descrito na Seção 1.1, são dispositivos que convertem diretamente energia química em elétrica(16), e há grande interesse em tais sistemas tanto do ponto de vista comercial como fundamental. Existem vários tipos de células, usualmente classificados pelo eletrólito, i.e. o elemento trocador de íons, temperatura de operação, e combustível; sendo que cada tipo possui suas particularidades em relação às condições operacionais e desafios tecnológicos e teóricos a serem superados. Dada a complexidade destes sistemas, sua imensa variabilidade de desenhos e interesse comercial, o uso de simulação tem sido largamente empregado, como pode ser observado no número de trabalhos compilados em $(17,25,26,13,15)$, com diferentes graus de sucesso na reprodução ou previsão de resultados experimentais.

No grupo de pesquisa onde este trabalho foi desenvolvido, tradicionalmente focado em experimentos, também foi reconhecida a necessidade e utilidade da abordagem computacional. Considerando o mencionado acima, foi desenvolvido um trabalho que visa, de maneira geral, simular os dispositivos desenvolvidos e utilizados neste grupo, de modo a reproduzir satisfatoriamente os resultados experimentais e eventualmente auxiliar no desenvolvimento e otimização de novos dispositivos. Além do interesse prático, o debate em torno dos processos físicos que regem tais dispositivos, e sua descrição matemática, ainda segue de maneira intensa (por exemplo (17)). Assim, a simulação dos dispositivos resulta também no avanço do entendimento dos fenômenos físicos observados na natureza, objetivo fundamental do método científico. Neste contexto, será descrito brevemente a seguir o sistema sob estudo e a abordagem escolhida para fazê-lo. Deve-se notar, no entanto, que não se pretende prover uma fundamentação completa de ambos tópicos, mas sim naqueles que são focos deste trabalho. Serão dadas a seguir, portanto, as descrições básicas de células a combustível de membrana de troca protônica (PEMFC, proton exchange membrane fuel cell) e de métodos de simulação de processos físicos, em particular o método dos elementos finitos (FEM, finite elements methods). Descrições mais detalhadas são facilmente encontradas na literatura, notavelmente em (13, 25, 16, 17, 27, 14, 28, 29), sendo particularmente relevantes a este trabalho.

\subsection{Células a Combustível}

Conforme mencionado anteriormente, células a combustível são dispositivos que convertem direta e espontaneamente energia química em energia elétrica, notavelmente por dispensar a combustão de um combustível ou o uso de partes mecânicas(16). Mais especificamente, trata-se de um dispositivo que utiliza reações eletroquímicas, oxidando um combustível no compartimento anódico, e reduzindo um oxidante no compartimento 
Figura 1 - Esquema simplificado de uma célula a combustível, em particular uma PEMFC operando com $\mathrm{H}_{2}$ e $\mathrm{O}_{2}$, indicando as componentes usualmente utilizadoa: placas bipolares (BP), canais de escoamento (FC), membrana de troca protônica (PEM) e as camadas porosas de transporte (PTL), compostas do substrato macroporoso (MPS), camada microporosa (MPL) e camada catalítica (CL).

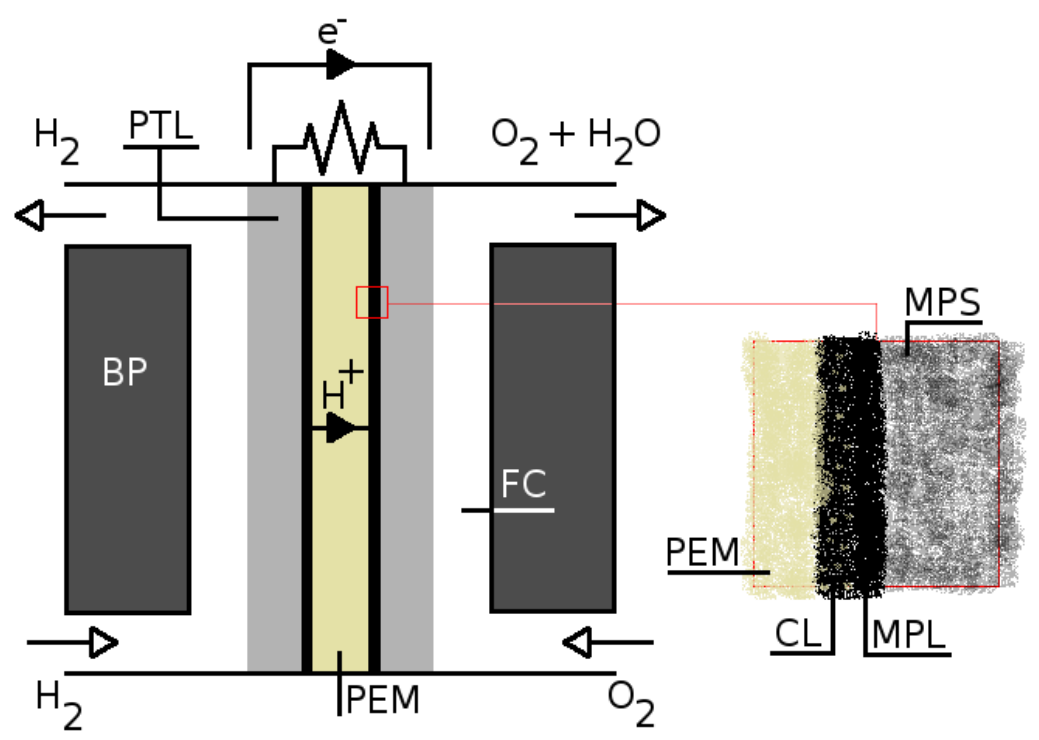

Fonte: Autoria própria.

catódico. As equações prototípicas representando tais sistemas são a oxidação do gás hidrogênio, $\mathrm{H}_{2}$, acompanhada da redução do gás oxigênio $\mathrm{O}_{2}$ :

$$
\begin{aligned}
\mathrm{H}_{2}(g) & \rightarrow \mathrm{H}_{2}(a q) \\
\mathrm{H}_{2}(a q)+2 \mathrm{H}_{2} \mathrm{O}(l) & \rightarrow 2 \mathrm{H}_{3} \mathrm{O}^{+}(a q)+2 e^{-}(s) \\
\mathrm{O}_{2}(g) & \rightarrow \mathrm{O}_{2}(a q) \\
\mathrm{O}_{2}(a q)+4 \mathrm{H}_{3} \mathrm{O}^{+}(a q)+4 e^{-}(s) & \rightarrow 6 \mathrm{H}_{2} \mathrm{O}(l)
\end{aligned}
$$

onde $g, l, a q$ e $s$, representam, neste caso, os estados gasoso, líquido, solubilizado (aquoso), e sólido, respectivamente, neste último caso indicando que o elétron é transportado por um condutor eletrônico sólido. Nota-se que células a combustível não se restringem ao uso de $\mathrm{H}_{2}$ como combustível, sendo possível utilizar, por exemplo, combustíveis orgânicos, como metanol e etanol. Somando-se as duas meia-reações, e balanceando a estequiometria, tem-se a reação global usual que descreve uma célula a combustível operando com $\mathrm{H}_{2} / \mathrm{O}_{2}$ :

$$
2 \mathrm{H}_{2}(g)+\mathrm{O}_{2}(g) \rightarrow 2 \mathrm{H}_{2} \mathrm{O}(l)
$$

Conforme sugerido, as reações ocorrem em compartimentos distintos, sendo conectadas por um sistema externo que conduz os elétrons produzidos na oxidação, e um trocador de íons que transporta os íons hidrônios e isola eletronicamente os compartimentos, conforme ilustrado na Figura 1. 
A Fig. 1 apresenta de forma bastante simplificada um esquema de uma PEMFC, um caso específico de uma PEFC (polymer eletrolyte fuel cell). No esquema são identificados os elementos que compõem a estrutura interna do dispositivo: as placas mono- ou bipolares (BP, mono-, bipolar plates), os canais de escoamento de gases (FC, flow channel), as camadas porosas de transporte (PTL, porous transport layer), e a membrana trocadora de prótons (PEM, proton exchange membrane) ou, de maneira mais geral, o eletrólito polimérico. A PTL possui ainda subdivisões, indicadas na região aumentada na Fig. 1, usualmente composta de um substrato macroporoso (MPS, macroporous substrate) e da camada catalítica (CL, catalyst layer), podendo ainda conter uma camada microporosa (MPL, microporous layer). A natureza destes componentes (no caso do FC os que neles escoam) influenciam de maneira drástica na resposta de cada sistema, sendo particularmente importantes a PEM e as CLs. Tais componentes, juntamente com o restante das PTLs, são normalmente denominados conjuntos membrana-eletrodos (MEA, membrane-electrode assembly). Vale notar que, apesar da Fig. 1 representar uma PEMFC, de maneira geral as células a combustível possuem uma esquemática semelhante, diferindo no desenho e natureza dos componentes e combustíveis (veja, por exemplo, Seção 1.3 de (16)).

Dada a natureza das PEMFCs, e a introdução dada acima, alguns pontos podem ser identificados como sendo de interesse nestes dispositivos. Em primeiro lugar, tem-se a distribuição de reagentes, tanto combustível como oxidante, ao longo de todo volume da CL. Várias estratégias podem ser empregadas, com consequências particulares a cada uma, que incluem notavelmente a escolha da geometria dos FCs (veja Seção 6.1.4 e, por exemplo, $(23,30,31)$ ) e composição da PTL (veja por exemplo (24) e referências). O acoplamento entre as variáveis de uma PEMFC resulta na necessidade de se considerar paralelamente à distribuição de reagentes as consequências desta. Muita atenção tem sido dada à manutenção da fase líquida(17), decorrente da possibilidade de condensação de $\mathrm{H}_{2} \mathrm{O}$, e da possibilidade de degradação da CL devido à escassez de espécies reagentes, em particular no ânodo. Assim, o estudo da distribuição de reagentes precisa levar em conta tais variáveis, sendo que, por outro lado, qualquer estudo da degradação da CL, por exemplo, deveria levar em conta a geometria dos FCs.

A manutenção da temperatura no interior do dispositivo também é de suma importância, dado que esta interfere significativamente em inúmeros processos, como por exemplo a integridade da PEM, a velocidade das reações e manutenção da fase líquida. Usualmente PEMFCs são operadas em temperaturas próximas a $353 \mathrm{~K}$, em uma tentativa de balancear os processos mencionados anteriormente, porém células que operem em $T>373 \mathrm{~K}$ existem (por exemplo (23)). Tais temperaturas de operação, juntamente com o calor gerado no dispositivo devido a diversos efeitos (como efeito Joule, calores de reação e equilíbrio de fase), fazem com que o dispositivo necessite aquecimento em dadas situações e resfriamento em outras. Assim, uma manutenção adequada da temperatura é indispensável para evitar perdas de desempenho, como por exemplo i) acúmulo de fase líquida, levando ao 
encharcamento do eletrodo, mais comumente o cátodo, e consequentemente reduzindo a distribuição de espécies; e ii) o ressecamento da PEM, levando a um drástico aumento da resistência à transferência de íons, dado que os eletrólitos comumente utilizados em PEMFCs dependem de água líquida para funcionamento (ver Seções 3.1 e 4.1 de (14)).

Dado o propósito do dispositivo, o ponto-chave de uma célula a combustível é a geração de corrente elétrica. Usualmente percebida como consequência das condições operacionais do dispositivo, apresentada na forma de curvas de polarização, onde a força eletromotriz $\Delta E$ (ou diferença de potencial elétrico) é graficada em função da corrente exigida do dispositivo, $I$; a corrente é de interesse fundamental dado que reflete, e também influencia, nos demais processos. A Figura 2a apresenta um exemplo de curva de polarização, apontando os principais processos que contribuem para a forma geral observada. Um dos pontos mais visados atualmente se refere à capacidade dos catalisadores utilizados de aumentar $\Delta E$ para um dado valor de $I$, levando assim a um aumento da potência gerada pelo dispositivo $(\Delta E \times I)$, apresentada na Figura 2b. Considerando a Fig. 2, isto se dá pela diminuição do chamado sobrepotencial de ativação, $\eta_{\mathrm{ct}}(32)$, ou de transferência de carga, que está relacionado à cinética da reação eletroquímica(32). Porém esta também reflete a distribuição de reagentes e a integridade da PEM, contribuindo para a degradação da PTL e PEM. Dois motivos podem ser apontados, em primeira abordagem: i) baixas concentrações de reagentes, sejam por má distribuição ou altas correntes, podem levar à reações paralelas envolvendo os materiais que compõem a PTL, por exemplo o suporte condutor da CL(17); por outro lado, ii) uma alta corrente local leva ao aumento da temperatura local, potencialmente diminuindo a hidratação da membrana e aumentando a resistência a transferência de íons, o que por sua vez pode levar a um aumento do calor gerado via efeito Joule: um ciclo de retroalimentação se instala, podendo levar à danos irreversíveis. Estes pontos podem ser identificados na Fig. 2 sendo relacionados, respectivamente, ao sobrepotencial de transporte de massa, $\eta_{\mathrm{mt}}$, e ao sobrepotencial de queda ôhmica, $\eta_{R}$; porém, pouca informação é obtida sobre tais processos, sendo que nenhuma informação espacial é fornecida. Logo, o estudo da distribuição espacial de corrente, apesar de relativamente novo e pouco disseminado (compare, por exemplo, (13) e (17)), é de fundamental importância para o controle de células a combustível.

Considerando, assim, o interesse fundamental e comercial em PEMFCs, e outros dispositivos semelhantes, o estudo dos processos que regem estes sistemas tem atraído considerável interesse (mais uma vez, considere as referências de (17)). Weber e colaboradores(17) apontaram recentemente vários pontos que merecem atenção, tanto do ponto de vista experimental como teórico. Neste trabalho, foi dado foco na contribuição do transporte convectivo no desempenho dos dispositivos estudados, em particular na distribuição de espécies. Isto se deve ao recente desenvolvimento de uma técnica para visualizar diretamente o escoamento em uma PTL similar ao cátodo de uma PEMFC(33). Conforme já mencionado, o acoplamento entre as variáveis impede, mesmo com técnicais como a 
Figura 2 - Exemplos de a) curva de polarização e b) curva de potência para uma PEMFC típica, apontando as principais contribuições para a perda de desempenho: sobrepotencial de ativação $\eta_{\text {ct }}$, sobrepotencial de queda ôhmica $\eta_{R}$, e sobrepotencial de transferência de massa $\eta_{\mathrm{mt}}$. As linhas tracejadas indicam um desempenho perfeito, dado pelo potencial termodinâmico $E^{0}$.

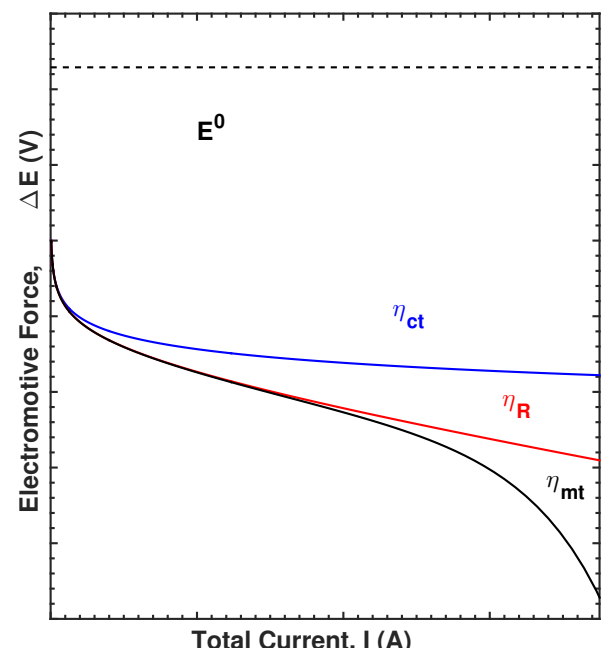

(a)

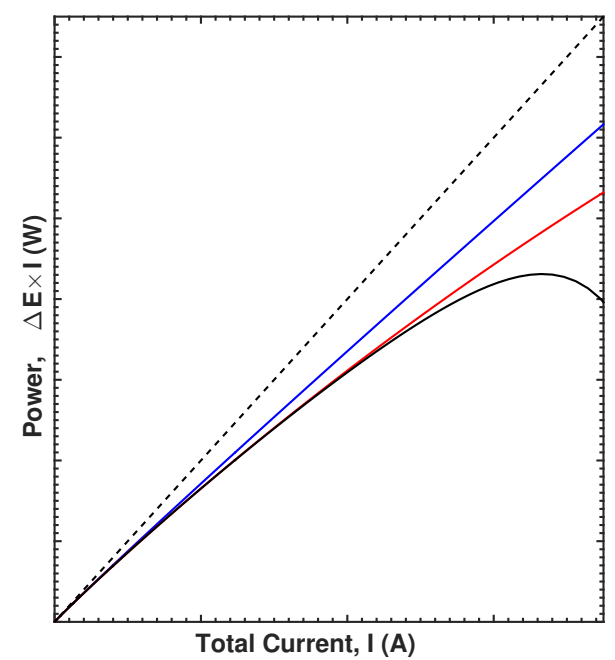

(b)

Fonte: Autoria própria.

descrita por Lopes e colaboradores(33), uma completa separação dos efeitos presentes em um dispositivo real. Neste ponto, a simulação dos processos físicos, e a possibilidade de habilitá-los seletivamente durante o procedimento, oferece informações inacessíveis experimentalmente.

\subsection{Simulação de Processos Físicos}

Conforme já mencionado, existem várias abordagens e métodos para a simulação de processos físicos. Todos se baseiam em alguma formulação matemática que busca descrever a realidade, e envolvem uma tentativa de se obter o comportamento dos processos sendo descritos no sistema sob estudo. Notavelmente, existe a possibilidade de se simular os processos físicos de um sistema através de um sistema similar, empiricamente, porém com maior controle, de modo a se obter informações indisponíveis ao sistema original, assumindo, ou demonstrando, a similaridade entre ambos. Este é exatamente o caso de Lopes e colaboradores(33), de particular interesse neste trabalho, como também de diversos outros trabalhos na literatura. Como o interesse neste caso se dá no uso das ferramentas computacionais, estas se dividem em dois grandes grupos: analíticas e numéricas(29) (o uso indiscriminado dos termos "abordagem", "método", entre outros; se dá por motivos didáticos, não sendo importante no atual momento a distinção, quando existente, entre estes). A abordagem analítica também pode ser dita "simbólica", i.e. sem o envolvimento 
direto de números durante sua formulação e resolução. Exemplos de tal abordagem podem ser encontrados largamente em exercícios didáticos e textos de graduação, onde uma equação geral existe para descrever o comportamento do sistema, sendo que as particularidades são dominadas por parâmetros a serem determinados para a obtenção de números. De grande disseminação e valia podem ser citados exemplos como: i) o cálculo da partição de uma substância entre dois solventes, dado pela equação do equilíbrio (Seção 11.5 de (34)); ii) a equação de movimento de um oscilador harmônico unidimensional, dada pela resolução de uma equação diferencial de primeira ordem (Capítulo XII de (35)); iii) o comportamento da corrente Faradaica em resposta à aplicação de uma diferença de potencial elétrico em um eletrodo, dado pela resolução das equações de Fick quando sujeitas a certas condições de contorno (Seção 5.2 de (32)); iv) o comportamento dos domínios magnéticos próximos à transição ferromagnética considerando interações de curto alcance, dado pelo modelo de Ising (Capítulo XIII de (36)); ou v) o escoamento laminar de um fluido Newtoniano incompressível em um duto significativamente mais longo que seu diâmetro, dado pelas equações de Navier-Stokes sujeito a certas condições de contorno (Capítulo I de (29)).

A abordagem numérica, por outro lado, consiste no uso de métodos para a obtenção de resoluções aproximadas para problemas específicos, cujo nome pode ser remetida ao cálculo explícito através de números. Tal abordagem se tornou particularmente comum com o advento de computadores pessoais, porém tais métodos existem muito antes disto, com exemplos notáveis dados pelo método de Jacobi de transformação de matrizes(37) e do método de Hartree para átomos multieletrônicos(38). De particular interesse no uso desta abordagem são sistemas de equações diferenciais parciais onde, de modo geral, não existem soluções gerais, i.e. não há soluções analíticas. Tipicamente tais problemas envolvem geometrias peculiares, bi- ou tridimensionais, e/ou a evolução temporal de variáveis(29). Vale apontar que dentre os exemplos acima para resoluções analíticas, iii) iv) e v) são casos especiais de sistemas mais complexos: iii) só apresenta resolução analíticas para algumas condições de contorno e para uma dimensão espacial e temporal, sendo um sistema de equações diferenciais parciais; iv) só apresenta soluções analíticas para o caso unidimensional sendo, por acaso, um problema de muito interesse nos casos bie tridimensionais; e v) é um dos poucos casos onde as equações de Navier-Stokes pode ser resolvidas analiticamente, resultando na equação de Hagen-Poiseuille e no perfil de escoamento de mesmo nome.

Neste ponto cabe mencionar que sistemas de equações diferenciais parciais usualmente possuem variáveis acopladas, i.e. variáveis que dependam entre si explicitamente ou através de outros efeitos, como espaço ou tempo. Tal característica é notória em sistemas eletroquímicos (como exemplo, ver os capítulos 6, 9, 13 e 14 de (32)) e, não completamente surpreendente, de células a combustível. Em particular, células a combustível possuem diversas variáveis que dependem entre si, como mencionado na Seção 1.1 acima, mas que 
apresentam, também, dependências temporal e espacial (por exemplo, ver Capítulo 7 de (16) e as Seções 4.1.1 e 4.2.2 deste trabalho). Apesar de inúmeros trabalhos pioneiros que buscavam resoluções analíticas para tais sistemas e problemas associados, notavelmente os trabalhos de J. Newman e T. E. Springer, para PEMFCs; a complexidade de acoplar as diversas variáveis de interesse, e de se explorar os comportamentos espacial e temporal destas, justifica largamente a disseminação do uso de métodos numéricos para a busca do conhecimento sobre estes sistemas, além da contribuição dos apelos comercial e ambiental destes dispositivos, dado pelo interesse em otimizar e implementar tais tecnologias.

Entre os métodos numéricos, os aplicáveis à resolução de equações diferenciais, interesse principal deste trabalho, se resumem basicamente à discretização do sistema e busca de uma solução que respeite as condições de contorno impostas no mesmo. Por discretização entende-se a separação do sistema de estudo em um número finito de elementos, temporais e/ou espaciais, de modo que no limite de tamanho (intervalo de tempo, comprimento, área, etc) tendendo a zero, a resolução seja, em princípio, a solução exata do conjunto de equações. Existem vários métodos aplicados à resolução de equações diferenciais ordinárias e/ou parciais, sendo o mais intuitivo dado pelo Método das Diferenças Finitas (FDM, finite difference method), que se baseia, de maneira simples, na definição de uma derivada(29):

$$
\frac{\mathrm{d} f(x)}{\mathrm{d} x}=\lim _{\delta x \rightarrow 0} \frac{f(x+\delta x)-f(x)}{\delta x}
$$

porém desconsiderando o limite a zero, e tomando $\delta x$ como um intervalo pequeno porém finito. É possível, portanto, ao se separar o sistema de interesse em $N$ elementos, obter uma aproximação numérica para a derivada $f^{\prime}(x)$ no $i$-ésimo ponto:

$$
\left.\frac{\mathrm{d} f(x)}{\mathrm{d} x}\right|_{i}=f_{i}^{\prime}(x)=\frac{f_{i+1}(x)-f_{i}(x)}{\delta x}
$$

onde $x_{i+1}-x_{i}=\delta x$ e $i \in[1, N]$. Rearranjando a equação, tem-se que:

$$
f_{i+1}(x)=f_{i}(x)+\delta x f_{i}^{\prime}(x)
$$

Tal forma também pode ser obtida através da expansão de uma função $f(x)$ em uma série de Taylor, dado que $f(x)$ seja contínua no intervalo $[a, b]$ e contenha $M$ derivadas contínuas no mesmo intervalo. Assim, pode-se escrever:

$$
f(x)=f\left(x_{0}\right)+\left.\sum_{i=1}^{M} \frac{\Delta x^{i}}{i !} \frac{\mathrm{d}^{i} f(x)}{\mathrm{d} x^{i}}\right|_{x_{0}}
$$

onde $\Delta x=x-x_{0}$. Considerando agora uma discretização do intervalo $[a, b]$ em pontos igualmente espaçados, temos que $x_{i}-x_{i-1}=\Delta x$. Desta maneira, o interesse existe em determinar $f\left(x_{i}+\Delta x\right)$ utilizando a série de Taylor:

$$
f\left(x_{i}+\Delta x\right)=f\left(x_{i}\right)+\left.\Delta x \frac{\mathrm{d} f(x)}{\mathrm{d} x}\right|_{i}+\left.\frac{\Delta x^{2}}{2} \frac{\mathrm{d}^{2} f(x)}{\mathrm{d} x^{2}}\right|_{i}+\ldots
$$


Para obter a forma da Eq. 1.8, nota-se que $\Delta x=\delta x, f\left(x_{i}\right)=f_{i}(x)$ e $f\left(x_{i}+\Delta x\right)=f_{i+1}(x)$. Truncando, portanto, a série no termo de primeira ordem, i.e. $M=1$, obtém-se:

$$
f_{i+1}(x)=f_{i}(x)+\delta x f_{i}^{\prime}(x)+\mathcal{O}\left(\delta x^{2}\right)
$$

onde o último termo indica termos de ordem $\delta x^{2}$ e superiores. No caso limite $\delta x \rightarrow 0$, tais termos podem ser desprezados, e após rearranjo da equação obtém-se novamente a definição de derivada. É digno de nota que tal derivação, usando séries de Taylor, deixa explícita a existência de erros de truncamento, proporcionais a $\mathcal{O}\left(\delta x^{2}\right)$ neste caso, que aparecem sempre que uma série é truncada.

No caso da resolução de equações diferenciais ordinárias, onde conhece-se $f^{\prime}(x)$, este método é conhecido como método de Euler explícito, e trata-se de uma aproximação de primeira ordem. Tal método é exemplificado na Figura 3, onde observa-se a função $f(x)$ desejada, contínua em um intervalo $0 \leq x \leq 10$. Para a aplicação do método de Euler, o intervalo é discretizado em elementos de $\delta x=1$, e estabelece-se a condição inicial, ou de contorno, neste caso $f(x=0)=f_{i=0}=10$ (Fig. 3a). Conhecendo-se a derivada $f^{\prime}(x)$, aplica-se o método de Euler, que projeta a solução de maneira progressiva, i.e. através de diferenças progressivas, obtendo-se a aproximação de primeira ordem da função $f(x), g(x)$ (Fig. 3b). Pode-se observar que, quantitativamente, o resultado não é satisfatório, porém qualitativamente é uma boa aproximação de $f(x)$, com um custo mínimo de apenas uma operação por ponto, comumente representado por $\mathcal{O}(N)$. Por outro lado, concordâncias significativamente melhores podem ser obtidas, neste exemplo simples, apenas trabalhando com a Eq. 1.7, utilizando uma projeção da solução chamada de diferenças centrais, ou ainda dobrando o número de pontos e, portanto, melhorando a resolução. Nota-se que, aumentando-se o número de variáveis, e.g. $f(x, t)$, tem-se que é necessário discretizar também $t$, e a generalização do método de Euler explícito resulta no método de diferenças finitas progressivo (ou contrariamente, tal método reduz ao método de Euler explícito).

Assim, apesar da fundamentação ser praticamente geral, os métodos se diferenciam de acordo com o tipo de projeção da solução (progressiva, atrasada ou central), no formato da equação (explícita ou implícita), na discretização (linear ou polinomial), e na forma com que as equações são resolvidas (derivadas ou integrais)(29). Uma busca na literatura revela uma grande variedade de métodos de diferenças finitas e similares, cada qual com suas devidas vantagens e áreas de aplicação. Também observa-se que as fronteiras entre os métodos se tornam difusas, com vários métodos implementados de maneira conjunta para melhor lidar com um dado problema, fato comumente observado em pacotes comerciais para a resolução de equações diferenciais. No entanto, entre a gama de métodos disponível, dois métodos se sobressaem, em particular para problemas que contenham escoamento de fluidos, que são o Método dos Elementos Finitos (FEM, finite elements method) e o Método dos Volumes Finitos (FVM, finite volume method), contribuindo largamente para o campo de dinâmica de fluidos computacional (CFD, computational fluid 
Figura 3 - Exemplo de aplicação do método de Euler para integração de uma função $f^{\prime}(x)$ conhecida sobre um intervalo $0 \leq x \leq 10$ : a) discretização utilizada $\delta x=1$ (०), condição inicial $f(x=0)=f_{i=1}=10$ e a função $f(x)$ a ser obtida (linha tracejada); b) integrações realizadas utilizando diferenças progressivas (o), diferenças centrais (o), e com diferenças progressivas porém com $\delta x=0.5(\circ)$. A linha sólida preta indica o $y=0$.

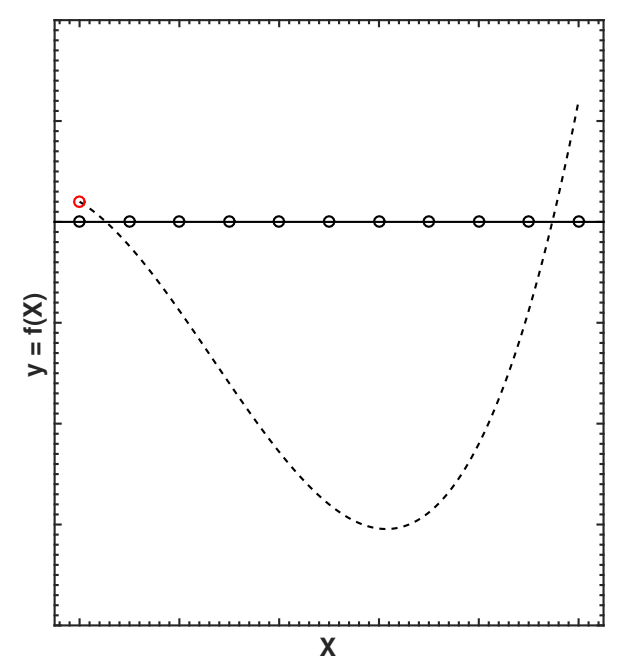

(a)

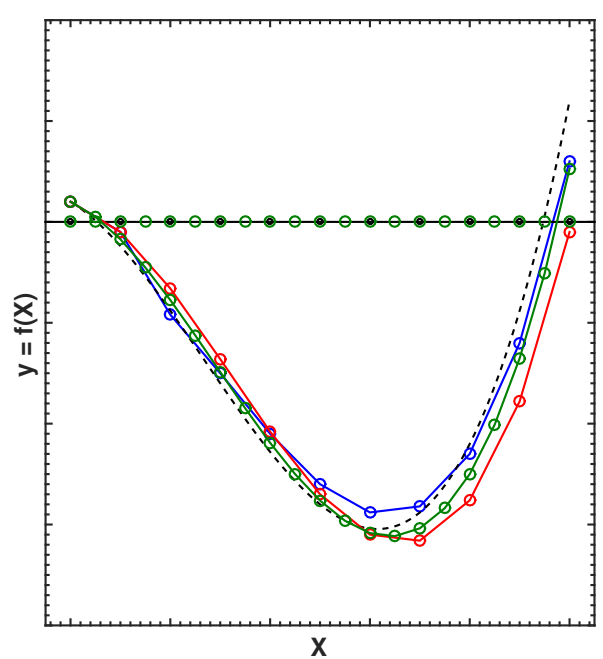

(b)

Fonte: Autoria própria.

dynamics)(29). Estes métodos diferem principalmente na forma das equações: o FEM se baseia em uma formulação variacional do problema, descrevendo-o através de soluções fracas e minimizando o erro entre a solução exata e a solução proposta; enquanto que o FVM se baseia no cálculo de fluxos entre elementos, utilizando o teorema do divergente em integrais de volume, de modo que a conservação do fluxo entre elementos é levada em conta.

Além de serem métodos largamente utilizados em CFD, FEM e FVM são o cerne do conjunto de técnicas numéricas exploradas neste trabalho, sendo implementados no software comercial COMSOL Multiphysics ${ }^{\circledR}$. Uma descrição detalhada dos métodos, sua implementação e processo de uso estão além do escopo deste trabalho. No entanto, uma descrição básica do processo que envolve o uso de técnicas numéricas, não necessariamente COMSOL, pode ser dada como:

1. Determinação do sistema a ser estudado.

2. Determinação da formulação matemática dos processos físicos do sistema.

3. Escolha do método para formulação numérica do sistema analítico.

4. Construção da geometria do sistema sob estudo.

5. Determinação da discretização das variáveis de interesse. 
6. Escolha do método de resolução do sistema numérico.

onde alguns passos podem incluir subdivisões devido a particularidades do sistema em estudo. O último passo enumerado, não mencionado anteriormente, envolve fatores relacionados a aspectos técnicos da simulação, como tipo de equações, método escolhido, critério de convergência, estabilidade numérica, entre outros(29). Tais detalhes não são cruciais neste momento, e são deixados ao encargo da literatura especializada.

Não se pode deixar de notar que a grande variedade de métodos numéricos, considerando agora o caso geral, possivelmente eclipsa o número de classes de problemas aos quais estes se propõem a resolver. Vários fatores podem ser mencionados para tal fato, como as particularidades e o interesse da comunidade para cada classe de problemas, porém um fator em particular é digno de nota: a disponibilidade de recursos computacionais. Refere-se à disponibilidade de computadores, em particular capacidade de processamento, espaço de armazenamento e memória; e tempo de máquina suficientes para a resolução de um dado problema. Como exemplo da demanda de tais recursos, e as limitações impostas or esta, apontam-se o cálculo de estrutura eletrônica, i.e. o cálculo da função de onda dos elétrons de um átomo, molécula ou cristal; e o problema de turbulência em CFD. Ambos exemplos gozam de pleno interesse da comunidade acadêmica e da iniciativa privada, possuindo, em princípio, a possibilidade de resolução através de formulações matemáticas e métodos numéricos conhecidos. No entanto, o custo de recursos computacionais para tais cálculos são completamente proibitivos: no caso do problema de estrutura eletrônica, o escalonamento do número de operações, e portanto custo de recursos computacionais, é $>\mathcal{O}\left(N^{4}\right)(39)$, sendo $N$ o número de elétrons no sistema; e, no caso do problema de turbulência, $\mathcal{O}\left(\operatorname{Re}^{3}\right)(40)$, onde Re é o número de Reynolds do escoamento, tipicamente Re $>10^{2}-10^{3}$ para escoamentos turbulentos. Portanto, uma parte crucial da abordagem computacional é o desenvolvimento de estratégias mais eficientes para a resolução de sistemas cada vez mais complexos e maiores, e isto implica em pesquisas em todos os passos enumerados acima.

Por fim, outro aspecto crítico não só para a abordagem computacional, mas de fato para o conhecimento humano como um todo, é a validação dos resultados obtidos teórica ou computacionalmente. A validação nada mais é que comparar os resultados obtidos com resultados empíricos bem estabelecidos. Isto tem dois objetivos maiores: i) comprovação da hipótese ou modelo original, frente às observações já estabelecidas; e ii) garantir que os resultados teóricos ou computacionais sejam legítimos e não meramente coincidências. Como o próprio método científico, trata-se de um processo cíclico, de modo a permitir o refino dos conhecimentos estabelecidos e o desenvolvimento de novas ideias. No caso de simulações computacionais, é particularmente importante o rigor e a continuidade de tal processo, dado que muitas vezes tais resultados vão guiar a busca de evidências empíricas, ou ainda à implementação prática de um dado conhecimento. Assim, é importante o desenvolvimento de novos métodos experimentais, de modo a fornecer evidências de que 
as metodologias teórica e computacional são robustas e condizentes com a realidade. Isto permite que outros setores da comunidade, ou mesmo da sociedade como um todo, se apoiem e façam proveito destes conhecimentos.

Considerando o contexto dado pelo estudo de células a combustível, em particular PEMFCs, e do uso e importância de métodos computacionais na construção do conhecimento humano, este trabalho encontra-se na interface destas áreas, utilizando uma abordagem computacional no estudo de PEMFCs e os processos físicos que as regem. A seguir serão apresentados os objetivos gerais e específicos deste trabalhos. O restante deste documento encontra-se dividido como segue. O Capítulo 3 descreve o dispositivo e apresenta as metodologias utilizadas para a obtenção dos resultados experimentais utilizados na validação de um dos modelos computacionais estudado. O Capítulo 4 apresenta as metodologias computacionais empregadas no estudo dos sistemas experimentais. Nota-se que algumas metodologias descritas são fruto da interpretação de resultados anteriores, portanto há uma grande proximidade com os resultados computacionais. O Capítulo 5 apresenta os dados coletados com o dispositivo experimental. O Capítulo 6 apresenta os resultados obtidos com os modelos computacionais, validando-os e discutindo possíveis implicações destes. O Capítulo 7 sumariza e conclui o trabalho, sendo apresentadas, também, perspectivas para trabalhos futuros. 


\section{OBJETIVOS}

O objetivo geral deste trabalho é o estudo de sistemas do tipo PEMFC através de simulações computacionais, sendo desenvolvidos e validados modelos com o intuito de auxiliar na interpretação de resultados experimentais e no desenvolvimento de dispositivos buscando a melhoria no desempenho. Para tal, os seguintes objetivos específicos foram estabelecidos:

- Desenvolver e explorar modelos computacionais de PEMFCs baseados em argumentos teóricos acerca dos processos físicos existentes nestes sistemas.

- Validar os modelos desenvolvidos através da comparação a resultados experimentais de curvas de polarização e distribuições espaciais de corrente e temperatura.

- Avaliar a influência da geometria dos canais de escoamento e do transporte convectivo nestes dispositivos. 



\section{METODOLOGIAS EXPERIMENTAIS}

Será descrita neste Capítulo a metodologia empregada na coleta de dados experimentais, utilizados para a validação dos resultados computacionais. A metodologia utilizada se baseia na descrita em (41), sendo adaptada conforme necessário. De maneira breve, foi realizada a obtenção de curvas polarização de uma PEMFC, com área geométrica de eletrodo de $49 \mathrm{~cm}^{2}$, operando com $\mathrm{H}_{2} / \mathrm{Ar}$ umidificados à temperatura de 368, $2 \mathrm{e}$ 358,3 K, respectivamente, sem pressurização. Foram utilizados dois MEAs comerciais, com catalisadores nanoparticulados a base de Pt, sendo que para cada MEA a célula fora montada três vezes, com a aquisição de três curvas de polarização por montagem; totalizando um conjunto de dados com um número total de replicatas $N=18$. Um procedimento de break-in foi realizado para o MEA \#2, sendo considerado desnecessário para o \#1 devido a uso prévio no laboratório. Toda a manipulação de dados foi realizada utilizando a distribuição R2012a do software MATLAB ${ }^{\circledR}$.

\subsection{Dispositivo}

Mais especificamente, o dispositivo utilizado é uma célula a combustível comercial (S++ Simulation Services, Alemanha), desenvolvida para uso conjunto com uma placa de medida de distribuição de corrente da mesma fabricante ( $\mathrm{S}++$ current scan shunt, 1100). O dispositivo completo contém as seguintes componentes: MEA; espaçadores; placas monopolares; placa para medida de distribuição de corrente; auxílio para contato; coletores de corrente; isolantes; e placas externas. A ordem de montagem e as componentes podem ser observadas na Figura 4. Demais componentes relevantes, externos ao sistema, incluem somente o sistema de umidificação e controle de alimentação. A seguir é apresentado uma descrição mais detalhada de cada componente.

O MEA é de origem comercial (Alfa-Aesar, MEA 5-layer 45369), com área geométrica dos eletrodos de $(7 \times 7) \mathrm{cm}^{2}$, dispondo de uma quantidade escassa de informações. É composto das seguintes camadas: eletrólito, camadas catalíticas, e camadas de transporte de gases. O eletrólito é uma membrana de polímero trocador de prótons (ionômero) estruturado, possivelmente baseado em tetrafluoroetileno sulfonado, com características semelhantes ao Nafion ${ }^{\circledR}$ e Aquivion ${ }^{\circledR}$. As camadas catalíticas (CLs) são baseadas em catalisadores de Pt nanoparticulados dispersos em carbono de alta área superficial, possivelmente com algum tratamento hidrofóbico, e.g. politetrafluoroeteno (PTFE), e adição de uma solução do eletrólito para melhoria do contato iônico com a membrana. As camadas de transporte de gases são baseadas em papel de carbono (MPS), também possivelmente incluindo tratamento hidrofóbico, com a presença de uma camada microporosa (MPL) em contato com cada CL. Deve-se notar que é indicado o lado correto do MEA para uso na 
Figura 4 - Esquema da célula a combustível utilizada. a) Ordem de montagem dos componentes: i) placa externa, ii) isolante, iii) coletor de corrente, iv) auxílio para contato, v) placa de distribuição de corrente, vi) placa monopolar, vii) espaçador e viii) MEA, composto de dois eletrodos e a membrana polimérica. b) Detalhes da geometria de canal utilizado nas placas monopolares.

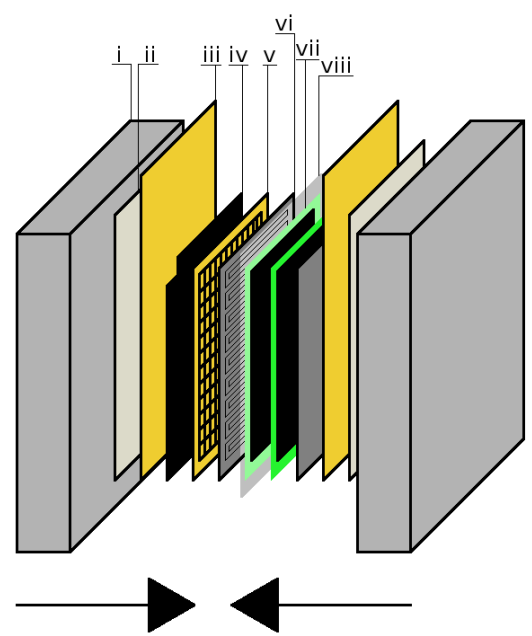

(a)

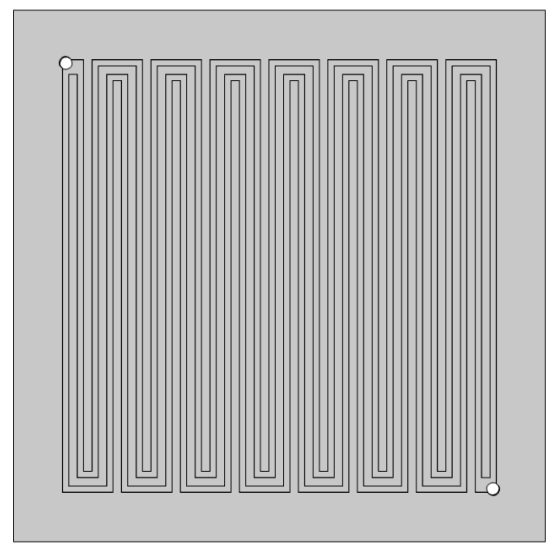

(b)

Fonte: Autoria própria.

célula, i.e. ânodo e cátodo, e evidências existem de que o cátodo é significativamente mais espesso que o ânodo (microscopia eletrônica de varredura, imagens não apresentadas), indicando cargas de catalisador distintas.

Os espaçadores foram obtidos a partir de um elastômero comercial, sendo cortados de forma a circunscrever, da maneira mais próxima possível, os eletrodos do MEA em ambas as faces.

As placas monopolares foram fornecidas juntamente com o dispositivo, também de origem comercial $(\mathrm{S}++)$. Estas são feitas à base de grafite, possivelmente na forma de um compósito com resina fenólica. A geometria dos canais de escoamento utilizado foi o de serpentina ininterrupta de dois canais (Fig. 4b), para ambos eletrodos, utilizando aproximadamente $(7 \times 7) \mathrm{cm}^{2}$ da área total de $(8,4 \times 8,4) \mathrm{cm}^{2}$. Os canais possuem largura de 0,8 e profundidade de aproximadamente $1 \mathrm{~mm}$, com separação (terraças) de $1 \mathrm{~mm}$.

A placa para medida de distribuição de corrente trata-se de uma placa de circuito impresso, composta de duas partes: uma parte condutora, banhada com $\mathrm{Au}$, onde as medidas são realizadas; e o restante do circuito para obtenção e exportação dos dados. A parte condutora é um grid de $12 \times 12$ quadrados, sendo os pontos de coleta de corrente, cobrindo a área geométrica dos eletrodos e dos canais de escoamento, i.e. $49 \mathrm{~cm}^{2}$. Nota-se que os pontos coincidentes com a entrada e saída de gases não possuem a mesma área que os demais. Durante todos os experimentos reportados, a placa de distribuição de corrente 
estava situada no cátodo.

O auxílio para contato mencionado foi incluído entre a placa monopolar catódica e de distribuição corrente, sendo um pedaço de tecido de carbono (Zoltek Panex 030) cobrindo o grid de pontos de coleta de corrente, excetuando-se os pontos de entrada e saída de gases.

Os coletores de corrente são placas de uma liga $\mathrm{Cu}-\mathrm{Au}$, situadas entre a placa bipolar ou de distribuição de corrente, e as placas externas, para o ânodo ou o cátodo, respectivamente.

As placas externas são feitas de aço inoxidável, contendo os circuitos de aquecimento da célula e os parafusos para compressão dos componentes internos. Entre as placas externas e coletoras de corrente, foram incluídos pedaços de PTFE, de modo a isolar eletricamente os componentes internos. A célula foi fechada através da aplicação de torque nos parafusos, em uma sequência de 1,0; 1,5 e 2, $0 \mathrm{~N} \mathrm{~m}$, obedecendo a ordem de parafusos recomendada em (41). O circuito de temperatura foi controlado externamente através de um controlador digital (Flyever FE05SN).

Por fim, o sistema de umidificação é composto de garrafas de aço, preenchidas com água deionizada (Milli-Q), com um sistema de aquecimento controlado externamente e com proteção contra perda de calor. O gás de entrada é injetado no fundo da garrafa, após a determinação da vazão de entrada, seguindo para as entradas de gases da célula. $\mathrm{O}$ sistema de aquecimento foi controlado através de controladores digitais (Flyever FE05S).

As condições de operação da célula dependem do procedimento, conforme descrito em (41), particularmente a corrente total exigida, $I$, e as vazões de entrada do ânodo e cátodo, $Q_{\text {ano }}$ e $Q_{\text {cat }}$, respectivamente. Por outro lado, todas as medidas foram realizadas em regime galvanostático, através de uma carga dinâmica (electronic load, Chroma 6314A); com vazões de entrada controladas através de controladores de massa (Aalbor GFC16 para $\mathrm{H}_{2}$, e GFC37 para ar); e alimentação de $\mathrm{H}_{2}$ e ar seco sintético, no ânodo e cátodo, respectivamente. Demais condições fixas durante todas as coletas de dados foram: temperaturas de umidificação, $T_{\mathrm{in}, \text { ano }}=363,2 \mathrm{~K}$ e $T_{\text {in,cat }}=358,2 \mathrm{~K}$, para o ânodo e cátodo, respectivamente; e temperatura da célula $T_{\text {cell }}=353,2 \mathrm{~K}$. Ao contrário do recomendado em (41), não foi realizada pressurização da célula. A temperatura e pressão ambientes não foram controladas ou registradas.

\subsection{Break-in}

O procedimento de break-in foi realizado para o MEA \#2, dado que o foi verificado que o MEA \#1 I já encontrava-se condicionado. Este procedimento consiste nas seguintes etapas(41):

1. Aquecimento do sistema de umidificação e célula até respectivas temperaturas de operação. 
2. Polarização da célula em $E=0,6 \mathrm{~V}$ durante $60 \mathrm{~min}$.

3. Polarização da célula em $E=0,7 \mathrm{~V}$ durante $20 \mathrm{~min}$.

4. Polarização da célula em $E=0,5 \mathrm{~V}$ durante $20 \mathrm{~min}$.

5. Repetir passos 3 e 4 oito vezes.

6. Exigência de corrente $I=10$ A durante 720 min.

Sendo que a alimentação de gases foi feita de maneira a atender os requisitos de estequiometria $\lambda_{i}(16)$ :

$$
\begin{aligned}
\lambda_{i} & =\frac{\dot{N}_{i}}{R_{i}} \\
& =\frac{n_{i} F \dot{N}_{i}}{I}
\end{aligned}
$$

onde $\dot{N}_{i}$ é o fluxo molar de entrada da espécie adequada, $R_{i}=I / n_{i} F$ é a taxa de consumo, $n_{i}$ é o número de elétrons da reação e $F$ é a constante de Faraday. As estequiometrias utilizadas foram de $\lambda_{\text {ano }}=1,2$ e $\lambda_{\text {cat }}=2$ para o ânodo e cátodo, respectivamente. O fluxo molar de entrada foi calculado utilizando a lei dos gases ideais e considerando uma fração volumétrica de 0,22 para o $\mathrm{O}_{2}$ em ar. A umidade relativa de alimentação é considerada como $100 \%$.

Para verificação do procedimento de break-in, foram obtidas um mínimo de três curvas de polarização, segundo (41), até a obtenção de um desvio no potencial de $\delta E(I=40 \mathrm{~A})<$ $5 \mathrm{mV}$. As condições foram as mesmas utilizadas para o break-in, notando-se que o sistema não fora pressurizado, e que as curvas foram obtidas até $I=40 \mathrm{~A}$. Tal modificação foi feita em decorrência do modelo computacional a ser validado (ver Seção 4.2), que desconsidera a presença de água líquida. Assim, as condições operacionais foram limitadas de modo a evitar o acúmulo de água líquida.

\subsection{Aquisição de Dados}

As curvas de polarização foram coletadas para cada MEA após o procedimento de break-in, quando realizado. Cada MEA foi utilizado para a coleta de nove conjuntos de dados, sendo que a célula fora montada três vezes, com a aquisição de três conjuntos de dados por montagem. O seguinte protocolo foi obedecido para cada ciclo de montagem do dispositivo:

1. Montagem da célula.

2. Aquecimento do sistema de umidificação e célula até respectivas temperaturas de operação, 
3. Condição de stand-by: $Q_{\text {ano }}=8$ e $Q_{\text {cat }}=33 \mathrm{~cm}^{3} \min ^{-1}, I=10$ A.

4. Estabilização da temperatura da célula.

5. Coleta de conjunto de dados, segundo Tabela 1.

6. Condição de stand-by.

7. Repetir passos 4 a 6 duas vezes.

8. Resfriamento do sistema de umidificação.

9. Resfriamento da célula.

10. Interrupção da alimentação de gases.

11. Limpeza dos canais de escoamento com Ar.

12. Desmontagem da célula.

A Tabela 1 apresenta os valores de $Q_{\text {ano }}, Q_{\text {cat }}$ e $I$ para a realização das curvas de polarização. Para cada curva, são coletados valores da diferença de potencial elétrico, $\Delta E$, de um multímetro (Minipa ET-2110) conectado às placas coletoras de corrente; temperaturas de umidificação e da célula; e superfícies de distribuição de corrente e de temperatura do cátodo. A aquisição dos dados de distribuição de corrente e temperatura são feitas através do software CurrentVIEW ( $\mathrm{S}++$ Simulation Services, Alemanha). Sempre que possível, o protocolo fora realizado continuamente ao longo de um dia.

Tabela 1 - Parametrização adotada para curvas de polarização

\begin{tabular}{|c|c|c|c|}
\hline$\#$ & $\begin{array}{r}\text { Vazão anódica, } Q_{\text {ano }} \\
\text { (L m }\end{array}$ & $\begin{array}{l}\text { Vazão catódica, } Q_{\text {cat }} \\
\left.\text { in }^{-1}\right)\end{array}$ & $\begin{array}{c}\text { Corrente total, } I \\
\text { (A) }\end{array}$ \\
\hline $\mathrm{I}$ & 0,04 & 0,16 & $0-5$, passo de 0,5 \\
\hline II & 0,08 & 0,33 & $0-10$, passo de 1 \\
\hline III & 0,16 & 0,66 & $0-20$, passo de 2 \\
\hline IV & 0,25 & 0,99 & $0-30$, passo de 3 \\
\hline
\end{tabular}

Usando as curvas de polarização, foram avaliados o potencial de equilíbrio e a resistência ôhmica total do sistema. O potencial de equilíbrio foi estimado e analisado através do potencial de circuito aberto, $\Delta E(I=0)$. A resistência ôhmica, $R_{\Omega}$, foi obtida da regressão linear da região central da curva de polarização, utilizando o modelo linear dado pela lei de Ohm:

$$
E(I)=E^{*}-R_{\Omega} I
$$

onde $E^{*}$ é simplesmente o intercepto da reta, enquanto a inclinação é interpretada como a resistência ao transporte de carga pelos materiais do sistema. A região considerada linear 
foi determinada visualmente, sendo diferente para cada conjunto definido na Tab. 1: $2-5$ (I), $3-8$ (II), $8-16$ (III) e 9-21 A (IV). A regressão foi realizada através da rotina NonLinearModel.fit, com valores iniciais de $E_{0}^{*}=1$ e $R_{\Omega, 0}=1$.

Para a avaliação das superfícies de distribuição de corrente, foi utilizada uma grandeza denominada corrente relativa:

$$
I_{R}=I / I_{\lambda}
$$

onde $I_{\lambda}$ é a corrente máxima para um dado conjunto de vazão, descrita na Tab. 1. 


\section{METODOLOGIAS COMPUTACIONAIS}

Neste Capítulo serão descritas as metodologias computacionais e a descrição matemática empregadas para os experimentos in silico. A descrição da metodologia será dividida entre dois sistemas estudados: i) um protótipo de célula, de aproximadamente $5 \mathrm{~cm}^{2}$ de área geométrica de eletrodo, com foco na dinâmica de fluidos e distribuição de espécies; e ii) uma célula a combustível completa, de aproximadamente $50 \mathrm{~cm}^{2}$ de área geométrica de eletrodo, com foco na dinâmica de fluidos e impacto na distribuição espacial de corrente.

Para todos os procedimentos computacionais descritos a seguir, o sistema utilizado foi um desktop com processador Intel ${ }^{\circledR}$ Core $^{\text {TM }}$ i7-3930K e um kit de RAM instalada de 8 pentes de 8GB Kingston ${ }^{\circledR}$ HyperX ${ }^{\circledR}$ KHX1600C10D3B1. O sistema operacional em uso é uma distribuição Debian 8 64bits baseada em GNU/Linux. Os modelos computacionais foram elaborados utilizando o software comercial COMSOL Multiphysics ${ }^{\circledR}$ versão 5.2, juntamente com os módulos de Baterias e Células a Combustível e CFD. A descrição das formulações matemáticas foi obtida dos manuais de referência do software. Toda a manipulação de dados foi realizada utilizando as distribuições R2012a e R2015a do software MATLAB ${ }^{\circledR}$.

\subsection{Protocélula}

Durante o estudo do protótipo de célula, um modelo base foi estabelecido, denominado Alfa, que foi utilizado para explorar aspectos do sistema referentes à dinâmica de fluidos. Abaixo será descrita a formulação matemática do modelo, e em seguida apresentados os detalhes computacionais das simulações e refinamentos realizados com o mesmo.

Brevemente, o sistema sob estudo é um protótipo do cátodo de uma célula a combustível tipo $\operatorname{PEM}(33)$, tendo como objetivo a observação direta da dinâmica de fluidos nos meios porosos. Um traçador é adicionado ao fluido, neste caso ar sintético enriquecido com ozônio, de modo que este interage com um pigmento disperso na camada catalítica, emitindo luz. Esta quimioluminescência é diretamente proporcional à pressão parcial de ozônio, que pode ser relacionada à de oxigênio. Portanto, imagens obtidas da CL deste protótipo providenciam informações sobre o escoamento de gases no cátodo de uma PEMFC. Maiores detalhes a respeito do dispositivo experimental podem ser encontrados em (33). Devido às condições reportadas para o sistema experimental, o modelo Alfa foi estabelecido como o transporte isotérmico de uma espécie diluída em regime estacionário. A espécie em questão é o ozônio, $\mathrm{O}_{3}$, diluído em ar sintético. O modelo é composto dos seguintes domínios computacionais: o canal de escoamento de gases (FC), o substrato macroporoso (MPS), e camada catalítica (CL). Os detalhes da geometria e propriedades dos materiais simulados serão descritos para cada estudo realizado. 


\subsubsection{Formulação Matemática}

O transporte de espécies é dado pela equação de advecção, definida em todos os domínios:

$$
\nabla \cdot\left(-D_{\mathrm{O}_{3}} \nabla C_{\mathrm{O}_{3}}\right)+(\mathbf{u} \cdot \nabla) C_{\mathrm{O}_{3}}=R_{\mathrm{O}_{3}}
$$

onde $D$ é o coeficiente de difusão de Fick e $C$ é a concentração da espécie de interesse; u é o vetor de velocidade do solvente, e $R$ é o termo total de reação. Nos meios porosos, i.e. MPS e CL, o coeficiente de difusão foi corrigido através dos modelos de tortuosidade e de Bruggeman:

$$
\begin{aligned}
& D_{\text {eff }}=\frac{\epsilon}{\tau} D_{\mathrm{O}_{3}}, \text { no MPS } \\
& D_{\text {eff }}=\epsilon^{3 / 2} D_{\mathrm{O}_{3}}, \text { na CL }
\end{aligned}
$$

onde $\tau$ é a tortuosidade do MPS, e $\epsilon$ é a porosidade do domínio. O termo de reação $R_{\mathrm{O}_{3}}$ foi definido somente na CL, representando a interação do ozônio com um catalisador, aproximada pro uma reação de decomposição de primeira ordem:

$$
R_{\mathrm{O}_{3}}=-k C_{\mathrm{O}_{3}}
$$

onde $k$ é a constante de velocidade aparente da reação.

O campo de velocidades u é dado pela formulação de Darcy-Brinkman (DB) para gases compressíveis, definida em todos os domínios:

$$
\frac{\rho}{\epsilon}(\mathbf{u} \cdot \nabla)\left(\frac{\mathbf{u}}{\epsilon}\right)=\nabla \cdot\left[-P \mathbf{I}+\frac{\mu}{\epsilon}\left(\nabla \mathbf{u}+(\nabla \mathbf{u})^{\mathrm{T}}\right)-\frac{2 \mu}{3 \epsilon}(\nabla \cdot \mathbf{u}) \mathbf{I}\right]-\frac{\mu}{\kappa} \mathbf{u}
$$

onde $\rho$ e $\mu$ são a densidade e viscosidade dinâmica do fluido, respectivamente; $\kappa$ é a permeabilidade absoluta do meio; $P$ é a pressão e $\mathbf{I}$ é a matriz identidade. A título de comparação (ver Seções 4.1 .2 e 6.1.1), outras duas formulações para u foram utilizadas. A formulação de Stokes-Darcy (SD) consiste no uso da equação de Navier-Stokes para gases compressíveis, no domínio do FC:

$$
\rho(\mathbf{u} \cdot \nabla) \mathbf{u}=\nabla \cdot\left[-P \mathbf{I}+\mu\left(\nabla \mathbf{u}+(\nabla \mathbf{u})^{\mathrm{T}}\right)-\frac{2}{3} \mu(\nabla \cdot \mathbf{u}) \mathbf{I}\right]
$$

juntamente com a lei de Darcy, nos domínios do MPS e CL:

$$
\mathbf{u}=-\frac{\kappa}{\mu} \nabla P
$$

A terceira formulação utilizada, denominada Stokes-Brinkman(SB), consiste no uso da Eq. 4.6 no FC, acoplada à Eq. 4.5 no MPS e CL. Adicionalmente, as formulações SD e SB possuem uma condição de velocidade de deslizamento (slip velocity) na fronteira entre o FC e o MPS, dada por:

$$
\mathbf{u}=\frac{L_{s}}{\mu} \tau_{n, t}
$$


onde $\tau_{n, t}$ é a tensão de cisalhamento tangencial na fronteira, e $L_{s}$ é o comprimento de deslizamento, dado pela forma geral(42):

$$
L_{s}=c \sqrt{\frac{\kappa}{\epsilon}}
$$

onde $c$ é uma constante, tomada como a unidade neste caso. Além da condição de deslizamento, nota-se que a condição de acoplamento entre as Eqs. 4.6 e 4.7 ou 4.5, para as formulações SD e SB respectivamente, é dada pela continuidade da pressão $P$ na fronteira entre o domínio do FC e do MPS.

Independente da formulação para o escoamento, também é definida em todos os domínios a equação da continuidade:

$$
\nabla \cdot(\rho \mathbf{u})=0
$$

deixando evidente que nenhum termo de fonte ou consumo de momento fora utilizado. Todos os cálculos foram sujeitos a uma pressão de referência $P_{\text {ref }}$.

A condição de entrada de fluido é dada por uma velocidade normal à fronteira representando a entrada de gases, definida pela vazão $Q$ :

$$
\mathbf{u} \cdot \mathbf{n}=Q / A_{\text {in }}
$$

onde $\mathbf{n}$ é o vetor normal à superfície e $A_{\text {in }}$ é a área da entrada de gases. A saída de fluido é definida por uma condição de pressão fixa, com supressão de refluxo:

$$
\left[-P \mathbf{I}+\mu\left(\nabla \mathbf{u}+(\nabla \mathbf{u})^{\mathrm{T}}\right)-\frac{2}{3} \mu(\nabla \cdot \mathbf{u}) \mathbf{I}\right] \mathbf{n}=-P_{\text {out }} \mathbf{n}
$$

As entradas e saídas de espécies coincidem com as de fluido, sendo que a condição de entrada é dada por uma condição de concentração fixa, $C_{\mathrm{O}_{3}}=C_{\text {in }}$, e a saída é dada por:

$$
-\mathbf{n} \cdot D_{\mathrm{O}_{3}} \nabla C_{\mathrm{O}_{3}}=0
$$

Por fim, as propriedades do solvente, ar seco, são obtidas através do software, utilizando uma equação de gases ideais para a densidade:

$$
\rho_{\mathrm{ar}}(P, T)=\frac{P}{R_{\mathrm{ar}} T}
$$

onde $R_{\mathrm{ar}}=287,0 \mathrm{~J} \mathrm{~kg}^{-1} \mathrm{~K}^{-1}$ é a constante específica para ar seco. A viscosidade dinâmica é dada por um polinômio em função da temperatura $T$ :

$$
\begin{aligned}
\mu_{\mathrm{ar}}(T)= & -8,38278 \times 10^{-7}+8,35717 \times 10^{-8} T-7,69430 \times 10^{-11} T^{2} \\
& +4,64373 \times 10^{-14} T^{3}-1,06586 \times 10^{-17} T^{4}
\end{aligned}
$$

definido no intervalo de $200 \mathrm{~K} \leq T \leq 1600 \mathrm{~K}$. 


\subsubsection{Validação}

A validação do modelo Alfa foi feita através da comparação dos resultados simulados, em regime estacionário, obtidos com as três formulações do campo de velocidades, aos resultados experimentais. Estes foram providenciados pelos autores de (33), contendo tanto resultados publicados como inéditos. Qualitativamente, foram comparadas as superfícies de distribuição espacial de pressão parcial de ozônio, $\mathbf{P}_{\mathrm{O}_{3}}(\mathbf{r} ; Q)$, para diferentes valores de vazão de entrada; o consumo total de ozônio em função da vazão de entrada, $\Delta \mathrm{O}_{3}(Q)$; e o perfil da pressão parcial de ozônio ao longo do caminho do FC, projetado na CL. Quantitativamente, apenas a perda de carga $\Delta P(Q)$, i.e. a diferença entre a pressão de saída e de entrada, em função da vazão de entrada fora avaliada. Para o consumo de ozônio, foram avaliados o erro médio absoluto (MAE, mean average error), o erro máximo (MaxE, maximum error) e o coeficiente de correlação de Pearson (R).

A geometria utilizada para a validação, apresentada na Figura 5, é baseada no sistema experimental descrito em (33). Os detalhes das dimensões utilizadas são apresentados na Tabela 2. A curva observada na CL (Fig. 5a) é a projeção do centro do caminho dos gases, dado pelo FC. Deve-se notar ainda que, ao contrário do suposto no sistema experimental, efeitos de compressão nas camadas porosas não foram considerados.

Tabela 2 - Dimensões utilizadas na geometria do modelo Alfa durante a validação.

\begin{tabular}{cc}
\hline Dimensão & Valor $\left(10^{-3} \mathrm{~m}\right)$ \\
\hline Largura do canal & 0,8 \\
Comprimento do canal & 22 \\
Profundidade do canal & 1,0 \\
Largura de terraça & 1,6 \\
Diâmetro de entrada/saída & 0,8 \\
Aresta dos meios porosos & $x=25,0$ \\
& $y=26,8$ \\
Espessura do MPS & 0,19 \\
Espessura da CL & 0,15 \\
\hline
\end{tabular}

Fonte: Autoria própria.

As variáveis globais $\Delta P(Q)$ e $\Delta \mathrm{O}_{3}(Q)$ são resultados diretos das simulações, e são obtidas simplesmente pela diferença entre os valores de entrada e saída das respectivas variáveis. A pressão parcial de ozônio, por outro lado, é obtida da concentração de $C_{\mathrm{O}_{3}}$, que é a variável resolvida no modelo Alfa:

$$
\mathbf{P}_{\mathrm{O}_{3}}(\mathbf{r} ; Q)=\frac{C_{\mathrm{O}_{3}}(\mathbf{r}) P_{A}(\mathbf{r} ; Q)}{C^{*}}
$$

onde $\mathbf{r}$ é o vetor posição e $C^{*}=1 \mathrm{~mol} \mathrm{~m}^{-3}$ é a concentração de referência. No caso do perfil de pressão parcial ao longo do caminho da $\mathrm{FC}$, esta foi obtida avaliando $\mathbf{P}_{\mathrm{O}_{3}}$ ao longo da trajetória mostrada na Fig. 5a, e subsequentemente normalizadas pelo maior 
Figura 5 - Geometria utilizada no modelo Alfa: a) visão superior, mostrando a superfície que acompanha o meio do canal de escoamento; b) visão inferior, indicando a entrada e saída de gases; e c) parte da seção transversal, no plano yz, explicitando os domínios.

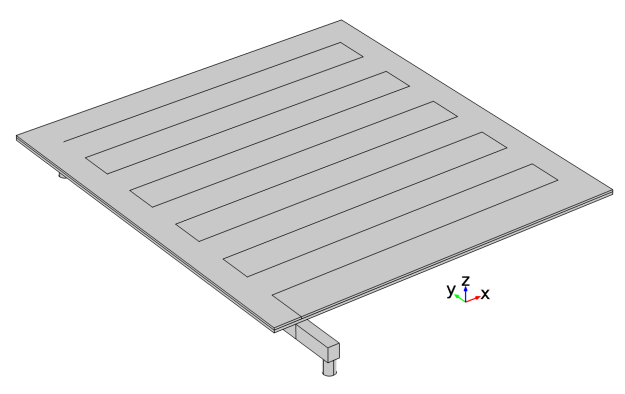

(a)

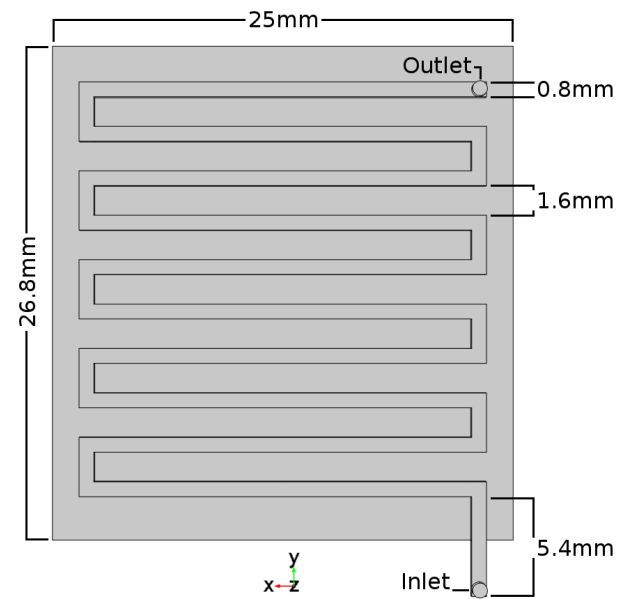

(b)

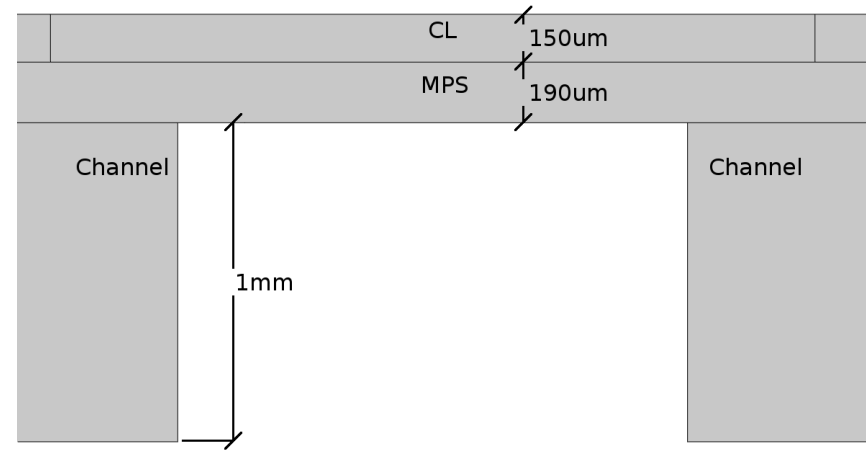

(c)

Fonte: Autoria própria.

valor de $\mathbf{P}_{\mathrm{O}_{3}}(\mathbf{r})$. Para os resultados experimentais do perfil de pressão parcial, foi utilizado a média entre dois pixels, ao longo de aproximadamente a mesma trajetória, também normalizados pelo maior valor da superfície.

Os parâmetros utilizados nas simulações encontram-se descritos na Tabela 3. Os valores foram buscados na literatura de modo a reproduzir da melhor maneira os materiais utilizados no sistema experimental(33). Os valores de pressão de referência e de saída foram cedidos pelos autores de (33). As propriedades de transporte da CL foram obtidos através de uma simulação de perda de carga em função da vazão, com os parâmetros resultando do ajuste da curva final utilizando a equação de Darcy-Forchheimer(21) (ver Apêndice A). Os valores de $Q$ simulados estiveram dentro de um intervalo de 200 a $450 \mathrm{~cm}^{3} \mathrm{~min}^{-1}$, sendo estimado o intervalo de número de Reynolds Re de aproximadamente 260 a 590 . O valor de $k$ foi variado dentro um intervalo de 10 a $10^{3} \mathrm{~s}^{-1}$, dado que não fora possível obter um valor 
teórico ou empírico. A concentração inicial de ozônio foi de $C_{\mathrm{O}_{3}}^{0}=1200 \times 10^{-6} \mathrm{~mol} \mathrm{~m}^{-3}$, as velocidades iniciais $\mathbf{u}^{0}=0$ e a pressão inicial de $P^{0}=10^{3} \mathrm{~Pa}$.

Tabela 3 - Parâmetros utilizados no modelo Alfa durante a validação.

\begin{tabular}{ccc}
\hline Parâmetro & Valor & Referência \\
\hline Coeficiente de difusão de $\mathrm{O}_{3}$ em $\mathrm{N}_{2}, D_{O_{3}}$ & $1,6 \times 10^{-5} \mathrm{~m}^{2} \mathrm{~s}^{-1}$ & $(43,44)$ \\
Pressão de referência, $P_{\text {ref }}$ & $1,027 \times 10^{5} \mathrm{~Pa}$ & ver texto \\
Pressão de saída, $P_{\text {out }}$ & $1,0994 \times 10^{5} \mathrm{~Pa}-P_{\text {ref }}$ & ver texto \\
Temperatura, $T$ & $298 \mathrm{~K}$ & $(33)$ \\
Concentração de $\mathrm{O}_{3}$ de entrada, $C_{\text {in }}$ & $1200 \times 10^{-6} \mathrm{~mol} \mathrm{~m}^{-3}$ & $(33)$ \\
Porosidade do MPS, $\epsilon_{\mathrm{MPS}}$ & 0,801 & $(45)$ \\
Permeabilidade do MPS, $\kappa_{\mathrm{MPS}}$ & $9,18 \times 10^{-12} \mathrm{~m}^{2}$ & $(22)$ \\
Tortuosidade do MPS, $\tau_{\mathrm{MPS}}$ & 1,199 & $(22)$ \\
Porosidade da CL, $\epsilon_{\mathrm{CL}}$ & 0,497 & ver texto \\
Permeabilidade da CL, $\kappa_{\mathrm{CL}}$ & $8,82 \times 10^{-11} \mathrm{~m}^{2}$ & ver texto \\
\hline
\end{tabular}

Fonte: Autoria própria.

A malha utilizada para os cálculos, i.e. a discretização do sistema contínuo em um número finito de elementos, pode ser visualizada na Fig. 6. Esta foi baseada em um esquema pré-definido do software denominado "fine". Uma análise da qualidade da malha foi feita (ver Apêndice C), e o esquema atual foi escolhido considerando o tempo e custo dos cálculos para um dado aprimoramento na resposta do modelo. O esquema consiste no uso de elementos triangulares nas fronteiras externas no modelo, com tamanho pré-definido como "finer" (tamanhos mínimo e máximo de elementos de 3,06 × $10^{-5}$ e $2,83 \times 10^{-4} \mathrm{~m}$, respectivamente; taxa de crescimento máxima de 1,1 ; fator de curvatura de 0,4 ; e resolução em regiões estreitas de 0,9 ). Os elementos de domínio são elementos tetraédricos de tamanho pré-definido como "coarse" (tamanhos mínimo e máximo de elemento de $2,29 \times 10^{-4}$ e $7,65 \times 10^{-4} \mathrm{~m}$, respectivamente; taxa de crescimento máxima de 1,2 , fator de curvatura 0,7 ; e resolução em regiões estritas de 0,7 ). Foram incluídos três elementos quadriláteros na direção normal às fronteiras do FC, denominados elementos de "camada limite". A malha completa consiste de elementos em um intervalo de 2, $03 \times 10^{-5}$ a $3,45 \times 10^{-4} \mathrm{~m}$, com uma qualidade média de elemento de 0,5432 e cerca de $1,7 \times 10^{6}$ elementos de domínio.

A resolução do sistema de equações foi feita utilizando um solver segregado de duas etapas: primeiramente as variáveis referentes à dinâmica de fluidos, em seguida a concentração de ozônio. Todas as variáveis foram discretizadas linearmente. Para cada etapa foi utilizado uma implementação do solver PARDISO(46) (Parallel Sparse Direct and Multi-Recursive Iterative Linear Solvers), com tolerância relativa de $10^{-3}$, e escala baseada nas condições iniciais. Uma varredura paramétrica foi utilizada para os valores de $Q$ e $k$, sendo que a condição inicial de cada novo ponto foi dada pela solução anterior. 
Figura 6 - Malha utilizada no modelo Alfa: a) visão superior, b) visão inferior, e c) visão lateral.

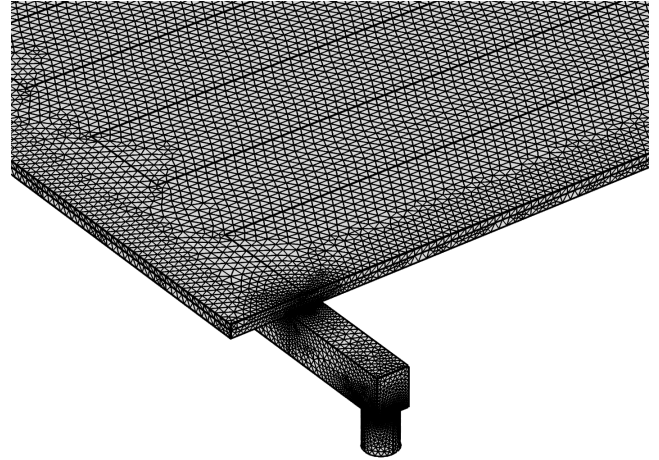

(a)

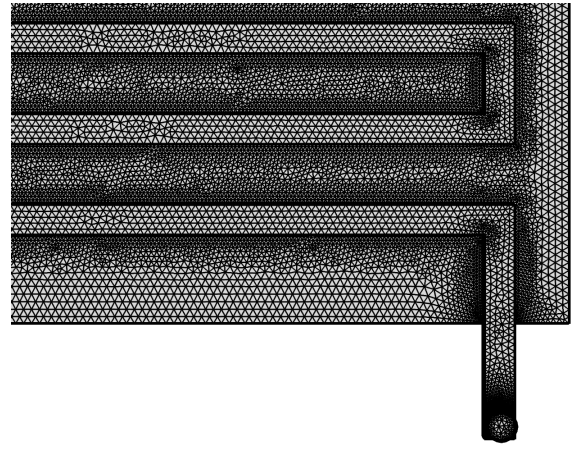

(b)

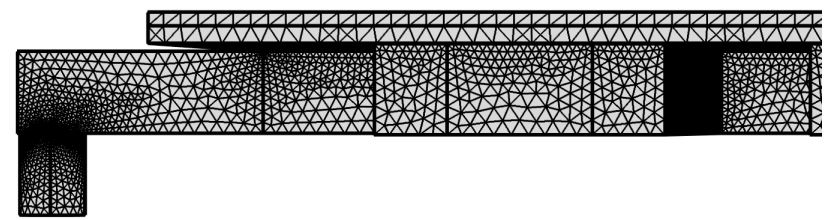

(c)

Fonte: Autoria própria.

\subsubsection{Estudo do Transporte Convectivo}

Para o estudo inicial do transporte convectivo no modelo Alfa, foram utilizadas as mesmas condições da validação, descritas na Seção 4.1.2. Foram analisadas as implicações do uso das diferentes formulações de dinâmica de fluidos em uma célula a combustível, além da contribuição da convecção no transporte de espécies nas camadas porosas.

Para a correlação entre a protocélula e uma célula a combustível real, foram construídas curvas de polarização utilizando analogias com as variáveis eletroquímicas. O potencial elétrico $E$ foi substituído por um sobrepotencial de concentração $\eta_{C}$, definido como(32):

$$
\eta_{C}=E-E_{\text {eq }}
$$

onde $E_{\text {eq }}$ é o potencial elétrico de equilíbrio, i.e. para corrente $I=0$. Para o sistema em questão, $\eta_{C}$ pode ser descrito utilizando a diferença entre a pressão parcial de ozônio local, $P_{\mathrm{O}_{3}}$, resultante da simulação; e a pressão parcial de referência, $P_{\mathrm{O}_{3}}^{*}$, dada apenas pela 
perda de carga do sistema, i.e. para $R_{\mathrm{O}_{3}}=0$. Desta maneira, obtém-se:

$$
\eta_{C}=\frac{R T}{n F} \log \left(\frac{P_{\mathrm{O}_{3}}}{P_{\mathrm{O}_{3}}^{*}}\right)
$$

onde $R$ é a constante universal dos gases, $F$ é a constante de Faraday e $n=1$ é o número de elétrons, neste caso sendo um valor arbritrário. Como $P_{\mathrm{O}_{3}}=P_{\mathrm{O}_{3}}(\mathbf{r})$, a média de $\eta_{C}$ calculada sobre o domínio da CL foi utilizada. A corrente $I$, por sua vez, é dada pela lei de eletrólise de Faraday(32):

$$
I=n F A \frac{\partial C_{\mathrm{O}_{3}}}{\partial t}
$$

onde $A$ é a área efetiva para reação na $\mathrm{CL}$, e o termo $A \partial C / \partial t$ pode ser tomado como a taxa total de reação. Como a variável $R_{\mathrm{O}_{3}}$ representa a taxa de reação por elemento de volume, tem-se que a corrente equivalente pode ser calculada pela equação

$$
I_{\mathrm{O}_{3}}=F \int_{\mathrm{CL}} R_{\mathrm{O}_{3}} \mathrm{~d} V
$$

Por fim, tomando a definição de $R_{\mathrm{O}_{3}}=-k C_{\mathrm{O}_{3}}$, nota-se que é possível "polarizar" o sistema através da variação do valor de $k$. O intervalo de valores utilizados para $k$ foram novamente de 10 a $10^{3} \mathrm{~s}^{-1}$.

Para o estudo da contribuição do transporte convectivo, foram realizadas simulações adicionais com um modelo Alfa modificado (Alfa-mod), onde o transporte convectivo é desacoplado do transporte de espécies nos domínios do MPS e CL, reduzindo a Eq. 4.1 para a equação de difusão:

$$
\nabla \cdot\left(-D_{\mathrm{O}_{3}} \nabla C_{\mathrm{O}_{3}}\right)=R_{\mathrm{O}_{3}}
$$

As seguintes comparações foram feitas entre os modelos Alfa e Alfa-mod. De maneira qualitativa, foram comparadas as superfícies de pressão parcial de ozônio na CL, e correlacionadas com superfícies e linhas de corrente representando as componentes de $\mathbf{u}$ no FC. Foi avaliada, de maneira quantitativa, a diferença relativa, $\Delta \mathbf{P}_{\mathrm{O}_{3}}$, entre as superfícies de pressão parcial, $\mathbf{P}_{\mathrm{O}_{3}}^{\text {mod }}$ e $\mathbf{P}_{\mathrm{O}_{3}}$, dos modelos Alfa-mod e Alfa respectivamente, definida por:

$$
\Delta P_{i j}=\frac{P_{i j}^{\bmod }-P_{i j}}{\max (\mathbf{P})}, i \in[1,536], j \in[1,500]
$$

onde a função $\max ()$ retorna o maior valor do argumento. A resolução das matrizes foi escolhida de modo a representar o sistema experimental, com resolução espacial de $50 \mu \mathrm{m}(33)$. Foram comparadas as contribuições convectiva e difusiva ao transporte total de ozônio à CL, através da integração da componente $z$ do fluxo molar ao longo da fronteira entre o MPS e a CL:

$$
\dot{N}_{\mathrm{O}_{3}}^{\mathrm{CL}}=\int_{\partial \Omega}\left(\mathbf{J}_{\mathrm{O}_{3}} \cdot \mathbf{k}\right) \mathrm{d} A
$$


onde $\dot{N}_{\mathrm{O}_{3}}^{\mathrm{CL}}$ é o transporte molar, $\mathbf{J}_{\mathrm{O}_{3}}$ é o vetor de fluxo de ozônio, k é o vetor unitário paralelo ao eixo $z$, e o subscrito $\partial \Omega$ indica integração sobre a fronteira. Por fim, foram avaliadas as implicações para uma célula a combustível, utilizando as curvas de polarização descritas acima.

A malha e solver utilizados foram os mesmos descritos para a Seção 4.1.2. O valor da constante de velocidade da decomposição do ozônio foi tomada como $k=250 \mathrm{~s}^{-1}$ (ver Seção 6.1.1).

\subsubsection{Estudo da Compressão do Substrato Macroporoso}

Conforme mencionado na Seção 4.1.2, para a validação e o estudo do efeito do transporte convectivo nos meios porosos, foram desconsiderados possíveis efeitos de compressão dos meios porosos. De modo a avaliar os possíveis efeitos desta compressão, e na tentativa de refinar o modelo, algumas modificações no modelo Alfa foram consideradas, sendo sumarizadas na Tabela 4 e descritas abaixo.

Tabela 4 - Modificações utilizadas no modelo Alfa para a compressão dos meios porosos.

\begin{tabular}{clcl}
\hline \# & Modificações realizadas & \# & Modificações realizadas \\
\hline I & Correção da espessura do MPS & III & Deformação do MPS (Eq. 4.32) \\
II & $\begin{array}{l}\text { Correção da espessura do MPS } \\
\text { Correção da permeabilidade } \kappa_{\mathrm{MPS}}\end{array}$ & IV & $\begin{array}{l}\text { Deformação do MPS } \\
\text { Correção da permeabilidade } \kappa_{\mathrm{MPS}}\end{array}$ \\
\hline
\end{tabular}

Fonte: Autoria própria.

A primeira modificação considerada é puramente geométrica, e envolve a redução da espessura do domínio do MPS, de acordo com o mencionado em (33). Segundo os autores, a espessura dos espaçadores utilizados no dispositivo experimental eram de $290 \mu \mathrm{m}$, implicando que o MPS sofreu uma compressão de $50 \mu \mathrm{m}$, de acordo com as especificações do material. Um fator de compressão, $f_{\text {comp }}$, foi aplicado à espessura do domínio do MPS, no modelo Alfa, de modo a representar tal mudança, sendo que $f_{\text {comp }}=l / l^{0} \approx 0,75$. Foi argumentado pelo autores que a CL não apresentou compressão.

A segunda modificação envolve a permeabilidade do domínio do MPS. A correção baseia-se no modelo de Millington e Quirk para permeabilidade de meios porosos(47), considerando que apenas a componente $z z$ do tensor de permeabilidade $\boldsymbol{\kappa}_{\text {MPS }}$ foi afetada. A correção é dada por:

$$
\kappa_{\mathrm{MPS}}^{\prime}=\kappa_{\mathrm{MPS}} f_{\mathrm{comp}}^{2}
$$

onde foi assumido que a porosidade $\epsilon_{\text {MPs }}$ pouco varia após a compressão. Desta maneira, diferentemente do descrito na Seção 4.1.1, onde os materiais são isotrópicos, a 
permeabilidade do MPS é dada por um tensor diagonal:

$$
\boldsymbol{\kappa}_{\mathrm{MPS}}=\left[\begin{array}{ccc}
\kappa_{\mathrm{MPS}} & 0 & 0 \\
0 & \kappa_{\mathrm{MPS}} & 0 \\
0 & 0 & \kappa_{\mathrm{MPS}}^{\prime}
\end{array}\right]
$$

Deve-se ser apontado neste momento que correções à porosidade foram consideradas. Uma possibilidade, proposta em (48), é dada pela equação:

$$
\epsilon_{\mathrm{MPS}}^{\prime}=1-\frac{1-\epsilon_{\mathrm{MPS}}}{f_{\mathrm{comp}}}
$$

porém nota-se que a equação não é válida para casos onde $f_{\text {comp }} \leq 1-\epsilon$, resultando em valores nulos ou negativos de porosidade. Assim, tal equação foi tomada como fisicamente absurda e descartada. Por outro lado, pode-se considerar uma abordagem geométrica, tomando a definição de porosidade:

$$
\epsilon=\frac{V_{p}}{V_{g}}
$$

onde $V_{p}$ é o volume total dos poros, i.e. de espaço vazio, e $V_{g}$ é o volume geométrico do material; e assumindo que o volume de poro pode ser dado pelo volume de um elipsóide:

$$
V_{p}=\frac{4 \pi}{3} \bar{r}_{a} \bar{r}_{b} \bar{r}_{c}
$$

onde $\bar{r}_{a}, \bar{r}_{b}$ e $r_{c}$ são os eixos semi-principais médios dos poros do material. Mantendo a hipótese utilizada na dedução da Eq. 4.24, que apenas uma das dimensões sofrera compressão, digamos $\bar{r}_{c}^{\prime} / \bar{r}_{c}=f_{\text {comp }}$, e ignorando a possibilidade de eliminação de poros, obtém-se que:

$$
V_{p}^{\prime}=f_{\text {comp }} V_{p}
$$

Entretanto, considerando o volume geométrico de um paralelepípedo, como é o caso do MPS, nota-se que a correção também é linear em $f_{\text {comp }}$ :

$$
V_{g}^{\prime}=f_{\text {comp }} V_{g}
$$

portanto, $\epsilon_{\mathrm{MPS}}^{\prime}=\epsilon_{\mathrm{MPS}}$ em uma primeira abordagem.

A última correção envolve o uso explícito de mecânica dos sólidos para simular a deformação do MPS, conforme descrito na Seção 4.1.4.1. Tal abordagem foi utilizada sob suspeitas que os argumentos para a compressão do MPS, devido à menor espessura dos separadores utilizados no dispositivo experimental em relação ao MPS, forçaram uma compressão não-homogênea deste. Desta maneira, as correções à permeabilidade, quando relevantes, são dependentes da compressão local, $\boldsymbol{\kappa}_{\mathrm{MPS}}=\boldsymbol{\kappa}_{\mathrm{MPS}}(\mathbf{r})$. Adicionalmente, variações das condições de contorno utilizadas nas modificações III e IV foram avaliadas, levando a subtipos (III.a, III.b, etc), conforme descrito na Seção 4.1.4.1. 
Além das modificações consideradas acima, em todos os casos foi alterada a condição de entrada de fluido, sendo agora definida por uma condição de vazão mássica:

$$
-\int_{\partial \Omega} \frac{\rho}{\rho_{\mathrm{std}}}(\mathbf{u} \cdot \mathbf{n}) \mathrm{d} S=Q
$$

onde $\rho_{\text {std }}$ é a densidade padrão, neste caso sendo dada pela Eq. 4.14 para $P_{\text {std }}=1$ atm e $T_{\text {std }}=273 \mathrm{~K}$. Tal mudança não afeta de maneira significativa o resultado das simulações, quando comparado ao modelo validado e aos resultados experimentais disponíveis (ver Apêndice D).

As variáveis analisadas foram as mesmas usadas durante a validação, i.e. pressão parcial de ozônio, consumo total e perda de carga. Da mesma maneira, quando relevante, foram utilizados o MAE, ME e R. Adicionalmente, para cada uma das modificações exploradas, foi variado o valor de $k$ de modo a reduzir o desvio quadrático entre o consumo total de ozônio experimental e os simulados. Utilizando um solver paramétrico, o valor de $k$ foi variado em passos de $10 \mathrm{~s}^{-1}$, resultando nos seguintes valores a serem utilizados: 170 (I), 260 (II), 200 (III.a, III.b e IV.b), 260 s $^{-1}$ (IV.a). A título de comparação, a formulação utilizada no modelo Alfa original (Seção 4.1.1) foi incluída na análise dos resultados, com o valor de $k$ ajustado para $200 \mathrm{~s}^{-1}$.

As malhas utilizadas para as simulações foram geradas conforme descrito na Seção 4.1.2, com a mudança dos elementos de domínio para a definição "normal" (elementos com tamanho entre $1,53 \times 10^{-4}$ e $5,12 \times 10^{-4} \mathrm{~m}$, taxa máxima de crescimento de 1,15 , fator de curvatura 0,6 e resolução em regiões estreitas de 0,7). O número de elementos variou levemente entre as modificações consideradas devido às diferenças da espessura do domínio do MPS.

O solver utilizado difere do utilizado nas Seções 4.1.2 e 4.1 .3 no tipo utilizado em cada passo, neste caso iterativos. Em ambos os passos, foi utilizada a implementação do solver GMRES(49) (Generalized Minimal Residual Method), conforme gerado pelo software. Para o passo 1, o número de níveis multigrid foi reduzido de 3 para 2. Para o passo 2, o fator de relaxação foi alterado de constante para atualizado automaticamente a cada iteração.

\subsubsection{Deformação mecânica do MPS}

No estado estacionário, as equações do movimento a serem resolvidas são(50):

$$
\nabla \cdot \mathbf{s}+\mathbf{F}_{V}=0
$$

onde $\mathbf{s}$ é o tensor de Cauchy de tensão mecânica, e $\mathbf{F}_{V}$ é o vetor de forças volumétricas agindo na geometria. A Eq. 4.32 é definida nos domínios do MPS e da CL, sendo ambos tratados como materiais elásticos e lineares. Desta maneira, o tensor de Cauchy é dado por:

$$
\mathbf{s}=\mathbf{s}_{\mathrm{ext}}+\mathbf{C}: \boldsymbol{\epsilon}_{\mathrm{el}}
$$


onde $\mathbf{s}_{\text {ext }}$ são contribuições extras à tensão mecânica, neste caso $\mathbf{s}_{\text {ext }}=0 ; \mathbf{C}$ neste caso é o tensor de elasticidade e $\boldsymbol{\epsilon}_{\mathrm{el}}=\boldsymbol{\epsilon}-\boldsymbol{\epsilon}_{\mathrm{in}}$ é o tensor de deformação elástica dado pela diferença entre o tensor de deformação total e o tensor de deformação inelástica. Neste caso, $\boldsymbol{\epsilon}_{\mathrm{in}}=0$, portanto $\boldsymbol{\epsilon}_{\mathrm{el}}=\boldsymbol{\epsilon}$. Por fim, o tensor de deformação é dado por:

$$
\boldsymbol{\epsilon}=\frac{1}{2}\left[(\nabla \mathbf{d})^{\mathrm{T}}+\nabla \mathbf{d}\right]
$$

onde $\mathbf{d}$ é o campo de deslocamentos da geometria. Adicionalmente, a CL foi tratada como um material aproximadamente incompressível, levando a uma modificação da Eq. 4.33:

$$
s=s_{\mathrm{ext}}+\mathbf{C}: \boldsymbol{\epsilon}_{\mathrm{el}}-\left(\frac{\operatorname{tr}\left(\mathbf{C}: \boldsymbol{\epsilon}_{\mathrm{el}}\right)}{3}+p_{w}\right) \mathbf{I}
$$

onde a função $\operatorname{tr}()$ retorna o traço do argumento, $p_{w}$ é uma pressão auxiliar utilizada no software, e I é a matriz identidade de ordem adequada. Tal modificação foi utilizada devido a observações, feitas durante a montagem do dispositivo experimental utilizado em (33), relatando sobre a aparente incompressibilidade do material utilizado na CL.

A determinação do tensor $\mathbf{C}$ depende da escolha das propriedades estruturais utilizadas para descrever o material. Embora a própria natureza dos materiais porosos sugiram comportamentos não-isotrópicos e não-lineares, e resultados apresentados em (51) confirmem tais expectativas; limitações do software possibilitam apenas a simulação de materiais isotrópicos e lineares. Desta maneira, o tensor $\mathbf{C}$ pode ser escrito como uma matriz quadrada de ordem 6, chamada de matriz de elasticidade:

$$
\mathbf{D}=\frac{E}{(1+\nu)(1-2 \nu)}\left[\begin{array}{cccccc}
1-\nu & \nu & \nu & 0 & 0 & 0 \\
\nu & 1-\nu & \nu & 0 & 0 & 0 \\
\nu & \nu & 1-\nu & 0 & 0 & 0 \\
0 & 0 & 0 & \frac{1-2 \nu}{2} & 0 & 0 \\
0 & 0 & 0 & 0 & \frac{1-2 \nu}{2} & 0 \\
0 & 0 & 0 & 0 & 0 & \frac{1-2 \nu}{2}
\end{array}\right]
$$

onde $E$ é o módulo de Young e $\nu$ é a razão de Poisson do material. No caso de materiais isotrópicos, é possível utilizar outras propriedades do material. No caso do MPS, foi utilizado o módulo de Young e o módulo de cisalhamento, $G$, relacionado a $E$ e $\nu$ por:

$$
G=\frac{E}{2(1+\nu)}
$$

No caso da CL, foram usados os valores de $E$ e $\nu$. A Tabela 5 apresenta os valores dos parâmetros estruturais, juntamente com os valores de densidade utilizados. Para o MPS, os valores apresentados na devida referência são levando em conta uma material ortotrópico, em específico os valores no plano do material. Como tal abordagem não é atualmente possível no modelo, os valores médios foram tomados. Para a CL, foram utilizados valores arbitrários que refletissem as observações feitas no dispositivo experimental, além do tratamento quasi-incompressível. 
Em relação à correção da permeabilidade, Eq. 4.24, quando relevante, esta fora feita utilizando a razão volumétrica $J$ como o fator de compressão $f_{\text {comp }}$. A razão volumétrica $J$ representa a razão entre elementos de volume infinitesimais das geometrias deformada e original:

$$
J=\frac{\mathrm{d} V^{\prime}}{\mathrm{d} V}
$$

onde $\mathrm{d} V^{\prime}$ é o elemento de volume após a deformação. No software, $J$ é dado pelo determinante do tensor gradiente de deformação $\mathbf{F}$ :

$$
\begin{aligned}
J & =\operatorname{det}(\mathbf{F}) \\
& =\operatorname{det}(\nabla \mathbf{d}+\mathbf{I})
\end{aligned}
$$

Dada a dependência com o campo de deslocamentos, nota-se que $J=J(\mathbf{r})$, resultando na dependência espacial da permeabilidade do MPS, conforme apontado anteriormente.

As condições de contorno utilizados na solução da equações do movimento levaram a diferentes subtipos das modificações, conforme mencionado na Seção 4.1.4. As condições de contorno avaliadas para tal subdivisão foram: a) $d_{z}(\mathrm{CL})=-50 \mu \mathrm{m}$, i.e. foi considerada uma compressão homogênea dada pelo deslocamento da CL; e b) $d_{z}=-50 \mu \mathrm{m}$ nas fronteiras laterais da CL, i.e. foi considerada uma compressão não-homogênea pela CL. Os valores utilizados para os deslocamentos da CL seguem o reportado em (33), conforme mencionado na Seção 4.1.4.

As demais condições de contorno utilizadas, comuns a todas as subdivisões, foram de $\mathbf{d}=0$ na fronteira inferior "livre" do MPS, que estaria em contato com a placa contendo o FC; deformação livre na fronteira em contato com o FC; e $d_{x}=d_{y}=0$ nas fronteiras laterais do MPS. As condições iniciais utilizadas foram de $\mathbf{d}=\partial \mathbf{d} / \partial t=0$.

Tabela 5 - Parâmetros utilizados para o cálculo de deformação mecânica.

\begin{tabular}{ccc}
\hline Parâmetro & Valor & Referência \\
\hline Módulo de Young do MPS, $E_{\mathrm{MPS}}$ & $8 \mathrm{GPa}$ & $(51)$ \\
Módulo de cisalhamento do MPS, $G_{\mathrm{MPS}}$ & $18,25 \mathrm{MPa}$ & $(51)$ \\
Densidade do MPS, $\rho_{\mathrm{MPS}}$ & $0,44 \mathrm{~g} \mathrm{~cm}^{-3}$ & $(52)$ \\
Módulo de Young da CL, $E_{\mathrm{CL}}$ & $10 \mathrm{GPa}$ & Ver texto \\
Razão de Poisson da CL, $\nu_{\mathrm{CL}}$ & 0,3 & Ver texto \\
Densidade da CL, $\rho_{\mathrm{CL}}$ & $1,0 \mathrm{~g} \mathrm{~cm}^{-3}$ & Ver texto \\
\hline
\end{tabular}

Fonte: Autoria própria.

Em relação ao solver, além dos passos mencionados anteriormente para a dinâmica de fluidos e transporte de espécies, um passo adicional é necessário para as variáveis do campo de deslocamentos. Neste caso, o passo adicional foi resolvido utilizando a implementação do solver direto MUMPS. A discretização usada para as variáveis do campo de deslocamentos foi linear. 


\subsubsection{Estudo da Geometria dos Canais}

Com o intuito de estudar o efeito da geometria dos canais no modelo Alfa, e providenciar previsões para a validação contínua do modelo, geometrias do FC adicionais foram utilizadas. As geometrias foram escolhidas por serem comumente utilizadas com células a combustível, além de estarem sendo estudados com o método descrito em (33). A Figura 7 apresenta as geometrias de FC utilizadas. Os domínios dos meios porosos foram mantidos conforme descrito nas Seções 4.1.2 e 6.1.3.1.

Duas formulações matemáticas foram utilizadas para avaliar as geometrias. A primeira segue a descrição dada na Seção 4.1.1, consistindo no modelo Alfa validado conforme descrito na Seção 6.1.1. A segunda formulação consiste no modelo Alfa utilizando a modificação IV.a descrita na Seção 4.1.4 e discutida na Seção 6.1.3. O valor de $k$ utilizado em cada caso corresponde ao valor otimizado, segundo descrito na Seção 4.1.4 e apresentado na Seção 6.1.3, sendo de $k_{\alpha}=200 \mathrm{~s}^{-1}$ para o modelo Alfa, e de $k_{\beta}=256,5 \mathrm{~s}^{-1}$ para o modelo Alfa com a modificação IV.a, a partir de agora chamado de Beta. O intervalo de vazão utilizado foi de $Q=200$ a $500 \mathrm{~cm}^{3} \mathrm{~min}^{-1}$.

Para a análise dos resultados, foram avaliadas as variáveis de interesse experimental: distribuição espacial de pressão parcial de ozônio, perda de carga e consumo total de ozônio. Na comparação entre os modelos, foi utilizada a diferença de pressão parcial de ozônio entre os modelos Alfa e Beta, $\boldsymbol{\Delta} \mathbf{P}_{\mathrm{O}_{3}}(Q)$, dada por:

$$
\Delta P_{\mathrm{O}_{3}, i j}(Q)=P_{\mathrm{O}_{3}, i j}^{\alpha}(Q)-P_{\mathrm{O}_{3}, i j}^{\beta}(Q), i \in[1,536], j \in[1,500]
$$

para uma dada geometria. A função $\Delta \mathbf{P}_{\mathrm{O}_{3}}(Q)$ foi analisada através da contagem de frequência de valores no intervalo $\left[0,\left\lceil\max \left(\boldsymbol{\Delta} \mathbf{P}_{\mathrm{O}_{3}}\right)\right\rceil\right]$, com passo de $0,1 \mathrm{~Pa}$, onde $\lceil f(x)\rceil$ é a função teto.

As malhas e solvers utilizados foram os mesmos descritos para o modelo Beta, na Seção 4.1.4. 
Figura 7 - Geometrias do FC adicionais utilizadas com o modelo Alfa: a) serpentina-2, b) serpentina-3, c) interdigital, e d) paralela.

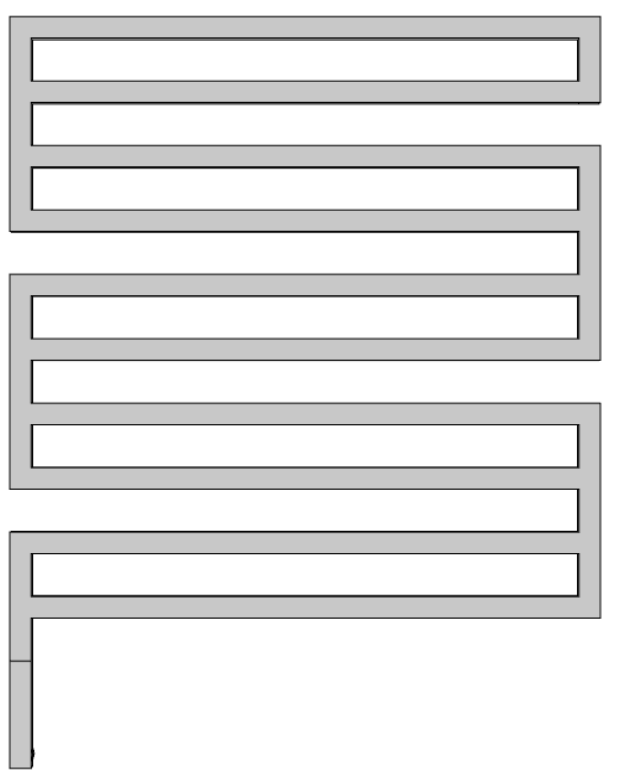

(a)

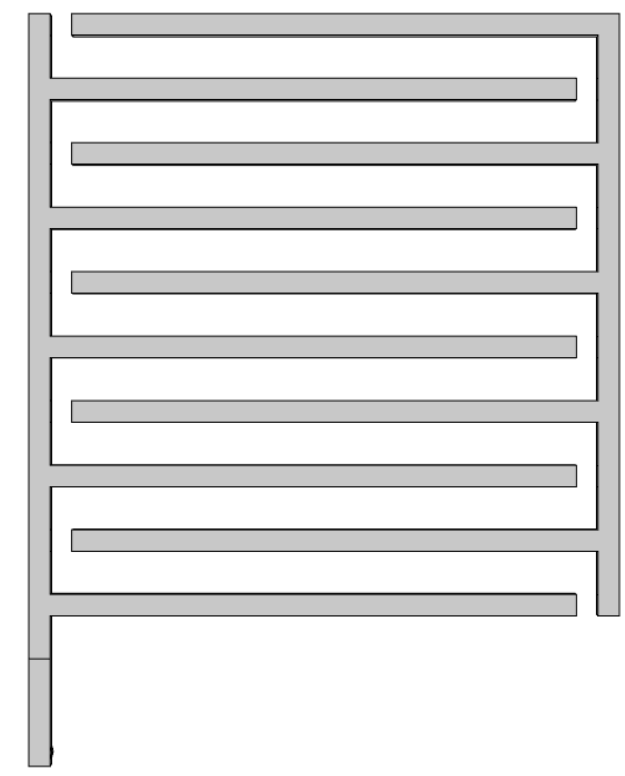

(c)

Fonte: Autoria própria.

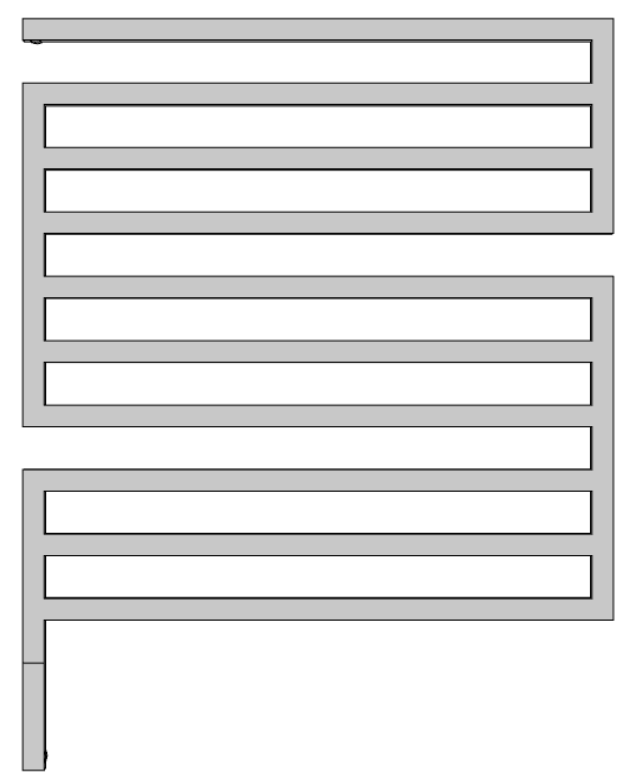

(b)

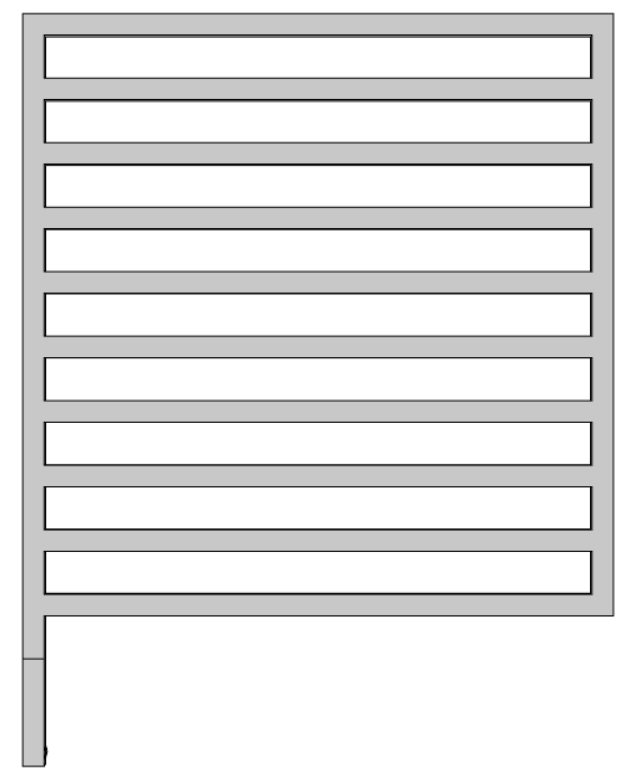

(d) 


\subsection{Célula a Combustível}

Nos estudos com células a combustível, vários modelos foram estabelecidos, sendo progressivamente refinados de acordo com a percepção do autor em relação aos processos físicos passíveis de existirem em tais dispositivos, assim como a partir de evidências na literatura sobre os mesmos. Ao longo do desenvolvimento do trabalho, um modelo base foi determinado como consistente o suficiente, no caso sendo o modelo FC mkII (Seção 4.2.2), onde a primeira tentativa de comparação com os resultados experimentais (Capítulo 5) foi realizada. Adicionalmente, considerando os resultados dos estudos decorrentes do modelo Alfa (Seções 4.1 e 6.1), foi analisado o impacto da formulação matemática da dinâmica de fluidos e da contribuição do transporte convectivo nos resultados eletroquímicos.

Considerando as condições experimentais descritas no Capítulo 3, o modelo FC mkII, foi estabelecido como um modelo estacionário, contendo descrições macroscópicas do transporte de momento, espécies, carga e calor. Brevemente, o transporte de momento, i.e. a dinâmica de fluidos, foi considerado para fluidos compressíveis em baixos valores do número de Mach $(\mathrm{Ma}<0,3)$, tanto em meio livre como em meios porosos. O transporte de espécies é dado considerando soluções gasosas concentradas, ou seja, considerando a interação entre espécies, sendo que a composição de cada mistura afeta as propriedades físicas das mesmas. O transporte de cargas foi considerado no regime da lei de Ohm, através da resistividade dos condutores eletrônicos e iônicos. As reações eletroquímicas foram tomadas de maneira efetiva, considerando as CL como eletrodos porosos, com as reações sendo tratadas globalmente, sem a consideração explícita de intermediários e de interações com a superfície dos eletrocatalisadores. Por fim, o transporte de calor é tratado também de maneira efetiva, considerando os processos de condução e convecção na transferência de calor. A parametrização escolhida busca refletir as condições experimentais descritas no Capítulo 3, na medida em que resultados experimentais ou valores padrões foram encontrados. A geometria do modelo, semelhante ao dispositivo experimental, juntamente com os detalhes do modelo e os estudos realizados, serão apresentados abaixo.

\subsubsection{Geometria e Parametrização}

A geometria utilizada nos modelos FC mkII e derivados, apresentada na Figura 8, é baseada no dispositivo experimental apresentado no Capítulo 3, apresentando possíveis diferenças na estrutura e propriedades do MEA, devido à ignorância sobre o mesmo. Assim, trata-se de um dispositivo com área geométrica dos eletrodos de $\approx 50 \mathrm{~cm}^{2}$, xibindo os seguintes domínios: placas monopolares (BPs) com superfície externa segmentada (Fig. 8a); canais de escoamento (FCs) do tipo serpentina ininterrupta de dois canais (Fig. 8b); substratos macroporosos (MPSs), camadas microporosas (MPLs) e camadas catalíticas (CLs) compondo o meio poroso (Fig. 8d); e membrana trocadora de prótons (PEM, Fig. 
Figura 8 - Geometria utilizada no modelo FC mkII: a) visão completa, b) geometria dos canais de escoamento utilizada, c) detalhes da geometria dos canais de escoamento, e d) detalhes da composição interna do modelo ao longo da espessura.

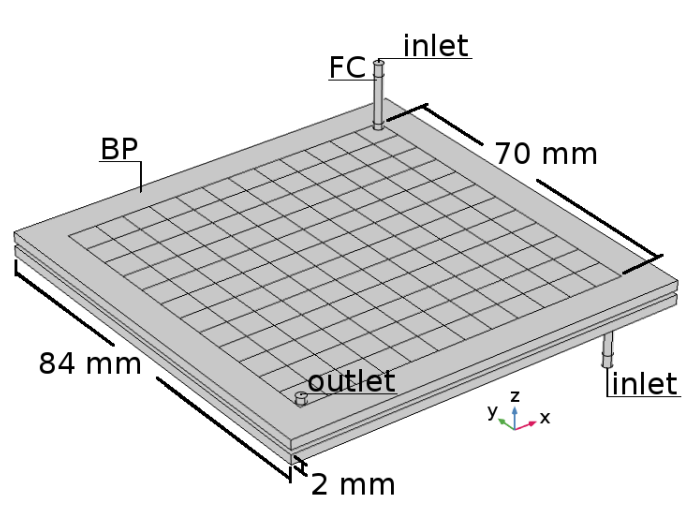

(a)

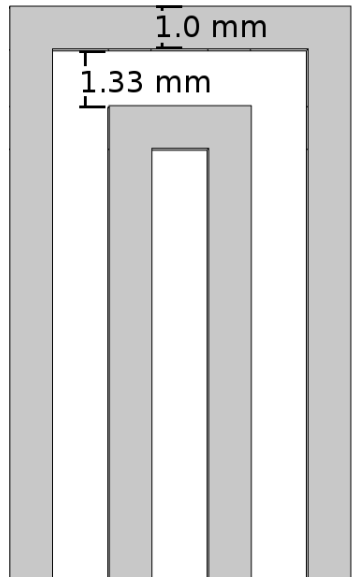

(c)

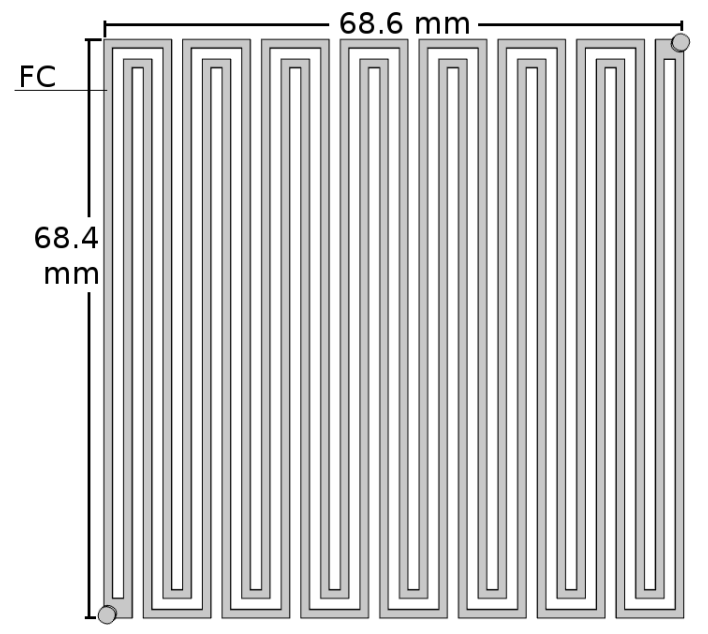

(b)

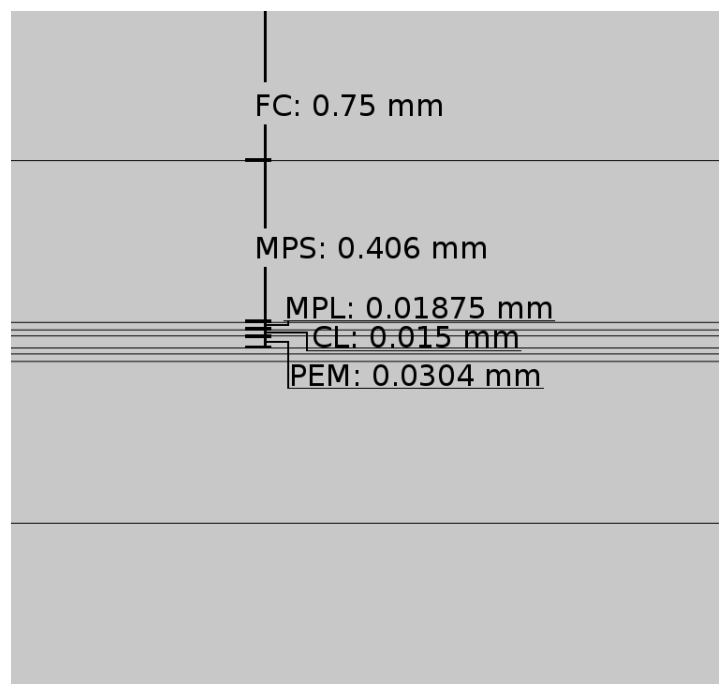

(d)

Fonte: Autoria própria.

8d). Os compartimentos anódico e catódico da geometria são compostos pelos mesmos domínios, sendo que os FCs são imagens especulares em relação ao plano $x z$.

As dimensões relevantes de cada domínio são apresentados na Tabela 6 e indicadas na Fig. 8a. Conforme mencionado anteriormente, o modelo busca refletir as configurações do dispositivo experimental estudado. Desta maneira, as medidas referentes aos domínios da $\mathrm{BP}$ e FC foram medidos diretamente, enquanto que as espessuras dos meios porosos refletem valores de materiais tipicamente utilizados em células PEM. Neste ponto, deve-se notar que o MPS foi considerado incompressível, enquanto que as CLs e a PEM foram considerados compressíveis, onde estimou-se uma compressão de $25 \%$ e $\approx 40 \%$, respectivamente. Deve-se apontar, ainda, que os comprimentos utilizados nas entradas e saídas de gás (Fig. 8a) são 
arbitrários, de modo que buscam minimizar o contraste entre as condições de contorno utilizadas no transporte de calor (ver Seção 4.2.2.3).

Tabela 6 - Dimensões utilizadas na geometria do modelo FC mkII.

\begin{tabular}{cccc}
\hline Dimensão & $\begin{array}{c}\text { Valor } \\
\left(10^{-3} \mathrm{~m}\right)\end{array}$ & Dimensão & $\begin{array}{c}\text { Valor } \\
\left(10^{-3} \mathrm{~m}\right)\end{array}$ \\
\hline Largura do canal & 1 & Comprimento da seção horizontal & 68,4 \\
Largura total & 68,6 & Profundidade do canal & 0,75 \\
Largura de terraça & 1,33 & Diâmetro de entrada/saída & 2 \\
Separação entrada/saída-terraça & 0,5 & Aresta da BP & 84 \\
Aresta dos meios porosos & 70 & Espessura da BP & 2 \\
Espessura do MPS & 0,406 & Espessura da MPL & 0,01875 \\
Espessura da CL & 0,015 & Espessura da PEM & 0,0305 \\
\hline
\end{tabular}

Fonte: Autoria própria.

Em relação à parametrização, diferentemente dos estudos realizados com o protótipo de célula (Seção 4.1), a utilizada nos modelos FC manteve-se basicamente constante em todos os estudos detalhados abaixo, com poucas exceções de natureza exploratória. Adicionalmente aos parâmetros, também foram utilizadas relações constitutivas para os fluidos utilizados. Estes serão apresentados a seguir, de acordo com a relação a cada propriedade de transporte incluída no modelo.

\subsubsection{Transporte de momento}

Os parâmetros requeridos para o transporte de momento são relacionados às propriedades dos fluidos e dos meios porosos. As propriedades dos fluidos foram tomadas como dependentes da composição, sendo dadas por:

$$
\begin{aligned}
\rho(n, P, T) & =\frac{\bar{M}(n, P, T) P}{R T} \\
\mu(n, T) & =\left(\sum_{i} \frac{\chi_{i}}{\mu_{i}^{*}(T)}\right)^{-1}
\end{aligned}
$$

onde $P$ é a pressão absoluta, $R$ é a constante dos gases ideais, $T$ é a temperatura, $\chi_{i}$ é a fração molar e $\mu_{i}^{*}(T)$ a viscosidade do fluido puro para a $i$-ésima componente da mistura. O termo $\bar{M}(n, P, T)$ é a massa molar média, dada por:

$$
\bar{M}(n, P, T)=\left(\sum_{i} \frac{\omega_{i}}{M_{i}(P, T)}\right)^{-1}
$$

onde $\omega_{i}$ é a fração mássica e $M_{i}$ a massa molar da componente $i$ da mistura (ver Seção 4.2.1.2). Vale notar que a descrição da viscosidade dada pela Eq. 4.42 não é completamente correta, sendo que nem mesmo soluções ideais apresentam aditividade. Porém, o recíproco da viscosidade, como usado na Eq. 4.42, apresenta um comportamento mais próximo do real, como sugerido em (53), apesar de ser, ainda, uma aproximação. A viscosidade dos 
componentes puros, $\mu_{i}^{*}=\mu_{i}^{*}(T)$, foram obtidas pela regressão não-linear de valores obtidos de (54), para um intervalo de temperatura de $273,16 \mathrm{~K} \leq T \leq 423,15 \mathrm{~K}$. As expressões utilizadas, são:

$$
\begin{aligned}
\mu_{\mathrm{H}_{2}}^{*}(T) & =3,1397 \times 10^{-6}+1,9413 \times 10^{-8} T \\
\mu_{\mathrm{O}_{2}}^{*}(T) & =5,1427 \times 10^{-6}+5,1709 \times 10^{-8} T \\
\mu_{\mathrm{N}_{2}}^{*}(T) & =4,5984 \times 10^{-6}+4,4494 \times 10^{-8} T \\
\mu_{\mathrm{H}_{2} \mathrm{O}}^{*}(T) & =4,6379 \times 10^{-6}+4,0751 \times 10^{-10} T^{1,6611}
\end{aligned}
$$

sendo que $\mu$ tem unidades de Pa s e $T$ tem unidades de $\mathrm{K}$.

As propriedades dos meios porosos relevantes foram tomados como constantes em relação à temperatura e pressão. Além disso, todos os materiais foram tomados como homogêneos e em geral isotrópicos, com a consideração de quebras de simetria quando possível. Os materiais são caracterizados pelas suas propriedades de transporte: porosidade $\epsilon_{\Omega}$ e permeabilidade $\kappa_{\Omega}$, onde $\Omega$ representa um dado domínio da geometria. Estes são apresentados na Tabela 7. Alguns pontos são dignos de nota: i) a permeabilidade do MPS foi tomada como diagonal, conforme mensurado em (21); ii) foi incluído um termo de segunda ordem na permeabilidade da MPL, a permeabilidade inercial $\kappa_{I}$, conforme sugerido em (21); iii) a porosidade da CL foi tomada como simplesmente o valor da MPL subtraído a carga de eletrólito adicionado para contato iônico:

$$
\epsilon_{\mathrm{CL}}=\epsilon_{\mathrm{MPL}}-\epsilon_{l}
$$

onde $\epsilon_{l}$ é a fração volumétrica de eletrólito na CL (ver Seção 4.2.2.4); e iv) a presença do eletrólito na CL foi desconsiderado na permeabilidade da mesma.

Tabela 7 - Parâmetros necessários ao transporte de momento no modelo FC mkII.

\begin{tabular}{ccc}
\hline Parâmetro & Valor & Referência \\
\hline$\epsilon_{\mathrm{MPS}}$ & 0,7 & $(45)$ \\
$\epsilon_{\mathrm{MPL}}$ & 0,94 & $(24)$ \\
$\kappa_{\mathrm{MPS}}$ & $\perp 13 \times 10^{-12} \mathrm{~m}^{2}$ & $(21)$ \\
& $\| 11,767 \times 10^{-12} \mathrm{~m}^{2}$ & $(21)$ \\
$\kappa_{\mathrm{MPL}}$ & $1,85 \times 10^{-12} \mathrm{~m}^{2}$ & $(19)$ \\
$\kappa_{I_{\mathrm{MPL}}}$ & $1 \times 10^{-8} \mathrm{~m}$ & $(21)$ \\
$\kappa_{\mathrm{CL}}$ & $1,85 \times 10^{-12} \mathrm{~m}^{2}$ & Ver texto \\
$\kappa_{I_{\mathrm{CL}}}$ & $1 \times 10^{-8} \mathrm{~m}$ & Ver texto \\
\hline Fonte: Autoria própria. &
\end{tabular}

\subsubsection{Transporte de espécies}

Os parâmetros requeridos ao transporte de espécies são relacionados ao transporte difusivo e interação entre as componentes de cada mistura. A densidade da mistura, Eq. 
4.41, é regida pela composição e pela massa molar média da mistura, variáveis referentes ao transporte de espécies. As massas molares foram corrigidas utilizando o fator de compressibilidade, $Z_{i}(T)$, de modo a corrigir desvios em relação ao modelo dos gases perfeitos descrito pela Eq. 4.41:

$$
M_{i}(P, T)=\frac{M_{i}^{*}}{Z_{i}(P, T)}
$$

onde $M_{i}^{*}$ é a massa molar convencional de cada espécie; com $Z_{i}$ sendo definido como:

$$
Z_{i}(P, T)=\frac{P M_{i}^{*}}{R T \rho_{i}^{*}(P, T)}
$$

onde $\rho_{i}^{*}(P, T)$ é a densidade do componente puro. As densidades dos fluidos puros foram obtidas por regressões polinomiais bidimensionais de valores obtidos de (54), em função da pressão e temperatura, nos intervalos de 0,1 bar $\leq P \leq 10$ bar e $273,16 \mathrm{~K} \leq T \leq 423,15 \mathrm{~K}$, respectivamente. As relações constitutivas utilizadas foram:

$$
\begin{aligned}
\rho_{\mathrm{H}_{2}}^{*}(P, T)= & 0,36021+0,14215 P-2,1028 \times 10^{-3} T-3,7968 \times 10^{-5} P^{2} \\
& +3,0152 \times 10^{-6} T^{2}-2,0466 \times 10^{-4} P T \\
\rho_{\mathrm{O}_{2}}^{*}(P, T)= & 5,9642+2,297 P-3,5025 \times 10^{-2} T+3,9292 \times 10^{-4} P^{2} \\
& +5,0511 \times 10^{-5} T^{2}-3,3648 \times 10^{-3} P T \\
\rho_{\mathrm{N}_{2}}^{*}(P, T)= & 5,5391+2,1362 P-0,034733 T+5,4066 \times 10^{-5} P^{2} \\
& 5,3922 \times 10^{-5} T^{2}-0,0033522 P T
\end{aligned}
$$

sendo que as unidades são $\mathrm{kg} \mathrm{m}^{-3}$, enquanto $P$ tem unidades de bar. A densidade da água em estado gasoso é dada pela pressão de vapor, e calculada pela equação dos gases ideais:

$$
\rho_{\mathrm{H}_{2} \mathrm{O}}^{*}(T)=\frac{M_{\mathrm{H}_{2} \mathrm{O}}^{*} P_{\mathrm{sat}}(T)}{R T}
$$

sendo que a pressão de saturação $P_{\text {sat }}$ também foi obtida de dados obtidos de (54), no mesmo intervalo de $T$ descrito acima. A expressão utilizada foi:

$$
P_{\text {sat }}(T)=\exp \left[11,643-\frac{3790,6}{T-47,175}\right]
$$

Os fatores de compressibilidade foram obtidos separadamente, de modo a evitar singularidades e problemas com unidades observados no software. As expressões utilizadas foram:

$$
\begin{aligned}
Z_{\mathrm{H}_{2}}(P, T)= & 0,99274+9,0422 \times 10^{-4} P-3,8433 \times 10^{-6} T+5,1417 \times 10^{-8} P^{2} \\
& +5,576 \times 10^{-9} T^{2}-1,0805 \times 10^{-6} P T \\
Z_{\mathrm{O}_{2}}(P, T)= & 0,97743-2,5294 \times 10^{-3} P+1,3201 \times 10^{-4} T+9,9551 \times 10^{-7} P^{2} \\
& -1,8945 \times 10^{-7} T^{2}+6,3436 \times 10^{-6} P T \\
Z_{\mathrm{N}_{2}}(P, T)= & 0,97728-2,0822 \times 10^{-3} P+1,3878 \times 10^{-4} T+1,9281 \times 10^{-6} P^{2} \\
& -2,1435 \times 10^{-7} T^{2}+6,2568 \times 10^{-6} P T
\end{aligned}
$$


Tal relação não foi utilizada para a água devido à interferência do equilíbrio vapor-líquido nas faixas de pressão e temperatura utilizadas.

Em relação aos coeficientes de difusão, foram utilizados coeficientes de difusão binários, refletindo as interações existentes nas misturas gasosas consideradas. De maneira similar às demais propriedades, os coeficientes foram obtidos de regressões não-lineares de dados experimentais compilados em (55), e (56) e referências, em um intervalo de temperatura de $273,15 \mathrm{~K} \leq T \leq 373,15 \mathrm{~K}$, à pressão de 1 atm e para misturas equimolares. As expressões utilizadas foram:

$$
\begin{aligned}
D_{\mathrm{H}_{2}-\mathrm{H}_{2} \mathrm{O}}(T) & =2,865 \times 10^{-8} \exp \left(-\frac{167,8}{T}\right) T^{3 / 2} \\
D_{\mathrm{O}_{2}-\mathrm{H}_{2} \mathrm{O}}(T) & =8,0721 \times 10^{-9} \exp \left(-\frac{133,49}{T}\right) T^{3 / 2} \\
D_{\mathrm{N}_{2}-\mathrm{H}_{2} \mathrm{O}}(T) & =9,1819 \times 10^{-9} \exp \left(-\frac{188,8}{T}\right) T^{3 / 2} \\
D_{\mathrm{N}_{2}-\mathrm{O}_{2}}(T) & =5,6772 \times 10^{-9} \exp \left(-\frac{107,2}{T}\right) T^{3 / 2}
\end{aligned}
$$

sendo que $D$ tem unidade de $\mathrm{m}^{2} \mathrm{~s}^{-1}$.

\subsubsection{Transporte de calor}

Os parâmetros requeridos para o transporte de calor são relacionados às propriedades térmicas dos fluidos e materiais estruturais. As propriedades dos fluidos são dependentes da composição, assumindo aditividade conforme o modelo de misturas ideais:

$$
\begin{aligned}
k(T) & =\sum_{i} \chi_{i} k_{i}^{*}(T) \\
C_{P}(P, T) & =\sum_{i} \chi_{i} C_{P_{i}}^{*}(P, T) \\
\gamma & =\sum_{i} \chi_{i} \gamma_{i}^{*}
\end{aligned}
$$

onde $k(T), C_{P}(P, T)$ e $\gamma$ são a condutividade térmica, capacidade calorífica a pressão constante e coeficiente adiabático, respectivamente. A condutividade térmica e a capacidade calorífica foram obtidos através de regressões não-lineares de dados obtidos de (54), nos intervalos de pressão e temperatura de 0,1 bar $\leq P \leq 10$ bar e $273,15 \mathrm{~K} \leq T \leq 423,15 \mathrm{~K}$, 
respectivamente. As expressões utilizadas foram:

$$
\begin{aligned}
k_{\mathrm{H}_{2}}(T)= & 4,89383 \times 10^{-4}(T+79,48803) \\
k_{\mathrm{O}_{2}}(T)= & 8,0378 \times 10^{-5}(T+31,60965) \\
k_{\mathrm{N}_{2}}(T)= & 6,4833 \times 10^{-5}(T+100,64) \\
k_{\mathrm{H}_{2} \mathrm{O}}(T)= & 0,012716+2,9537 \times 10^{-11} T^{3,3526} \\
C_{P_{\mathrm{H}_{2}}}(P, T)= & 24,239+0,014028 P+0,024125 T-5,4417 \times 10^{-6} P^{2} \\
C_{P_{\mathrm{O}_{2}}}(P, T)= & -2,9344 \times 10^{-5} T^{2}-2,8208 \times 10^{-5} P T \\
& +2,7423 \times 10^{-5} T^{2}-2,654 \times 10^{-4} P T \\
C_{P_{\mathrm{N}_{2}}}(P, T)= & 30,436+0,13254 P-0,0088843 T+2,2939 \times 10^{-6} P^{2} \\
& +1,5011 \times 10^{-5} T^{2}-2,9629 \times 10^{-4} P T \\
C_{P_{\mathrm{H}_{2} \mathrm{O}}}(P, T)= & 33,258+\frac{345,97}{1+\exp (-(T-626,53) / 57,699)}
\end{aligned}
$$

onde $k$ tem unidades de $\mathrm{W} \mathrm{m}^{-1} \mathrm{~K}^{-1}$ e $C_{P}$ tem unidades de $\mathrm{J} \mathrm{mol}^{-1} \mathrm{~K}^{-1}$. Os coeficientes adiabáticos foram tomados como constantes, e são apresentados na Tabela 8, sendo usados os valores referentes a $T=298,15 \mathrm{~K}$.

Tabela 8 - Parâmetros necessários ao transporte de calor no modelo FC mkII.

\begin{tabular}{ccc}
\hline Parâmetro & Valor & Referência \\
\hline$\gamma_{\mathrm{H}_{2}}^{*}$ & 1,404 & $(54)$, ver texto \\
$\gamma_{\mathrm{O}_{2}}^{*}$ & 1,399 & $(54)$, ver texto \\
$\gamma_{\mathrm{N}_{2}}^{*}$ & 1,401 & $(54)$, ver texto \\
$\gamma_{\mathrm{H}_{2} \mathrm{O}}^{*}$ & 1,324 & $(54)$, ver texto \\
$k_{\mathrm{BP}}^{*}$ & $55 \mathrm{~W} \mathrm{~m}^{-1} \mathrm{~K}^{-1}$ & $(57)$ \\
$k_{\mathrm{MPS}}^{*}$ & $0,31 \mathrm{~W} \mathrm{~m}^{-1} \mathrm{~K}^{-1}$ & $(58)$ \\
$k_{\mathrm{MPL}}^{*}$ & $1,59 \mathrm{~W} \mathrm{~m}^{-1} \mathrm{~K}^{-1}$ & $(59)$, ver texto \\
$k_{\mathrm{CL}}^{*}$ & $1,535 \mathrm{~W} \mathrm{~m}^{-1} \mathrm{~K}^{-1}$ & Ver texto \\
$k_{\mathrm{PEM}}^{*}$ & $0,43 \mathrm{~W} \mathrm{~m}^{-1} \mathrm{~K}^{-1}$ & $(20)$, ver texto \\
$C_{P_{\mathrm{BP}}}^{*}$ & $0,853 \mathrm{~J} \mathrm{~g}^{-1} \mathrm{~K}^{-1}$ & $(60)$, ver texto \\
$C_{\mathrm{MPS}}^{*}$ & $0,741 \mathrm{~J} \mathrm{~g}^{-1} \mathrm{~K}^{-1}$ & $(58)$ \\
$C_{P_{\mathrm{MPL}}^{*}}^{*}$ & $0,853 \mathrm{~J} \mathrm{~g}^{-1} \mathrm{~K}^{-1}$ & $(60)$, ver texto \\
$\rho_{\mathrm{BP}}^{*}$ & $1,90 \mathrm{~g} \mathrm{~cm}^{-3}$ & $(57)$ \\
$\rho_{\mathrm{MPS}}^{*}$ & $1,75 \mathrm{~g} \mathrm{~cm}^{-3}$ & $(61)$ \\
$\rho_{\mathrm{MPL}}^{*}$ & $0,264 \mathrm{~g} \mathrm{~cm}^{-3}$ & $(62)$ \\
$\rho_{\mathrm{PEM}}^{*}$ & $1,97 \mathrm{~g} \mathrm{~cm}^{-3}$ & $(63)$, ver texto \\
\hline
\end{tabular}

Fonte: Autoria própria.

As propriedades térmicas dos materiais estruturais foram tomados como constantes, em relação à pressão e temperatura, e isotrópicas, com exceção da PEM. Além das propriedades térmicas, são necessárias também as densidades de cada material, também tomadas como constantes e isotrópicas. Tais parâmetros são apresentados na Tab 8. Similarmente ao transporte de momento, alguns pontos devem ser ressaltados: i) as propriedades térmicas 
das MPLs foram tomadas como idênticas ao grafite amorfo; ii) as propriedades das CL são tomadas como contribuição do material da MPL e do eletrólito (ver Seção 4.2.2.4):

$$
\begin{aligned}
k_{\mathrm{CL}}^{*} & =\left(1-\epsilon_{l}\right) k_{\mathrm{MPL}}^{*}+\epsilon_{l} k_{\mathrm{PEM}}^{*} \\
C_{P_{\mathrm{CL}}}^{*}(T) & =\left(1-\epsilon_{l}\right) C_{P_{\mathrm{MPL}}}^{*}+\epsilon_{l} \frac{C_{P_{\mathrm{H}_{2} \mathrm{O}, 1}}(T)}{M_{\mathrm{H}_{2} \mathrm{O}}^{*}} \\
\rho_{\mathrm{CL}}^{*} & =\left(1-\epsilon_{l}\right) \rho_{\mathrm{MPL}}^{*}+\epsilon_{l} \rho_{\mathrm{PEM}}^{*}
\end{aligned}
$$

onde $C_{P_{\mathrm{H}_{2} \mathrm{O}, l}}(T)$ é a capacidade calorífica (ver abaixo) da água líquida; iii) a capacidade calorífica da BP foi tomada como sendo a do grafite; iv) a PEM é considerada como composta de $50 \%$ de água líquida, com as propriedades tomadas como a soma das contribuições individuais:

$$
\begin{aligned}
k_{\mathrm{PEM}}(T) & =\frac{1}{2}\left(k_{\mathrm{PEM}}^{*}+k_{\mathrm{H}_{2} \mathrm{O}, l}^{*}(T)\right) \\
C_{P_{\mathrm{PEM}}}(T) & =\frac{1}{2} C_{P_{\mathrm{H}_{2} \mathrm{O}, l}}(T) \\
\rho_{\mathrm{PEM}}(T) & =\frac{1}{2}\left(\rho_{\mathrm{PEM}}^{*}+\rho_{\mathrm{H}_{2} \mathrm{O}, l}(T)\right)
\end{aligned}
$$

com exceção da capacidade calorífica que não foi encontrada, portanto sendo considerada apenas a contribuição da água. As propriedades da água líquida foram consideradas como dependente da temperatura, e obtidas através de regressões polinomiais de dados obtidos de (54), no intervalo de temperatura de $273,15 \mathrm{~K} \leq T 373,15 \mathrm{~K}$. As expressões utilizadas foram:

$$
\begin{aligned}
k_{\mathrm{H}_{2} \mathrm{O}, l}(T)= & -0,59797+6,4873 \times 10^{-3} T-8,2023 \times 10^{-6} T^{2} \\
C_{P_{\mathrm{H}_{2} \mathrm{O}, l}}(T)= & 2400,2-33,104 T+0,18794 T^{2}-5,3164 \times 10^{-4} T^{3} \\
& +7,4895 \times 10^{-7} T^{4}-4,1997 \times 10^{-10} T^{5} \\
\rho_{\mathrm{H}_{2} \mathrm{O}, l}(T)= & 490,93+4,3733 T-0,01142 T^{2}+8,1925 \times 10^{-6} T^{3}
\end{aligned}
$$

As funções tem unidades de $\mathrm{W} \mathrm{m} \mathrm{m}^{-1} \mathrm{~K}^{-1}, \mathrm{~J} \mathrm{~mol}^{-1} \mathrm{~K}^{-1}$ e $\mathrm{kg} \mathrm{m}^{-3}$, respectivamente.

\subsubsection{Transporte de carga}

Os parâmetros necessários ao transporte de cargas são relacionados à propriedades elétricas, seja de condução iônica ou eletrônica, e à cinética eletroquímica das reações anódica e catódica. Os parâmetros são apresentados na Tabela 9. Alguns pontos devem ser mencionados, em adição aos apresentados na Seção 4.2.2.4: i) a fração volumétrica de eletrólito nas CLs, $\epsilon_{l}$, foi calculado da razão mássica, e densidades $\rho_{\mathrm{PEM}}^{*}$ e $\rho_{\mathrm{MPL}}^{*}$, tipicamente adicionada em dispositivos utilizados no laboratório onde este trabalho foi desenvolvido; ii) a densidade de sítios ativos, $A_{v}$, também foi tomado de valores de área ativa específica e quantidade típicas de catalisadores utilizados no grupo; e iii) o valor do coeficiente de Tafel, $b$, para a reação catódica possui uma dependência com $\eta$, e está relacionado aos intermediários de reação; porém como tais intermediários não são considerados, foi selecionado o valor que, em princípio, é condizente com o regime simulado. 
Tabela 9 - Parâmetros necessários ao transporte de carga no modelo FC mkII.

\begin{tabular}{|c|c|c|}
\hline Parâmetro & Valor & Referência \\
\hline \multirow[b]{2}{*}{$\sigma_{\mathrm{BP}}$} & $\perp 5,26 \mathrm{kS} \mathrm{m}^{-1}$ & $(57)$ \\
\hline & $\| 11,1 \mathrm{kS} \mathrm{m}^{-1}$ & $(57)$ \\
\hline$\sigma_{\mathrm{MPS}}$ & $66,7 \mathrm{kS} \mathrm{m}^{-1}$ & (64) \\
\hline$\sigma_{\mathrm{MPL}}$ & $450 \mathrm{~S} \mathrm{~m}^{-1}$ & (18) \\
\hline & $\perp 5,05 \mathrm{~S} \mathrm{~m}^{-1}$ & (63) \\
\hline$\sigma_{\mathrm{PEM}}^{*}$ & $\| 7,2 \mathrm{~S} \mathrm{~m}^{-1}$ & $(63)$ \\
\hline$\epsilon_{l}$ & 0,0476 & Ver texto \\
\hline$A_{v}$ & $1,1016 \times 10^{7} \mathrm{~m}^{-1}$ & Ver texto \\
\hline$i_{0_{\text {an }}}^{*}$ & $417,50 \mathrm{~mA} \mathrm{~cm}^{-2}$ & $(65)$ \\
\hline$\alpha_{f}$ & 0,5 & $(65)$ \\
\hline$E_{\text {eqan }}$ & $0 \mathrm{~V}$ & $(66)$ \\
\hline$i_{0_{\text {cat }}^{*}}^{*}$ & $2,55 \times 10^{-7} \mathrm{~mA} \mathrm{~cm}^{-2}$ & (67) \\
\hline$b^{\text {cat }}$ & $60 \mathrm{mV} \mathrm{\textrm {dec } ^ { - 1 }}$ & (67), ver texto \\
\hline$E_{\text {eq at }}$ & $1,229 \mathrm{~V}$ & $(66)$ \\
\hline
\end{tabular}

Fonte: Autoria própria.

\subsubsection{Formulação Matemática}

\subsubsection{Transporte de momento}

O transporte de momento no modelo FC mkII é dado pela equação de Darcy-Brinkman (Eq. 4.5) para gases compressíveis:

$$
\frac{\rho}{\epsilon}(\mathbf{u} \cdot \nabla)\left(\frac{\mathbf{u}}{\epsilon}\right)=\nabla \cdot\left[-P \mathbf{I}+\frac{\mu}{\epsilon}\left(\nabla \mathbf{u}+(\nabla \mathbf{u})^{\mathrm{T}}\right)-\frac{2 \mu}{3 \epsilon}(\nabla \cdot \mathbf{u}) \mathbf{I}\right]-\frac{\mu}{\kappa} \mathbf{u}+\mathbf{F}
$$

sendo definida nos domínios $\Omega=$ [FC, MPS, MPL, CL]. O termo $\mathbf{F}$ representa forças volumétricas generalizadas, nesse caso representando a ação da gravidade no fluido, $F_{x}=-g \rho$ e $F_{y}=F_{z}=0$, onde $g$ é a aceleração da gravidade. Nos domínios $\Omega=$ [MPL, CL], foi incluído no lado direito da equação de DB o termo de Forchheimer:

$$
-\left(\frac{\rho}{\kappa_{I}}|\mathbf{u}|\right) \mathbf{u}
$$

dado que resultados de ensaios de descarga, descritos em (21), sugerem a existência de termos de maior ordem que a simples permeabilidade dada pelo equação de Darcy (Eq. 4.7) nos materiais representados em tais domínios. Um último termo foi acrescentado nos domínios das CLs, representando a variação de massa devido às reações eletroquímicas:

$$
-\left(\frac{Q_{\mathrm{ms}}}{\epsilon^{2}}\right) \mathbf{u}
$$

onde $Q_{\mathrm{ms}}$ representa o termo de fonte de massa, dado por (ver Seção 4.2.2.4):

$$
Q_{\mathrm{ms}}=\sum_{j} \sum_{i} R_{i j} M_{i}^{*}
$$


onde o somatório é feito sobre todas as reações e espécies definidas no domínio e $R_{i j}$ são as respectivas velocidades de reação. Além da equação de DB e os demais termos definidos nos domínios apropriados, uma equação da continuidade é definida nos domínios $\Omega=[\mathrm{FC}, \mathrm{MPS}, \mathrm{MPL}, \mathrm{CL}]$ :

$$
\nabla \cdot(\rho \mathbf{u})=Q_{\mathrm{ms}}
$$

onde $Q_{\mathrm{ms}}=0$ nos domínios $\Omega=[\mathrm{FC}, \mathrm{MPS}, \mathrm{MPL}]$.

A entrada de fluido, definida nas fronteiras apontadas na Fig. 8a, é dada por uma condição de vazão mássica, relativa a uma vazão padrão (ver Seção 4.1 .4 e Apêndice D):

$$
-\int_{\partial \Omega} \frac{\rho}{\rho_{\mathrm{std}}}(\mathbf{u} \cdot \mathbf{n}) \mathrm{dS}=Q_{\mathrm{std}}
$$

onde $Q_{\text {std }}$ é a vazão volumétrica em unidades padrão e $\rho_{\text {std }}$ é a densidade padrão:

$$
\rho_{\text {std }}=\frac{P_{\text {std }}}{R_{\text {air }} T_{\text {std }}}
$$

onde $P_{\text {std }}=1$ atm, $T_{\text {std }}=293,15 \mathrm{~K}$ e $R_{\text {air }}=287,058 \mathrm{~J} \mathrm{~kg}^{-1} \mathrm{~K}^{-1}$. A condição de saída, definida nas superfícies indicadas (e inferida por simetria) na Fig. 8a, são dadas por uma condição de pressão constante, com supressão de refluxo:

$$
\left[-P \mathbf{I}+\mu\left(\nabla \mathbf{u}+(\nabla \mathbf{u})^{\mathrm{T}}\right)-\frac{2 \mu}{3}(\nabla \cdot \mathbf{u}) \mathbf{I}\right] \mathbf{n}=-\hat{P}_{\text {out }} \mathbf{n}
$$

sendo requerido que $\hat{P}_{\text {out }} \leq P_{\text {out }}$, com $P_{\text {out }}=0$.

As demais fronteiras, externas, dos domínios $\Omega=[\mathrm{FC}, \mathrm{MPS}, \mathrm{MPL}, \mathrm{CL}]$ estão sujeitas à condição de não-deslizamento $($ no-slip $) \mathbf{u}=0$. Uma pressão de referência $P_{\text {ref }} \approx 0,9 \mathrm{~atm}$ e valores iniciais de $\mathbf{u}_{0}=0$ e $P_{0}=0$ foram utilizados em todos os cálculos. A discretização utilizada foi do tipo P1 + P1, i.e. o campo de velocidades e a pressão foram discretizados linearmente.

\subsubsection{Transporte de espécies}

As misturas consideradas no modelo FC mkII são $\mathrm{H}_{2}-\mathrm{H}_{2} \mathrm{O}$ no compartimento anódico, e $\mathrm{N}_{2}-\mathrm{O}_{2}-\mathrm{H}_{2} \mathrm{O}$ no compartimento catódico. O transporte de espécies é dado pela equação de advecção, juntamente com a definição do vetor fluxo mássico total, $\mathbf{N}_{i}$, para cada espécie $i$ da mistura:

$$
\begin{aligned}
\nabla \cdot \mathbf{J}_{i}+\rho(\mathbf{u} \cdot \nabla) \omega_{i} & =R_{i} \\
\mathbf{N}_{i} & =\mathbf{J}_{i}+\rho \mathbf{u} \omega_{i}
\end{aligned}
$$

onde $\omega_{i}$ é a fração mássica e $R_{i}$ é o termo total de reação da componente $i$. O vetor fluxo difusional, J, é dado por:

$$
\mathbf{J}_{i}=-\left(\rho D_{i}^{\mathrm{eff}} \nabla \omega_{i}+\rho \omega_{i} D_{i}^{\mathrm{eff}} \frac{\nabla \bar{M}}{\bar{M}}+D_{i}^{T} \frac{\nabla T}{T}\right)
$$


onde os coeficientes difusionais efetivos $D_{i}^{\text {eff }}$ são obtidos através de:

$$
D_{i}^{\mathrm{eff}}=\left(\frac{1}{D_{i}^{m}}+\frac{1}{D_{i}^{K}}\right)^{-1}
$$

e representam a contribuição da aproximação de mistura do modelo de Maxwell-Stefan e da difusão Knudsen, respectivamente:

$$
\begin{aligned}
D_{i}^{m} & =\frac{1-\omega_{i}}{\sum_{k \neq i} \chi_{k} / D_{i k}} \\
D_{i}^{K} & =\frac{\lambda_{i}}{3} \sqrt{\frac{8 R T}{\pi M_{i}^{*}}}
\end{aligned}
$$

onde $D_{i k}$ são os coeficientes de difusão binários, e $\lambda$ é o livre caminho médio. O vetor $\mathbf{J}_{i}$ também considera o efeito Soret de difusão térmica (último termo do lado direito), sendo que o coeficiente de difusão térmico é dado por:

$$
D_{i}^{T}=\frac{k_{i} M_{i}^{*}}{C_{P_{i}}}
$$

As equações acima são definidas nos domínios $\Omega=$ [FC, MPS, MPL, CL]. Nos domínios representativos dos materiais porosos, os coeficientes de difusão binários e térmicos, $D_{i k}$ e $D_{i}^{T}$, são corrigidos utilizando o modelo de Millington e Quirk(47) para a tortuosidade:

$$
\begin{aligned}
D_{\Omega}^{\mathrm{eff}} & =\frac{\epsilon_{\Omega}}{\tau_{\Omega}} D^{\mathrm{eff}} \\
\tau_{\Omega} & =\epsilon_{\Omega}^{-1 / 3}
\end{aligned}
$$

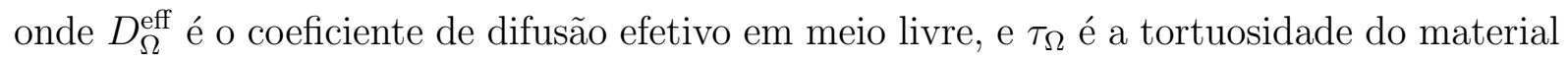
representanto do domínio $\Omega$.

Para a difusão Knudsen, deve-se definir o caminho livre médio. Para o domínio do FC, este foi utilizado segundo a Teoria Cinética dos Gases(68):

$$
\lambda_{i}=\frac{k_{B} T}{\pi P d_{i}^{2} \sqrt{2}}, \Omega=[\mathrm{FC}]
$$

onde $d_{i}$ é o diâmetro de colisão da componente $i$ em um gás, dado por:

$$
d_{i}^{2}=\frac{2,67 \times 10^{-20} \sqrt{M_{i}^{*} T}}{\mu_{i}^{*}}
$$

No caso dos meios porosos, onde espera-se que a difusão Knudsen contribua mais significativamente, o livre caminho médio é dado em função das propriedades de transporte dos materiais, segundo o modelo de Millington e Quirk(47):

$$
\lambda_{i}=2 \sqrt{\frac{8 \kappa_{\Omega}}{\epsilon_{\Omega}^{4 / 3}}}, \Omega=[\mathrm{MPS}, \mathrm{MPL}, \mathrm{CL}]
$$


O termo de reação, $R_{i}$, é diferente de zero somente nos domínios das CLs, refletindo a cinética eletródica em cada compartimento da célula (ver Seção 4.2.2.4). De maneira geral, o termo é definido como:

$$
R_{i}=M_{i} \sum_{j} R_{i j}-\omega_{i} \sum_{i} M_{i} \sum_{j} R_{i j}
$$

No caso do acoplamento com a cinética eletródica, o termo individual é dado por:

$$
R_{i j}=\frac{\nu_{i j} i_{v, j}}{n_{j} F}
$$

onde $\nu_{i j}$ é o coeficiente estequiométrico da espécie $i$ na reação $j, i_{v, j}$ é a densidade volumétrica de corrente, $n_{j}$ é o número de elétrons transferidos, e $F$ é a constante de Faraday (ver Seção 4.2.2.4). No modelo FC mkII, as reações consideradas foram:

$$
\begin{aligned}
2 \mathrm{e}^{-} & \leftrightarrow \mathrm{H}_{2}(\mathrm{~g}) \\
\mathrm{O}_{2}(\mathrm{~g})+4 \mathrm{e}^{-} & \leftrightarrow 2 \mathrm{H}_{2} \mathrm{O}(\mathrm{g})
\end{aligned}
$$

ou seja, não são considerados explicitamente íons hidrônio, intermediários reacionais ou a presença de água líquida.

A condição de entrada de espécies, definidas nas mesmas fronteiras das entradas de fluidos (Fig. 8a), são dadas pela determinação da fração mássica das componentes, $\omega_{i}=\omega_{\text {in }, i}$. Estas são dadas pelas densidades dos fluidos puros:

$$
\omega_{\mathrm{in}, i}=\frac{\rho_{i}^{*}(P, T)}{\sum_{k} \rho_{k}^{*}(P, T)}
$$

com o somatório feito sobre as respectivas espécies em cada compartimento do modelo. A condição de saída, condizente com a saída de fluido, é dada por:

$$
-\mathbf{n} \cdot \rho D_{i}^{\mathrm{eff}} \nabla \omega_{i}=0
$$

As demais fronteiras, externas, dos domínios $\Omega=[\mathrm{FC}, \mathrm{MPS}, \mathrm{MPL}, \mathrm{CL}]$ estão sujeitas à condição de impermeabilidade, $-\mathbf{n} \cdot \mathbf{N}_{i}=0$. As condições iniciais utilizadas foram dadas de maneira análoga às frações mássicas de entrada:

$$
\omega_{0, i}=\frac{\rho_{i}^{*}\left(P_{0}, T_{0}\right)}{\sum_{k} \rho_{k}^{*}\left(P_{0}, T_{0}\right)}
$$

para $P_{0}=P_{\text {ref }}$ e $T_{0}=353,15 \mathrm{~K}$. As frações mássicas foram discretizadas linearmente, e foi utilizado regularização das mesmas, i.e. foi assegurado que $\omega_{i} \geq 0$. Adicionalmente, foi optado pelo cálculo total dos resíduos para fins de estabilização numérica. 


\subsubsection{Transporte de calor}

O transporte de calor é dado pela equação do calor, que é basicamente uma formulação da conservação de energia, juntamente com a equação de Fourier:

$$
\begin{aligned}
\rho_{\Omega} C_{P_{\Omega}} \mathbf{u} \cdot \nabla T+\nabla \cdot \mathbf{q} & =Q_{\mathrm{hs}} \\
\mathbf{q} & =-k_{\Omega} \nabla T
\end{aligned}
$$

onde q é o vetor de fluxo de calor e $Q_{\mathrm{hs}}$ são fontes generalizadas de calor. Todos os domínios da geometria são inclusos no tratamento do transporte de calor. Os domínios porosos, $\Omega=$ [MPS, MPL, CL], possuem propriedades térmicas efetivas, considerando a porosidade dos mesmos:

$$
\begin{aligned}
k_{\Omega} & =\epsilon_{\Omega} k(T)+\left(1-\epsilon_{\Omega}\right) k_{\Omega}^{*} \\
C_{P_{\Omega}} & =\epsilon_{\Omega} C_{P}(P, T)+\left(1-\epsilon_{\Omega}\right) C_{P_{\Omega}}^{*} \\
\rho_{\Omega} & =\epsilon_{\Omega} \rho(P, T)+\left(1-\epsilon_{\Omega}\right) \rho_{\Omega}^{*}
\end{aligned}
$$

onde as grandezas com $*$ e subscrito $\Omega$ representam as grandezas referentes aos materiais representados no domíno $\Omega$. Não foram incluídos efeitos de dispersão. Os domínios $\Omega=[\mathrm{BP}, \mathrm{PEM}]$ foram considerados como sólidos, sendo que a PEM foi tomada como composta de $50 \%$ de água líquida (ver Seção 4.2.1.3).

Nos domínios $\Omega=$ [BP, MPS, MPL, CL, PEM] foi considerado o calor dissipado pelos processos eletroquímicos (ver Seção 4.2.2.4):

$$
Q_{\mathrm{hs}}=Q_{\mathrm{JH}}+\sum_{j} Q_{\mathrm{EC}_{j}}
$$

dados pelo efeito Joule, $Q_{\mathrm{JH}}$ e pelas reações eletródicas $Q_{\mathrm{EC}_{j}}$. Não foram considerados termos de dissipação viscosa ou por gradientes de pressão.

No domínio da FC, nas superfícies condizentes com as entradas de fluidos e espécies (Fig. 8a), foram estabelecidas condições de temperatura constante, $T=T_{\mathrm{in} \text {,an }}=T_{0}+15 \mathrm{~K}$ e $T=T_{\text {in,cat }}=T_{0}+5 \mathrm{~K}$, para o compartimento anódico e catódico, respectivamente. As superfícies condizentes com as saídas de fluidos e espécies possuem uma condições de saída de calor:

$$
-\mathbf{n} \cdot \mathbf{q}=0
$$

No domínio da BP foram estabelecidas as condições de troca de calor com o ambiente. Nas fronteiras superior e inferior da geometria no eixo $z$ (seções com segmentação) foram estabelecidas condições de temperatura constante $T=T_{0}$. Nas demais fronteiras livres, com exceção das laterais em $-x$, foi definido uma condição de fluxo convectivo:

$$
-\mathbf{n} \cdot \mathbf{q}=h\left(T_{\mathrm{ext}}-T\right)
$$


onde $T_{\text {ext }}=298,15 \mathrm{~K}$ é a temperatura do ambiente, e $h=55 \mathrm{~W} \mathrm{~m}^{-2} \mathrm{~K}^{-1}$ o coeficiente de transferência de calor com o ambiente, sendo um valor médio sugerido em (69).

As demais fronteiras estão sujeitas à condição de isolamento térmico, $-\mathbf{n} \cdot \mathbf{q}=0$. A condição inicial utilizada foi $T_{0}=373,15 \mathrm{~K}$. Foi utilizada uma discretização linear para a temperatura.

\subsubsection{Transporte de carga}

O transporte de cargas é dado por uma formulação da lei de Ohm, considerando tanto condutores iônicos como eletrônicos, respectivamente:

$$
\begin{aligned}
\mathbf{i}_{l_{\Omega}} & =-\sigma_{l_{\Omega}} \nabla \phi_{l}, \Omega=[\mathrm{CL}, \mathrm{PEM}] \\
\mathbf{i}_{s_{\Omega}} & =-\sigma_{s_{\Omega}} \nabla \phi_{s}, \Omega=[\mathrm{BP}, \mathrm{MPS}, \mathrm{MPL}, \mathrm{CL}]
\end{aligned}
$$

onde $\mathbf{i}_{l}$ e $\mathbf{i}_{s}$ são os vetores de densidade volumétrica de corrente para o eletrólito e eletrodos, respectivamente; $\sigma_{l, s}$ são as condutividades dos meios; e $\phi_{l, s}$ o potencial elétrico em cada meio. As condutividades, juntamente com os demais parâmetros utilizados, são apresentados na Tabela 9. Adicionalmente, são impostas as respectivas equações de conservação de carga:

$$
\begin{aligned}
\nabla \cdot \mathbf{i}_{l_{\Omega}} & =0, \Omega=[\mathrm{PEM}] \\
\nabla \cdot \mathbf{i}_{s_{\Omega}} & =0, \Omega=[\mathrm{BP}, \mathrm{MPS}, \mathrm{MPL}]
\end{aligned}
$$

onde nenhum termo de fonte externa de densidade de corrente foi utilizado.

Os domínios das CLs são tratados como eletrodos porosos, sendo que a condutividade do eletrólito foi corrigida utilizando o modelo de Bruggeman:

$$
\sigma_{l_{\mathrm{CL}}}=\epsilon_{l}^{3 / 2} \frac{\operatorname{tr}\left(\sigma_{\mathrm{PEM}}^{*}\right)}{3}
$$

Nota-se que o eletrólito foi tomado como sendo o mesmo do domínio da PEM, porém, dado que a condutividade do material representado na PEM é representado por uma matriz diagonal, a média destes valores foi utilizada. A condutividade eletrônica não foi corrigida dado que foi assumido que a porosidade do material contribui para o valor utilizado. Como reações eletroquímicas tomam lugar nas CLs, as equações de conservação de carga incluem um termo adicional:

$$
\begin{aligned}
\nabla \cdot \mathbf{i}_{l_{\mathrm{CL}}} & =i_{v} \\
\nabla \cdot \mathbf{i}_{s_{\mathrm{CL}}} & =-i_{v}
\end{aligned}
$$

onde $i_{v}$ é a densidade volumétrica total de corrente dada pelas reações eletroquímicas:

$$
i_{v}=\sum_{j} A_{v} i_{j}
$$


onde $A_{v}$ é a área ativa por unidade de volume e $i_{j}$ são as contribuições individuais de cada reação eletroquímica.

Conforme mencionado na Seção 4.2.2.2, as reações eletroquímicas consideradas são:

$$
\begin{aligned}
2 \mathrm{e}^{-} & \leftrightarrow \mathrm{H}_{2}(\mathrm{~g}) \\
\mathrm{O}_{2}(\mathrm{~g})+4 \mathrm{e}^{-} & \leftrightarrow 2 \mathrm{H}_{2} \mathrm{O}(\mathrm{g})
\end{aligned}
$$

nos compartimentos anódico e catódico, respectivamente. Desta maneira, a corrente de troca para cada processo, i.e. a cinética na ausência de potencial elétrico aplicado, é modulada pela pressão parcial dos reagentes:

$$
\begin{aligned}
i_{0_{\mathrm{an}}} & =i_{0_{\mathrm{an}}}^{*} \frac{P_{\mathrm{H}_{2}}}{P^{*}} \\
i_{0_{\mathrm{cat}}} & =i_{0_{\mathrm{cat}}}^{*} \frac{P_{\mathrm{O}_{2}}}{P^{*}}
\end{aligned}
$$

onde $i_{0_{j}}^{*}$ é a corrente de troca na condição padrão, $P_{i}$ é a pressão parcial da espécie $i$, e $P^{*}=1$ bar é a pressão de referência. Isto foi feito de modo a considerar o efeito da pressão parcial dos reagentes na cinética eletródica mesmo utilizando as equações aproximadas, descritas abaixo, dado que o software permite a incorporação explícita deste efeito apenas ao se utilizar a equação de Butler-Volmer generalizada(70). No caso da equação catódica, a influência da pressão parcial da água foi desconsiderada dado que, em princípio, o produto desta reação é água líquida, cuja atividade pode ser aproximada da unidade.

O modelo utilizado para descrever a cinética anódica foi a equação de Butler-Volmer linearizada(32):

$$
i_{\mathrm{an}}=i_{0_{\mathrm{an}}}\left[\frac{F}{R T}\left(\alpha_{f}+\alpha_{b}\right)\right] \eta_{\mathrm{an}}
$$

onde $\alpha_{f, b}$ são os coeficientes de transferência catódico e anódico, sendo idealmente relacioandos por $\alpha_{b}=1-\alpha_{f}$; e $\eta_{\text {an }}$ é o sobrepotencial anódico:

$$
\eta_{\mathrm{an}}=\phi_{s}-\phi_{l}-E_{\mathrm{eqan}}
$$

onde $E_{\text {eq }}$ é o potencial de equilíbrio da reação. Foram desconsiderados efeitos termodinâmicos no potencial de equilíbrio, e.g. variações devido à mudança de temperatura e coeficientes de atividade, portanto $E_{\text {eq }}=E^{0}$, o potencial termodinâmico. A equação de Butler-Volmer linearizada pode ser utilizada em regimes próximos do equilíbrio, correspondente a valores pequenos de $\eta$. Assume-se, assim, que a cinética da reação é rápida nas escalas temporais consideradas.

Para a cinética catódica, foi utilizada a equação de Tafel(32):

$$
i_{\text {cat }}=i_{0_{\text {cat }}} \times 10^{-\eta_{\text {cat }} / b}
$$

onde $b$ é conhecido como coeficiente de Tafel. Também foram desconsiderados efeitos termodinâmicos no potencial de equilíbrio desta reação. A equação de Tafel é uma 
aproximação da Eq. de Butler-Volmer para altos valores de $\eta$, onde assume-se uma limitação cinética para o processo, i.e. o sobrepotencial de ativação é significativamente alto. Desta maneira, o processo reverso (neste caso a oxidação da água) é desfavorecido, sendo assim desconsiderado no modelo.

Conforme mencionado na Seção 4.2.2.3, duas contribuições ao calor são de origem eletroquímica: o efeito Joule e o calor das reações. O calor dissipado pelo efeito Joule é dado por(70):

$$
Q_{\mathrm{JH}}=-\left(\mathbf{i}_{s} \cdot \nabla \phi_{s}+\mathbf{i}_{l} \cdot \nabla \phi_{l}\right)
$$

enquanto que o calor dissipado pelas reações eletroquímicas são dados por:

$$
\begin{aligned}
Q_{\mathrm{EC}_{j}} & =i_{j}\left(\phi_{s}-\phi_{l}-E_{\mathrm{eq}_{j}}\right) \\
& =i_{j} \eta_{j}
\end{aligned}
$$

onde, novamente, são desconsiderados efeitos de variação do potencial de equilíbrio com a temperatura.

As condições relacionadas à aplicação de corrente foram definidas nas fronteiras superior e inferior, no eixo $z$, das BPs. Na BP anódica, tanto a região segmentada como a externa foram consideradas como aterradas, $\phi_{s}=0$. Na BP catódica, ambas as regiões foram sujeitas à condição de corrente total aplicada:

$$
\int_{\partial \Omega} \mathbf{i}_{s} \cdot \mathbf{n d S}=-I
$$

onde $I$ é a corrente total aplicada e a integração é feita sobre a fronteira. Um valor inicial de $\phi_{s_{\partial \Omega}}=0,9 \mathrm{~V}$ foi utilizado. No caso da região segmentada, $I$ é o parâmetro utilizado na simulação de curvas de polarização, enquanto que na região externa $I=0$ em todos os casos. Isso foi feito de modo a garantir a continuidade do potencial elétrico e da densidade de corrente nas BPs.

As demais superfícies estão sujeitas à uma condição de isolamento elétrico, $-\mathbf{n} \cdot \mathbf{i}_{l}=$ $-\mathbf{n} \cdot \mathbf{i}_{s}=0$. As condições iniciais utilizadas foram $\phi_{l}=0$, e $\phi_{s}=0$ e $\phi_{s}=0,9 \mathrm{~V}$ para os compartimentos anódico e catódico, respectivamente. Foi utilizada uma discretização linear para ambos os potenciais descritos pela formulação.

\subsubsection{Malha e solver}

A malha utilizada para os cálculos foi personalizada, seguindo a hierarquia estabelecida abaixo:

1. Definição de tamanho para "normal", com calibração para dinâmica de fluidos, em todos os domínios.

2. Definição de tamanho para "coarse", com calibração para dinâmica de fluidos, para os domínios $\Omega=$ [FC, MPS, MPL]. 
3. Definição de tamanho para "finer", sem calibração em específico, para os domínios $\Omega=[\mathrm{CL}]$.

4. Definição de tamanho para "fine", com calibração para dinâmica de fluidos, para as fronteiras externas dos domínios $\Omega=[\mathrm{FC}, \mathrm{MPL}, \mathrm{CL}]$ e as fronteiras em contato entre os domínios $\Omega=$ [BP, MPS].

5. Refino para regiões estreitas nas mesmas fronteiras do passo anterior.

6. Geração de elementos tetraédricos em todos os domínios.

7. Inclusão de elementos quadriláteros nos domínios dos FCs, adjacentes às fronteiras, incluindo a fronteira em contato com os MPSs, e excluindo as fronteiras de entrada e saída de fluidos.

As especificações de cada tamanho pré-estabelecido de elementos são apresentadas na Tabela 10. A malha é exemplificada na Figura 9, para os diversos domínios do modelo. Não foi feita análise de convergência dos resultados em função da malha utilizada, dado que o custo computacional utilizando a malha descrita acima já beira os limites disponíveis.

Tabela 10 - Especificações para tamanhos de elementos pré-estabelecidos para a geração da malha do modelo FC mkII.

\begin{tabular}{cccccc}
\hline Definição & $\begin{array}{c}\text { Tamanho } \\
\text { Máximo }(\mathrm{m})\end{array}$ & $\begin{array}{c}\text { Tamanho } \\
\text { Mínimo }(\mathrm{m})\end{array}$ & $\begin{array}{c}\text { Taxa de } \\
\text { Crescimento }\end{array}$ & $\begin{array}{c}\text { Fator de } \\
\text { Curvatura }\end{array}$ & Resolução \\
\hline Coarse & $5,22 \times 10^{-3}$ & $1,57 \times 10^{-3}$ & 1,2 & 0,7 & 0,6 \\
Normal & $3,5 \times 10^{-3}$ & $1,04 \times 10^{-3}$ & 1,15 & 0,6 & 0,7 \\
Fine & $4,62 \times 10^{-3}$ & $3,36 \times 10^{-4}$ & 1,4 & 0,4 & 0,7 \\
Finer & $2,77 \times 10^{-3}$ & $5,22 \times 10^{-4}$ & 1,13 & 0,5 & 0,8 \\
\hline
\end{tabular}

Fonte: Autoria própria.

O modelo foi resolvido para o estado estacionário, usando um solver paramétrico para a construção das curvas de polarização. Os valores de $Q_{\text {std }}$ e $I$ utilizados são os mesmos utilizados na obtenção das curvas de polarização do sistema experimental, descritos na Tab. 1. Os passos utilizados diferiram de acordo com a região da curva de polarização, de modo a melhorar a resolução, mas nunca excederam o passo usado no dispositivo experimental. Foi utilizado um escalonamento baseado nas condições iniciais, e uma tolerância relativa para convergência de $10^{-2}$. Foi utilizado um solver segregado de 6 passos, consistindo no seguinte:

- Passos 1 e 2, responsáveis pelas variáveis do transporte de momento, consistem em solvers iterativos do tipo GMRES, com 1 (2) nível (níveis) multigrid para os conjuntos de $Q_{\text {std }}$ I e II (III e IV). O método não-linear utilizado para o relaxamento foi constante, com fator de relaxamento de 1 . 
Figura 9 - Malha utilizada no modelo FC mkII: a) visão completa, b) detalhe dos domínios internos, c) detalhe dos domínios de meios porosos.

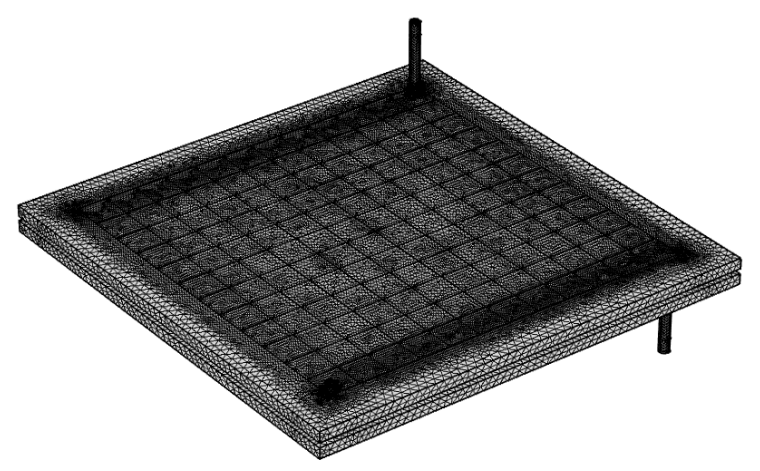

(a)

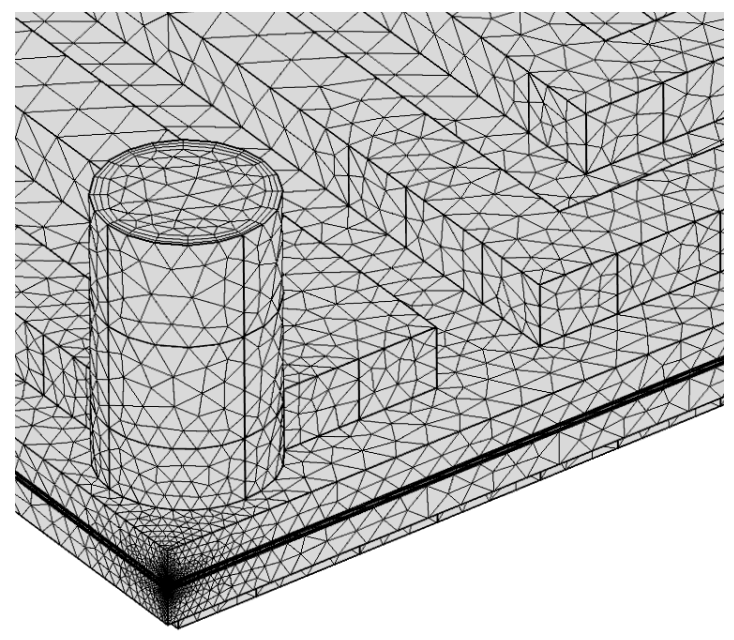

(b)

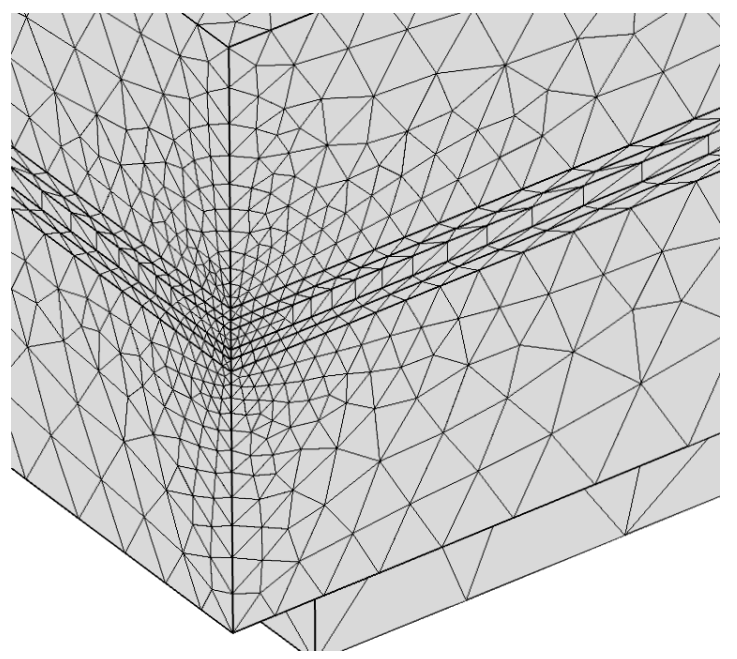

(c)

Fonte: Autoria própria.

- Passo 3, responsável pela temperatura, consiste em um solver iterativo do tipo GMRES, com 1 nível multigrid. O método não-linear utilizado foi constante, com fator de relaxamento de 0,7 .

- Passo 4, responsável pelas variáveis do transporte de carga, consitem em um solver direto do tipo MUMPS, com fator de alocação de memória de 1,2. O método não-linear utilizado foi constante, com fator de relaxamento de 1 .

- Passos 5 e 6, responsáveis pelas variáveis do transporte de espécies, consistem em solver iterativos do tipo GMRES, com 1 nível multigrid e um número máximo de iterações de 400. O método não-linear utilizado foi automático, com fator inicial de relaxamento de 1 e mínimo de $10^{-4}$.

O critério de convergência deve ser obedecido por cada passo do solver. Adicionalmente, ao final da iteração uma restrição é aplicada à temperatura, de modo que esta seja $T>0$. 
Um número máximo de 15 iterações do solver segregado foram estabelecidas, sendo que o cálculo é terminado caso este número seja excedido. Por fim, cada passo do estudo paramétrico foi utilizado como condição inicial para o próximo, sendo que o primeiro valor resolvido sempre foi de $I=0,1 \mathrm{~A}$.

\subsubsection{Comparação aos resultados experimentais}

O modelo FC mkII foi desenhado de modo a possibilitar comparação direta com as variáveis experimentais de maior interesse. A comparação entre as variáveis elétricas, i.e. curvas de polarização e distribuição espacial de corrente, são feitas diretamente. As curvas de polarização são obtidas através do potencial elétrico resultante na fronteira onde a corrente é aplicada, no compartimento catódico (Seção 4.2.2.4), sendo graficadas em função do módulo da corrente total aplicada, ou simplesmente $I$. O potencial de eletrodo, $E$ é assim obtido dado que a fronteira equivalente no comportamento anódico é considerada aterrada, i.e. $\phi_{s}=0$. Das curvas de polarização, também são obtidos valores referentes ao potencial de equilíbrio e resistência a polarização por queda ôhmica, $E(I=0)$ e $R_{\Omega}$, respectivamente. Estes foram obtidos da mesma maneira que os valores experimentais, conforme descrito na Seção 3.3, com a diferença que os valores de $E(I=0)$ simulados são dados aproximadamente pelo valor a $I=0,1 \mathrm{~A}$.

Para a distribuição de corrente, um resultado direto da solução do modelo é o vetor densidade de corrente $\mathbf{i}_{s}$. Porém, como descrito na Seção 3.1, o dispositivo experimental é capaz de mensurar a corrente total em pontos de um grid. Desta maneira, o resultado simulado é obtido de maneira semelhante, integrando-se a densidade de corrente sobre cada sub-região da fronteira segmentada no compartimento catódico:

$$
I_{i j}=\int_{\partial \Omega_{i j}} \mathbf{i}_{s} \mathrm{dS}, \mathrm{i}, \mathrm{j} \in[1,12]
$$

onde a numeração do grid é dada de maneira a orientar as entradas e saídas de gases da mesma maneira que no dispositivo experimental. A comparação com os resultados experimentais foi feita normalizando-se $\mathbf{I}$ com a soma entre todos os pontos (idealmente $\left.I=\sum_{i, j} I_{i j}\right)$, dado que os valores de corrente total experimental, ao somar-se sobre todos os pontos de coleta, difere do valor nominal aplicado na carga dinâmica. Para uma comparação mais rigorosa com os resultados experimentais, também foi utilizada uma representação linearizada das matrizes I experimentais e computacionais. A matriz I $12 \times 12$ é transformada em um vetor coluna de 144 elementos, com o mapeamento do tipo $[i, j] \rightarrow k=12(i-1)+j$. Desta maneira, a entrada de gás catódica se dá para altos valores de $k$, enquanto a saída se dá para baixos valores.

Dado que também estão disponíveis valores médios de temperatura de operação nos compartimentos anódico e catódico, além da distribuição espacial de temperatura no compartimento catódico, uma comparação entre os resultados computacionais e experimentais 
também foi realizada. Para as temperaturas médias, estas foram obtidas diretamente da média sobre os devidos compartimentos:

$$
\left\langle T_{\text {an,cat }}\right\rangle=\frac{\int_{\text {an,cat }} T d V}{\int_{\text {an,cat }} \mathrm{dV}}
$$

onde a integração é feita sobre os domínios $\Omega=[\mathrm{BP}, \mathrm{FC}, \mathrm{MPS}, \mathrm{MPL}, \mathrm{CL}]$ de cada compartimento.

No caso da distribuição espacial de temperatura, a condição de contorno de temperatura constante imposta ao modelo mkII impede a comparação direta com os resultados experimentais. No entanto, uma comparação qualitativa foi feita através da integração do fluxo total de calor normal à superfície segmentada da BP catódica:

$$
Q_{\mathrm{xc}_{i j}}=\int_{\partial \Omega_{i j}}\left(\mathbf{J}_{q} \cdot \mathbf{n}\right) \mathrm{dS}, \mathrm{i}, \mathrm{j} \in[1,6]
$$

onde $Q_{\mathrm{xc}_{i j}}$ foi tomado como o calor trocado entre o reservatório de calor e o modelo. O fluxo calor total, $Q_{\mathrm{xc}}$, foi usado para providenciar uma escala de desvio de temperatura, conforme descrito no Apêndice E, com base no desvio de temperatura do compartimento catódico em relação a $T_{0}$ :

$$
T_{\text {cat }}-T_{0}=0,2086 \times \operatorname{erf}\left(0,3524 \times Q_{\text {xc }}\right)
$$

A equação acima foi então utilizada para converter a matriz $\mathbf{Q}_{\mathrm{xc}}$ em uma matriz de desvios de temperatura simulados, $\Delta \mathbf{T}_{\text {sim }}$, em seguida comparada à matriz de desvios experimentais $\Delta \mathbf{T}_{\exp }=\mathbf{T}_{\exp }-T_{0}$. Similarmente às distribuições de corrente, também foram utilizadas distribuições linearizadas dos desvios de temperatura, neste caso o mapeamento para o vetor coluna sendo dado por $[i, j] \rightarrow k=6(i-1)+j$.

\subsubsection{Estudo do Transporte Convectivo}

Similarmente ao estudo conduzido com os modelos de protocélula (Seções 4.1 e 6.1), foram avaliados os efeitos da formulação do transporte de momento e da contribuição do transporte convectivo nos meios porosos para a performance de uma célula a combustível.

As formulações utilizadas foram as mesmas avaliadas para o modelo Alfa: StokesDarcy (SD) e Darcy-Brinkman (DB), sendo que a formulação híbrida Stokes-Brinkman foi desconsiderada. A formulação SD foi utilizada como descrita na Seção 4.1.1, com exceção da condição de entrada, que segue o descrito para os modelos FC, e a inclusão de um termo de fonte de momento devido às reações eletroquímicas, conforme descrito na Seção 4.2.2.4. A formulação DB e as demais formas de transporte seguem exatamente o modelo FC mkII.

Para a avaliação da contribuição do transporte convectivo, também foi utilizada a metodologia descrita para o modelo Alfa (Seção 4.1.3), i.e. desacoplando o transporte 
de momento do transporte de espécies nos domínios representativos dos meios porosos, $\Omega=[\mathrm{MPS}, \mathrm{MPL}, \mathrm{CL}]$. Conforme já descrito para o modelo Alfa, o transporte de momento ainda contribui para a pressão e, portanto, para a densidade e demais propriedades das misturas gasosas, sendo que apenas o campo de velocidades das espécies são nulos.

Diferentemente do realizado para os modelos Alfa e Beta, e dado que os modelos FC representam células a combustível propriamente ditas, a comparação entre as formulações SD e DB, e entre os modelos mkII e mkII-mod (com e sem transporte convectivo, respectivamente), foi feita utilizando as variáveis de interesse experimental, conforme detalhado na Seção 4.2.2.6. Por outro lado, dado o interesse nas previsões do impacto do transporte convectivo do modelo Alfa, as curvas de sobrepotencial de concentração descritas na Seção 4.1.3 foram replicadas para o modelo FC mkII. Os sobrepotenciais de concentração de $\mathrm{H}_{2}$ e $\mathrm{O}_{2}, \eta_{\mathrm{H}_{2}}$ e $\eta_{\mathrm{O}_{2}}$ respectivamente, foram calculados de maneira análoga à $\eta_{C}$ :

$$
\eta_{i}=\frac{R T}{n_{i} F} \log \left(\frac{P_{i}}{P_{i}^{*}}\right)
$$

com a consideração correta do número de elétrons de cada reação, $n_{i}$. 


\section{RESULTADOS EXPERIMENTAIS}

Neste Capítulo serão apresentados os resultados referentes aos experimentos de bancada. Estes foram obtidos com o intuito de validar os modelos computacionais de célula completa (Seção 4.2). A seguir serão apresentados os resultados, e uma breve discussão será dada. A comparação com os resultados computacionais é feita na Seção 6.2.1.

Os resultados experimentais serão apresentados conforme a seguinte divisão: i) curvas de polarização, ii) distribuição de corrente e iii) distribuição de temperatura. Conforme mencionado no início do Capítulo 3, dois MEAs foram utilizados. A análise considerará o conjunto de dados de cada MEA separadamente, em cada divisão, sendo posteriormente utilizadas em plenitude para obter-se uma visão geral do dispositivo e dos resultados obtidos. Demais dados coletados, temperaturas de umidificação e da célula, são apresentados na Tabela 11. Neste caso, não foi feita distinção entre MEAs, dado que tais variáveis não dependem dos mesmos.

Tabela 11 - Temperaturas médias registradas durante a coleta de dados experimentais.

\begin{tabular}{clccc}
\hline \multirow{2}{*}{$\#$} & \multicolumn{2}{l}{ Temperatura de Umidificação (K) } & \multicolumn{2}{c}{ Temperatura da Célula (K) } \\
& Ânodo & Cátodo & Ânodo & Cátodo \\
\hline I & $363 \pm 1$ & $358,4 \pm 0,5$ & $353,2 \pm 0,2$ & $353,1 \pm 0,3$ \\
II & $358 \pm 0$ & $358,4 \pm 0,5$ & $353,3 \pm 0,2$ & $353,2 \pm 0,1$ \\
III & $363 \pm 1$ & $358,3 \pm 0,4$ & $353,4 \pm 0,3$ & $353,2 \pm 0,1$ \\
IV & $363 \pm 1$ & $358,3 \pm 0,4$ & $353,5 \pm 0,4$ & $353,3 \pm 0,1$ \\
\hline
\end{tabular}

Fonte: Autoria própria.

\subsection{Curvas de Polarização}

As curvas de polarização obtidas são apresentadas na Figura 10, para ambos os MEAs e os quatro conjuntos de vazões considerados (Tab. 1). Pode-se observar que os MEAs utilizados produziram respostas estatisticamente distintas para todos os conjuntos considerados. Para os conjuntos II, III e IV, observa-se concordância entre os MEAs para baixos valores de corrente, com divergência em altos valores.

Por se tratar de um resultado global do dispositivo, pouco pode ser afirmado sobre a origem das diferenças entre os MEAs. Alguns pontos podem ser apontados, no entanto, considerando regiões tipicamente associadas a processos bem-comportados: polarização por i) ativação e ii) queda ôhmica. Assumindo que o transporte de espécies através da membrana, e que processos não-lineares de transporte de cargas, são neglegíveis, podem ser sugeridas possíveis origens para a diferença entre os MEAs. A Tabela 12 apresenta os valores médios obtidos para os dois MEAs utilizados e os quatro conjuntos de vazões analisados. Pode-se observar que, dentro da incerteza experimental, os valores de $E(I=0)$ 
Figura 10 - Curvas de polarização experimentais obtidas com MEA \#1 (×) e \#2 (+), para os conjuntos definidos na Tab. 1: I (azul), II (vermelho), III (preto) e IV (verde). a) Conjunto completo de dados, e b) conjuntos individuais. As barras de erro representam um desvio em relação à média.

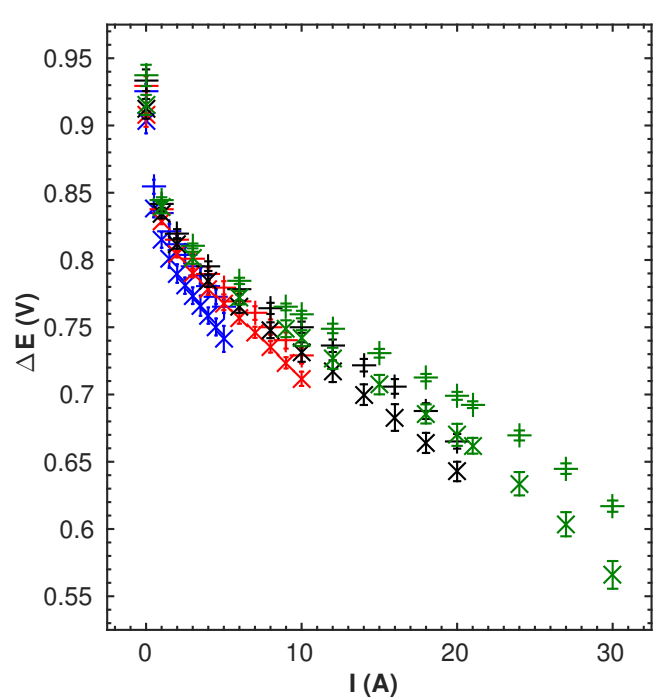

(a)
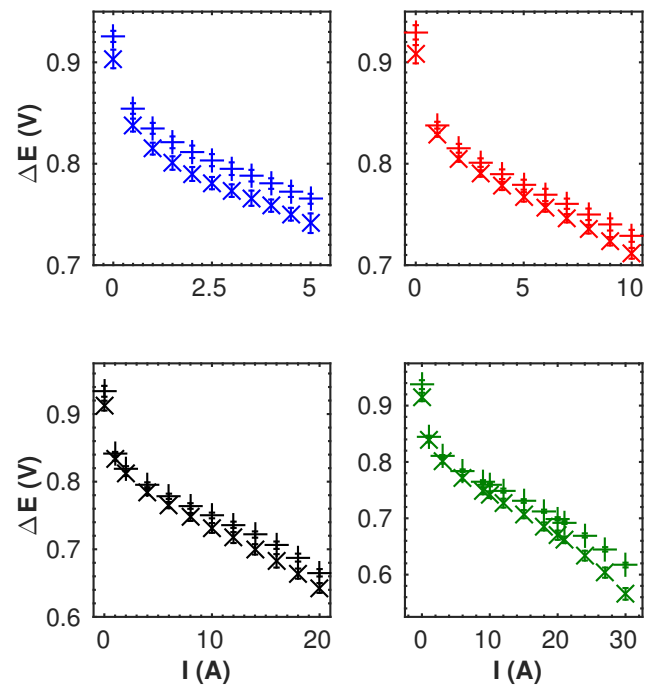

(b)

Fonte: Autoria própria.

são iguais para um mesmo MEA, apesar da diferença de vazões e, portanto, pressão parcial dos reagentes. Por outro lado, nota-se que os MEAs \#1 e \#2 são estatisticamente distintos. Para $R_{\Omega}$, observam-se diferentes valores para cada conjunto de vazões, no entanto nota-se que os MEAs são estatisticamente iguais entre si.

Tabela 12 - Valores médios para o potencial de equilíbrio e polarização por queda ôhmica para os conjuntos de dados experimentais.

\begin{tabular}{cccc}
\hline Grandeza & Conjunto & MEA \#1 & MEA \#2 \\
\hline \multirow{3}{*}{$E(I=0)(\mathrm{mV})$} & I & $900 \pm 10$ & $929 \pm 5$ \\
& II & $906 \pm 10$ & $933 \pm 6$ \\
& III & $910 \pm 8$ & $938 \pm 7$ \\
& IV & $912 \pm 8$ & $941 \pm 7$ \\
& & & \\
$R_{\Omega}(\mathrm{m} \Omega)$ & I & $15,4 \pm 5,0$ & $15,1 \pm 2,4$ \\
& II & $11,8 \pm 1,9$ & $10,9 \pm 2,0$ \\
& III & $8,30 \pm 1,0$ & $7,24 \pm 0,56$ \\
& IV & $7,34 \pm 1,3$ & $6,05 \pm 0,81$ \\
\hline
\end{tabular}

Nota: Valores de resistência obtidos nos seguintes intervalos de corrente: $2-5$ (I), $3-8$ (II), $8-16$ (III) e $9-20$ A (IV).

Fonte: Autoria própria. 
Figura 11 - Superfícies de corrente experimentais médias, obtidas para os conjuntos I, para os MEAs \#1 (linha superior) e \#2 (linha inferior). Em cada coluna é indicado o valor de $I_{R}$ aplicado no dispositivo. As entradas de gases se dão pelo canto inferior esquerdo e direito para o cátodo e ânodo, respectivamente. As saídas se dão no canto superior direito e esquerdo, para o cátodo e ânodo respectivamente.

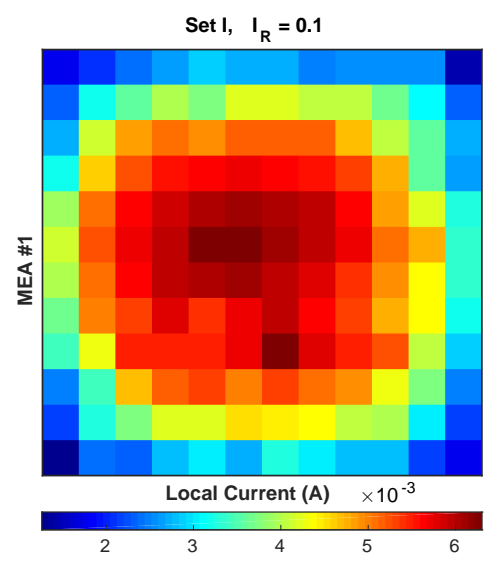

(a)

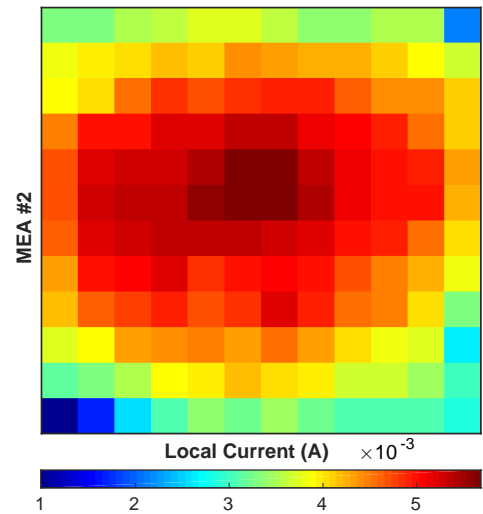

(d)

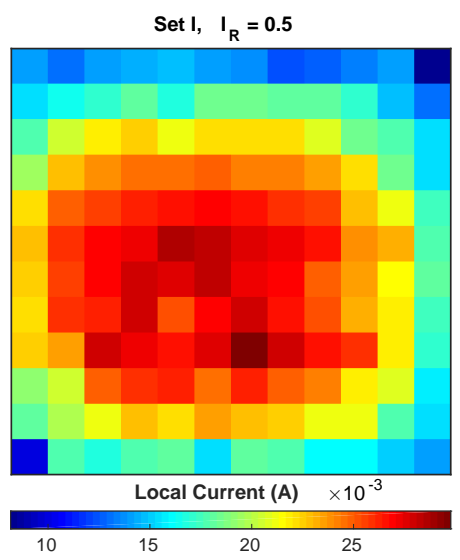

(b)

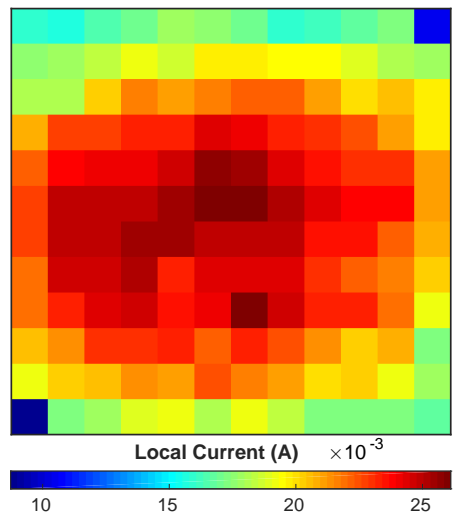

(e)

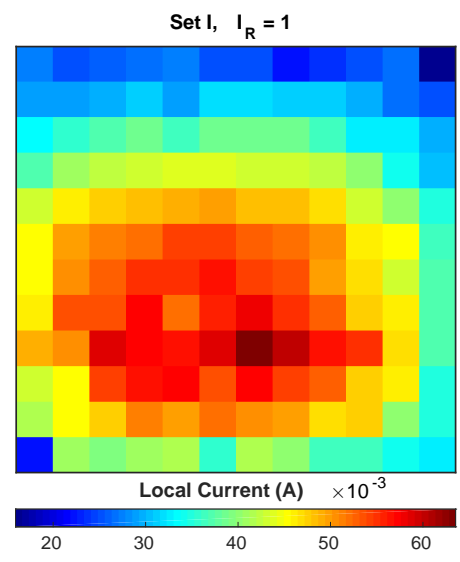

(c)

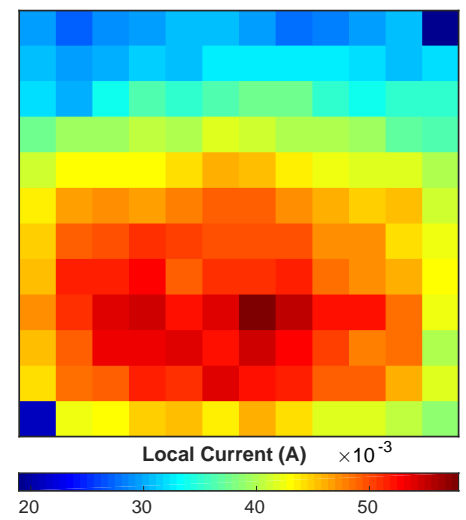

(f)

Fonte: Autoria própria.

\subsection{Distribuição de Corrente}

Superfícies de distribuição de corrente representativas de cada MEA são apresentadas nas Figuras 11 e 12, para os conjuntos I e IV, respectivamente. Pode ser observado que, apesar das diferenças entre os MEAs, o comportamento espacial da corrente, I, é basicamente o mesmo à medida que o valor de $I$ aumenta para um dado conjunto de vazões, i.e. $I_{R}$ se aproxima de 1 . Observa-se em baixos valores de $I_{R}$ uma concentração de corrente nas regiões centrais do dispositivo, com um deslocamento para o canto inferior esquerdo à medida que $I_{R}$ aumenta. Tal comportamento também é observado nos conjuntos II e III. Apesar da assimetria de $\mathbf{I}$ em relação ao eixo $x$ ser menor que em $y$, tal deslocamento é observado em todos os casos, podendo estar correlacionado às entradas de gases e, assim, ao consumo de reagentes. 
Figura 12 - Superfícies de corrente experimentais médias, obtidas para os conjuntos IV, para os MEAs \#1 (linha superior) e \#2 (linha inferior). Em cada coluna é indicado o valor de $I_{R}$ aplicado no dispositivo. As entradas de gases se dão pelo canto inferior esquerdo e direito para o cátodo e ânodo, respectivamente. As saídas se dão no canto superior direito e esquerdo, para o cátodo e ânodo respectivamente.

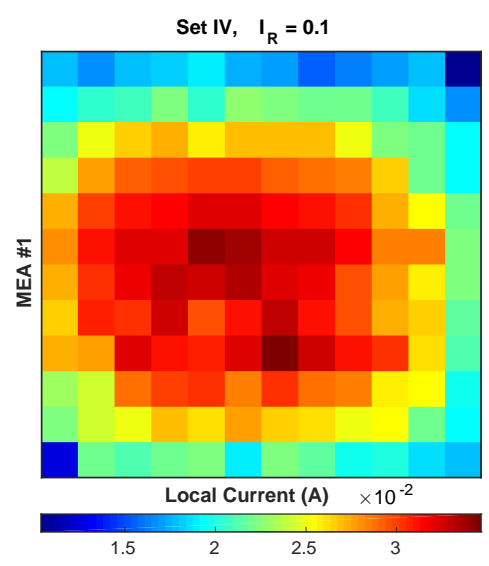

(a)

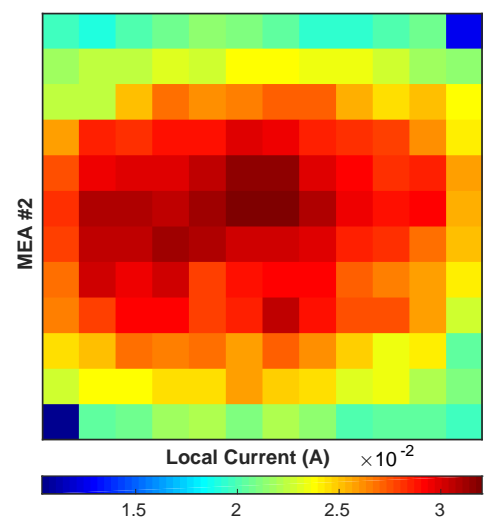

(d)

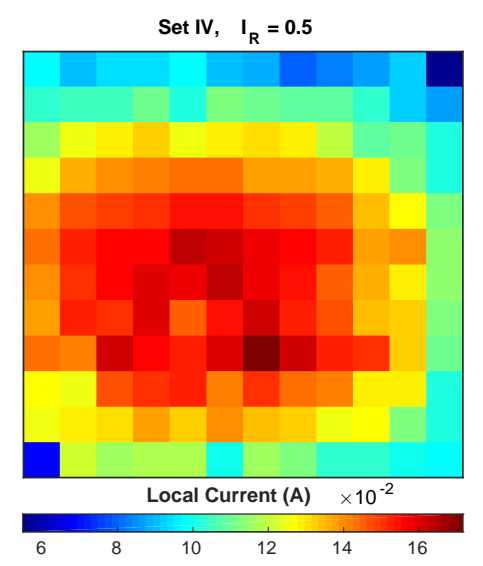

(b)

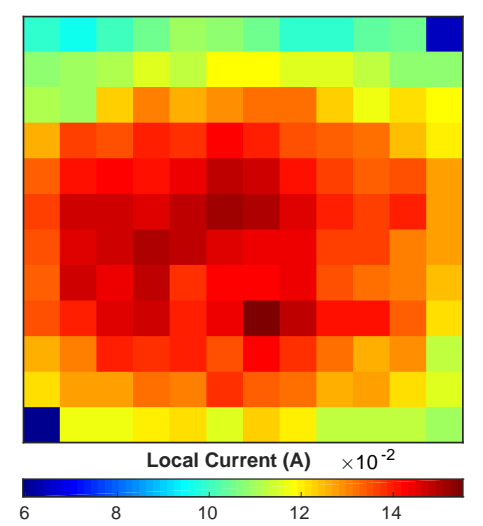

(e)

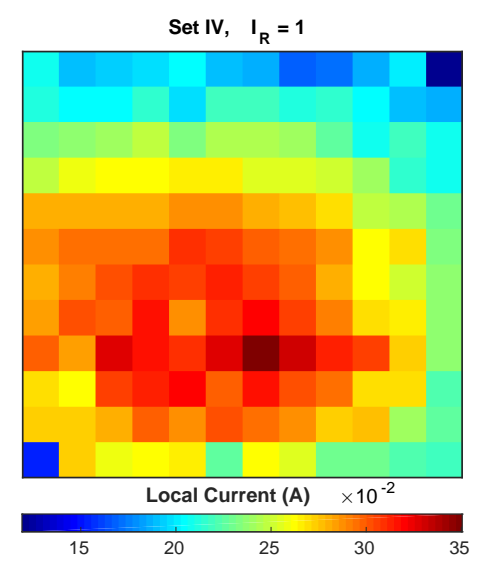

(c)

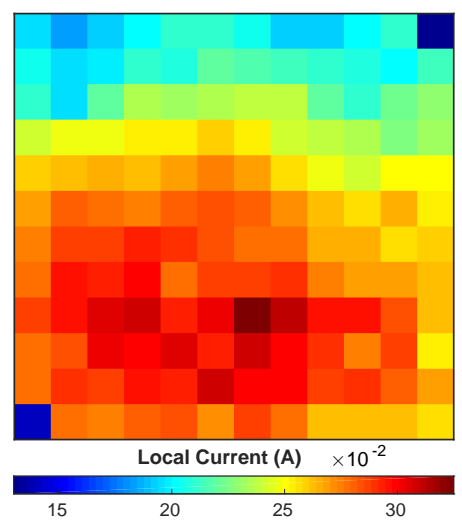

(f)

Fonte: Autoria própria.

Uma comparação mais rigorosa entre os MEAs \#1 e \#2 é feita na Figura 13, que compara as médias de $I_{i j}$ entre os dois MEAs. Os valores de corrente total aplicada são os mesmos apresentados nas Figs. 11 e 12. De maneira geral, um comportamento semelhante ao apresentado nas Figs. 11 e 12 pode ser observado: para os diferentes conjuntos, os valores de corrente escolhidos apresentam aproximadamente o mesmo comportamento. É possível observar, conforme apontado anteriormente, que não se observa uma correlação perfeita entre os MEAs, mesmo considerando os desvios em relação à média. A Tabela 13 apresenta os coeficientes de Pearson $(\mathrm{R})$ entre $I_{i j}$ dos MEAs \#1 e \#2 para os valores $I_{R}=0.1,0.5,1$ de cada conjunto de vazões. Nota-se que, ao contrário do sugerido por inspeção visual, os dados da região resistiva (coluna central) apresentam maior correlação, sendo consistentes ao longo dos conjuntos I a IV. Por outro lado, as regiões de ativação (coluna esquerda) e de transporte de massa (coluna direita) possuem maior variação nos 
Figura 13 - Valores médios de $I_{i j}$ do MEA\#2 em função do MEA \#1, para valores representativos de $I_{R}$ : conjunto I (linha superior) e IV (linha inferior). As barras de erro representam um desvio em relação à média. As linhas vermelhas representam correlação linear perfeita.

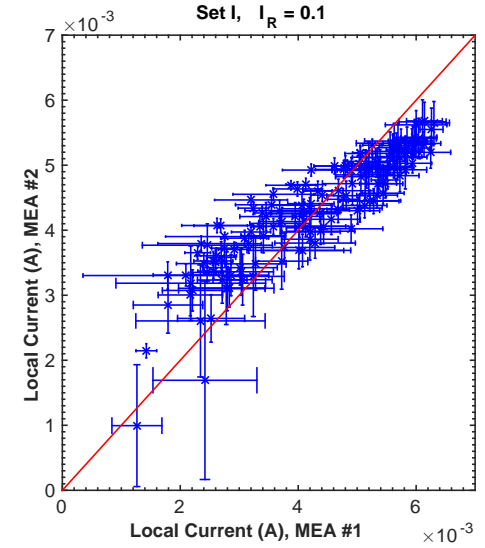

(a)

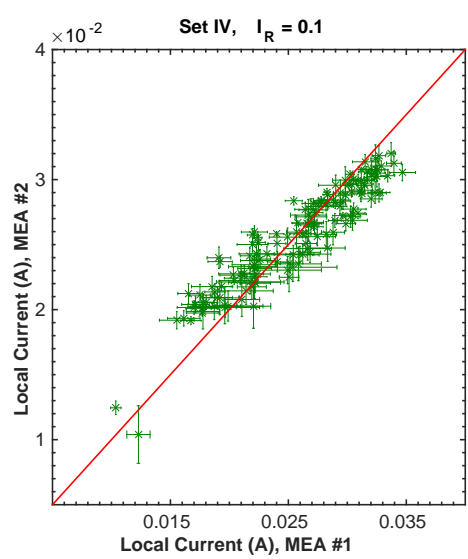

(d)

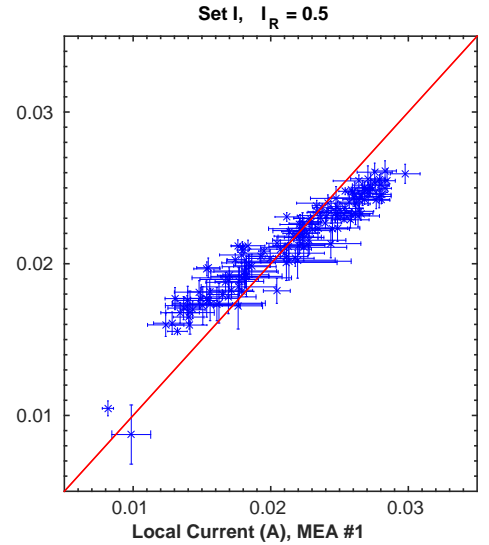

(b)

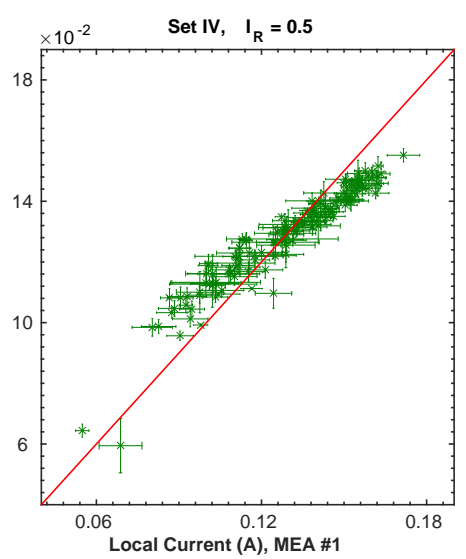

(e)

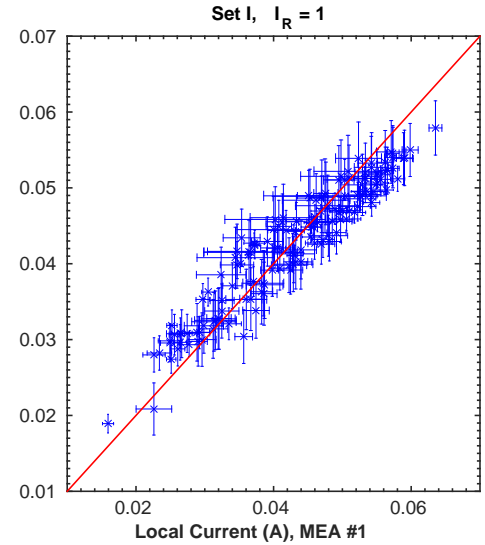

(c)

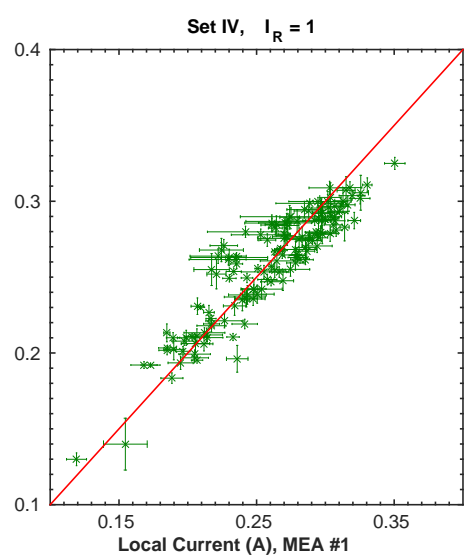

(f)

Fonte: Autoria própria.

coeficientes de correlação, porém de maneira geral inferiores aos da região resistiva.

Tabela 13 - Coeficientes de Pearson (R) entre distribuições de corrente dos MEAs \#1 e \#2, para valores representativos de $I$.

\begin{tabular}{cccccc}
\hline Conjunto & $I$ (A) & $\mathbf{R}$ & Conjunto & $I(\mathbf{A})$ & $\mathbf{R}$ \\
\hline \multirow{3}{*}{ I } & 0,5 & 0,9001 & & 1 & 0,8789 \\
& 2,5 & 0,9503 & III & 10 & 0,9581 \\
& 5,0 & 0,9484 & & 20 & 0,8805 \\
& & & & & \\
II & 2 & 0,9059 & & 3 & 0,9387 \\
& 5 & 0,9591 & IV & 15 & 0,9549 \\
& 10 & 0,9236 & & 30 & 0,9151
\end{tabular}

Fonte: Autoria própria. 
Figura 14 - Distribuições de temperatura experimentais médias obtidas para o conjunto I, para os MEAs \#1 (linha superior) e \#2 (linha inferior): a-b) e d-e) superfícies de temperatura para $I_{R}=0,1$ e 1, respectivamente; e c) f) distribuições linearizadas para $I_{R}=0,1(\times), 0,5(\times)$ e $1(\times)$. Barras de erro representam um desvio em relação à média.

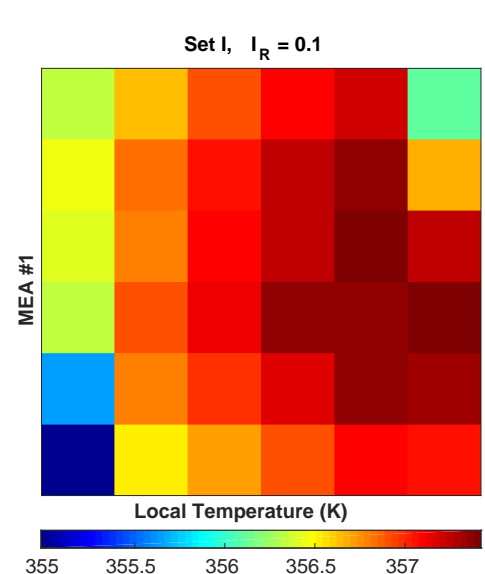

(a)

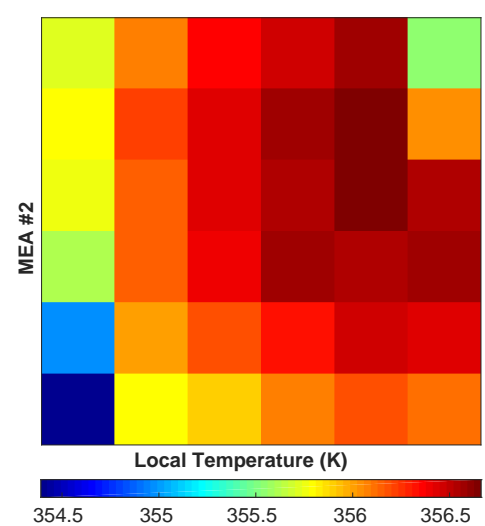

(d)

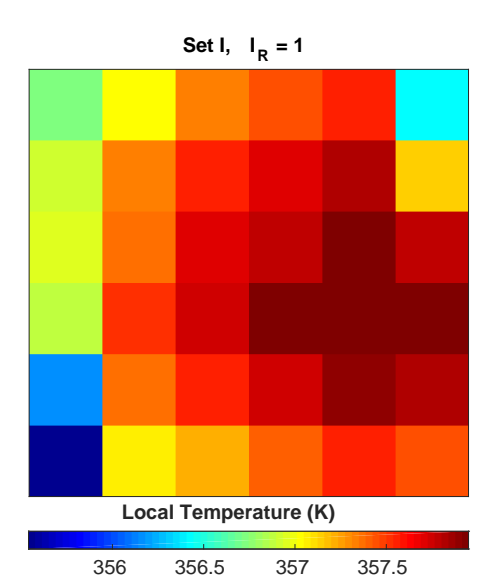

(b)

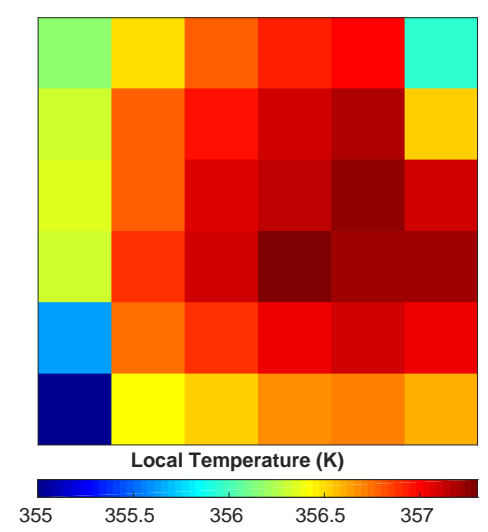

(e)

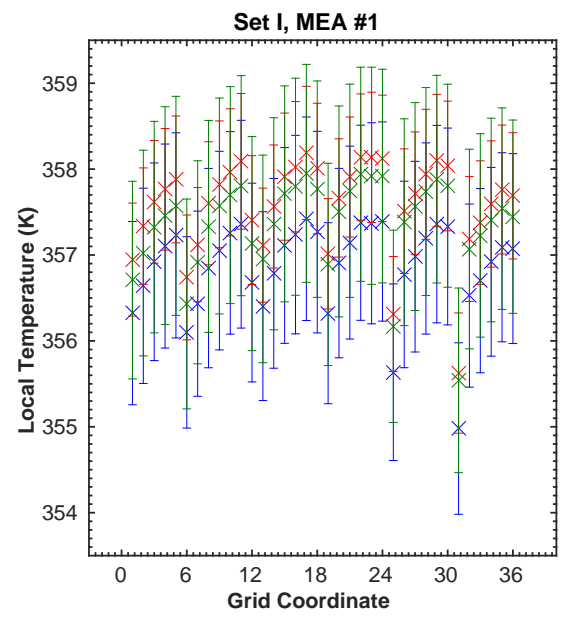

(c)

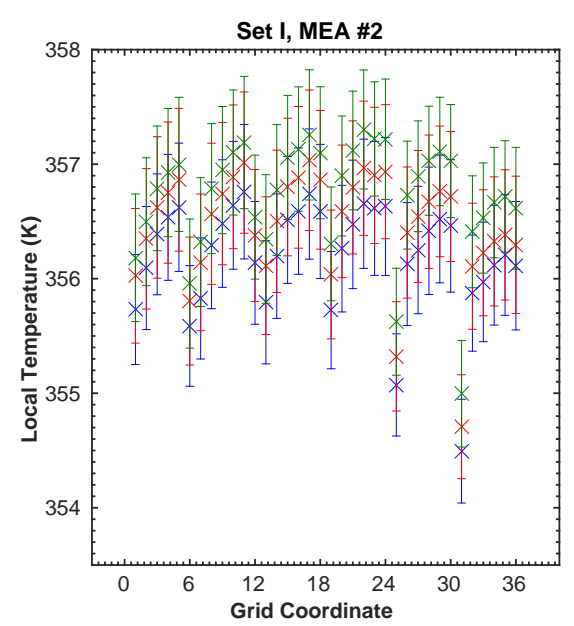

(f)

\subsection{Distribuição de Temperatura}

Superfícies de distribuição de temperatura representativas para os conjuntos I e IV são dadas na Figuras 14 e 15, respectivamente. Diferentemente do observado para a distribuição de corrente (Figs. 11 e 12), poucas mudanças são observadas em função da corrente aplicada $I$ para um dado conjunto. Isto é particularmente evidente para o conjunto I, nas Figs. 14c e 14f, onde é possível observar que, apesar da variação dos valores médios, estes são estatisticamente iguais. O mesmo é observado para conjunto II (não apresentado).

Por outro lado, para os conjunto III e IV, foi observado um aumento estatisticamente significativo da temperatura, como pode ser observado na Fig. 15 para o conjunto IV. Para o conjunto IV, observa-se um aumento significativo da temperatura a partir de $I_{R}=0,5$ 
Figura 15 - Distribuições de temperatura experimentais médias obtidas para o conjunto IV, para os MEAs \#1 (linha superior) e \#2 (linha inferior): a-b) e d-e) superfícies de temperatura para $I_{R}=0,1$ e 1 , respectivamente; e c) f) distribuições linearizadas para $I_{R}=0,1(\times), 0,5(\times)$ e $1(x)$. Barras de erro representam um desvio em relação à média.

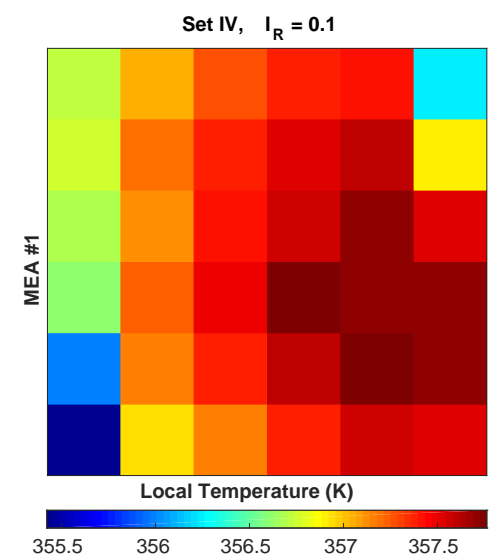

(a)

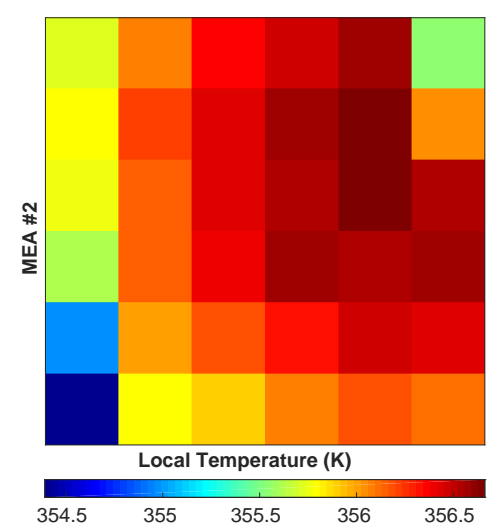

(d)

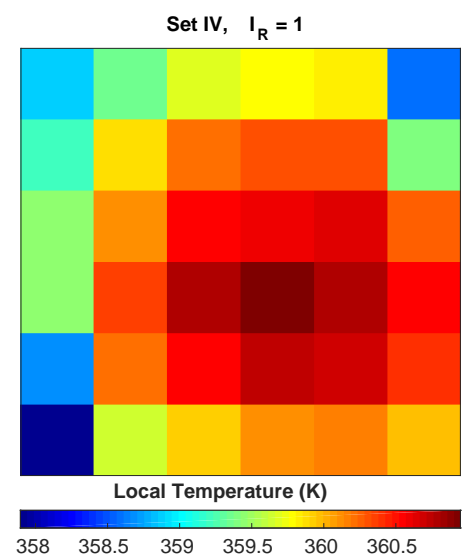

(b)

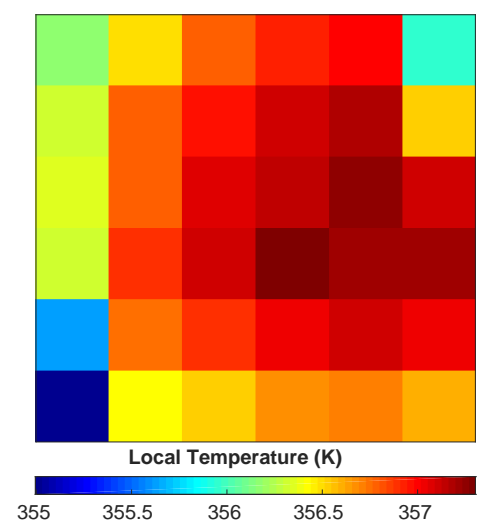

(e)

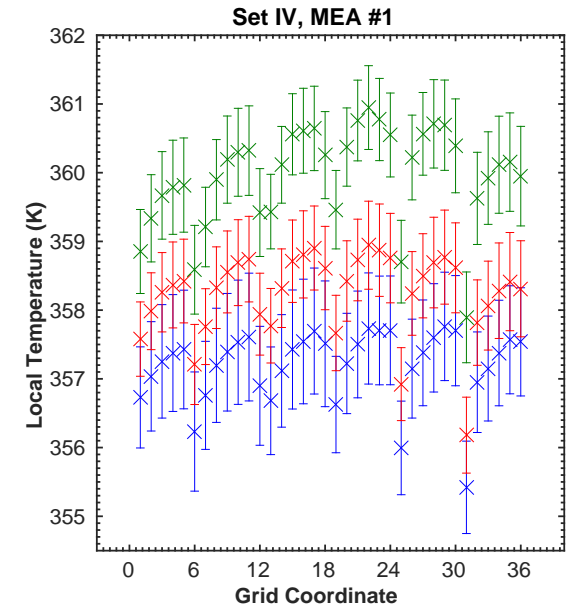

(c)

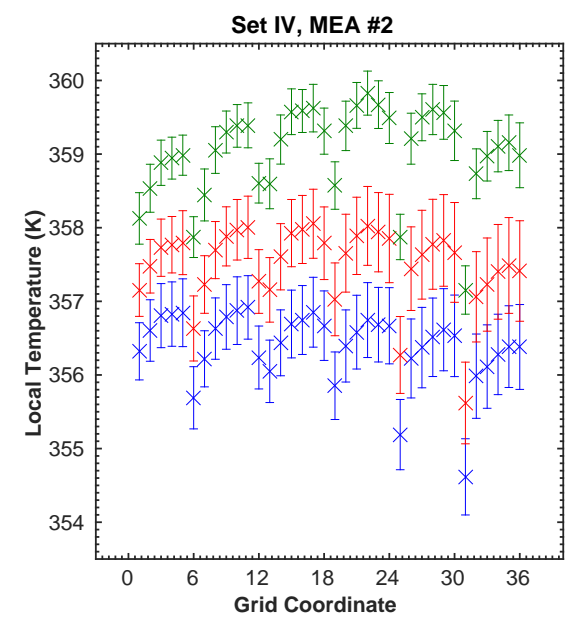

(f)

em quase todas as regiões do dispositivo (Figs. 15c e 15f), sendo particularmente notável em $I_{R}=1$. Algo similar é observado para o conjunto III (não apresentado), porém com menores diferenças ao longo do aumento de $I$.

De maneira geral, observa-se que o comportamento dos dois MEAs é virtualmente o mesmo em relação ao aumento da corrente aplicada. Os maiores valores de temperatura, para um dado valor de $I_{R}$, tendem a se agrupar no quadrante inferior direito, apontando novamente, para uma correlação com as entradas de gases. Mais rigorosamente, a mesma análise dos valores individuais de $T_{i j}$ pode ser feita observando-se a Figura 16. Diferentemente da corrente, maior uniformidade é observada para $\mathbf{T}$, portanto poucos valores de $I$ foram selecionados para representar os resultados gerais. Os valores de $R$ são apresentados na Tabela 14. Como pode ser observado, apesar de valores de $R$ próximos à unidade em geral, observa-se valores de $T_{i j}$ consistentemente maiores para o MEA \#1, em particular 
Figura 16 - Valores médios de $T_{i j}$ do MEA\#2 em função do MEA \#1, para valores representativos de $I_{R}$ : conjunto I (linha superior) e IV (linha inferior). As barras de erro representam um desvio em relação à média. As linhas vermelhas representam correlação linear perfeita.

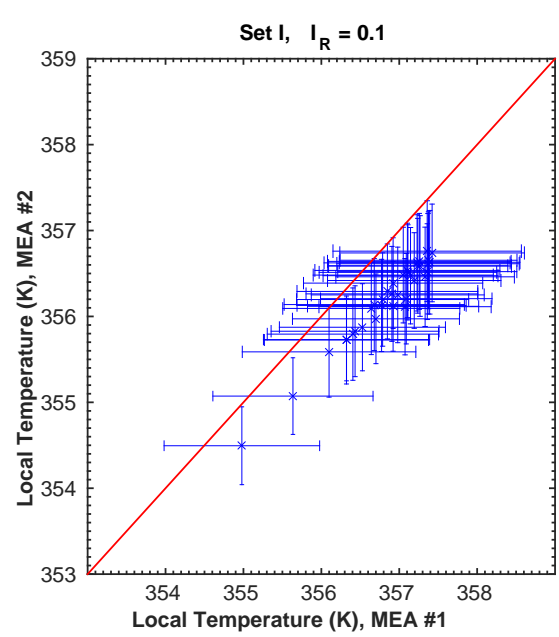

(a)

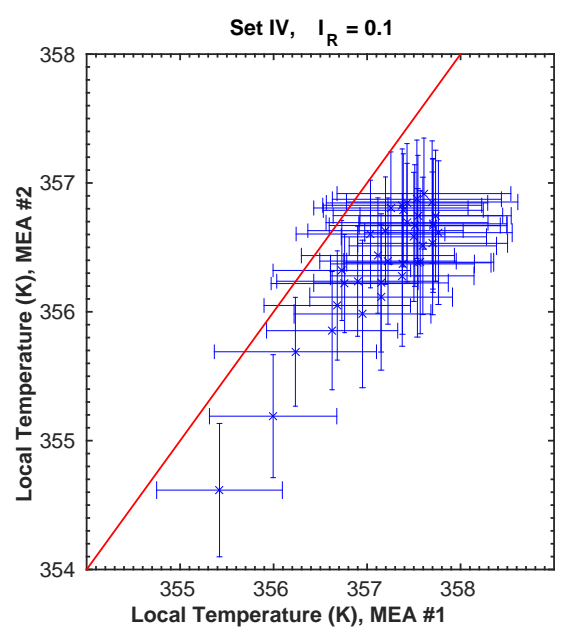

(c)

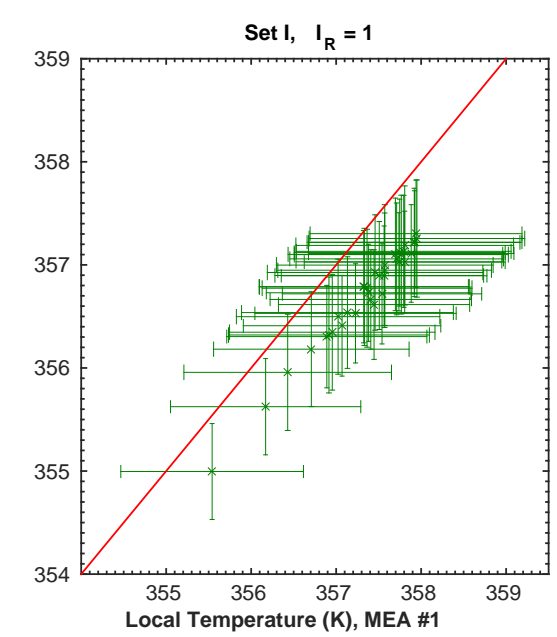

(b)

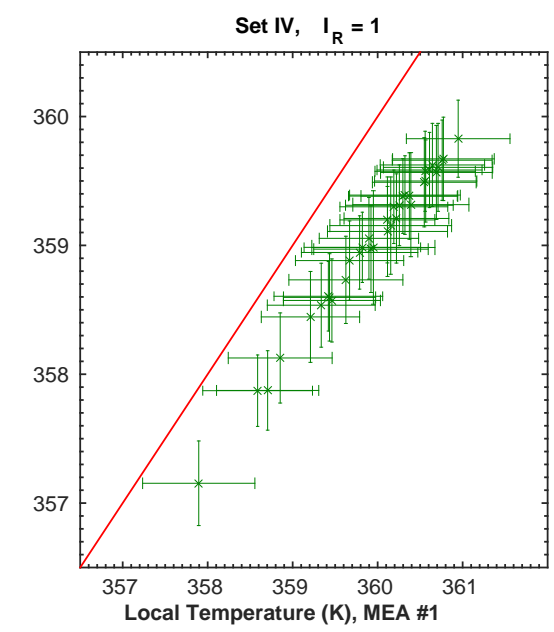

(d)

Fonte: Autoria própria.

para altos valores de $I$ nos conjuntos III e IV (Fig. 16d, não apresentado para III). Para baixos valores de $I$, especialmente nos conjuntos I e II (Figs. 16a e 16b, não apresentado para II), observa-se que os resultados são em geral estatisticamente iguais.

\subsection{Discussão}

Os resultados apresentados nas Seções acima sugerem que os conjuntos de dados obtidos para cada MEA são estatisticamente distintos, em um intervalo de confiança de 95\%. Considerando os dados disponíveis, não é possível estabelecer causalidade entre os resultados observados e o conhecimento acerca do dispositivo e seus componentes. Neste ponto, deve-se notar que outras fontes de incerteza existem, principalmente em relação ao 
Tabela 14 - Coeficientes de Pearson (R) entre distribuições de temperatura dos MEAs \#1 e \#2, para valores representativos de $I$.

\begin{tabular}{cccccc}
\hline Conjunto & $I(\mathbf{A})$ & $\mathbf{R}$ & Conjunto & $I(\mathbf{A})$ & $\mathbf{R}$ \\
\hline \multirow{2}{*}{ I } & 0,5 & 0,9795 & II & 1 & 0,9797 \\
& 5,0 & 0,9893 & & 10 & 0,9957 \\
\multirow{2}{*}{ III } & 2 & 0,9504 & \multirow{2}{*}{ IV } & 3 & 0,8986 \\
& 20 & 0,9871 & & 30 & 0,9956 \\
\hline
\end{tabular}

Fonte: Autoria própria.

uso do MEA \#1 e a própria natureza dos materiais utilizados.

Por outro lado, pode ser especulado quanto à origem das diferenças tendo em vista que os resultados apresentados acima convergem em alguns pontos. Em primeiro lugar, os valores de $\Delta E(I=0)$ obtidos das curvas de polarização apontam para a possibilidade de diferença em atividade catalítica entre os MEAs (Tab. 12), dado que o potencial de equilíbrio também reflete o estado da superfície dos catalisadores, além da atividade dos reagentes. Isto é suportado pelo relativo baixo valor do coeficiente de correlação entre os dados de distribuição de corrente para baixos valores de $I$ (Tab. 13). Nota-se, no entanto, que o cálculo de $R$ não leva em conta o desvio experimental, e os resultados apresentados na Fig. 13 sugerem que a falta de correlação linear entre os dados de ambos os MEAs pode ser explicado largamente pelos desvios experimentais.

Em segundo lugar, sugere-se que há diferenças nas propriedades de transporte de espécies entre os MEAs. Isto é suportado pelas diferenças em distribuição espacial de corrente (Figs. 11 e 12), sendo particularmente notável em altos valores de corrente para cada conjunto de dados. Os baixos valores de $R$ observados entre os MEAs para estas regiões suportam tal observação; porém, como no caso apontado no parágrafo acima, a falta de correlação linear também pode ser atribuída em grande parte a desvios experimentais. As diferenças nas distribuições de temperatura também podem ser interpretadas nesta maneira. As maiores temperaturas observadas para o MEA \#1 (Figs. ?? e ??) são consistentes ao longo de todas as medidas, ao mesmo tempo mantendo uma forte correlação linear (Tab. 14) em grandes intervalos de corrente, com os desvios experimentais apontando para grande equivalência estatística entre os MEAs. Em altos valores de corrente, no entanto, para os conjunto III e IV são observados distanciamentos de uma correlação linear (Fig. 16), mesmo considerando os desvios experimentais. Considerando que as resistências dos MEAs são estatisticamente iguais, e que portanto o calor gerado devido ao efeito Joule é semelhante, tal resultado sugere que o MEA \#1 dissipa calor de maneira menos eficiente que o MEA \#2, possivelmente devido às diferenças nas propriedades de transporte de espécies.

Deve-se apontar, no entanto, que os tempos de relaxação para a temperatura são significativamente maiores que para a corrente, e não pode ser assumido que o dispositivo 
estava em equilíbrio térmico, dentro das restrições aplicadas ao mesmo, em nenhuma das medidas. Por outro lado, as replicatas foram feitas de maneira a minimizar resultados espúrios, e portanto aumentar a confiança nas observações realizadas.

Por fim, as diferenças observadas nas distribuições de corrente entre os MEAs poderiam ser minimizadas, e potencialmente justificadas, considerando a possibilidade de resistências de contato no MEA \#1. Como pode ser visto nas Figs. 11 e 12, para correntes nulas, o MEA \#1 apresenta uma concentração de flutuações na região central das superfícies, sugerindo um melhor contato nesta região. Adicionalmente, os gráficos de correlação linear (Fig. 13) na região de controle resistivo sugerem um correlação linear, porém com inclinação diferente da unidade, sugerindo resistências diferentes. Os argumentos contra este ponto são a observação de resistências globais estatisticamente iguais para os MEAs, já apontado acima, e na observação contrária do efeito esperado de resistência de contato com a montagem da célula: a pressão exercida pela montagem da célula se dá ao redor do cerne do dispositivo, portanto uma maior resistência de contato é esperada na região central das superfícies de $\mathbf{I}$, contrário ao observado experimentalmente em $I=0$. De fato, o auxílio de contato utilizado entre a placa de distribuição de corrente e a placa monopolar catódica (Seção 3.1) foi introduzido para minimizar tal possibilidade.

Levando a discussão acima em consideração, os conjuntos de dados obtidos com os dois MEAs serão utilizados juntamente para comparação com o modelo numérico desenvolvido. Espera-se que a diferença entre os MEAs não seja um artefato, mas que represente incertezas existentes no processo de fabricação e as adicionadas pela montagem e operação do dispositivo experimental. Naturalmente que os resultados apresentados são apenas uma pequena amostragem da população possível. É necessário, e desejado, um acúmulo contínuo de dados de modo a se obter uma estimativa robusta das grandezas avaliadas e possiblitar um entendimento das mesmas. 


\section{RESULTADOS COMPUTACIONAIS}

São apresentados neste Capítulo os resultados computacionais referentes aos modelos Alfa e FC mkII. Para cada modelo é feita uma comparação aos dados experimentais disponíveis, seguida de estudos computacionais associados ao transporte convectivo dos sistemas.

\subsection{Protocélula}

A seguir serão apresentados os resultados referentes ao modelo Alfa, aplicado à protocélula descrita em (33). Primeiramente será discutida a validação do modelo frente aos resultados experimentais disponíveis. Em seguida, serão apresentados resultados exclusivamente computacionais, referentes ao transporte convectivo nos meios porosos e ao estudo da geometria dos canais do dispositivo.

\subsubsection{Validação}

\subsubsection{Comparação aos resultados experimentais}

Inicialmente são reproduzidos exemplos dos resultados experimentais de emissão de luz de Lopes et al.(33), apresentados na Figuras 17a e 17e. Dada a calibração descrita em (33), a intensidade luminosa é diretamente proporcional à concentração e, consequentemente, à pressão parcial de ozônio na CL do dispositivo experimental. Juntamente aos resultados experimentais, são apresentadas na Figura 17 as superfícies de pressão parcial simuladas para os mesmos valores de $Q$, usando as três formulações para o escoamento de ar. Apesar de ser uma comparação qualitativa, observa-se que, de modo geral, as superfícies simuladas concordam com a distribuição experimental de ozônio. Neste caso, a constante de velocidade da reação de decomposição do ozônio utilizada foi $k=250 \mathrm{~s}^{-1}$, por motivos a serem discutidos adiante.

Em particular, observa-se que a formulação SD superestima a distribuição de ozônio para baixos valores de $Q$ (Fig. 17b), apesar de manter uma correlação apropriada para valores superiores (Fig. 17f). A diferença mais marcante entre a formulação SD e os resultados experimentais são observados nas proximidades e na seção vertical das voltas. Os resultados experimentais apresentam um estreitamento relativamente abrupto nas proximidades da volta, enquanto que a simulação produz um estreitamento contínuo ao longo da seção horizontal do canal. Nota-se, também, nos resultados experimentais, que a pressão parcial apresenta um mínimo local no primeiro canto da volta (ver também Fig. 19), enquanto que a formulação SD prevê um mínimo aproximadamente no meio da seção vertical da volta. Tal efeito é observado também na primeira volta, que não apresenta 
Figura 17 - Superfícies de pressão parcial de $\mathrm{O}_{3}$ para $Q=250$ (linha superior) e $450 \mathrm{~cm}^{3} \mathrm{~min}^{-1}$ (linha inferior): a) e e) resultados experimentais; b) e f) formulação SD; c) e g) formulação DB; e d) e h) formulação SB.

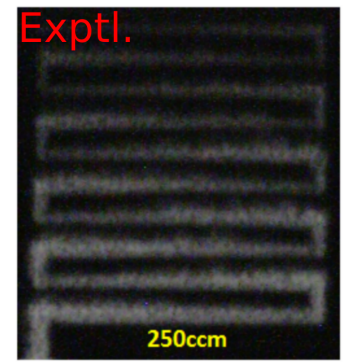

(a)

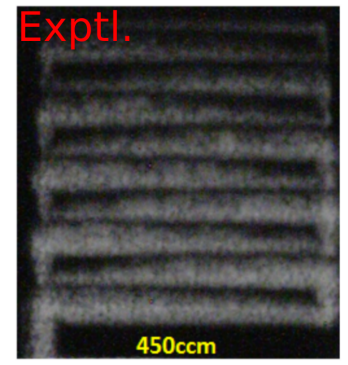

(e)

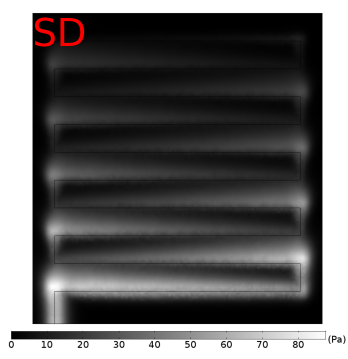

(b)

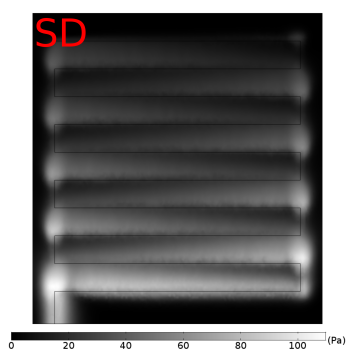

(f)

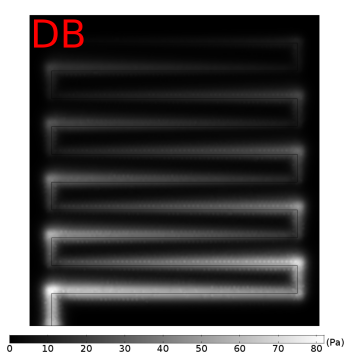

(c)

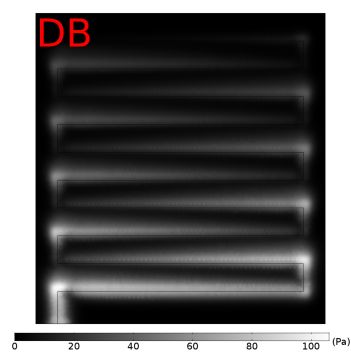

$(\mathrm{g})$

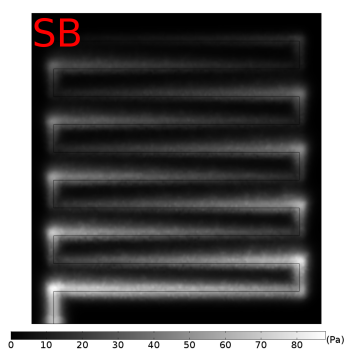

(d)

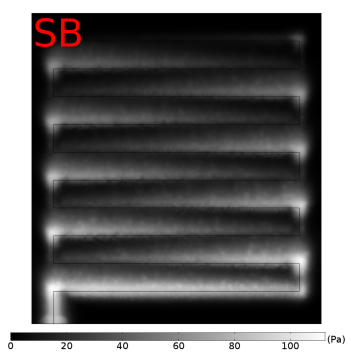

(h)

Fonte: a) e e): adaptadas de (33). Demais figuras: autoria própria.

contribuição de ozônio de voltas anteriores, sugerindo que trata-se de um efeito do campo de velocidades resultante, ao invés da escolha do valor de $k$ (ver Seção 6.1.1.2).

As formulações DB e SB prevêem superfícies muito similares, particularmente para valores baixos de $Q$ (Figs. 17c e 17d). De maneira semelhante à SD, o estreitamento da distribuição de ozônio é aproximadamente contínua ao longo das seções horizontais do canal, entretanto com valores absolutos menores aos produzidos por aquela. O mínimo local de pressão parcial aparenta ser condizente com os resultados experimentais, estando próximo do início de cada volta. No entanto, observa-se que, para um mesmo valor de $k$, a formulação SB prevê maior cruzamento de ozônio entre voltas que a DB para altos valores de $Q$ (Figs. $17 \mathrm{~g}$ e $17 \mathrm{~h})$.

A Figura 18 apresenta a comparação entre resultados experimentais e computacionais para as variáveis globais do sistema, $\Delta P$ e $\Delta \mathrm{O}_{3}$. Para a perda de carga, Figura 18a, foram calculadas as incertezas das medidas de pressão e vazão experimentais, apresentadas como barras de erro. Observa-se que as formulações SD e DB reproduzem os resultados experimentais dentro da incerteza das medidas, enquanto a formulação SB superestima a perda de carga.

Para o consumo de ozônio, Figura 18b, deve-se apontar mais uma vez que não foi encontrado na literatura um valor para a constante de velocidade $k$ da reação de decom- 
Figura 18 - Variáveis globais em função de $Q$, simuladas com a formulação SD $(\square)$, DB $(\triangle)$, $\mathrm{SB}(\diamond)$, comparadas aos resultados experimentais (०): a) perda de carga, com barras de erro representando a incerteza das medidas; e b) consumo de $\mathrm{O}_{3}$, com barras de erro representando um desvio padrão nas medidas.

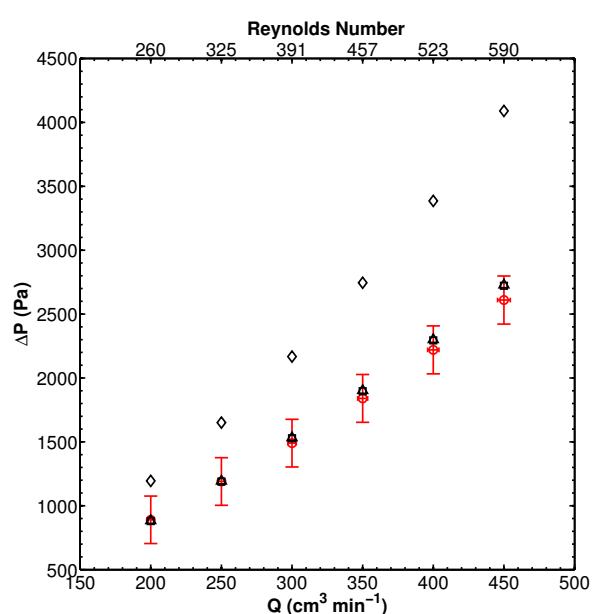

(a)

Fonte: Autoria própria.

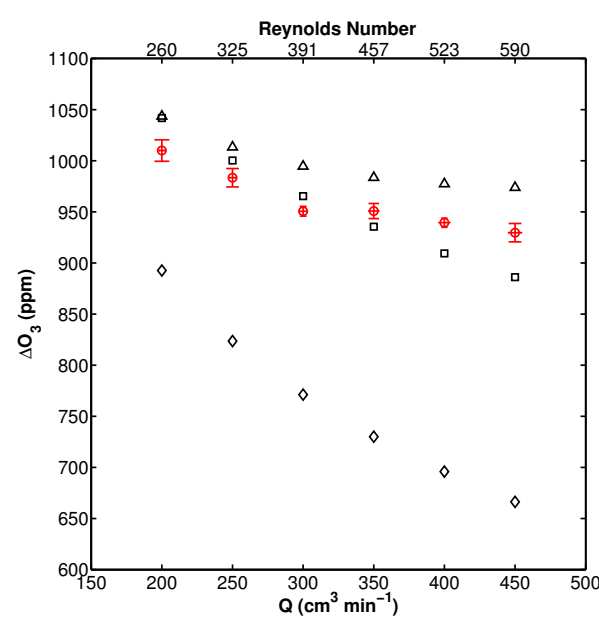

(b)

posição catalítica do ozônio. Como mencionado na Seção 4.1.2, o valor de $k$ foi variado entre 10 e $10^{3} \mathrm{~s}^{-1}$, sendo escolhido o valor de $250 \mathrm{~s}^{-1}$ como representativo da cinética aparente da reação. A escolha foi baseada na reprodução, visual, das superfícies de pressão parcial de ozônio quando comparadas às experimentais (ver Seção 6.1.1.2).

Tendo este aspecto do modelo em mente, a comparação entre os resultados apresentados na Fig. 18b é de natureza qualitativa. A Tabela 15 apresenta os valores de MAE, ME e de R para as formulações SD e DB para análise. Primeiramente nota-se que todos os resultados são estatisticamente diferentes dos resultados experimentais. As formulações SD e DB apresentam resultados coerentes quando comparados aos experimentais, enquanto que a formulação SB apresenta um desvio notável dos valores absolutos. Nota-se que as formulações SD e DB prevêem comportamentos distintos para $\Delta \mathrm{O}_{3}(Q)$, sendo que os resultados de $\mathrm{SD}$, para $k=250 \mathrm{~s}^{-1}$, aparentam ter um desvio numérico menor. De fato, a comparação do MAE e ME suportam tal conclusão. No entanto, dado o grau de liberdade imposto pelo desconhecimento do valor real de $k$, tal análise é pouco conclusiva. O valor de R, por outro lado, entre os resultados simulados e experimentais suporta a hipótese contrária. Isto indica que a formulação DB pode ser um melhor descritor do que a SD. Isto é corroborado pelo valor de $\mathrm{R}$ para os resultados em relação à $Q, \mathrm{R}^{Q}$, também mostrados na Tab. 15. Os valores indicam que, conforme observado na Fig. 18b, todos os resultados apresentam correlação negativa $\operatorname{com} Q$. No entanto, o valor para a formulação SD indica quase total correlação linear com $Q$, diferente dos demais, que por sua vez concordam entre si. 
Tabela 15 - Descritores estatísticos utilizados na comparação entre as formulações $\mathrm{SD}$ e DB em relação aos dados de $\Delta \mathrm{O}_{3}(Q)$ apresentados Fig. 18b.

\begin{tabular}{ccccc}
\hline Formulação & MAE $(\mathbf{p p m})$ & $\mathbf{M E}(\mathbf{p p m})$ & $\mathrm{R}$ & $\mathrm{R}^{Q}$ \\
\hline Stokes-Darcy (SD) & 25,37 & 31,77 & 0,9688 & $-0,9943$ \\
Darcy-Brinkman (DB) & 37,04 & 44,14 & 0,9856 & $-0,9394$ \\
Experimental & & & & $-0,9441$ \\
\hline Fonte: Autoria própria. & & & &
\end{tabular}

Fonte: Autoria própria.

Por fim, é apresentado na Figura 19 o perfil de $\mathbf{P}_{\mathrm{O}_{3}}$, obtido na CL ao longo da trajetória mostrada na Fig. 5a. É possível notar a correlação entre os perfis e as respectivas superfícies de pressão parcial, em particular os máximos locais de pressão parcial no segundo cotovelo de cada volta. De maneira geral, as três formulações reproduzem o comportamento, em particular os máximos locais de pressão parcial após as voltas e o decaimento ao longo de toda a trajetória. Também observa-se que as simulações superestimam a pressão parcial próximo à entrada de gases. Em uma análise mais detalhada, pode-se observar que a formulação SD prevê um comportamento diferente do experimental nas seções horizontais do FC. O perfil experimental apresenta um decaimento aproximadamente linear, enquanto que a formulação SD apresenta um comportamento não-linear, com um aumento de pressão parcial de maneira gradual, e não abrupta, na região das voltas. Por outro lado, as formulações DB e SB reproduzem o comportamento experimental de maneira satisfatória.

\subsubsection{Avaliação da constante de velocidade}

Como mencionado na Seção 6.1.1.1, a escolha para o valor da constante de velocidade de $k=250 \mathrm{~s}^{-1}$ foi feita visualmente, através da comparação entre as superfícies de pressão parcial de ozônio computacionais e experimentais (Fig. 17). Idealmente, o conhecimento do valor de $k$ é necessário para a validação rigorosa do modelo. Na falta deste, a influência do valor de $k$ nos resultados pode ser usada de modo a identificar, dentro das formulações matemáticas exploradas, aquela que pode vir a reproduzir o comportamento experimental dado o valor adequado de $k$.

A Figura 20 apresenta exemplos de superfícies de pressão parcial de ozônio para valores selecionados de $Q$ e $k$, simuladas usando as três formulações. Observa-se que, conforme sugerido pela formulação do modelo Alfa, o valor de $k$ pouco influencia na forma qualitativa da superfície de pressão parcial. Por outro lado, ao comparar os exemplos dados na Fig. 20 com os resultados experimentais da Fig. 17, nota-se que o intervalo de $k$ explorado compreende, de fato, a cinética aparente do dispositivo experimental. É importante apontar que, para a formulação SD, mesmo valores altos de $k$ (Fig. 20c), observa-se uma distribuição de ozônio significativamente maior que as demais formulações, mais uma vez indicando que trata-se de um efeito do campo de velocidades.

Em relação ao consumo de ozônio, a Figura 21 apresenta resultados para as três formulações e valores selecionados de $k$. É possível notar que, conforme sugerido pela 
Figura 19 - Perfil de pressão parcial normalizada de $\mathrm{O}_{3}$ ao longo do caminho do FC, para $Q=350 \mathrm{~cm}^{3} \mathrm{~min}^{-1}$ : dados simulados com as fomulações SD (azul), DB (preto) e SB (verde); e dados experimentais (vermelho).

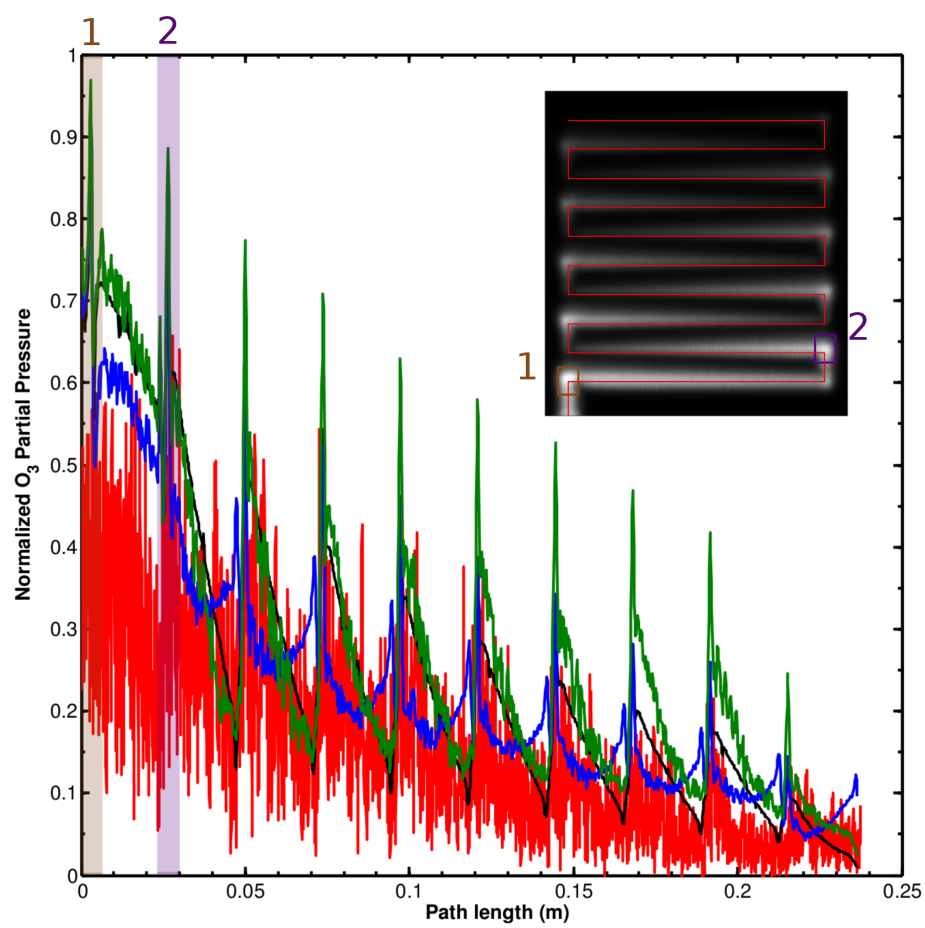

Fonte: Autoria própria.

comparação às superfícies de pressão parcial, o valor de $k=250 \mathrm{~s}^{-1}$ é de fato representante da cinética aparente do dispositivo experimental, ao menos para as formulações SD e DB. Para a formulação SB, valores maiores de $500 \mathrm{~s}^{-1}$ seriam necessários, porém a distribuição de ozônio na CL restringe tal valor consideravelmente (e.g. Fig. 20i).

Um ponto digno de nota na Fig. 21 é a influência do valor de $k$ no comportamento da função $\Delta \mathrm{O}_{3}(Q)$ para a formulação $\mathrm{DB}$, em particular para altos valores de $Q$. Observa-se que, diferente do observado na Fig. 20, o valor de $k$ é essencial para reproduzir o comportamento experimental. Isto impõem fortes restrições no valor de $k$ a ser utilizado, e reforça a escolha do valor $k=250 \mathrm{~s}^{-1}$. A formulação SD, no entanto, não apresenta variações significativas no comportamento de $\Delta \mathrm{O}_{3}(Q)$ e função de $k$, mantendo-se aproximadamente linear para valores menores que $500 \mathrm{~s}^{-1}$, sugerindo um comportamento não-linear apenas para valores superiores.

Por fim, a influência do valor de $k$ no perfil de pressão parcial ao longo do FC é analisada. A Figura 22 apresenta os perfis simulados para as três formulações e valores selecionados de $Q$ e $k$. Em relação às formulações $\mathrm{SD}$ e $\mathrm{DB}$, observa-se que o valor de $k$ pouco influência no perfil de pressão parcial de ozônio. Dignos de nota são a quase completa independência de $k$ para a formulação DB (Figs. 22b e 22e), e o perfil para 
Figura 20 - Superfícies de pressão parcial simuladas: a)-c) formulação SD; d)-f) formulação DB; e g)-i) formulação SB. Os valores de $Q$ e $k$ utilizados foram 200 e 50 (coluna esquerda), 350 e 100 (coluna central), e $450 \mathrm{~cm}^{3} \mathrm{~min}^{-1}$ e $500 \mathrm{~s}^{-1}$ (coluna direta) respectivamente.

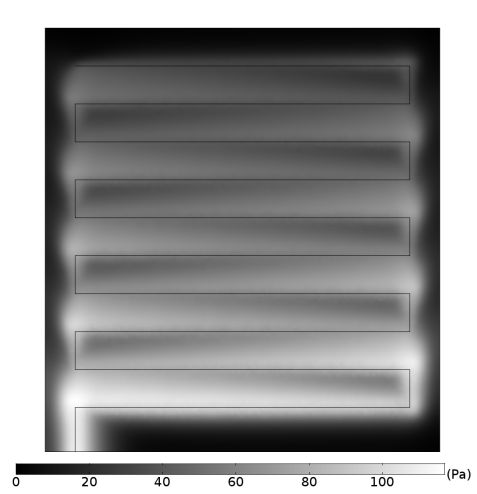

(a)

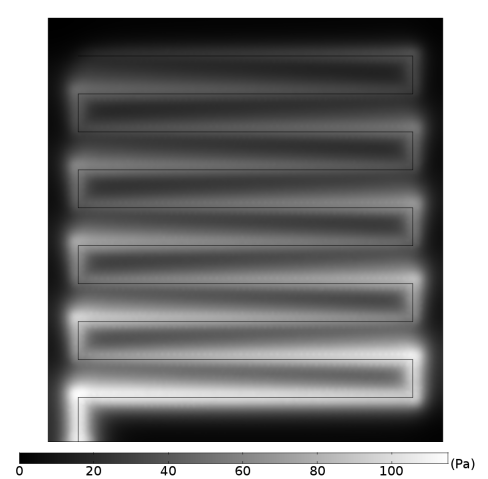

(d)

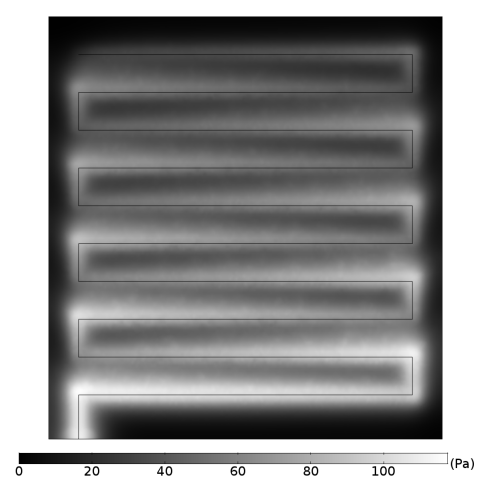

(g)

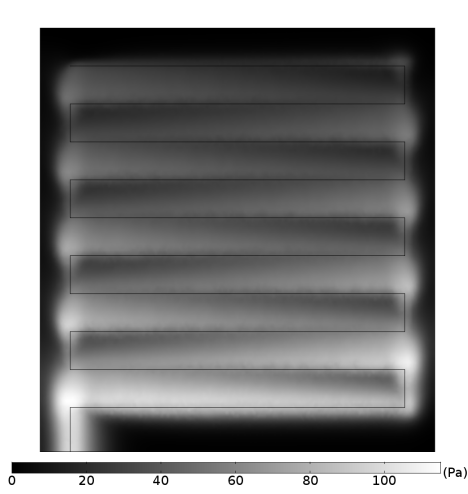

(b)

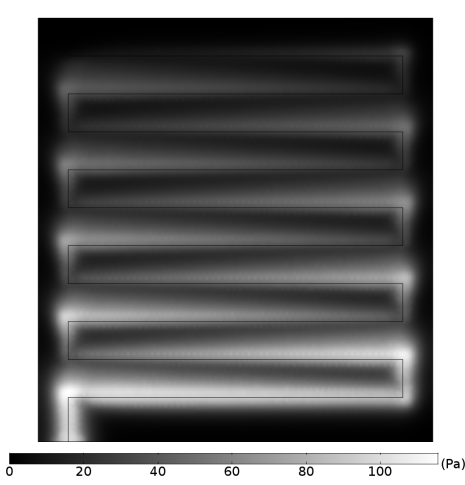

(e)

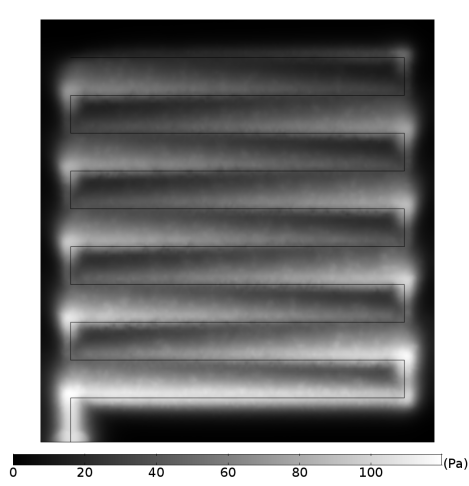

(h)

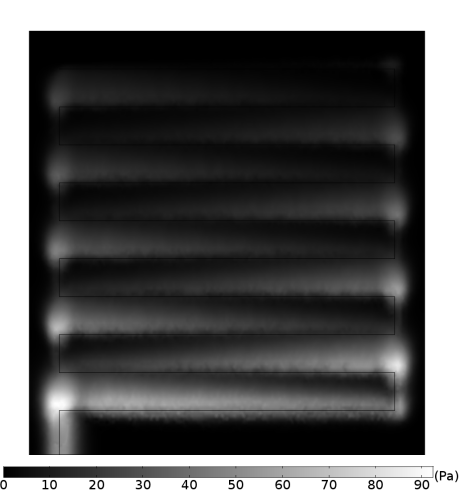

(c)

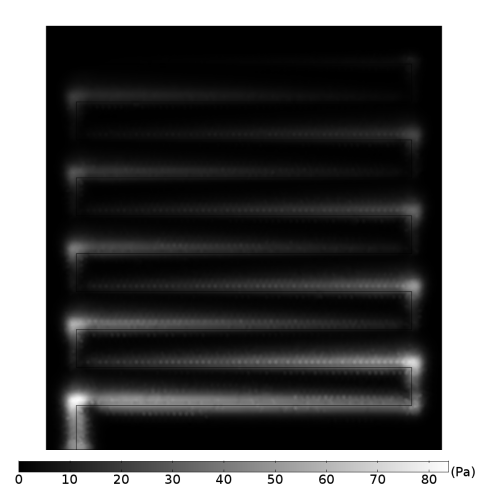

(f)

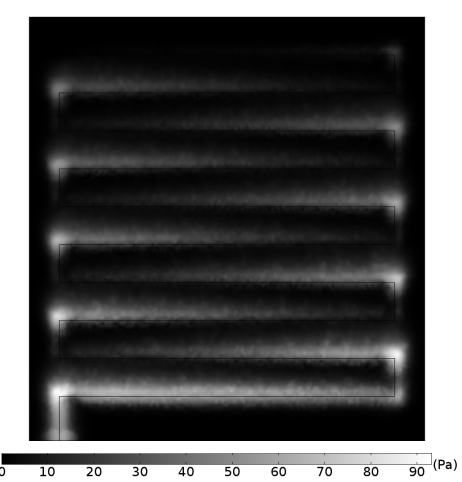

(i)

Fonte: Autoria própria. 
Figura 21 - Consumo ozônio em função da vazão, simulado com as formulações $\mathrm{SD}(\square)$, DB $(\triangle)$ e SB $(\diamond)$. Valores de $k$ utilizados: 50 (azul), 100 (verde), 250 (preto), e $500 \mathrm{~s}^{-1}$ (amarelo). Valores experimentais (o) foram incluídos como referência.

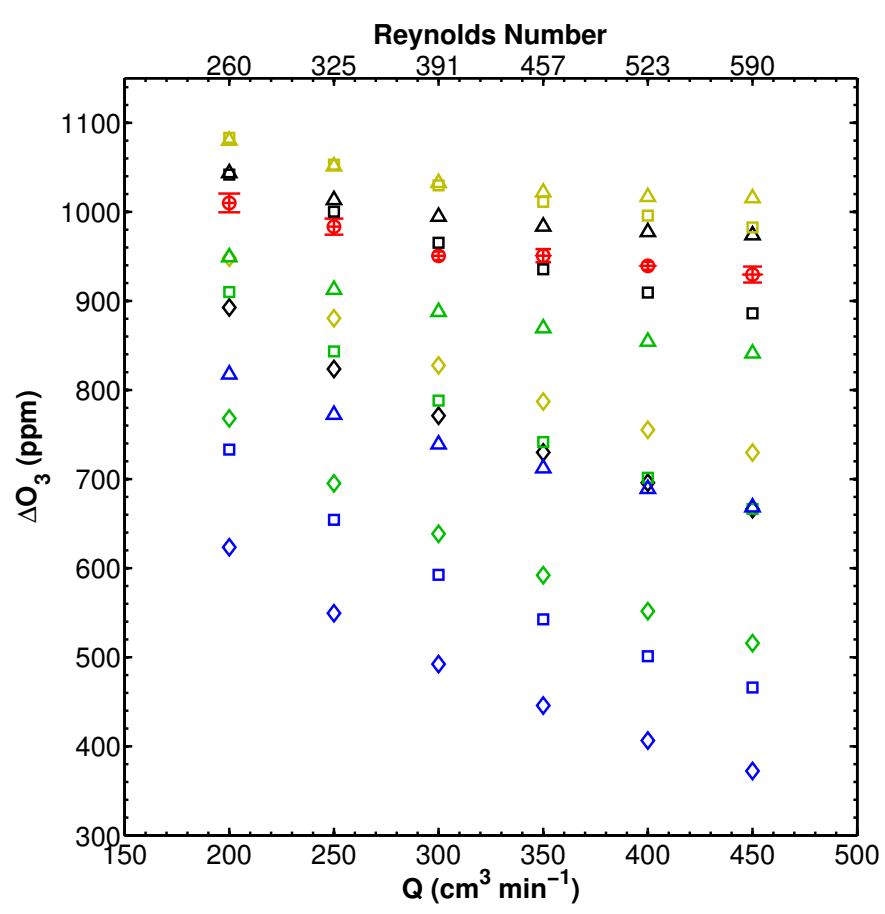

Fonte: Autoria própria.

$Q=350 \mathrm{~cm}^{3} \mathrm{~min}^{-1}$ e $k=500 \mathrm{~s}^{-1}$ utilizando a formulação SD (Fig 22a). Neste último, em particular, observa-se um comportamento mais próximo do experimental (ver Fig. 19): o aumento gradual da pressão parcial antes das voltas é suprimido, indicando menor transposição das terraças devido à cinética aumentada. Entretanto, tal supressão desaparece para $Q=450 \mathrm{~cm}^{3} \mathrm{~min}^{-1}$, mesmo para $k=500 \mathrm{~s}^{-1}$ (Fig. 22d). Para a formulação SB (Figs. 22c e 22f), observa-se uma dependência inversa em relação à SD: menores valores de $k$ combinados a maiores valores de $Q$ tendem a reproduzir o comportamento da formulação $\mathrm{SD}$, i.e. o aumento gradual da pressão parcial de ozônio ao longo da seção horizontal do FC.

Os resultados computacionais apresentados nesta seção impõem fortes restrições ao modelo matemático, em particular à combinação do valor de $k$ e à formulação usada para o campo de velocidades. Especificamente, é observado que, para a reprodução do consumo e perfil de pressão parcial de ozônio, são necessário valores de $k \geq 500 \mathrm{~s}^{-1}$ para as formulações SD e SB. No entanto, a distribuição de ozônio, dada pelas superfícies de pressão parcial, impõem limitações em todas as formulações para valores de $k \leq 500 \mathrm{~s}^{-1}$. 
Figura 22 - Pressão parcial normalizada de $\mathrm{O}_{3}$ no domínio da CL ao longo do FC, para $Q=350$ (linha superior) e $Q=450 \mathrm{~cm}^{3} \mathrm{~min}^{-1}$ (linha inferior), usando as formulações SD (coluna esquerda), DB (coluna central) e SB (coluna direita). Os valores de $k$ contemplados são: 50 (azul), 100 (verde), 250 (preto) e $500 \mathrm{~s}^{-1}$ (amarelo). A normalização é feita em relação ao maior valor da respectiva superfície de pressão.

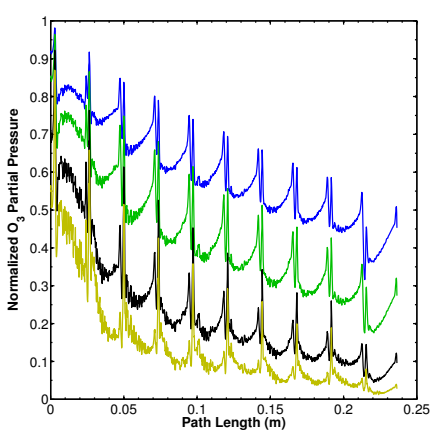

(a)

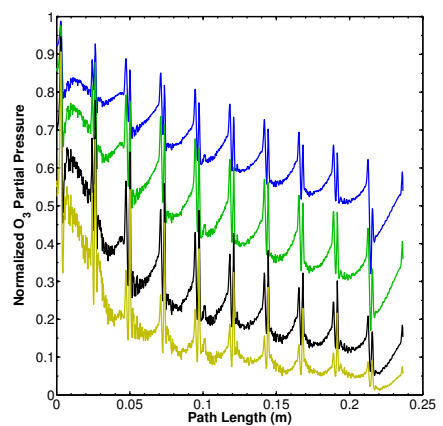

(d)

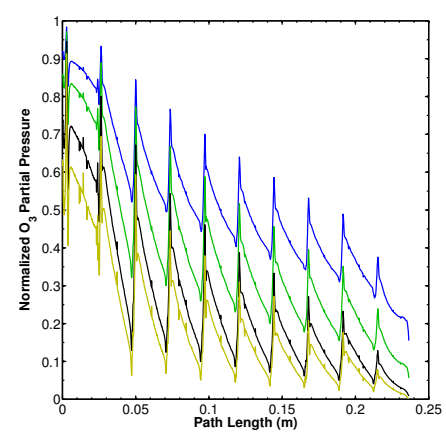

(b)

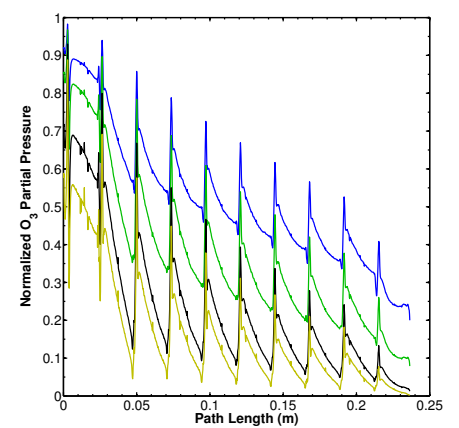

(e)

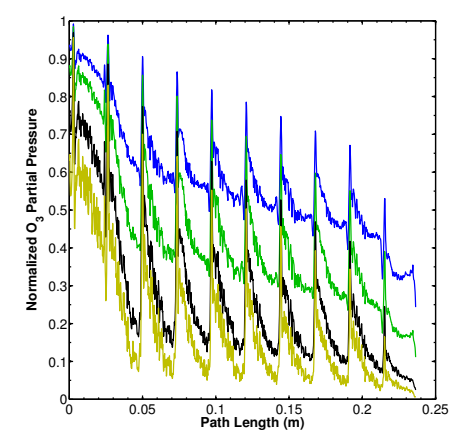

(c)

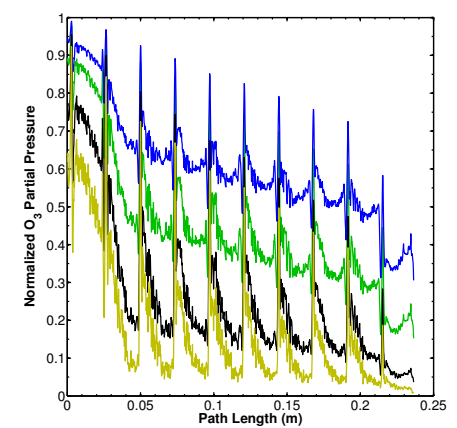

(f)

Fonte: Autoria própria.

\subsubsection{Comparação entre formulações matemáticas}

Considerando os resultados apresentados nas Seções 6.1.1.1 e 6.1.1.2, alguns pontos podem ser estabelecidos com respeito à formulação matemática do modelo Alfa. Primeiramente, tomando a comparação com os resultados experimentais e a parametrização do modelo (Seção 4.1.2), pode ser estabelecido que as formulações SD e DB reproduzem razoavelmente bem os resultados experimentais disponíveis, tanto qualitativamente quanto quantitativamente, quando possível. A formulação SB, por outro lado, apresentou resultados qualitativos adequados, particularmente para a distribuição de espécies na CL (Fig. 17). Entretanto, esta falhou em prever corretamente a perda de carga e a dependência do consumo de ozônio com a vazão de entrada (Fig. 18). A escolha entre as formulações SD e DB depende do peso dado à cada comparação qualitativa apresentada. Um ponto a ser considerado, no entanto, é o menor número de variáveis na formulação SD e o uso de escalas de comprimento diferentes para os domínios de escoamento livre e poroso. Assim, 
pode ser argumentado que, se os resultados das formulações SD e DB são similarmente satisfatórios quando comparados aos resultados experimentais, a SD é preferível dado seu menor custo computacional e flexibilidade de escala.

Em segundo lugar, tomando as restrições que emergem ao considerar a influência do valor de $k$ nos resultados, outra perspectiva pode ser adotada. A formulação SB se mantém como inferior às demais, considerando que são necessários valores de $k \geq 500 \mathrm{~s}^{-1}$ para uma reprodução adequada do consumo de ozônio (Fig. 21). Isto, por sua vez, subestimaria significativamente a distribuição de ozônio na CL (Fig. 20i). Ainda assim, a função $\Delta \mathrm{O}_{3}(Q)$ dada pela formulação SB ainda prevê um declínio do consumo mais acentuado que os dados experimentais. Para a formulação SD, uma situação mais complicada emerge. Observa-se que valores diferentes de $k$ seriam necessários para reproduzir corretamente diferentes seções da curva $\Delta \mathrm{O}_{3}$, apesar de próximos do valor estabelecido de $k=250 \mathrm{~s}^{-1}$. No entanto, o perfil de pressão parcial (Figs. 22a e 22d) apresenta diferenças qualitativas em relação ao experimental para valores de $k \leq 500 \mathrm{~s}^{-1}$ e $Q \geq 350 \mathrm{~cm}^{3} \mathrm{~min}^{-1}$. Mas o uso de tais valores para $k$ também subestimaria significativamente a distribuição de ozônio na CL (Fig. 20c). Por outro lado, a formulação DB aparenta reproduzir de maneira adequada todos os resultados apresentados, obedecendo as restrições impostas pelo valor de $k$ : observa-se que o consumo de ozônio exige um valor levemente menor que $k=250 \mathrm{~s}^{-1}$, o que não influenciaria de maneira significativa na distribuição e no perfil de ozônio na CL.

Além dos aspectos computacionais, também é importante considerar os aspectos físicos e matemáticos das formulações sob análise. Whitaker mostrou que a lei de Darcy, Eq. 4.7, pode ser derivada da equação de $\operatorname{Stokes(71).~Devido~à~restrições~das~escalas~de~}$ comprimento durante a derivação, e o uso da Eq. de Stokes como ponto de partida, obtém-se uma equação que não contempla efeitos inerciais ou viscosos. A formulação DB (Eq. 4.5), por outro lado, pode ser derivada diretamente das equações de Navier-Stokes(42) (Eq. 4.6), enquanto que Ochoa-Tapia e Whitaker(72) mostram que as chamadas correções de Brinkman podem ser derivadas de maneira similar à lei de Darcy, i.e. a partir da Eq. de Stokes. Uma diferença significativa entre as Eqs. 4.7 e 4.5 está na falta de restrições de escalas de comprimento para a formulação DB, permitindo o uso de apenas uma equação para escoamentos livres e em meios porosos. Também é digno de nota que a lei de Darcy é recuperada ao se tomar o limite de baixa porosidade da Eq. 4.5. Isto corrobora o fato que a formulação DB é, em princípio, mais abrangente que a formulação SD, apesar de derivada através de aproximações.

Considerando o mencionado acima, deve-se apontar que a falta de efeitos viscosos na lei de Darcy leva a uma má retratação da região interfacial entre os escoamentos livre e em meio poroso $(42,72)$, sendo necessário a a modificação do comportamento da lei de Darcy na região da interface ou a extensão artificial do domínio de validade das equações de Navier-Stokes(42). Foi discutido por Le Bars e Worster(42) a necessidade de uma condição de contorno apropriada para que a formulação SD se aproxime da formulação DB, 
sendo que o erro é proporcional ao número de Darcy, Da $=\kappa / L^{2}$, onde $L$ é o comprimento característico do escoamento, usualmente tomado como uma seção do meio poroso. No caso do sistema estudado, $L=190 \mu \mathrm{m}$, o que significa uma influência pequena do escoamento livre na região interfacial, descrito pela espessura da zona de transição viscosa, $\delta=\sqrt{\mathrm{Da} / \epsilon} \approx 0,02$. O valor de $\delta$ é um indicativo do quanto o escoamento livre penetra no meio poroso, conforme predito pela formulação $\mathrm{DB}(42)$, representando aproximadamente a profundidade em que observa-se um decaimento exponencial da velocidade de escoamento. Assim, a formulação SD seria capaz de descrever o sistema adequadamente, quando usada uma condição de contorno apropriada. No entanto, em uma derivação da lei de Darcy por Whitaker(71), é sugerido que $L$ seja descrito por uma região representativa do meio, não necessariamente toda sua espessura. Da caracterização de materiais semelhantes ao usado aqui(45), nota-se que tal representatividade pode ser obtida com $L \sim 50 \mu \mathrm{m}$. Isso resulta em um valor de $\delta^{\prime} \approx 0.07$, o que sugere uma influência significativamente maior do escoamento livre, considerando-se o decaimento da velocidade com o aumento da profundidade (ver Fig. 5 de (42)). Desta maneira, esperam-se erros significativos ao se utilizar a formulação SD em detrimento da DB. De modo a verificar se é o caso, foi avaliado a componente $x$ da velocidade de escoamento, ao longo do eixo $z$, no meio da primeira seção horizontal do canal de escoamento. A Figura 23 apresenta os perfis para as três formulações.

A Fig. 23 apresenta outros pontos dignos de nota. A formulação DB prevê um decaimento não-linear da velocidade até o limite superior da CL, tendendo a zero devido à condição de contorno estabelecida. O mesmo é visto para a formulação SB, porém a transição no MPS é distinta: velocidades menores próximo à interface FC-MPS são observadas, com um aumento até a interface MPS-CL, seguido de decaimento similar à DB. Isso sugere um motivo para o fato de que a formulação SB descreve as superfícies de pressão parcial relativamente bem, enquanto que as variáveis globais (perda de carga e consumo de reagentes) são prejudicadas: maiores velocidades na CL compensam a má descrição do escoamento no MPS, devido à condição de contorno utilizada. Assim, globalmente, a formulação SB falha em descrever corretamente o sistema. Por outro lado, a formulação SD exibe perfis de velocidade constantes em cada meio poroso, esperados devido à lei de Darcy. No entanto, comparado à formulação DB, observa-se que a velocidade no MPS é subestimada, enquanto que na CL esta é superestimada. Isso também pode explicar o comportamento nas superfícies de pressão parcial, onde uma maior distribuição de espécies é observada para a formulação SD. A Fig. 23 reitera a necessidade de descrever corretamente a interface FC-MPS ao se utilizar aproximações multidomínios em sistemas como o estudado aqui. Porém esta evidencia a necessidade de também tratar a interface MPS-CL corretamente, seja através de um gradiente suave de propriedades de transporte entre os materiais, ou através de condições de contorno que exijam a continuidade da velocidade de escoamento. 
Figura 23 - Perfil da componente $x$ da velocidade de escoamento ao longo do eixo $z$, para $Q=350 \mathrm{~cm}^{3} \mathrm{~min}^{-1}$, obtido no meio da primeira seção horizontal do canal de escoamento: formulação SD (azul), DB (preto) e $\mathrm{SB}$ (verde). As linhas vermelhas tracejadas indicam a interface entre domínios.

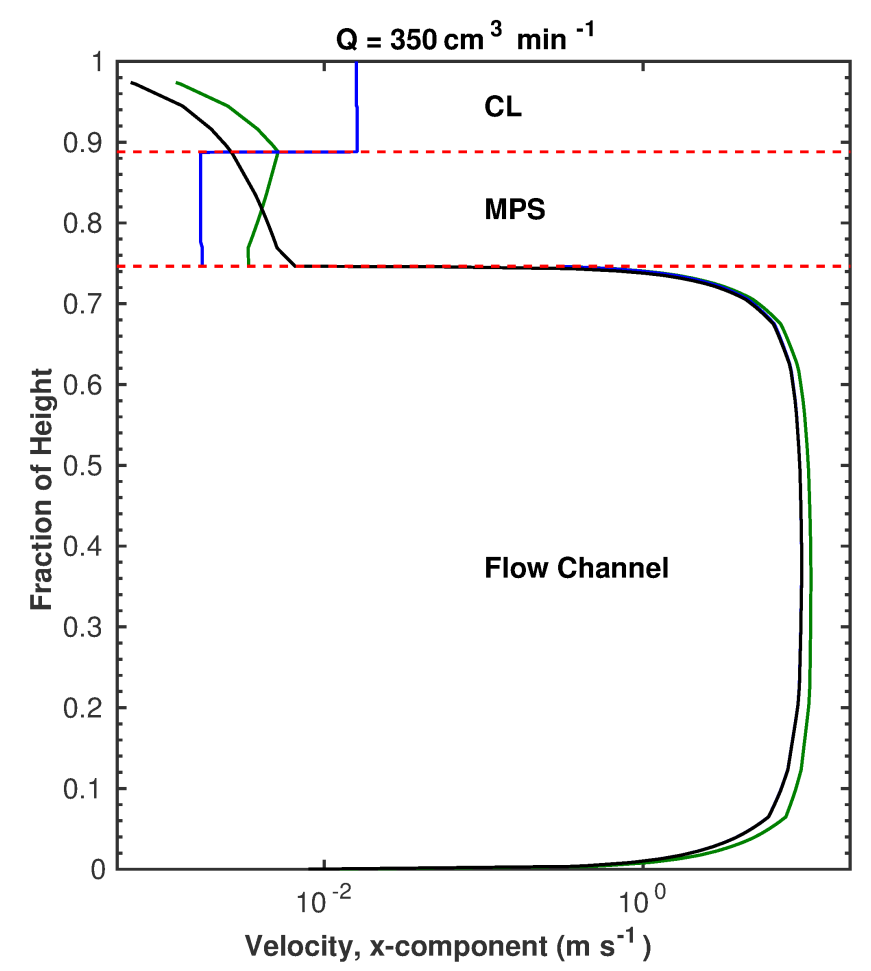

Fonte: Autoria própria.

Admite-se que mais deve ser feito para estabelecer com exatidão a origem das diferenças entre as formulações estudadas. No entanto, fica evidente que um tratamento adequado das interfaces é essencial. Considerando o sistema em estudo, e as possíveis ramificações para células a combustível, entende-se que o uso da formulação SD está sujeita a incertezas e erros adicionais. Isso contrabalancearia as vantagens de utilizá-la, ao mesmo tempo correndo o risco de uma descrição incorreta da dinâmica de fluidos do sistema. A formulação SB, apesar dos resultados pouco expressivos, pode ser remediada desde que trabalhada a questão da interface. No entanto, dificuldades semelhantes persistem, e o fato de que a formulação DB leva tais efeitos em conta naturalmente, favorece o uso da mesma.

Assim, levando em conta a discussão fornecida, a parametrização do modelo e as restrições que surgem da comparação entre os resultados simulados e experimentais, considera-se que, para o sistema estudado em (33), a formulação DB é mais adequada do ponto de vista físico para ser utilizado em experimentos computacionais. Como o dispositivo representa um protótipo de uma célula a combustível do tipo PEM, é tentador estender as conclusões aqui apresentadas para tais sistemas. Entretanto, é necessário cautela, dado que o modelo foi validado em um limite relativamente estreito de $Q$, e 
considerando apenas o transporte do traçador. Espera-se que, como sugerido em (33), o dispositivo experimental e o modelo Alfa sejam representativos do cátodo de uma célula PEM operada a ar. Por outro lado, outros fluidos, e particularmente a presença de escoamento bifásico, devem ser avaliados cuidadosamente.

\subsubsection{Estudo do Transporte Convectivo}

\subsubsection{Implicações para uma célula a combustível}

Os resultados e discussão apresentados na Seção 6.1.1 apontam para a formulação DB como sendo a mais apropriada para estudar o transporte convectivo no dispositivo experimental. Conforme mencionado acima, espera-se que tal escolha seja adequada, também, para o cátodo de células a combustível. De modo a ilustrar as implicações disto, foi utilizada a analogia com curvas de polarização descrita na Seção 4.1.3.

A Figura 24 apresenta o sobrepotencial de concentração, $\eta_{C}$, definido na Eq. 4.18, em função da corrente equivalente do dispositivo simulado, $I_{\mathrm{O}_{3}}$, definida na Eq. 4.20. As três formulações exploradas na Seção 6.1.1 foram utilizadas, para o mesmo intervalo de valores para $Q$ e $k$. Pode-se observar que, conforme notado na Seção 6.1.1, as formulações SD e SB superestimam a distribuição de ozônio, levando a valores significativamente menores de $\eta_{C}$ para uma dada corrente equivalente. Por exemplo, para $Q=350 \mathrm{~cm}^{3} \mathrm{~min}^{-1}$ e $k=250 \mathrm{~s}^{-1}$, as formulações $\mathrm{SD}$ e $\mathrm{SB}$ resultam em correntes $\approx 1,4$ vezes o valor obtido pela formulação $\mathrm{DB}$, com um respectivo sobrepotencial $\approx 0,85$ da mesma. Observa-se, ainda, que o desvio em relação à formulação DB aumenta com o valor de $Q$. Esta representação sumariza os possíveis erros devido ao transporte convectivo em trabalhos que utilizam a formulação SD e variantes em modelos computacionais de células a combustível tipo PEM.

\subsubsection{Transporte de espécies na "camada difusora de gases"}

Em relação ao transporte convectivo, um ponto levantado por Lopes et al.(33) é referente à contribuição de escoamentos secundários, na forma de vórtices, para a distribuição de espécies na CL. A existência de tal escoamento secundário foi sugerida através de anemometria a laser in operando em uma célula a combustível(73). A Figura 25 apresenta as componentes do campo de velocidades na terceira volta do FC, para $Q=350 \mathrm{~cm}^{3} \mathrm{~min}^{-1}$ $(\operatorname{Re} \approx 457)$, nos planos $x y$ e $x z$. Cada superfície apresenta as respectivas componentes perpendiculares ao plano, com as demais componentes representadas como linhas de corrente. As linhas de corrente exibem escoamentos secundários, e comprovam a formação de vórtices, além de um deslocamento do escoamento em relação ao centro do canal. É digno de nota a presença de um movimento circulatório na volta, visto no plano $x z$, levando à projeção do fluido em direção ao MPS. O campo de velocidades mostrado na Fig. 25 apresenta correlação com as características observadas nas superfícies de pressão parcial, 
Figura 24 - Sobrepotencial de concentração médio em função da corrente total equivalente, definidos nas Eqs. 4.18 e 4.20 respectivamente, para as formulações SD $(\square)$, $\mathrm{DB}(\triangle)$ e SB $(\diamond)$. Valores de $Q$ usados: 250 (azul), 350 (vermelho) e $450 \mathrm{~cm}^{3} \mathrm{~min}^{-1}$ (preto).

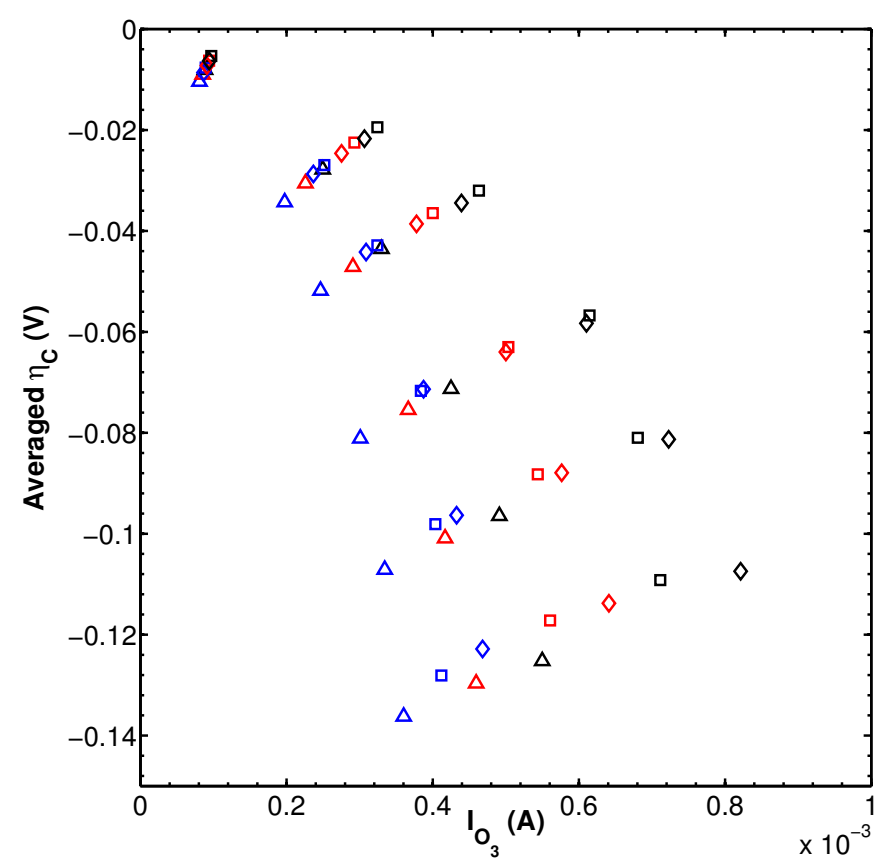

Fonte: Autoria própria.

tanto experimental como simuladas, corroborando a ideia de que escoamentos secundários no FC são importantes para a distribuição espacial de espécies nos meios porosos.

A presença de escoamentos secundários é esperada, dado que trata-se de um fluido real confinado em um volume finito. O interesse maior está na contribuição destes na distribuição de espécies. Para tal, foi utilizado o modelo Alfa-mod, conforme descrito na Seção 4.1.3. Este modelo desacopla o transporte de espécies, no caso o traçador, do escoamento nos meios porosos. A Figura 26 apresenta superfícies de $\mathbf{P}_{\mathrm{O}_{3}}$ para valores selecionados de $Q$. Os valores absolutos da pressão parcial observados são, como esperado, menores que os observados para o modelo Alfa (e.g. Figs. 17c e 17g), porém aproximadamente constante apesar do incremento de $Q$.

O ponto mais notável, no entanto, é a perda de diversas características observadas no modelo Alfa, ou mesmo em relação aos resultados experimentais, em particular nas regiões próximas às voltas do FC. Isto é melhor observado na Figura 27, que apresenta a diferença normalizada da pressão parcial entre os modelos Alfa-mod e Alfa, dada pela Eq. 4.22, a um valor de $Q=350 \mathrm{~cm}^{3} \mathrm{~min}^{-1}(\mathrm{Re} \approx 457)$. A superfície representa, em azul, a subestimativa de pressão parcial local pelo modelo Alfa-mod e, em vermelho, a superestimativa. Como mencionado acima, as maiores diferenças são observadas nas regiões próximas às voltas, sendo particularmente notável imediatamente após a volta, onde observa-se redução para 
Figura 25 - Campo de velocidades do escoamento na terceira volta do FC, para $Q=350 \mathrm{~cm}^{3} \mathrm{~min}^{-1}$ $(\mathrm{Re} \approx 457)$. À esquerda, seção transversal à meia altura no plano $x y$, onde a superfície mapeia a componente $z$ de $\mathbf{u}$, enquanto as linhas de corrente mapeiam as componentes $x \mathrm{e}$ $y$. À direita, seção transversal, no meio da volta, no plano $x z$, onde a superfície mapeia a componente $y$ de $\mathbf{u}$, enquanto as linhas de corrente mapeiam as componentes $x$ e $z$.

Surface: Velocity field, $z$ component $(\mathrm{m} / \mathrm{s})$ Streamline: Velocity field

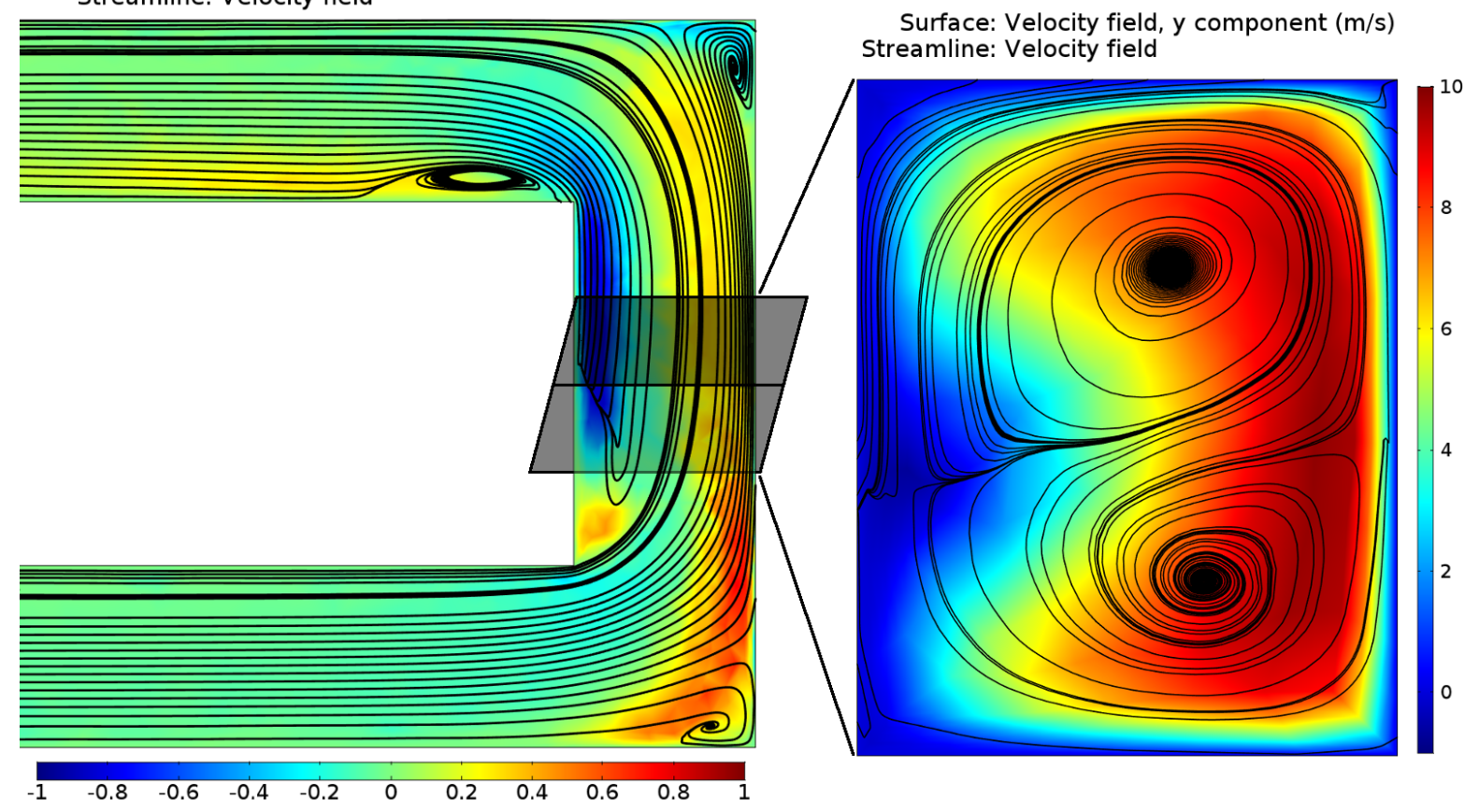

Fonte: Autoria própria.

Figura 26 - Superfícies de pressão parcial de $\mathrm{O}_{3}$ usando o modelo Alfa-mod: a) $Q=250$, b) 350 e c) $450 \mathrm{~cm}^{3} \mathrm{~min}^{-1}$.

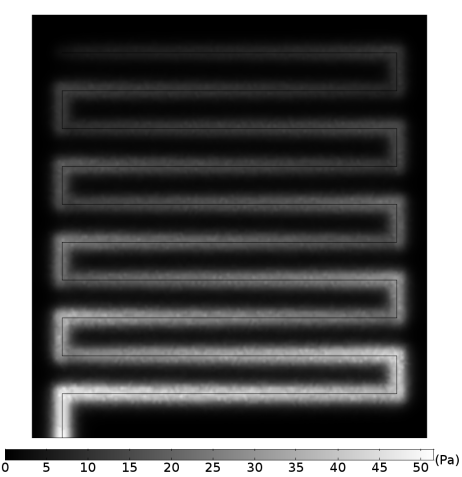

(a)

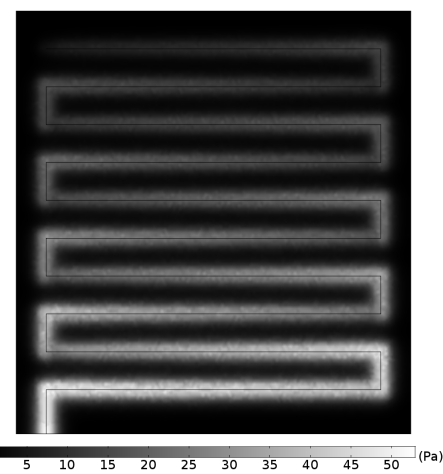

(b)

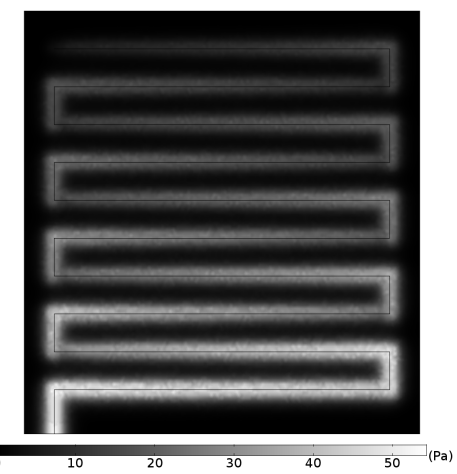

(c)

Fonte: Autoria própria. 
Figura 27 - Diferença normalizada da pressão parcial entre os modelos Alfa-mod e Alfa, dada pela Eq. 4.22, para $Q=350 \mathrm{~cm}^{3} \mathrm{~min}^{-1}(\mathrm{Re} \approx 457)$. Ciano representa subestimativa, vermelho superestimativa, em relação ao modelo Alfa. A linha cinza representa a projeção do centro do FC.

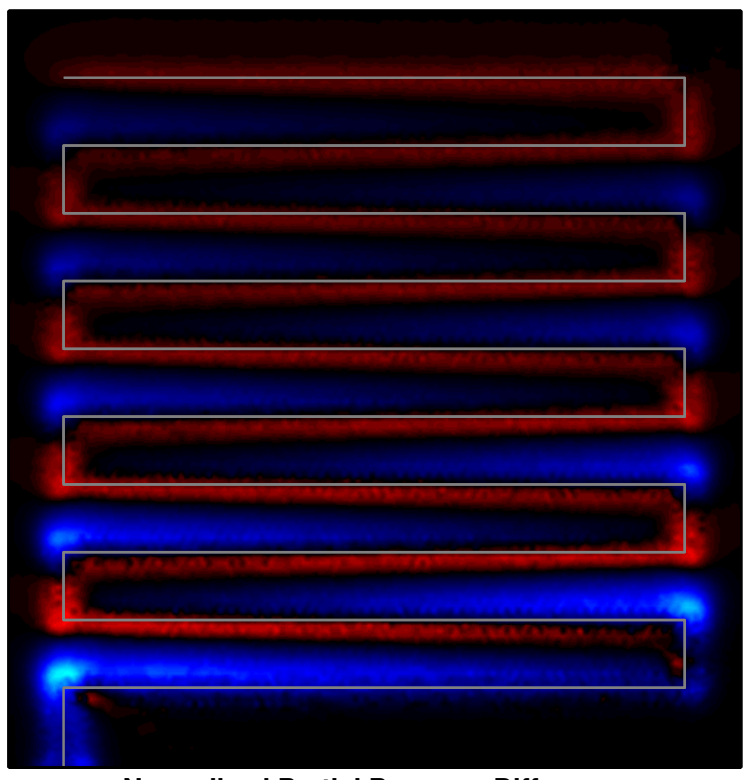

Normalized Partial Pressure Difference

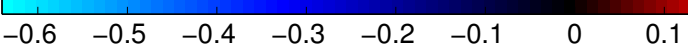

Fonte: Autoria própria.

até aproximadamente 0,65 do valor do modelo Alfa. Considerando o intervalo total de $Q$ avaliado, observa-se que os valores podem atingir de 1,1 a 1,2 vezes o valor do modelo Alfa, principalmente próximo ao início de cada volta; e até 0,4 a 0,65 próximo ao final de cada volta. Deixando valores absolutos de lado, a Fig. 27 enfatiza a importância do transporte convectivo nos meios porosos. Devido à natureza estacionário do modelo, não é possível afirmar que as diferenças observadas são diretamente consequência dos escoamentos secundários observados. Entretanto, pode-se afirmar que a transposição de terraças através dos meios poroso se deve, principalmente, ao transporte convectivo.

As informações apresentadas nas Figs. 25 a 27 corroboram a interpretação de Lopes et al. em relação aos resultados experimentais reportados em (33). Foi proposto que a convecção tem papel importante na distribuição de espécies nos meios porosos, chamando atenção para a otimização não só de canais de escoamento, mas também da chamada "camada difusora de gases", de modo a maximizar o desempenho de um dado dispositivo. No entanto foi apontado, em (33), que o transporte convectivo atinge uma saturação nos meios porosos. Isto foi identificado como uma mudança da inclinação da curva de intensidade luminosa em função da vazão de entrada, em Re $\approx 480$. Dado que os resultados apresentados acima não fornecem tal informação, a análise de tal hipótese 
Figura 28 - Transporte molar de ozônio, dado pela Eq. 4.23, para os modelos Alfa (preto) e Alfa-mod (vermelho): transporte total $(\diamond)$, convectivo $(\triangle)$ e difusivo $(\square)$.

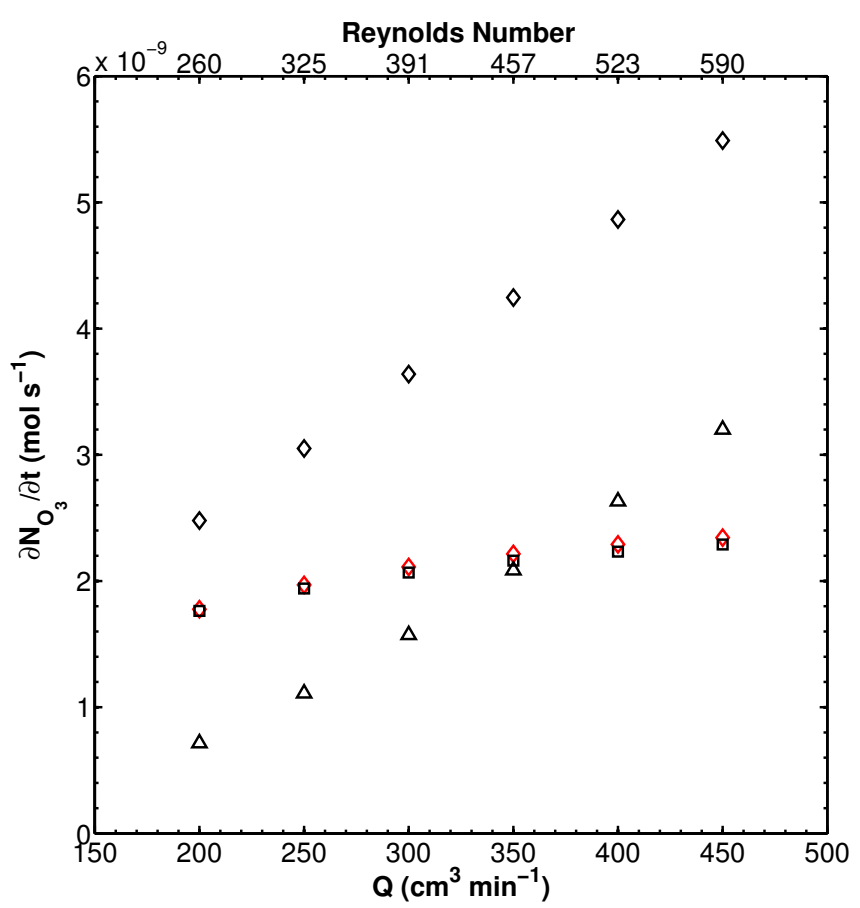

Fonte: Autoria própria.

foi feita através do transporte molar de ozônio à CL, usando a Eq. 4.23. A Figura 28 apresenta as contribuições à componente $z$ do fluxo molar integrado, $\dot{N}_{\mathrm{O}_{3}}$, para os modelos Alfa e Alfa-mod. Esta quantidade pode ser entendida como a quantidade de matéria transportada para a CL por unidade de tempo, e, conforme esperado, o modelo Alfa apresenta valores significativamente maiores que o Alfa-mod. Mais importante, no entanto, é o comportamento da contribuição difusional nos dois modelos. Numericamente muito semelhantes, estas apresentam um comportamento assintótico, enquanto a contribuição convectiva, no modelo Alfa, aumenta de forma aproximadamente linear em todo intervalo de de $Q$. Portanto, contrário ao sugerido por Lopes et al., a contribuição convectiva ao transporte de espécies aumenta ao longo de todo o intervalo de vazão investigado, representando 0, 29 a 0, 58 do transporte total de ozônio à CL.

De certo modo, o comportamento da contribuição difusional ao transporte molar, observado na Fig. 28, é esperado. O transporte difusional é dado pelo gradiente de espécies, como visto nas Eqs. 4.1 e 4.21, e este é majoritariamente produzido pelo consumo de espécies, neste caso pela interação entre o ozônio e o catalisador. Apesar de ser influenciado pelo transporte convectivo, é a capacidade do catalisador, i.e. sua frequência de turnover, que determina o transporte difusional. Assim, dado um catalisador e condições operacionais, o transporte difusional está fadado à saturação. O transporte convectivo, por outro lado, providencia uma contribuição quase independente ao transporte de espécies, 
Figura 29 - Sobrepotencial de concentração médio em função da corrente total equivalente, definidos nas Eqs. 4.18 e 4.20 respectivamente, para o modelo Alfa $(\triangle)$ e Alfa-mod $(\square)$. Valores de $Q$ usados: 250 (azul), 350 (vermelho) e $450 \mathrm{~cm}^{3} \mathrm{~min}^{-1}$ (preto).

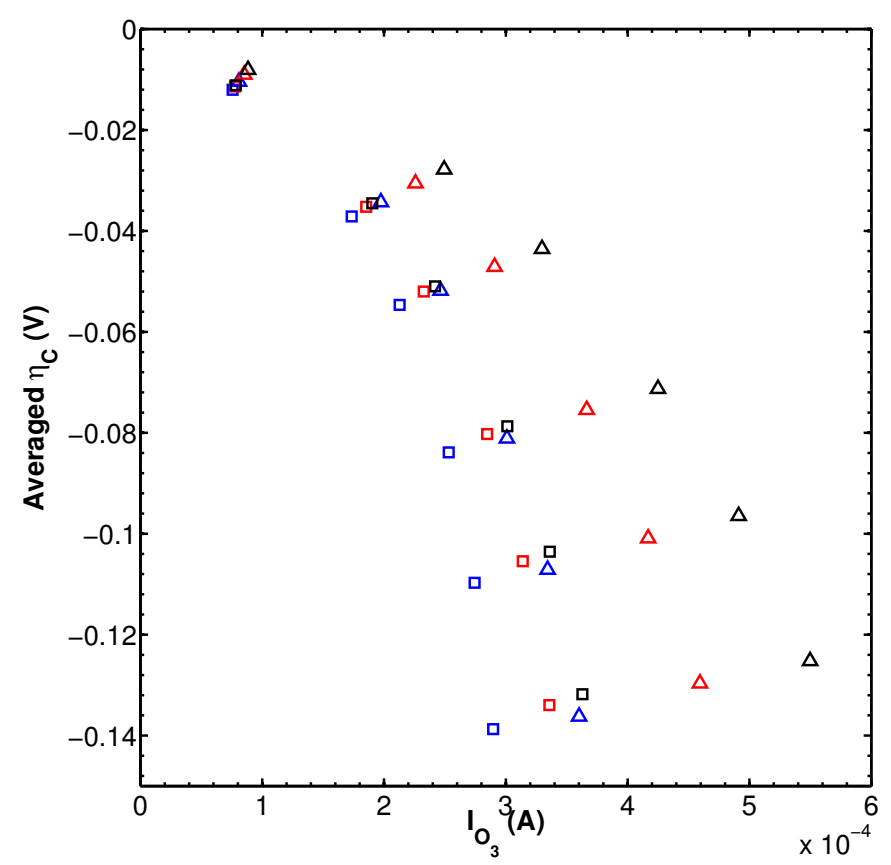

Fonte: Autoria própria.

possibilitando uma distribuição maior de espécies nos meios porosos.

Por fim, a analogia com curvas de polarização apresentada na Seção 6.1.2.1 será utilizada para ilustrar, de outra maneira, a contribuição do transporte convectivo em células a combustível. A Figura 29 apresenta $\eta_{C}$ em função de $I_{\mathrm{O}_{3}}$ para os modelos Alfa e Alfa-mod para valores selecionados de $Q$. Observa-se que o transporte convectivo nos meios porosos diminui de maneira significativa o valor de $\eta_{C}$ para uma dada corrente equivalente. Em particular, para $Q=350 \mathrm{~cm}^{3} \mathrm{~min}^{-1}$, a presença do transporte convectivo nos meios porosos diminui o sobrepotencial em 3 a 21\%, em relação ao modelo Alfa-mod, enquanto a corrente equivalente aumenta em 10 a $37 \%$.

Os resultados apresentados na Fig. 29 podem parecer de pequena importância quando analisados em termos absolutos. Por exemplo, a diferença absoluta $\eta_{C}$ entre os modelos Alfa e Alfa-mod encontra-se dentro de um intervalo de 1,3 a 7,4 mV enquanto o aumento de corrente equivalente situa-se dentro de um intervalo de $3,96 \times 10^{-6}$ a $1,87 \times 10^{-4} \mathrm{~A}$. Entretanto, deve-se lembrar que trata-se de um dispositivo lidando com uma concentração relativa de reagente $\sim 10^{-3} \mathrm{~mol} \mathrm{~mol}^{-1}$, enquanto que dispositivos reais possuem concentrações relativas da ordem de $\sim 10^{-1} \mathrm{~mol} \mathrm{~mol}^{-1}$. A expectativa é que a contribuição em dispositivos reais seja significativa, especialmente considerando os intervalos de vazão comumente utilizados. (e.g. (41)). Adicionalmente, espera-se que o transporte convectivo 
Figura 30 - Razão volumétrica (Eq. 4.38) após a deformação do MPS, para as modificações a) III.a (IV.a) e b) III.b (IV.b). As superfícies foram obtidas no plano $x y$ imediatamente acima do domínio do FC. O contorno observado representa a projeção do domínio do FC.

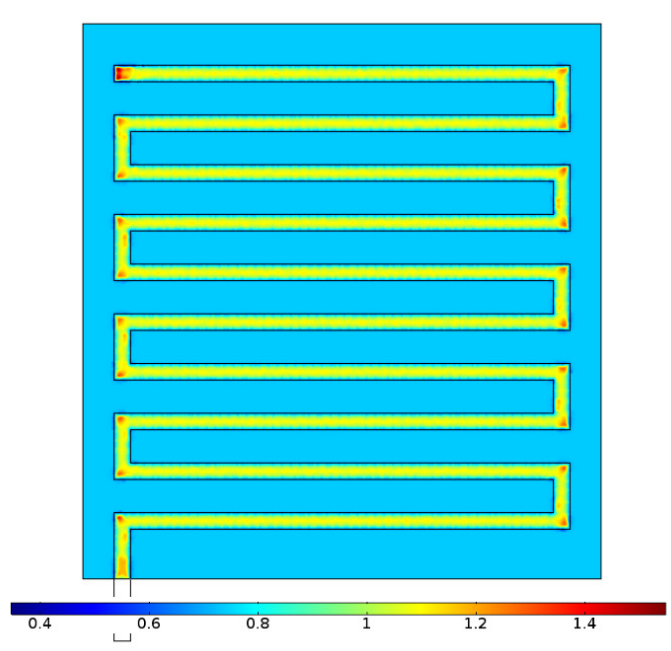

(a)

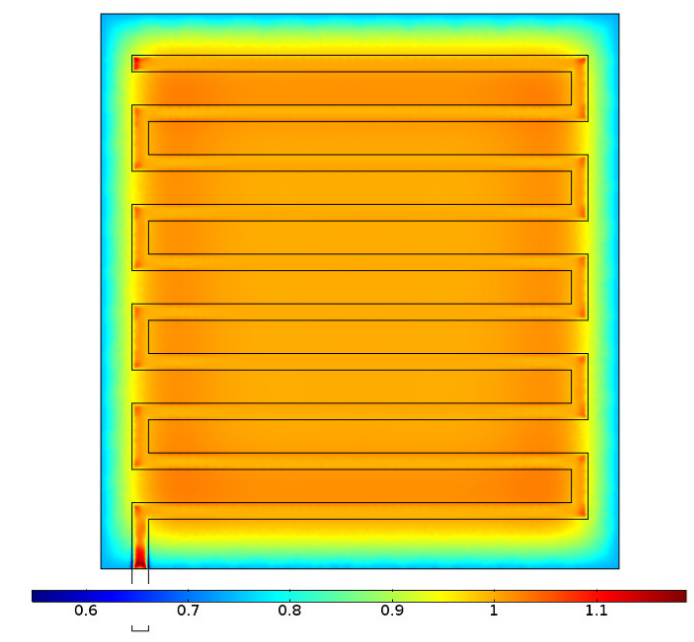

(b)

Fonte: Autoria própria.

contribua com mais do que o mostrado pelo modelo Alfa, principalmente na manutenção de água em células a combustível do tipo PEM. Os resultados do modelo Alfa sugerem que a escolha de desenhos e materiais de modo a otimizar a contribuição do transporte convectivo em dispositivos reais pode contribuir significativamente na performance dos mesmos.

\subsubsection{Estudo da Compressão do Substrato Macroporoso}

\subsubsection{Avaliação da deformação do MPS}

Inicialmente será avaliado o efeito da deformação do MPS nas modificações III e IV, considerando as subdivisões III.a (IV.a) e III.b (IV.b). Conforme mencionado na Seção 4.1.4, o parâmetro utilizado para a correção da permeabilidade, e portanto de maior interesse no atual momento, foi a razão volumétrica $J$. A Figura 30 apresenta superfícies do MPS, no plano xy e imediatamente acima do FC, mostrando a variação espacial de $J$ para cada subdivisão utilizada. Apesar de não apresentado, a variação de $J$ ao longo da espessura do MPS é praticamente nula, sendo observados valores muito próximos aos apresentados na Fig. 30.

Alguns pontos são dignos de nota. Em primeiro lugar, observam-se valores de $J \geq 1$ nas regiões sobre o FC, indicando que houve expansão sobre o domínio do mesmo. Ao longo da espessura, o valor de $J$ se aproxima de 1 rapidamente, indicando que não observa-se compressão significativa no MPS nas regiões acima do FC. Tais observações 
são esperadas, é claro, dado a configuração destes dispositivos e as condições de contorno utilizadas. Entretanto, os resultados de tal efeito, tanto geométrico como nas propriedades de transporte do MPS, são potencialmente significativos, como discutido em (51).

Em segundo lugar, observa-se na Fig. 30b que o efeito da compressão não-homogênea proposta para a subdivisão III.b (IV.b) não surtiu o efeito desejado, sendo que a compressão só foi observada de maneira efetiva nas regiões externas ao FC. A hipótese levantada é de que a compressão se daria de maneira aproximadamente contínua ao longo do domínio, resultando em uma permeabilidade com um máximo na região central do MPS. Tal distribuição espacial de $\kappa$ poderia explicar a maior distribuição de ozônio nas regiões centrais dos resultados experimentais(33) em relação ao observado no modelo Alfa (Seção 6.1.1.1). Este resultado pode ser encarado (ao menos) de duas maneiras: i) a condição utilizada na subdivisão III.b (IV.b) não representa a hipótese levantada, levando a resultados diferentes dos esperados; e ii) o modelo utilizado para os materiais (lineares) não é adequado para representar de maneira precisa a natureza dos materiais utilizados no dispositivo experimental, em particular o MPS. Independente da causa, sabe-se que a compressão do materiais em uma célula é importante para a representação correta dos fenômenos físicos observados, e portanto, merece futuras considerações.

\subsubsection{Comparação entre modificações}

Em seguida, na mesma linha de raciocínio apresentada durante a validação do modelo Alfa (Seção 6.1.1), serão apresentadas as superfícies de pressão parcial de ozônio no topo da camada catalítica, para as diferentes modificações descritas na Seção 4.1.4. Vale lembrar que os valores de $k$ foram ajustados de modo a reduzir o desvio quadrático de $\Delta \mathrm{O}_{3}(Q)$ em relação aos valores experimentais. A Figura 31 apresenta as superfícies de $\mathbf{P}_{\mathrm{O}_{3}}$ para a vazão de $Q=350 \mathrm{~cm}^{3} \mathrm{~min}^{-1}$. Nota-se que as diferenças entre as modificações avaliadas, quali e quantitativas, são pequenas; assim como quando comparadas ao modelo Alfa não modificado (Fig. 31g).

Em seguida, são apresentadas as variáveis globais do sistema em função da vazão de entrada. A Figura 32a apresenta $\Delta P(Q)$, e a Figura $32 \mathrm{~b}$ apresenta $\Delta \mathrm{O}_{3}(Q)$. Para a perda de carga, nota-se que nenhuma das modificações consideradas causa mudanças significativas no comportamento do modelo, no sentido de que todos os resultados ainda se encontram dentro das incertezas experimentais. O resultado esperado e observado, é que a correção da permeabilidade devido à compressão, i.e. a diminuição da permeabilidade, leva a um leve aumento da perda de carga do sistema.

Por outro lado, $\Delta \mathrm{O}_{3}(Q)$ apresentou mudanças significativas em função da modificação utilizada. Pode-se observar que os resultados obtidos com as modificações apresentam diferentes comportamentos em relação aos resultados do modelo não modificado. Em específico, nota-se que os resultados obtidos com as modificações II e IV.b, em relação ao modelo não modificado, apresentam maiores valores de $\Delta \mathrm{O}_{3}$ para $Q \leq 300$ e levemente 
Figura 31 - Superfícies de pressão parcial de $\mathrm{O}_{3}$ para $Q=350 \mathrm{~cm}^{3} \mathrm{~min}^{-1}$ para as diversas modificações descritas na Tab. 4. O resultado sem modificações (g) foi incluído a título de comparação.

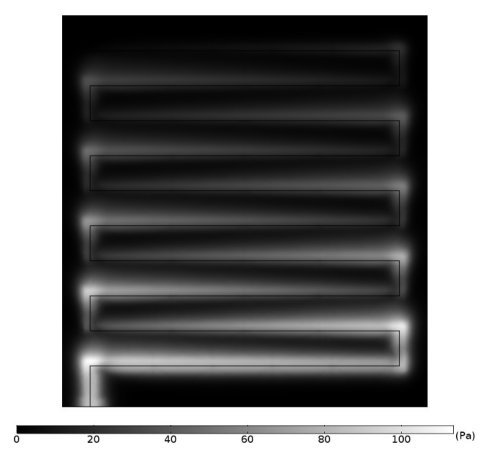

(a) I

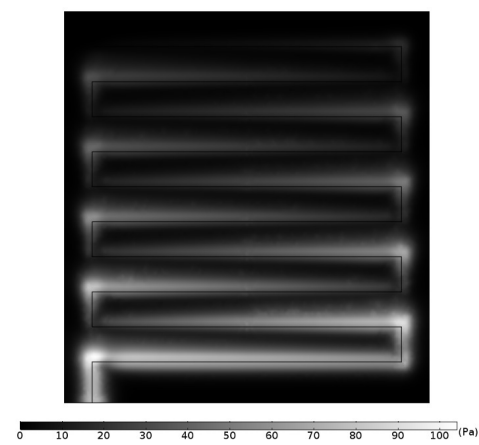

(d) III.b

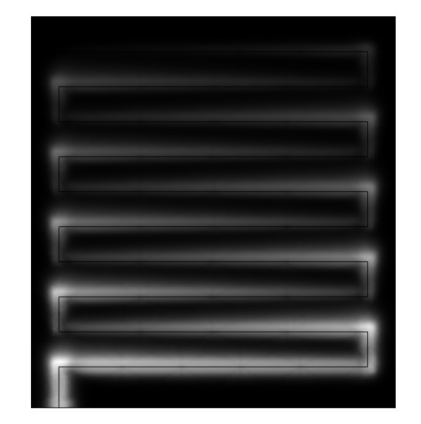

(b) II

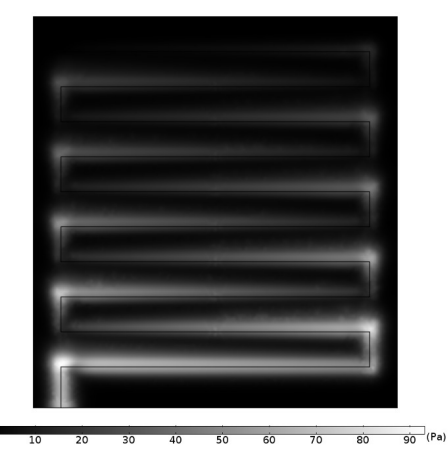

(e) IV.a

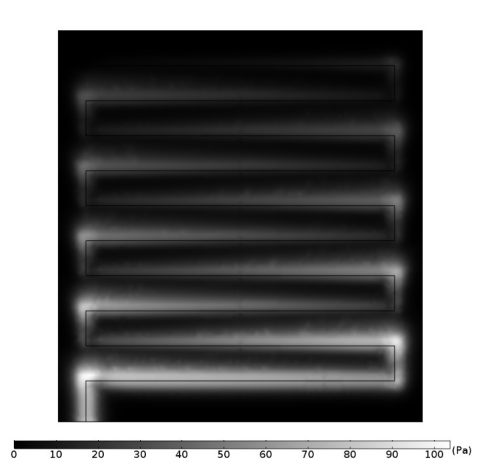

(g) Alfa

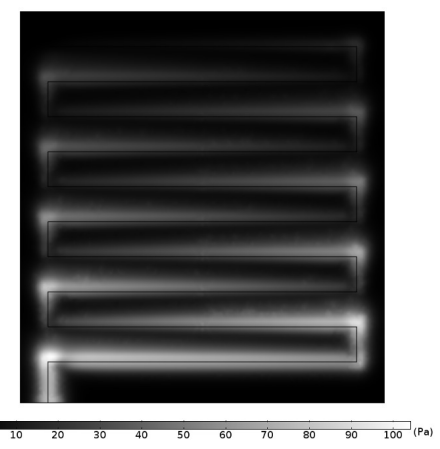

(c) III.a

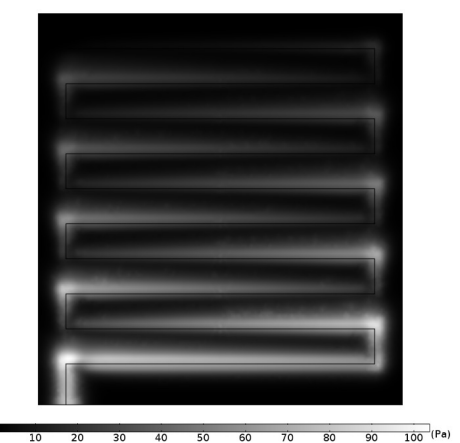

(f) IV.b

Fonte: Autoria própria. 
Figura 32 - a) Perda de carga e b) consumo total de $\mathrm{O}_{3}$ em função de $Q$ para as diversas modificações descritas na Tab. 4: I $(\square)$, III.a $(\diamond)$ e IV.a $(\triangle)$, com símbolos cheios; e II, III.b e IV.b com os mesmos respectivos símbolos porém vazios. Os resultados experimentais (o) e do modelo Alfa não modificado $(\bullet)$ foram incluídos a título de comparação. As barras de erro nos resultados experimentais representam a incerteza das medidas, no caso de $Q$ e $\Delta P$ e um desvio no caso de $\Delta \mathrm{O}_{3}$. Pode haver superposição de símbolos devido às escalas utilizadas.

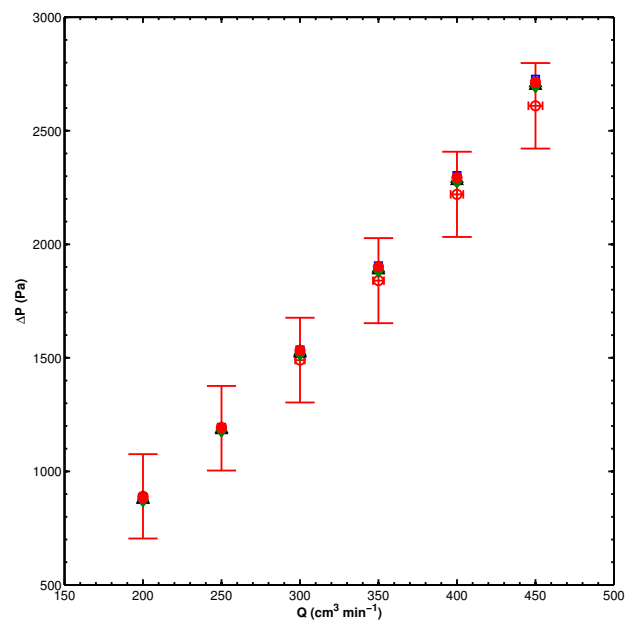

(a)

Fonte: Autoria própria.

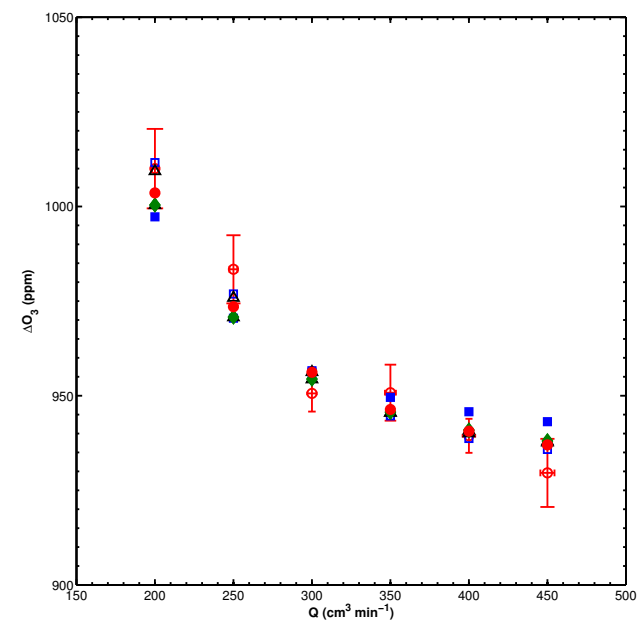

(b)

menores para $Q \geq 350 \mathrm{~cm}^{3} \mathrm{~min}^{-1}$. As demais modificações apresentam um comportamento contrário, sendo que a modificação I apresentou as maiores discrepâncias em relação ao modelo não modificado. Esta distinção de comportamento apresentada pelas modificações II e IV.b são particularmente importantes, conforme será discutido a seguir.

\subsubsection{Discussões}

Apesar das diferenças observadas entre as modificações e o modelo Alfa não modificado serem sutis, os resultados apresentados levantam vários pontos. Em primeiro lugar, pode-se considerar bem sucedida a incorporação das equações de mecânica dos sólidos ao modelo. Alguns motivos para tal podem ser apontados: i) as modificações III e IV não apresentaram resultados não-físicos, indicando que a formulação utilizada foi razoável; ii) as equações do campo de deslocamentos são independentes do escoamento e transporte de espécies, facilitando a resolução e mantendo virtualmente constante o custo computacional; e iii) permite a incorporação de fenômenos físicos sabidamente existentes no dispositivo experimental, aprimorando a descrição dada pelo modelo. Este último ponto é particularmente importante para este trabalho, dado que o objetivo é descrever da melhor maneira possível os fenômenos físicos que fazem parte do funcionamento do dispositivo experimental. Por outro lado, dois aspectos devem ser levados em conta em trabalhos futuros: i) o comportamento não-linear dos materiais tipicamente utilizados em 
células a combustível, e ii) o aumento do número de parâmetros e a necessidade de mais medidas para obtê-los.

Outro ponto envolve a natureza das diferenças observadas, especialmente no consumo total de ozônio (Fig. 32b), em relação ao modelo Alfa não modificado. Pelos resultados notam-se a influência de dois efeitos: geométrico e de transporte, neste caso relacionado à permeabilidade. O efeito geométrico é observado na diferença entre o modelo Alfa não modificado e as modificações I, III.a, III.b e IV.b, resultando na mudança de comportamento citada anteriormente para $\Delta \mathrm{O}_{3}$. No entanto, este parece pouco contribuir nos valores estacionários de $\mathbf{P}_{\mathrm{O}_{3}}$, aumentando levemente os valores, sendo a maior diferença observada para a modificação I (Fig. 31a), em relação ao não modificado (Fig. 31g). Considerando a análise da Seção 6.1.1.2, essas observações implicam que considerar simplesmente o efeito geométrico da compressão do MPS leva à divergências com os resultados experimentais: $\mathbf{P}_{\mathrm{O}_{3}}$ na $\mathrm{CL}$ e $\Delta \mathrm{O}_{3}$ variam inversamente entre si com $k$, portanto maiores valores de pressão parcial na CL e de consumo de ozônio para altos valores $Q$ são incompatíveis.

O efeito da permeabilidade, no entanto, compensa os efeitos geométricos, reduzindo levemente os valores de pressão parcial (Figs. 31b e 31e) e invertendo o caráter das diferenças do consumo de ozônio em relação ao modelo não modificado. Considerando mais uma vez o efeito de $k$ nas duas variáveis, nota-se que seria possível reconciliar o modelo não modificado e as modificações II e IV.a simplesmente variando $k$. Apesar da distinção feita entre os efeitos, sugere-se que a causa é comum: ambos os efeitos alteram o tempo de residência do ozônio na CL, para um dado valor de $Q$.

Mais notável é a observação de que, ao se considerar o efeito da permeabilidade sobre o geométrico, torna-se possível ajustar $k$ de modo que o consumo de ozônio simulado seja estatisticamente igual aos resultados experimentais, sendo que tal feito não é possível com as demais modificações ou com o modelo não modificado. Para verificar isto, o valor de $k$ para as modificações II e IV.a foi reduzido em passos de $1 \mathrm{~s}^{-1}$ de 260 a $255 \mathrm{~s}^{-1}$. Foi obtido que ambas modificações II e IV.a produzem valores de consumo de ozônio estatisticamente iguais aos experimentais, conforme apresentado na Figura 33, para os valores de $k=256$ e $257 \mathrm{~s}^{-1}$. Este resultado é particularmente promissor, deixando o modelo Alfa com as modificações II ou IV.a completamente de acordo com os resultados experimentais disponíveis.

Por fim, deve-se apontar que os resultados apresentados, apesar do sucesso das modificações II e IV.a, possuem incertezas significativas. Novamente, a consideração da deformação do MPS mostrou-se importante para a correta reprodução dos resultados experimentais disponíveis. No entanto, as condições assumidas potencialmente não abrangem todos os efeitos causados pela compressão dos meios porosos, por exemplo a compactação da CL e deformações não-homogêneas em ambos os meios porosos. De maneira mais geral, aproximações foram utilizadas no modelo Alfa, em particular no transporte de espécies. A falta de informações independentes sobre a cinética da reação de decomposição do ozônio, 
Figura 33 - Desvios no consumo total de $\mathrm{O}_{3}$ em relação aos resultados experimentais, em função de $Q$ : modificação II $(\square)$ e IV.a $(\triangle)$, para $k=256$ (azul) e $257 \mathrm{~s}^{-1}$ (preto). Os limites estabelecidos pelo desvios experimentais são dados por $(+)$.

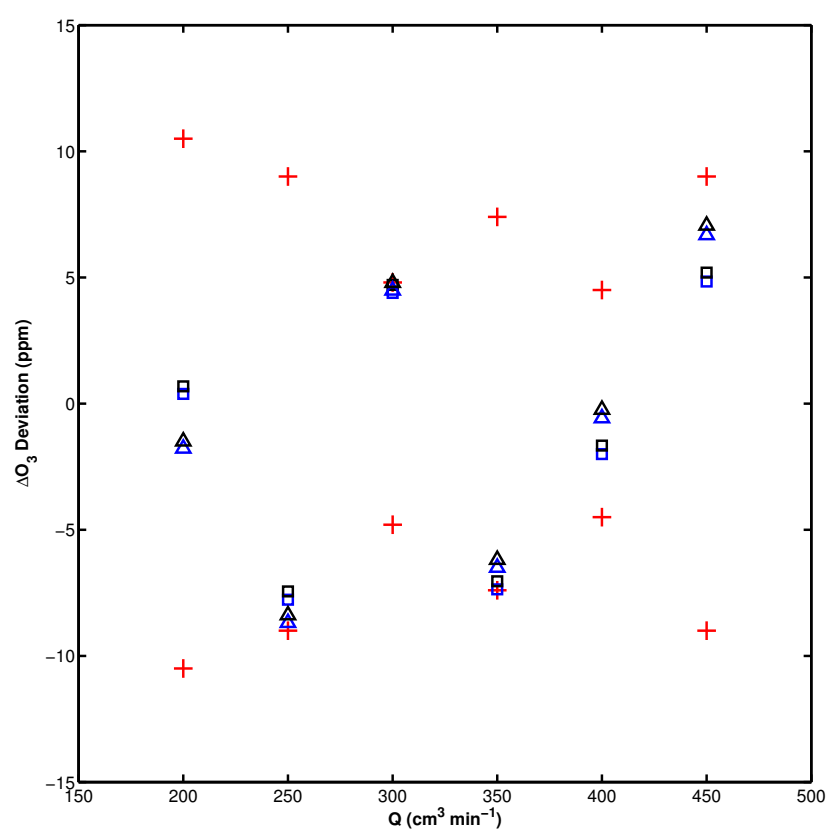

Fonte: Autoria própria.

Fonte: Autoria própria.

e o fato da reação ser em princípio uma reação de superfície, são especialmente críticos. A parametrização também apresenta lacunas, contribuindo para as incertezas dos resultados, como por exemplo a falta de informações sobre as propriedades de transporte da CL.

O fato de que o modelo reproduz os resultados experimentais é forte evidência para a validade da formulação matemática e da parametrização utilizada. No entanto, não se pode descartar a possibilidade de compensação de erros ou de simples coincidência, dada a quantidade limitada de evidências e o intervalo de valores em que o modelo fora testado. Tendo demonstrado a capacidade do modelo em reproduzir a realidade, os próximos passos são o refino das técnicas experimentais e aquisição de novos dados, de modo a buscar divergências com as previsões do modelo. Simultaneamente, dadas as incertezas apontadas para o modelo, também são necessários a obtenção independente de parâmetros e o aprimoramento da formulação matemática do modelo. 
Figura 34 - Superfícies de pressão parcial de $\mathrm{O}_{3}$ para $Q=250$ (linha superior) e $450 \mathrm{~cm}^{3} \mathrm{~min}^{-1}$ (linha inferior), para as diferentes geometrias de canais usando o modelo Beta: a e e) serpentina-2, b e f) serpentina-3, c g) interdigital e $\mathbf{d}$ e $\mathbf{h}$ ) paralela.

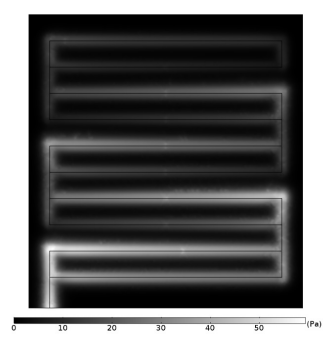

(a)

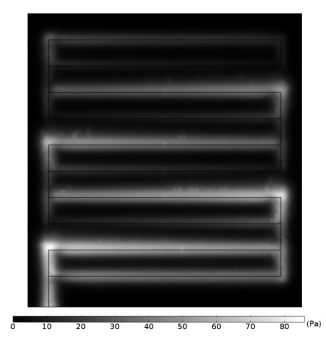

(e)

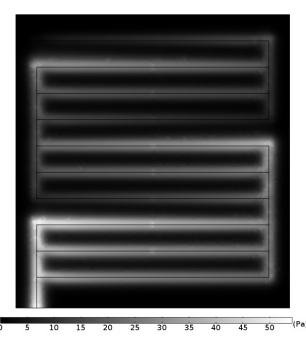

(b)

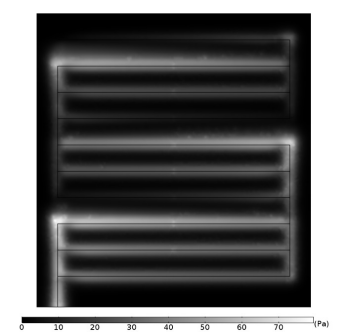

(f)

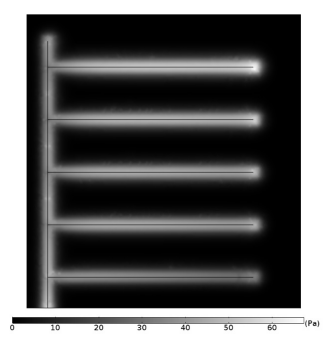

(c)

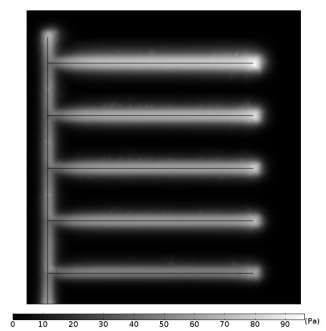

(g)

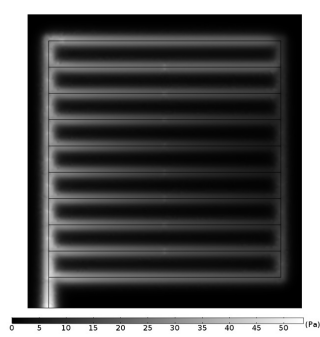

(d)

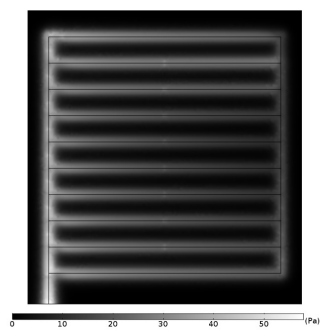

(h)

Fonte: Autoria própria.

\subsubsection{Estudo da Geometria dos Canais}

Seguindo a linha desenvolvida na Seção 6.1.1, serão apresentados resultados similares aos apresentados para a geometria de serpentina-1, i.e. de interesse experimental, utilizando diferentes geometrias de FC, com o intuito de futura validação. Em seguida será apresentada breve comparação entre os modelos utilizados, e então uma discussão acerca dos tipos de geometria simulados e possíveis impactos de seu uso em células a combustível.

\subsubsection{Efeitos da geometria de interesse experimental}

As superfícies de pressão $\mathbf{P}_{\mathrm{O}_{3}}$, obtidas no parte superior da CL, são apresentadas na Figura 34. Foram selecionados valores de vazão representativos do intervalo avaliado, $Q=250$ e $450 \mathrm{~cm}^{3} \mathrm{~min}^{-1}$, e são apresentados somente os resultados obtidos com o modelo Beta, dado que os resultados foram qualitativamente iguais aos obtidos com o modelo Alfa (ver Seção 6.1.3.2).

As superfícies resultantes para as geometrias de serpentina-2 e serpentina-3 são similares entre si, em relação à influência das voltas e da vazão, e também comparáveis às obtidas com serpentina-1. Em particular, são dignos de nota a súbita redução de pressão parcial de ozônio próximo às voltas, assim como os máximos locais imediatamente após as voltas. Por outro lado, a adição de canais paralelos permite a visualização de efeitos adicionais: i) o favorecimento do escoamento pelos canais mais externos em uma dada seção, isto é, 
Figura 35 - a) Perda de carga e b) consumo total de $\mathrm{O}_{3}$ em função da vazão para as geometrias de canal de escoamento avaliadas: serpentina-2 (०), serpentina-3 $(\square)$, interdigital $(\triangle)$ e paralela $(\diamond)$. São apresentados resultados para os modelos Alfa (símbolos vazios) e Beta (símbolos cheios).

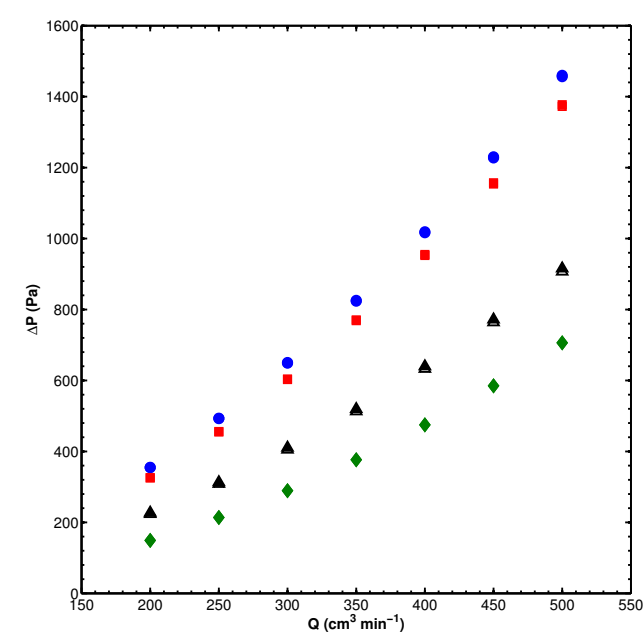

(a)

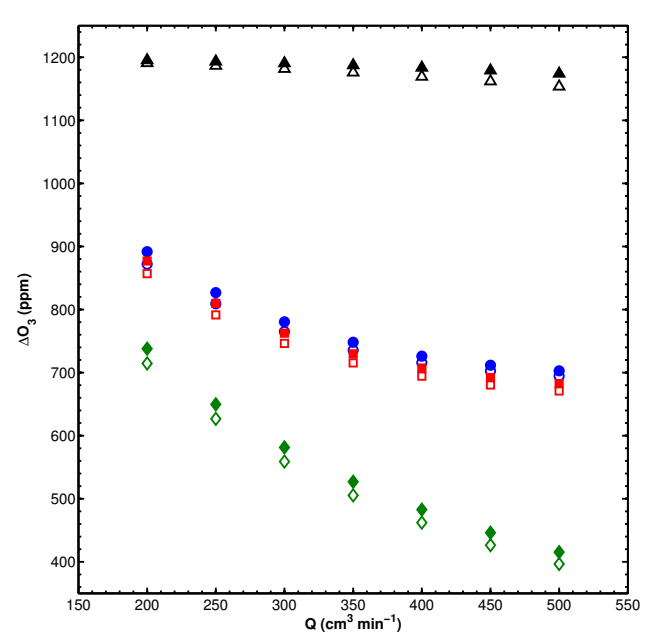

(b)

Fonte: Autoria própria.

aqueles apresentando cotovelo na segunda metade de uma dada volta; e ii) a diminuição da pressão parcial relativa entre canais de uma mesma seção horizontal com o aumento da vazão.

As superfícies da geometria interdigital, por outro lado, são marcadamente distintas das demais, por apresentarem de maneira aparente apenas metade dos canais, i.e. aqueles conectados à entrada de gases. A distribuição de gases relativa é pouco influenciada pela vazão, observando-se principalmente um alargamento das seções horizontais. As superfícies da geometria paralela apresentam a existência de caminhos preferenciais, conforme esperado pelo desenho. O aumento da vazão melhora a distribuição na região central, porém com pouco aumento na pressão parcial máxima.

As variáveis globais são apresentadas na Figura 35, desta vez apresentando resultados de ambos os modelos utilizados. Para $\Delta P$, Figura 35a, observa-se pouca diferença entre as formulações Alfa e Beta. Entre as geometrias, diferenças consideráveis são observadas, em particular entre as serpentinas e as demais, com taxas de aumento em função da vazão, $\delta(\Delta P) / \delta Q$, significativamente maiores para a serpentina-2 e serpentina-3.

Por outro lado, no caso de $\Delta \mathrm{O}_{3}$, Figura 35b, uma inversão de comportamento é observada. As geometrias serpentina-2 e serpentina-3 são, mais uma vez, similares à serpentina-1, apresentando uma diminuição do consumo com o aumento de $Q$, mas com tendência de estabilização. A geometria paralela apresenta um comportamento próximo, porém com valores de $\Delta \mathrm{O}_{3}$ significativamente menores. A geometria interdigital, por sua vez, apresenta comportamento e valores de $\Delta \mathrm{O}_{3}$ marcadamente diferentes: observa-se um consumo quase completo de ozônio em todas as vazões analisadas, porém o declínio 
do consumo com $Q$ é distinto das demais geometrias, não indicando estabilização. Em relação ao efeito da formulação, observam-se valores menores de $\Delta \mathrm{O}_{3}$ para o modelo Alfa, porém com comportamentos muito semelhantes. Digno de nota é o aumento da diferença entre as formulações Alfa e Beta para a geometria interdigital à medida que $Q$ aumenta, enquanto que um leve decréscimo da diferença é observada para as demais geometrias, sendo particularmente pequeno para a geometria paralela.

\subsubsection{Comparação entre modelos}

De modo a facilitar a análise posterior da influência da geometria dos canais no transporte de espécies, uma breve análise dos resultados de cada modelo será feita, sendo então estabelecidas suas diferenças para comparações futuras.

Em relação às superfícies de $\mathbf{P}_{\mathrm{O}_{3}}$ (Fig. 34), já fora mencionado que os modelos Alfa e Beta apresentam resultados qualitativamente similares. Nota-se, no entanto, que os valores de pressão parcial são, de maneira geral, maiores para o modelo Alfa. As diferenças variam para cada geometria avaliada, mas são de magnitude comparável à apresentada para a serpentina-1, na Seção 6.1.3. A título de esclarecimento, a Tabela 16 apresenta os valores médios, máximos e de desvio em relação à media da pressão parcial de ozônio, $\left\langle P_{\mathrm{O}_{3}}\right\rangle, \max \left(\mathbf{P}_{\mathrm{O}_{3}}\right)$ e $\delta P_{\mathrm{O}_{3}}$, respectivamente. Os valores foram obtidos para cada geometria estudada e valores de $Q=250$ e $Q=450 \mathrm{~cm}^{3} \mathrm{~min}^{-1}$. Observa-se que as diferenças apresentadas entre os modelos Alfa e Beta são maiores que o erro relativo das simulações, de $10^{-3}$, o que sugerem que são resultados da formulação e não numéricos.

Tabela 16 - Descritores estatísticos de $\mathbf{P}_{\mathrm{O}_{3}}$ para as diferentes geometrias avaliadas, utilizando os modelos Alfa e Beta e valores selecionados de vazão.

\begin{tabular}{|c|c|c|c|c|c|}
\hline Geometria & Modelo & $Q\left(\mathbf{c m}^{3} \min ^{-1}\right)$ & $\left\langle P_{\mathrm{O}_{3}}\right\rangle(\mathbf{P a})$ & $\max \left(\mathbf{P}_{\mathrm{O}_{3}}\right)(\mathbf{P a})$ & $\delta P_{\mathrm{O}_{3}}(\mathbf{P a})$ \\
\hline \multirow{4}{*}{ Serpentina-2 } & \multirow{2}{*}{ Alfa } & 250 & 13,112 & 69,192 & 12,358 \\
\hline & & 450 & 17,323 & 95,273 & 16,654 \\
\hline & \multirow{2}{*}{ Beta } & 250 & 10,035 & 58,932 & 10,168 \\
\hline & & 450 & 13,433 & 85,463 & 13,964 \\
\hline \multirow{4}{*}{ Serpentina-3 } & \multirow{2}{*}{ Alfa } & 250 & 13,176 & 62,374 & 11,684 \\
\hline & & 450 & 17,466 & 88,142 & 15,796 \\
\hline & \multirow{2}{*}{ Beta } & 250 & 10,058 & 53,688 & 9,596 \\
\hline & & 450 & 13,517 & 78,393 & 13,206 \\
\hline \multirow{4}{*}{ Interdigital } & \multirow{2}{*}{ Alfa } & 250 & 14,088 & 74,150 & 17,522 \\
\hline & & 450 & 20,855 & 100,577 & 23,583 \\
\hline & \multirow{2}{*}{ Beta } & 250 & 10,840 & 66,650 & 14,526 \\
\hline & & 450 & 16,332 & 95,448 & 20,211 \\
\hline \multirow{4}{*}{ Paralela } & \multirow{2}{*}{ Alfa } & 250 & 11,508 & 61,615 & 10,203 \\
\hline & & 450 & 14,049 & 65,844 & 11,571 \\
\hline & \multirow{2}{*}{ Beta } & 250 & 8,751 & 53,273 & 8,357 \\
\hline & & 450 & 10,787 & 57,408 & 9,571 \\
\hline
\end{tabular}

Fonte: Autoria própria. 
Figura 36 - Diferença relativa das variáveis globais: a) perda de carga e b) consumo de $\mathrm{O}_{3}$; entre os modelos Beta e Alfa, dada pelas Eqs. 6.1 e 6.2, respectivamente. As geometrias avaliadas foram: serpentina-2 $(\circ)$, serpentina-3 $(\square)$, interdigital $(\triangle)$ e paralela $(\diamond)$. As linhas sólidas indicam o limite de convergência das simulações, de $10^{-3}$.

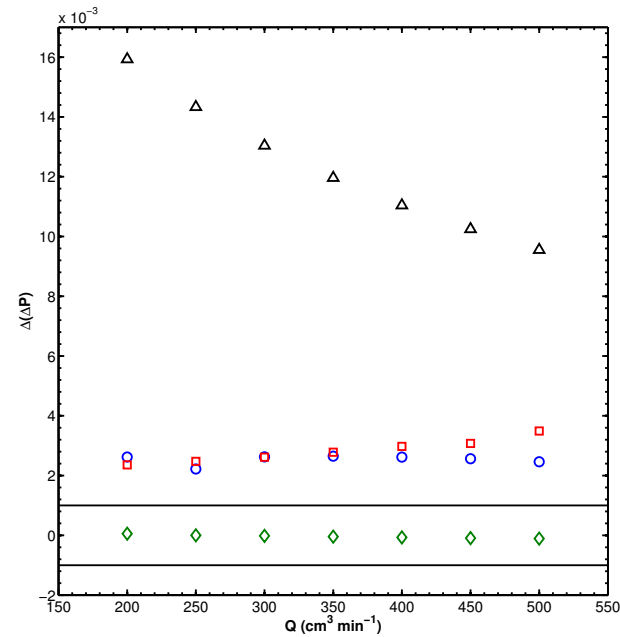

(a)

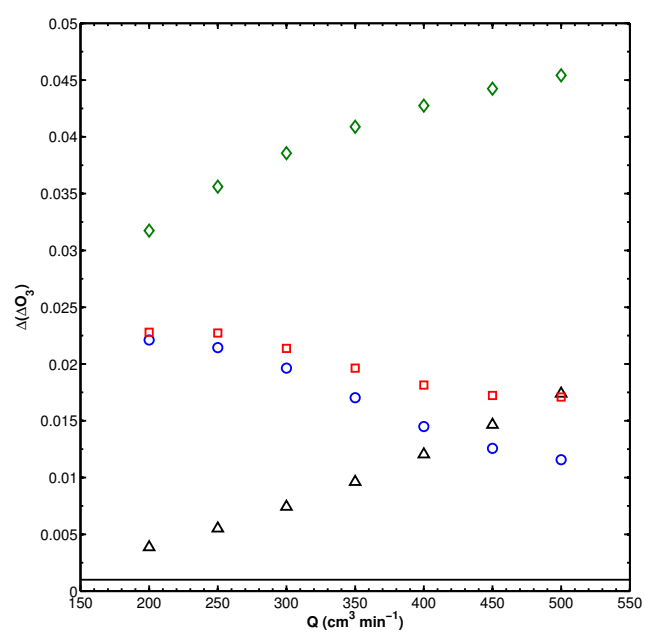

(b)

Fonte: Autoria própria.

De maneira similar, como pode ser observado na Fig. 35a, as perdas de carga resultantes para cada geometria são virtualmente independentes do modelo. A diferença relativa de $\Delta P$ entre os modelo Beta e Alfa, dada por

$$
\Delta(\Delta P)=\frac{\Delta P^{\beta}-\Delta P^{\alpha}}{\Delta P^{\beta}}
$$

é apresentada na Figura 36a para todas as geometrias. Observa-se, primeiramente, que apenas a geometria paralela apresenta valores inferiores ao limite de convergência das simulações, indicado pelas linhas em $10^{-3}$. Isto poderia indicar que existe uma diferença significativa, apesar de pequena, entre os modelos para as demais geometrias. Por outro lado, deve-se notar que o limite imposto nas simulações refere-se ao valor absoluto da pressão (desconsiderando a pressão atmosférica). Neste caso, a contribuição majoritária para a incerteza é devido à pressão de entrada, que é da ordem de $10^{4} \mathrm{~Pa}$ em todos os casos. Os valores absolutos de $\Delta(\Delta P)$ são da ordem de $10^{0}, 10^{0}, 10^{0}-10^{1}$ e $10^{-2}$ para as geometrias de serpentina-2, serpentina-3, interdigital e paralela, respectivamente. Assim, pode-se concluir que apenas a geometria interdigital apresenta diferenças significativas entre os modelos Alfa e Beta, no caso da perda de carga. Em segundo lugar, também é digno de nota as tendências observadas nas curvas para as geometrias serpentina-3 e interdigital. Isso sugere, e no caso da geometria interdigital corrobora, a contribuição de efeitos não capturados em um dos modelos, mais provavelmente o modelo Alfa.

No caso de $\Delta \mathrm{O}_{3}$, observam-se diferenças entre os modelos na Fig. 35b, sendo particularmente pronunciadas para as geometrias serpentina-3 e paralela. Conforme notado na 
Seção 6.1.4.2, o comportamento da diferença entre os modelos varia conforme a geometria. Isso é evidenciado na Figura 36b, que apresenta a diferença relativa de $\Delta \mathrm{O}_{3}$ entre os modelos Beta e Alfa, dada pela equação:

$$
\Delta\left(\Delta \mathrm{O}_{3}\right)=\frac{\Delta \mathrm{O}_{3}{ }^{\beta}-\Delta \mathrm{O}_{3}{ }^{\alpha}}{\Delta \mathrm{O}_{3}{ }^{\beta}}
$$

Primeiramente, observa-se que todos os valores encontram-se acima do limite dado pela convergência das simulações, indicado pela linha em $10^{-3}$. Observa-se, como no caso da perda de carga, que a incerteza está ligada ao valor da concentração de ozônio, e não diretamente a $\Delta \mathrm{O}_{3}$. Neste caso, sendo novamente o valor de entrada a maior fonte de incerteza, tem-se uma incerteza da ordem de $10^{0} \mathrm{ppm}$. As diferenças absolutas observadas entre os modelos Beta e Alfa, no entanto, são todas das ordem de $10^{1} \mathrm{ppm}$. Diferentemente da perda de carga, tem-se que o consumo de ozônio é significativamente diferente entre os modelos Alfa e Beta. Também observam-se tendências em todas as curvas, indicando a contribuição de efeitos capturados em apenas um dos modelos.

Assim, a comparação entre os modelo Alfa e Beta estabelece que existem diferenças significativas entre os dois em todas as variáveis de interesse experimental avaliadas. Isto facilita futuras comparações a resultados experimentais de modo a identificar o modelo que melhor represente a realidade. Por outro lado, a magnitude das diferenças observadas entre os modelos, tendo em vista as incertezas e desvios observados nos resultados experimentais (ver Seção 6.1.1.1), exigem um refino das medidas experimentais de modo a permitir a identificação do melhor modelo. Os mesmos resultados sugerem, no entanto, alternativas: vê-se que as diferenças possuem dependência com a geometria e com a vazão $Q$; aumentando para maiores valores de $Q$ e sendo particularmente grandes para a geometria interdigital. Portanto, pode ser possível obter resultados experimentais capazes de distinguir entre os modelos ao se explorar geometrias deste tipo, e altos valores de vazão $\left(Q>500 \mathrm{~cm}^{3} \mathrm{~min}^{-1}\right)$.

\subsubsection{Comparação entre geometrias}

Tendo estabelecido as diferenças entre os modelos Alfa e Beta para as diferentes geometrias avaliadas, a discussão dos efeitos da geometria será feita utilizando os resultados do modelo Beta, pelos motivos dados na Seção 6.1.3.3.

Seguindo a ordem de resultados apresentados na Seção 6.1.4.1, será analisado primeiramente a distribuição de ozônio na CL. Os fenômenos apontados posteriormente (Fig. 34) tem papel importante na distribuição de reagentes na CL, podendo contribuir significativamente para sobrepotenciais de concentração. Foi apontado principalmente a influência da vazão na distribuição relativa de ozônio em canais paralelos, em uma dada seção horizontal, no caso das serpentinas; ou em toda a geometria, no caso das geometrias interdigital e paralela. Na tentativa de melhor descrever tal efeito, foi avaliada a razão entre a a pressão parcial de ozônio da seção horizontal mais externa em uma dada geometria e as demais seções paralelas, ao longo da região central da seção horizontal em questão. 
Isto significa que, para as geometrias tipo serpentina, o canal mais distante da entrada de gases em uma dada seção horizontal foi tomada como referência, sendo os demais canais paralelos denominados de acordo com a distância da referência, em número de terraças, neste caso -1 e -2 . Para as geometrias interdigital e paralela, a seção horizontal mais distante foi tomada como referência, com a numeração dada da mesma maneira. A região central de cada seção horizontal foi escolhida de modo a minimizar efeitos de cotovelos e final do caminho, no caso da interdigital. Tais trajetórias são apresentadas na Fig. 37 para os valores de $Q=250,350$ e $450 \mathrm{~cm}^{3} \mathrm{~min}^{-1}$.

O comportamento observado pelos canais difere marcadamente para cada geometria, apresentado diferentes dependências com $Q$. Conforme foi possível visualizar numa primeira abordagem, os canais mais internos nas geometrias serpentina-2 e serpentina-3 apresentam uma atenuação significativa com o aumento de $Q$, no intervalo estudado. De maneira semelhante, porém com menor intensidade, a geometria interdigital apresenta comportamentos diferentes para cada canal, mas mantendo a tendência de aumento da preferência pelo canal mais externo da geometria. A geometria paralela, no entanto, apresenta um comportamento oposto às demais, apresentando aumento da contribuição dos canais paralelos ao referência, chegando ao extremo de apresentar maiores contribuições do canal -1 nas regiões próximas à saída de gases, em valores de $Q \geq 350 \mathrm{~cm}^{3} \mathrm{~min}^{-1}$. Estes resultados são esclarecedores no sentido de fornecer informações sobre o comportamento do transporte de espécies no sistema com diferentes geometrias. Entretanto são frustrantes ao evidenciarem a complexidade do mesmo: uma mesma estratégia para aprimorar a distribuição de espécies no dispositivo não necessariamente funcionaria para uma geometria diferente. Isso se torna particularmente importante ao se considerar uma célula a combustível em operação, dado que a concentração de espécies em torno de um canal preferencial é prejudicial à performance e durabilidade do dispositivo(17). Este ponto será melhor discutido adiante.

Sobre a perda de carga (Fig. 35a), os maiores valores, e taxas de incremento, das geometrias tipo serpentina são aparentemente contra intuitivas, quando considerado o desenho da geometria interdigital. Devido à descontinuidade dos canais, o esperado é uma redução significativa da velocidade de escoamento e, portanto, uma grande perda de carga. Por outro lado, em luz das informações providas pela análise do transporte convectivo nos domínios porosos (Seção 6.1.2), os relativamente baixos valores de $\Delta P$ para a geometria interdigital podem ser racionalizados, especialmente ao se considerar a similaridade com o perfil exibido pela geometria paralela. Foi verificado, com o modelo Alfa, que o transporte convectivo é significativo mesmo nos domínios porosos, possibilitando a transposição de terraças pelo fluido mesmo na presença de um caminho preferencial, como é o caso da serpentina-1. Assim, espera-se que a descontinuidade dos canais não seja uma barreira significativa, dado os parâmetros geométricos utilizados. Adicionalmente, a similaridade de comportamento com a geometria paralela sugere que tal comportamento seja devido, 
Figura 37 - Trajetórias de $P_{\mathrm{O}_{3}}$ relativa entre canais de uma seção horizontal ao canal mais distante da entrada de gases para a mesma seção horizontal, para as geometrias a) serpentina-2, b) serpentina-3, c) interdigital e d) paralela. Os valores de vazão contemplados foram $Q=250$ (linhas sólidas), 350 (linhas tracejadas) e $450 \mathrm{~cm}^{3} \mathrm{~min}^{-1}$ (linhas pontilhadas). A distância ao canal de referência, em número de terraças, é dado como -4 (azul), -3 (vermelho), -2 (preto) e -1 (verde).

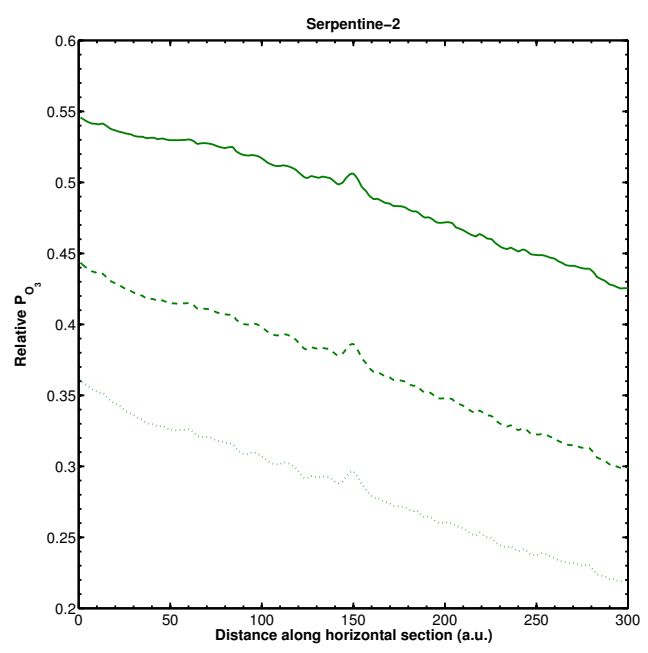

(a)

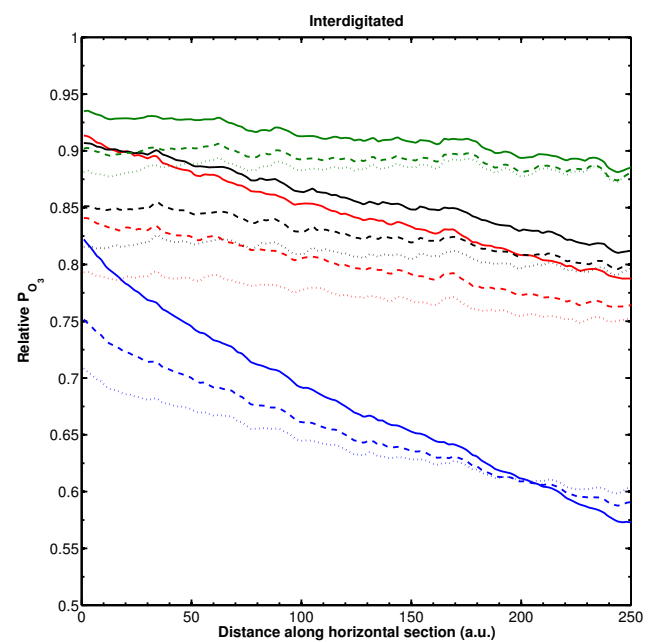

(c)

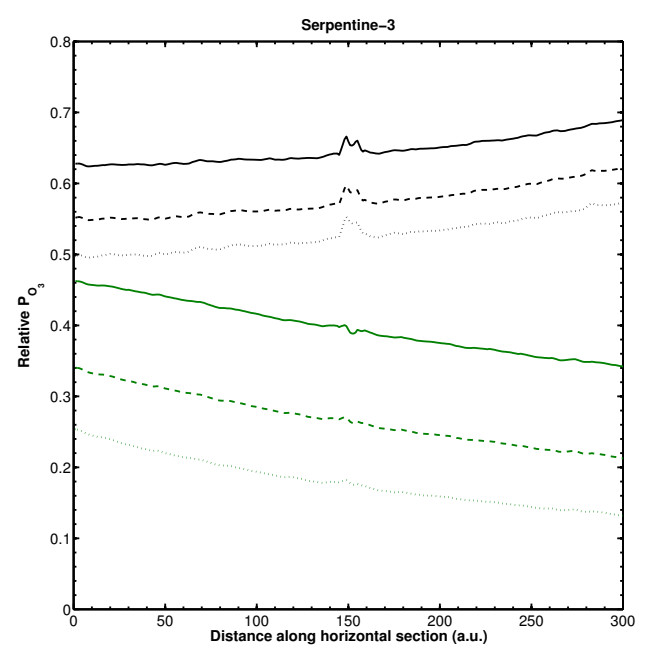

(b)

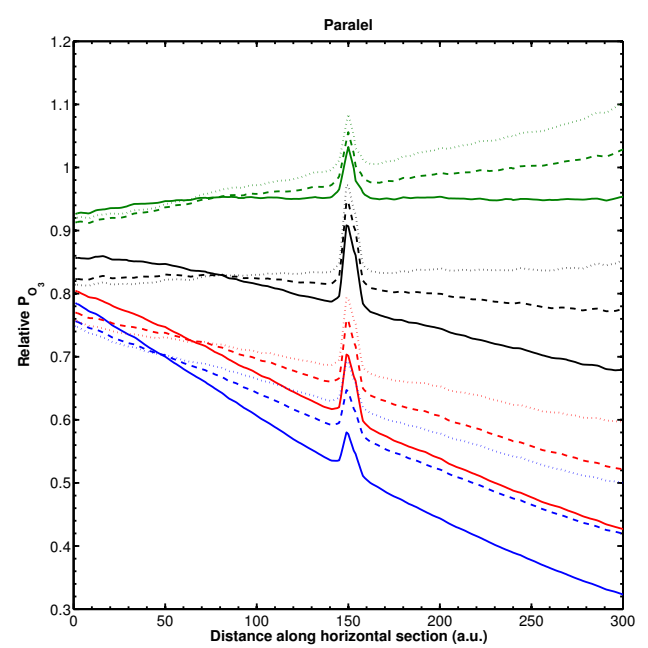

(d)

Fonte: Autoria própria. 
principalmente, às menores distâncias percorridas pelo fluido, em comparação às geometrias tipo serpentina.

Em contraste à perda de carga, o consumo de ozônio é marcadamente afetado pela geometria dos canais de escoamento (Fig. 35b). Conforme apontado na Seção 6.1.4.1, a geometria interdigital apresenta um comportamento para $\Delta \mathrm{O}_{3}$ significativamente diferentes das geometrias tipo serpentina. Enquanto que as serpentinas, incluindo a serpentina-1 explorada na Seção 6.1 .1 (Fig. 18b), apresentam um declínio de $\Delta \mathrm{O}_{3}$ com o aumento de $Q$, todas apresentam uma tendência de estabilização do consumo para $Q>450 \mathrm{~cm}^{3} \mathrm{~min}^{-1}$. Por outro lado, isto não é observado para as geometrias interdigital e paralela, no intervalo de $Q$ estudado. A geometria paralela, além de apresentar valores de $\Delta \mathrm{O}_{3}$ inferiores às demais, apresenta a maior taxa de declínio do consumo. Analisando a diferença entre cada ponto subsequente, i.e. $\approx \partial \Delta\left(\mathrm{O}_{3}\right) / \partial Q$, observa-se uma redução da inclinação instantânea de $\approx 65 \%$, de -88 para -31 ppm $\mathrm{cm}^{-3} \mathrm{~min}$. As geometrias serpentina-2 e serpentina-3, por outro lado, apresentam uma redução de $\approx 85 \%$, de $\approx-65$ para $\approx-9 \mathrm{ppm} \mathrm{cm}^{-3}$ min. No caso da geometria interdigital, observa-se um aumento da inclinação instantânea de

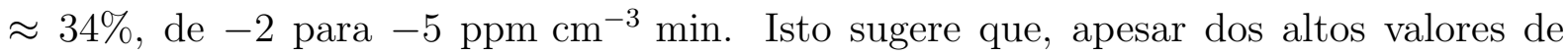
$\Delta \mathrm{O}_{3}$ para a geometria interdigital, o transporte convectivo é prejudicial ao consumo de reagentes.

Tal sugestão conflita com o observado para a serpentina-1 na Seção 6.1.2, e levanta o ponto sobre a contribuição do transporte convectivo nas demais geometrias. Assim, de maneira similar ao realizado para a serpentina-1, o transporte convectivo foi descoplado do transporte de espécies nas camadas porosas, conforme descrito na Seção 4.1.3. A Figura 38a apresenta as curvas de $\Delta \mathrm{O}_{3}(Q)$ para os modelos Beta e Beta-mod, i.e. com e sem transporte convectivo nos meios porosos, respectivamente. É possível notar, de maneira similar ao apresentado para a serpentina-1, que as geometrias de serpentina-2 e serpentina-3 apresentam contribuição do transporte convectivo para $\Delta \mathrm{O}_{3}$, possivelmente através dos mesmos mecanismos, i.e. recirculações e outros escoamentos secundários, que para a serpentina-1. A geometria interdigital, conforme sugerido pela análise da Fig. 35b, apresenta valores de $\Delta \mathrm{O}_{3}$ superiores para o modelo Beta-mod. Apesar das diferenças serem pequenas, nota-se a tendência de aumento proporcional à $Q$. Isto é evidenciado na Figura 38b, que apresenta a diferença relativa entre os modelos Beta e Beta-mod:

$$
\Delta\left(\Delta \mathrm{O}_{3}\right)=\frac{\Delta \mathrm{O}_{3}{ }^{\beta}-\Delta \mathrm{O}_{3 \mathrm{mod}}{ }^{\beta}}{\Delta \mathrm{O}_{3}{ }^{\beta}}
$$

Observa-se que o comportamento da curva $\Delta\left(\Delta \mathrm{O}_{3}\right)$ da geometria interdigital é aproximadamente exponencial, enquanto que as curvas das geometrias tipo serpentina são aproximadamente lineares. Talvez tão digno de nota quanto a contribuição negativa da convecção para a geometria interdigital, é a contribuição quase nula para a geometria paralela. Tal fato é contra intuitivo, considerando o observado na Fig. 37. Por outro lado, isto reforça a complexidade da interação entre os diferentes domínios e materiais 
Figura 38 - a) Consumo de $\mathrm{O}_{3}$ para os modelos Beta (símbolos vazios) e Beta-mod (símbolos cheios), e b) diferença relativa de $\Delta \mathrm{O}_{3}$ entre os modelos (Eq. 6.3, em função da vazão $Q$. As geometrias são codificadas como: serpentina-2(o), serpentina-3 $(\square)$, interdigital $(\triangle)$ e paralela $(\diamond)$.

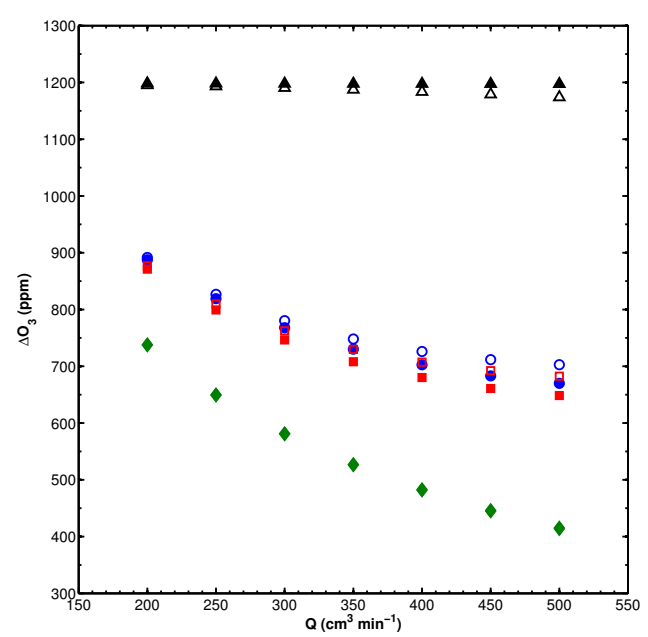

(a)

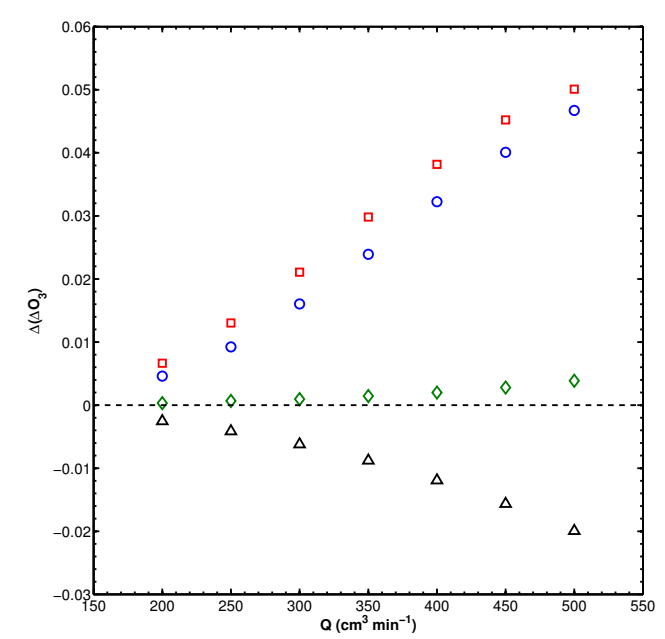

(b)

Fonte: Autoria própria.

em células a combustível, mesmo considerando as simplificações presentes no dispositivo idealizado por Lopes e colaboradores(33).

Deve-se apontar, em relação aos resultados apresentados na Fig. 38, que as diferenças observadas são significativas em relação ao limite de convergência das simulações. Considerando que no caso apresentado na Seção 6.1.4.2 as diferenças relativas eram da ordem de $10^{-2}$, semelhantes às observadas na Fig. 38b, o que se traduzia em diferenças absolutas ordem de $10^{1}$ ppm em $\Delta \mathrm{O}_{3}$; enquanto que a incerteza dada pelas simulações é da ordem de $10^{0} \mathrm{ppm}$. Entretanto, a geometria paralela apresenta diferenças na ordem de $\approx 10^{0} \mathrm{ppm}$, sugerindo que os valores de $\Delta \mathrm{O}_{3}$ são virtualmente iguais. A presença de tendência na curva sugere, no entanto, que tais desvios possam ser devido a processos físicos, porém é necessário refinar as simulações para confirmação.

Considerando os diferentes comportamentos observados na Fig. 38, é ilustrativo avaliar o impacto do transporte convectivo na distribuição de ozônio na CL, como mostrado na Seção 6.1.2 (Fig. 27). Para tal, a mesma grandeza foi avaliada, i.e. a diferença normalizada de pressão parcial de ozônio, $\boldsymbol{\Delta} \mathbf{P}_{\mathrm{O}_{3}}$. A Figura 39 apresenta tais superfícies para cada geometria, para $Q=350 \mathrm{~cm}^{3} \mathrm{~min}^{-1}$. Para as geometrias tipo serpentina, Figs. 39a e 39b, observa-se um comportamento muito similar ao da serpentina-1, principalmente pela presença dos escoamentos secundários após as voltas. Adicionalmente, é evidenciado os efeitos indicados anteriormente, nas Figs. 34 e 37: nota-se uma contribuição positiva da convecção para os canais mais externos da geometria, dado pela subestimativa de $\mathbf{P}_{\mathrm{O}_{3}}$ pelo modelo Beta-mod; enquanto que a contribuição é negativa para os canais mais internos. É digno de nota que o canal central da geometria de serpentina-3 não apresenta contribuição 
Figura 39 - Superfícies de $\boldsymbol{\Delta} \mathbf{P}_{\mathrm{O}_{3}}$, dada pela Eq. 78 para os modelos Beta-mod e Beta, com $Q=$ $350 \mathrm{~cm}^{3} \mathrm{~min}^{-1}$ e a seguintes geometrias de FC: a) serpentina-2, b) serpentina-3, c) interdigital e d) paralela. Na codificação atual, ciano representa subestimativa, enquanto vermelho representa superestimativa de pressão parcial de $\mathrm{O}_{3}$ em relação ao modelo Beta.

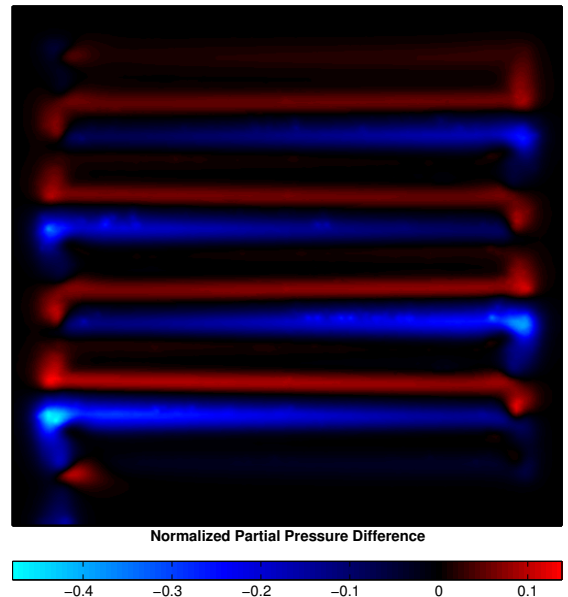

(a)

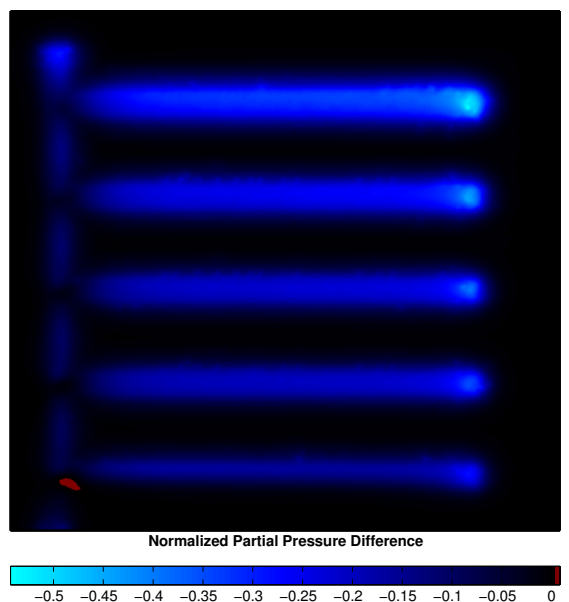

(c)

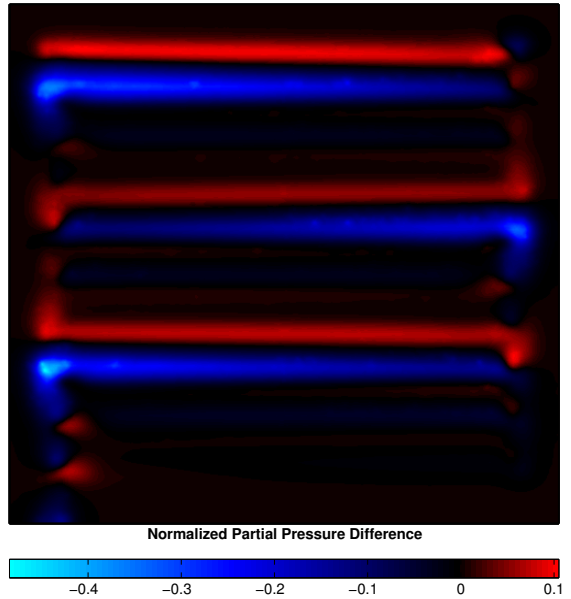

(b)

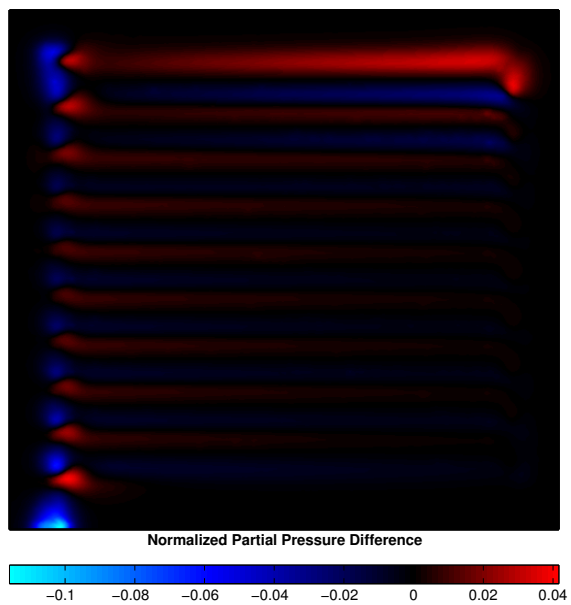

(d)

Fonte: Autoria própria.

significativa do transporte convectivo, contribuindo para a interpretação da Fig. 37.

Para a geometria interdigital, Fig. 39c, observa-se quase que exclusivamente uma subestimativa de $P_{\mathrm{O}_{3}}$ pelo modelo Beta-mod, além de grande fração da área sem qualquer contribuição do transporte convectivo. Em primeira abordagem, isto é contrastante com as informações anteriores, particularmente às apresentadas pela Fig. 38. Por outro lado, conforme apontado acima quando analisado a Fig. 35a, é possível racionalizar ambas as informações. O cenário que emerge é que, dada a obstrução dos canais, a convecção é a responsável em transportar espécies à CL. Entretanto, a magnitude das velocidades 
resultante é pequena, o que torna a difusão o principal meio de transporte à seção do FC conectada à saída de gases; resultando em um grande tempo de residência das espécies na CL, e assim um alto consumo de reagentes. Desta maneira, o comportamento da função $\Delta \mathrm{O}_{3}$ se dá pelo aumento da contribuição da convecção no transporte das espécies à saída, diminuindo assim o tempo de residência e, por consequência, o consumo.

O resultado para a geometria paralela, Fig. 39d, é mais direto, sendo largamente condizente com os resultados anteriores. Um ponto que pode aparentar incoerente se dá pelos pequenos desvios observados em grande parte da região central da geometria, especialmente nas regiões próximas à saída de gases, quando considerados os resultados da Fig. 37. Deve-se notar que tais resultados são relativos ao canal mais distante da saída, onde se observa contribuição do transporte convectivo. Assim, o aumento relativo da pressão parcial ao longo dos canais observados na Fig. 37d pode ser traçado para a contribuição negativa do transporte convectivo no canal tomado como referência. Por outro lado, os resultados da Fig. 38 correlacionam diretamente com as pequenas magnitudes observadas para a diferença relativa nesta geometria, corroborando a contribuição reduzida do transporte convectivo para a distribuição de espécies.

Por fim, de modo a sumarizar e prover outro ponto de vista em relação à performance das geometrias estudadas, curvas de polarização similares às apresentadas na Seção 6.1.2.1 serão avaliadas. A Figura 40 apresenta as curvas de $\eta_{C}$ em função de $I_{\mathrm{O}_{3}}$ para cada geometria, para valores selecionados de $Q$, utilizando ambos os modelos Beta e Beta-mod. Em primeiro lugar, a Figura 40a apresenta a comparação entre as geometrias. Observa-se, de maneira similar à Fig. 24, uma tendência aproximadamente linear da diminuição de $\eta_{C}$ e aumento de $I_{\mathrm{O}_{3}}$ com o aumento de $Q$. Por outro lado, nota-se uma diferença significativa no efeito da "polarização", i.e. a variação do valor de $k$, para a geometria interdigital em comparação às demais. Conforme sugerido pela análise da Fig. 35b, os maiores valores de $I_{\mathrm{O}_{3}}$ são observadas para esta, porém também observam-se grande valores de $\eta_{C}$. Também dentro do esperado é o resultado da geometria paralela, apresentando os menores valores de $I_{\mathrm{O}_{3}}$, porém com valores de $\eta_{C}$ levemente menores que os das geometrias tipo serpentina, que por sua vez são praticamente iguais. A tendência observada aqui concorda em geral com a observada ao se avaliar os valores de $\Delta \mathrm{O}_{3}$. No entanto, nota-se que a influência de $Q$ nas geometrias é diferente do observado na Fig. 35b, sendo que mesmo a geometria interdigital apresenta melhora de desempenho com o aumento de $Q$, enquanto observa-se uma diminuição de $\Delta \mathrm{O}_{3}$. De fato, as inclinações das curvas para um dado valor de $k$, i.e. $\partial \eta_{C} / \partial I_{\mathrm{O}_{3}}$, apontam a maior inclinação para a geometria interdigital:

$$
\begin{aligned}
\frac{\partial \eta_{C}}{\partial I_{\mathrm{O}_{3}}} & =74,898, \text { serpentina }-2 \\
& =70,038, \text { serpentina }-3 \\
& =116,97, \text { interdigital } \\
& =111,37, \text { paralela }
\end{aligned}
$$


Figura 40 - Sobrepotencial de concentração médio em função da corrente total equivalente, definidos nas Eqs. 4.18 e 4.20 respectivamente: a) comparação entre as geometrias utilizadas com o modelo Beta, e b) comparação individual entre os modelos Beta (símbolos vazios) e Beta-mod (símbolos cheios): serpentina-2 $(\circ)$, serpentina-3 $(\square)$, interdigital $(\triangle)$ e paralela $(\diamond)$. Os valores de $Q$ contemplados foram 250, 350 e $450 \mathrm{~cm}^{3} \mathrm{~min}^{-1}$, com a tendência indicada pela seta em a).

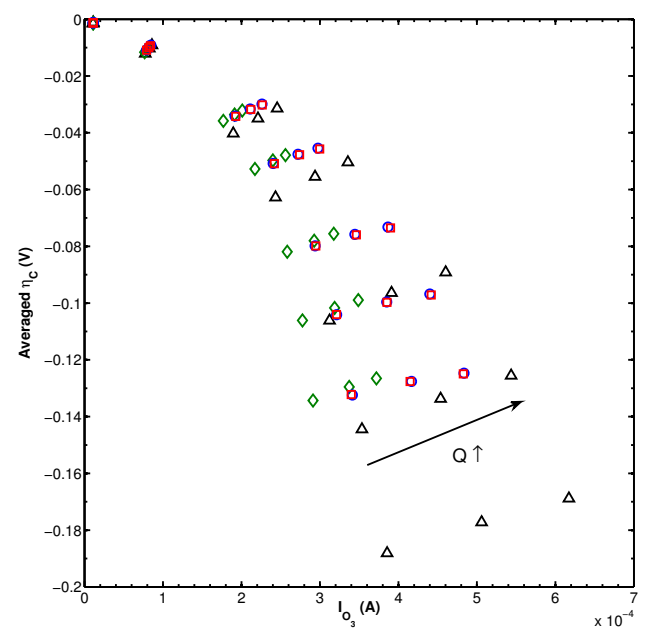

(a)
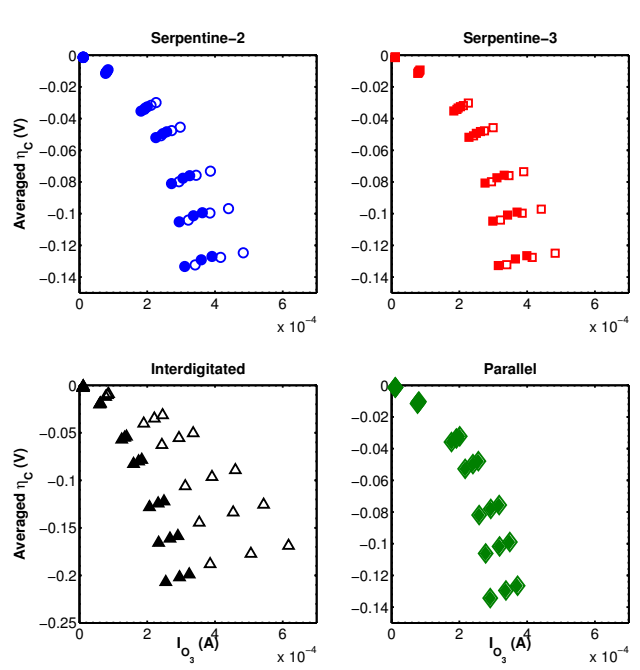

(b)

Fonte: Autoria própria.

para $k=256,5 \mathrm{~s}^{-1}$. Isto sugere que, em altos valores de $Q$, a geometria interdigital compense os altos valores de $\eta_{C}$ observados, que atinge um mínimo de $\approx 1,19$ relativo aos valores apresentados pelas geometrias tipo serpentina, para um máximo de $\approx 1,2$ dos valores de $I_{\mathrm{O}_{3}}$.

Em segundo lugar, ao se analisar a Fig. 40b, corrobora-se a análise feita acima, sendo observado que a geometria paralela apresenta quase nenhuma contribuição do transporte convectivo nos meios porosos, assim como o fato que as geometrias tipo serpentina apresentam uma contribuição significativa nos valores de $I_{\mathrm{O}_{3}}$ para um mesmo valor de $k$. Por outro lado, observa-se que a geometria interdigital apresenta contribuições positivas do transporte convectivo, i.e. no sentido de diminuir $\eta_{C}$ e aumentar significativamente $I_{\mathrm{O}_{3}}$ para um dado valor de $k$ e $Q$. Tal fato também difere do observado na Fig. 35b, porém, como notado acima, ao analisar-se a Fig. 39c, pode ser entendido como resultado da interação do campo de escoamento com as camadas porosas: o aumento da velocidade do reagente nas camadas porosas diminui o tempo de residência na CL, reduzindo o consumo total (comparado à ausência de transporte convectivo), mas por outro lado melhora a distribuição de reagente, o que contribui para a redução do sobrepotencial de concentração médio.

Apesar de representar apenas um ponto de vista diferenciado do apresentado pelo consumo total de reagente, as curvas de polarização da Fig. 40 sugerem um cenário diferente do observado na Fig. 35b. Enquanto que a análise de $\Delta \mathrm{O}_{3}$ apontaria a geometria 
interdigital como significativamente superior às demais, do ponto de vista de eficiência, as curvas $\eta_{C}$ vs $I_{\mathrm{O}_{3}}$ sugerem uma compensação negativa dada pelos altos valores absolutos de $\eta_{C}$ desta. Isto é mais facilmente observado na Figura 41a, que apresenta a perda de potência devido ao sobrepotencial de concentração, i.e. $\eta_{C} \times I_{\mathrm{O}_{3}}$, em função da corrente equivalente, para $k=256,5 \mathrm{~s}^{-1}$. Foram incluídos, a título de comparação, os resultados para a geometria de serpentina-1. Apesar das inclinações serem parecidas para todas as geometrias, $\approx-0,05 \mathrm{~W} \mathrm{~A}^{-1}$, a geometria interdigital apresenta uma "perda intrínseca", i.e. o valor to termo independente em um modelo linear, de $\approx-1,6 \times 10^{-5} \mathrm{~W}$, enquanto as demais geometrias apresentam valores entre $-0,8 \mathrm{e}-1,0 \times 10^{-5} \mathrm{~W}$. Assim, no intervalo de $Q$ avaliado, a perda de potência devido a efeitos de concentração é significativamente maior para a geometria interdigital, sendo aproximadamente igual entre as demais.

Deve-se notar, no entanto, que isto não significa que a geometria interdigital seja necessariamente inferior às demais em todos os casos. No caso de uma célula a combustível in operando, além dos efeitos adicionais não contemplados no protótipo estudado, é comum operar com corrente constante, ou ainda com estequiometria constante (Eq. 3.1):

$$
\begin{aligned}
\lambda_{\mathrm{O}_{3}} & =\frac{F \dot{N}_{\mathrm{O}_{3}}}{I_{\mathrm{O}_{3}}} \\
& =\frac{F Q C_{\mathrm{O}_{3}}^{0}}{I_{\mathrm{O}_{3}}}
\end{aligned}
$$

Neste caso, assumindo $\lambda$ como a variável de controle, a resposta de interesse é somente $\eta_{C}$. As curvas calculadas para $\eta_{C}(\lambda)$ são apresentadas na Figura $41 \mathrm{~b}$, para $k=256,5 \mathrm{~s}^{-1}$. Conforme esperado, a geometria interdigital apresenta o pior desempenho dentro do intervalo de $\lambda$ calculado para esta. As geometrias tipo serpentina apresentam o melhor desempenho, sendo que a serpentina-1 apresenta o menor valor absoluto de $\eta_{C}$ no intervalo considerado. A Fig. 41b é mais informativa, no entanto, permitindo estabelecer a melhor geometria para determinados intervalos de $\lambda$. Estudando as curvas foi possível estabelecer a seguinte relação, com o intuito de minimizar o sobrepotencial de concentração:

$$
\left\{\begin{array}{l}
\text { serpentina }-2 \text { ou } 3: 1 \leq \lambda<1,632 \\
\text { serpentina }-1: 1,623 \leq \lambda<3,04 \\
\text { interdigital }: \lambda \geq 3,04
\end{array}\right.
$$

onde foi usado um modelo do tipo $\left\langle\eta_{C}\right\rangle=a \lambda^{b}$ para a regressão não-linear dos pontos da Fig. 41b e localização dos pontos de intersecção.

Assim, considerando os pontos levantados acima e as análises feitas das diferentes geometrias estudadas, algumas conclusões podem ser estabelecidas. Em primeiro lugar, o cenário que surge da avaliação do transporte convectivo é que cada geometria tem contribuições e respostas diferenciadas, o que dificulta uma racionalização entre diferentes desenhos e, portanto, uma maneira direta de propor geometrias que maximizem a contribuição do transporte convectivo. Neste ponto, a técnica desenvolvida por Lopes e 
Figura 41 - a) Perda de potência $\eta_{C} \times I_{\mathrm{O}_{3}}$ em função de $I_{\mathrm{O}_{3}}$ e b) $\eta_{C}$ em função de $\lambda_{\mathrm{O}_{3}}$ (Eq. 6.4), para as geometrias estudadas com o modelo Beta: serpentina-2 (o), serpentina-3 ( $\square$ ), interdigital $(\triangle)$ e paralela $(\diamond)$, com adição da geometria serpentina-1 $(\times)$. Foi utilizado o valor de $k=256,5 \mathrm{~s}^{-1}$ para o cálculo das curvas.

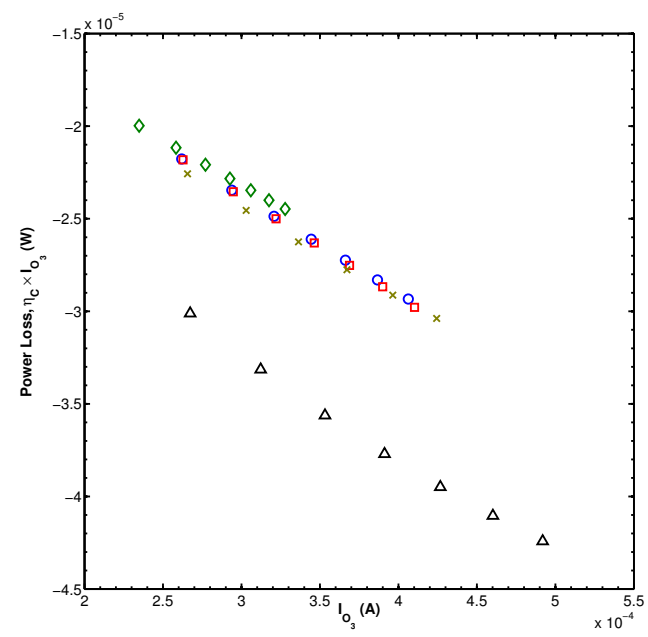

(a)

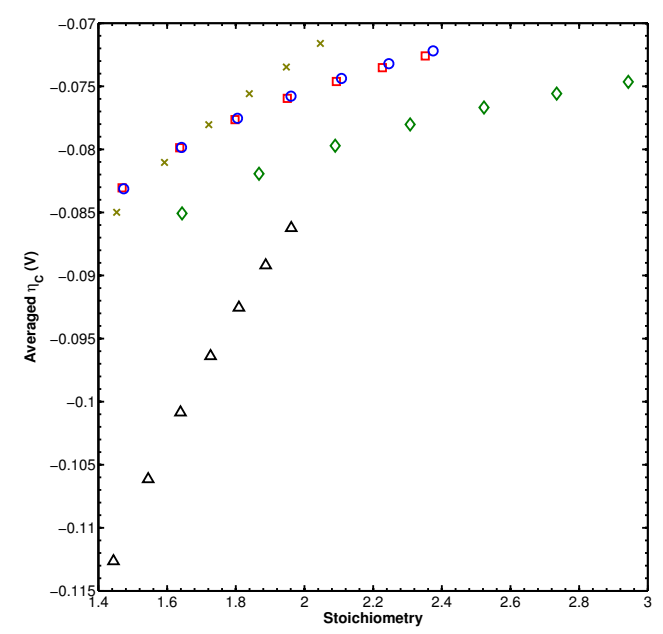

(b)

colaboradores(33), juntamente com o uso de simulações numéricas como as apresentadas aqui, permitem uma investigação inicial com um relativo baixo custo e curto intervalo de tempo. No entanto, e em segundo lugar, sugere-se que a simples avaliação do consumo total de reagente não é suficiente para indicar qual a natureza da resposta de uma dada geometria de canal em um dispositivo eletroquímico, dada a natureza das variáveis que devem ser avaliadas (sobrepotencial e corrente). Isso significa que um resultado experimental facilmente acessado é de pouca valia para tal análise. Por outro lado, como mostrado na validação do modelo Alfa (Seção 6.1.1) e no desenvolvimento do modelo Beta (Seção 6.1.3), tais resultados, acoplados às superfícies de pressão parcial de ozônio de Lopes e colaboradores, foram de grande valia na obtenção de um modelo capaz de reproduzir todos os aspectos experimentais disponíveis. O que leva ao terceiro ponto, que foi possível obter, utilizando tal modelo, uma relação indicando a geometria de melhor desempenho, dado um regime estequiométrico no dispositivo (Fig. 41b), seja dado pela vazão de entrada, cinética reacional ou concentração de reagente. Em particular, considerando a estequiometria recomendada para células a combustível operadas com ar, de $\lambda_{\mathrm{O}_{2}}(41)$, foi obtido que a geometria com melhor eficiência, em relação ao sobrepotencial de concentração, é a serpentina-1. Extrapolando cuidadosamente para o caso do hidrogênio, onde $\lambda_{\mathrm{H}_{2}}(41)$, sugere-se que as geometrias serpentina-2 ou serpentina-3 seriam superiores às demais estudadas.

Indo além, o estudo do sobrepotencial de concentração em função da estequiometria pode ser útil na otimização de geometrias. Estabelecendo tal relação como uma medida de mérito, é possível utilizar algoritmos para a minimização de $\eta_{C}$ para um dado valor de $\lambda_{\mathrm{O}_{3}}$. Tais 
geometrias e condições operacionais podem ser simuladas e validadas experimentalmente, através da técnica descrita por Lopes e colaboradores(33), culminando na aplicação em células a combustível. Isso demonstra o potencial em acoplar estudos experimentais e computacionais, abrindo a possibilidade que outras variáveis sejam avaliadas e validadas de maneira semelhante.

Deve-se ter em mente, no entanto, as limitações das análises e conclusões acima. Dentre os diversos fenômenos ignorados nos modelos Alfa e Beta, muitos de alta ordem e portanto razoavelmente negligenciáveis, é importante frisar a interação com fase líquida. No caso de células PEM, dispositivos alvo dos estudos com o protótipo descrito em (33) e das simulações apresentadas aqui, tais efeitos são extremamente importantes (ver, por exemplo, $(13,14,17))$ para entender tais dispositivos. Crucialmente, a presença de fase líquida influencia de maneira drástica no sobrepotencial de concentração em regimes de alta corrente, levando ao encharcamento do cátodo. Assim, a relação estabelecida acima deve, idealmente, ser reforçada com um estudo da influência da geometria na manutenção da fase líquida e, portanto, no sobrepotencial de concentração causado pelo deslocamento da fase gasosa. Por outro lado, a separação destes efeitos exige o conhecimento prévio da influência da geometria na ausência de fase líquida; objetivo considerado atingido no trabalho atual, ao menos para as geometrias consideradas. 


\subsection{Célula a Combustível}

A seguir serão apresentados os resultados referentes ao modelo FC mkII, que simula o dispositivo experimental utilizado. Primeiramente serão comparados os resultados do modelo mkII aos experimentais, e então serão discutidos alguns trabalhos recentes na literatura e o presente cenário em relação à validação de modelos computacionais. Por fim, com base nos estudos realizados com a protocélula (Seção 6.1), serão avaliadas a formulação e as contribuições do transporte convectivo no modelo mkII.

\subsubsection{Comparação aos Resultados Experimentais}

\subsubsection{Aspectos elétricos}

Em primeiro lugar, serão comparadas as curvas de polarização computacionais e experimentais. A Figura 42 apresenta ambos os resultados; sendo que deve-se notar que, conforme apontado no final do Capítulo 5, os resultados experimentais são compostos pelos dois conjuntos de dados experimentais apresentados anteriormente. A Fig. 42a apresenta os resultados simulados para os quatro conjuntos de vazão descritos na Tab. 1. A Fig. 42b compara os resultados computacionais aos experimentais para cada conjunto de vazão. Observa-se, de modo geral, boa concordância entre as curvas, notando-se que esta aumenta com a vazão. Digno de nota é a região para baixos valores de $I$, dominada pela polarização por ativação, cujas diferenças entre os resultados é particularmente notável para o conjunto I.

Para uma análise quantitativa do desempenho do modelo mkII, volta-se para a comparação entre os valores de $E(I=0)$ e $R_{\Omega}$ obtidos das curvas de polarização. A Tabela 17 apresenta tais valores, entre outros, obtidos dos resultados computacionais e os compara aos experimentais. Apesar do aumento do valor médio de $E(I=0)$ observado para os valores experimentais, estes encontram-se dentro do desvio experimental, concordando, também, com os resultados simulados. O aumento do valor médio experimental pode ser explicado largamente pelo aumento da pressão parcial de $\mathrm{O}_{2}$, fato que não foi considerado no modelo mkII. Mas pode ser observado que, no intervalo de vazão considerado, tal efeito é menos importante do que erros introduzidos nos resultados experimentais. Os valores de $R_{\Omega}$ obtidos da simulação também concordam amplamente com os experimentais, sendo que o conjunto III é o único apresentando diferenças estatisticamente significativas. Isto é satisfatório, dado a incerteza na natureza dos materiais utilizados no dispositivo experimental e em suas propriedades. Outra grandeza de interesse é o coeficiente de correlação de Pearson (R), calculado para os quatro conjunto de vazões, entre os resultados experimentais e computacionais. Como é possível observar na Tab. 17, os valores são muito próximos da unidade, indicando boa correlação linear positiva. 
Figura 42 - a) Curvas de polarização simuladas com o modelo FC mkII, para os conjuntos de vazão descritos na Tab. 1: I (o), II ( $\square)$, III $(\triangle)$ e IV $(\diamond)$. b) Comparação individual dos resultados simulados com resultados experimentais $(\times)$. O conjunto de vazões é indicado no título de cada subgráfico. As barras de erro nos resultados experimentais representam um desvio em relação à média.

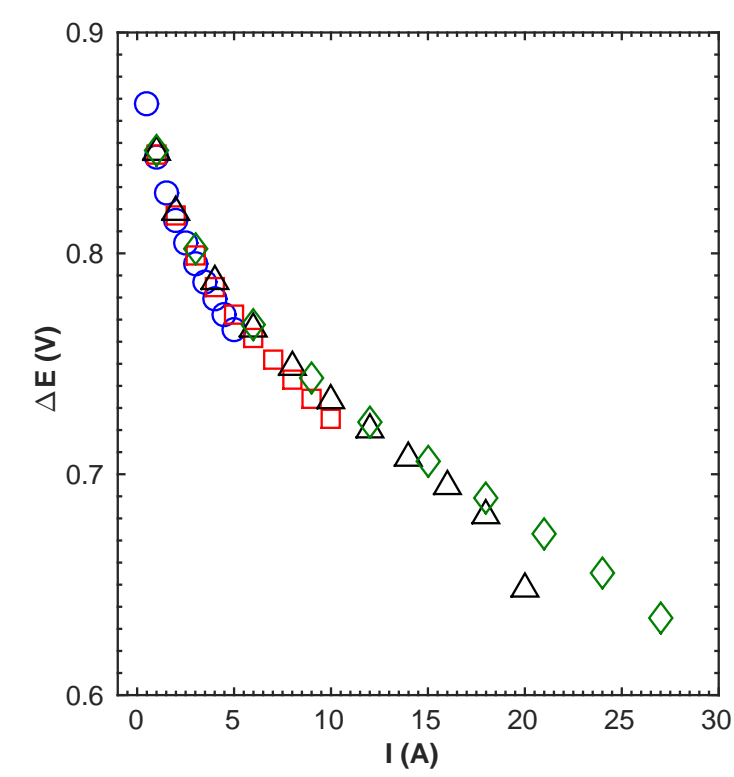

(a)
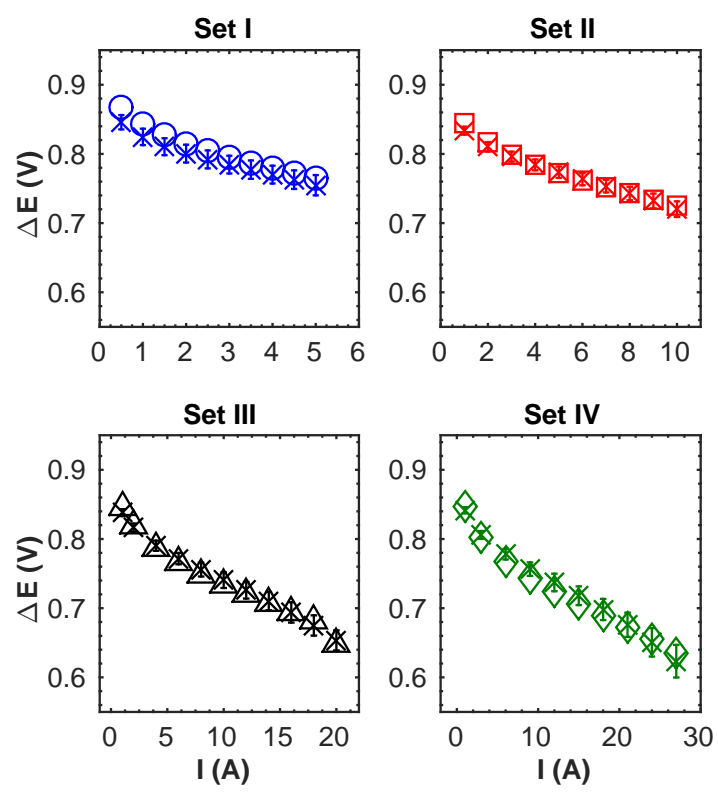

(b)

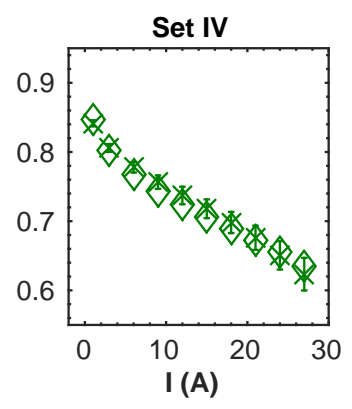

Fonte: Autoria própria.

Adicionalmente, são avaliados o erro médio (ME) e o erro absoluto máximo (MAE) entre o modelo FC mkII e os resultados experimentais, também apresentados na Tab. 17. Conforme apontado anteriormente, pode-se observar que o conjunto I possui os maiores $\mathrm{ME}$ e MAE, sendo que a tendência observada é I > IV II > III para ambos os valores. Nota-se que, exceto para o conjunto I, os valores relativos são da mesma ordem de magnitude do erro esperado devido ao critério de convergência do modelo FC mkII, $10^{-2}$, considerando que os valores de $E$ encontram-se entre $950-600 \mathrm{mV}$. Entende-se disto que as diferenças não são causadas por aspectos numéricos. Por outro lado, os erros do conjunto I são da mesma ordem de magnitude que desvios experimentais, sendo menores que estes para os outros conjuntos. Logo, tais valores, individualmente, não são suficientes para inferir boa concordância entre os resultados computacionais e experimentais. Isto é evidenciado na Figura 43 , que apresenta o resíduo relativo $\Delta_{\text {res }} E$, i.e. a diferença entre o modelo e os resultados experimentais, normalizados pelos resultados simulados, em função de $I$ para os conjuntos de vazão avaliado. Como pode ser observado, grande parte da região considerada dominada por polarização por queda ôhmica apresenta resíduos próximos de zero, ou dentro do intervalo de convergência do modelo. Combinado com a boa concordância dada pelos valores de $R_{\Omega}$, pode-se dizer que tal região é bem descrita pelo modelo. Por outro lado, tendências são observadas em todos os casos, i.e. o resíduo não é distribuído de maneira (aproximadamente) uniforme em torno de zero, o que sugere a contribuição de 
Tabela 17 - Grandezas analisadas para avaliação do desempenho do modelo FC mk2 em relação às curvas de polarização.

\begin{tabular}{cccc}
\hline Grandeza & Conjunto & Computacional & Experimental \\
\hline \multirow{4}{*}{$E(I=0)(\mathrm{mV})$} & I & 915 & $914 \pm 17$ \\
& II & 916 & $920 \pm 16$ \\
& III & 916 & $923 \pm 16$ \\
& IV & 917 & $927 \pm 16$ \\
$R_{\Omega}(\mathrm{m} \Omega)$ & I & $16,3 \pm 0,6$ & $15,0 \pm 1,6$ \\
& II & $11,1 \pm 0,5$ & $10,5 \pm 0,5$ \\
& III & $6,73 \pm 0,13$ & $7,71 \pm 0,61$ \\
ME $(\mathrm{mV})$ & IV & $5,85 \pm 0,13$ & $6,57 \pm 0,65$ \\
& I & 13,5 & - \\
& II & 2,41 & - \\
III & $-1,80$ & - \\
MAE (mV) & IV & $-4,34$ & - \\
& I & 13,5 & - \\
II & III & 4,28 & - \\
& IV & 8,94 & - \\
& I & 0,9992 & - \\
\hline Nota: Desvios indicados representam erros da regressão linear, no caso \\
de resultados computacionais, e desvio em relação à média, no \\
caso de resultados computacionais.
\end{tabular}

Fonte: Autoria própria.

fenômenos físicos não considerados no modelo mkII. Corroborando os resultados da Tab. 17, e a inspeção visual da Fig. 42b, isto é particularmente notável no caso do conjunto I, sendo que a Fig. 43 indica o mesmo nos demais conjuntos, ao contrário da análise acima. As observações sugerem que a redução de dimensionalidade, i.e. a análise apenas de grandezas pontuais, como a resistência total, potencial de circuito aberto e até mesmo o coeficiente de correlação; pode ser detrimental ao processo de validação, mascarando efeitos potencialmente importantes. Tais grandezas fornecem informações valiosas, mesmo quando avaliadas individualmente, porém observa-se que são incapazes de resumir toda a informação de maneira segura.

Considerando agora as superfícies de distribuição de corrente, em nível qualitativo, são comparadas na Figura 44 superfícies experimentais e computacionais, em valores representativos da corrente relativa para os conjuntos de vazão I, II e III. Apesar da nítida distinção entre resultados experimentais e computacionais, em particular pela maior homogeneidade e efeitos de borda destes, a evolução observada em função do aumento de I é similar: observa-se uma localização significativa da corrente para regiões próximas às entradas de gás, e um aumento do intervalo de valores observados em cada superfície. As 
Figura 43 - Resíduo relativo entre curvas de polarização simuladas pelo modelo FC mkII e experimentais. Conjunto de vazão são indicados no título de cada subgráfico: I $(\times)$, II $(\times)$, III $(\times)$ e IV $(\times)$. A linha sólida preta indica $\Delta_{\text {res }} E=0$, enquanto as linhas tracejadas indicam o limite relativo de convergência do modelo, $10^{-2}$. As barras de erro são os desvios experimentais em relação à média, normalizados pelos respectivos valores simulados.
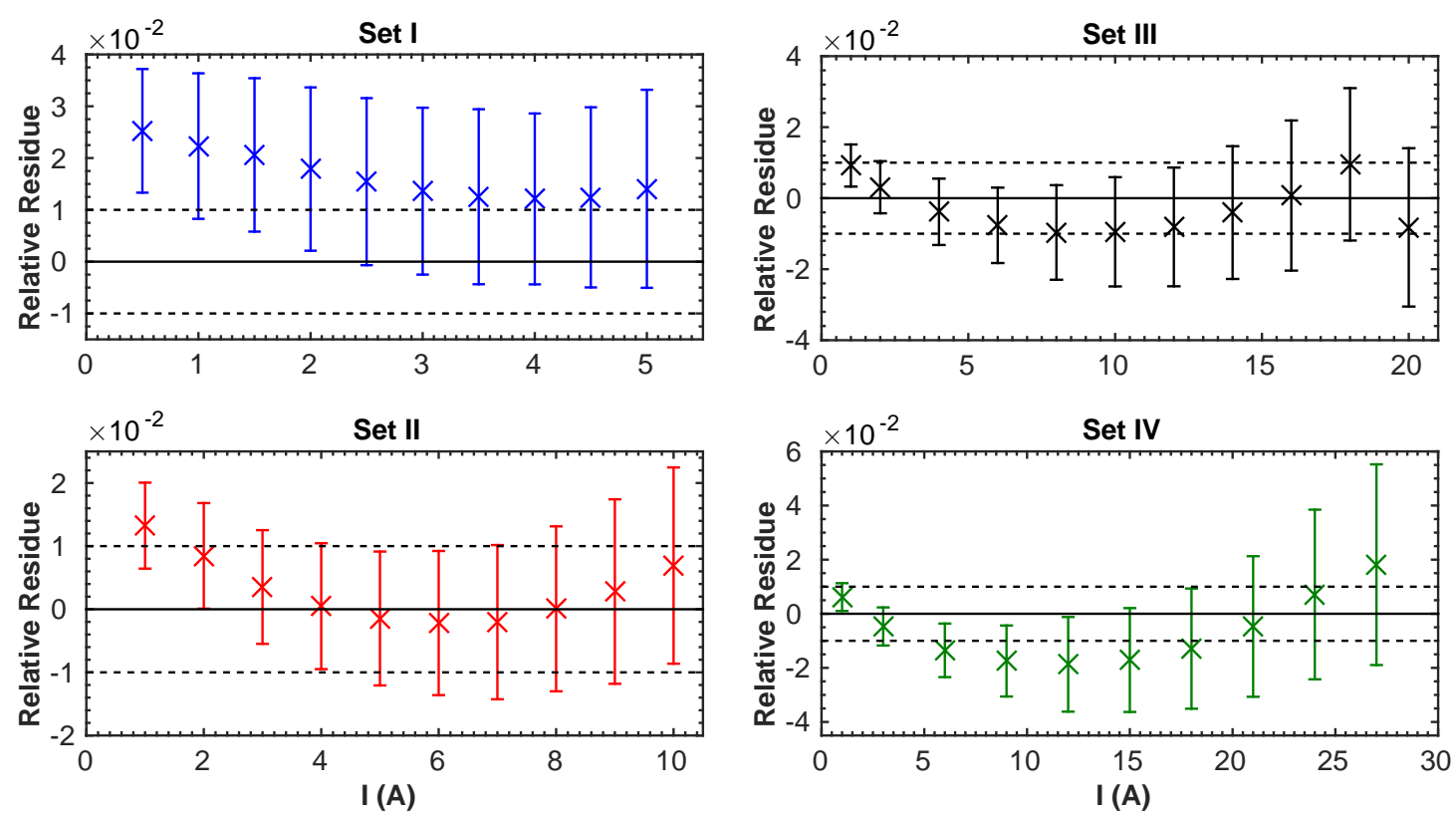

superfícies são qualitativamente similares para valores iguais de $I_{R}$ para todos os conjuntos, de maneira análoga ao apresentado no Capítulo 5. Um ponto digno de nota são os maiores valores de corrente observados, em geral, para os resultados experimentais. Isto pode ser observado na Fig. 44, mas também é obtido ao somar-se sobre todos os pontos de coleta, resultando em valores consistentemente acima de $I$, sendo de $\approx 1,23 \times I$ para os resultados experimentais, e de $\approx 0,92 \times I$ para os computacionais. Devido a esta discrepância, as comparações abaixo serão feitas normalizando-se os resultados em função da soma de I sobre os pontos de coleta.

Levando em conta as diferenças de corrente total de cada superfície, uma análise semiquantitativa será feita. De modo a visualizar a variabilidade experimental de cada superfície, e portanto possibilitar uma comparação mais rigorosa entre os resultados experimentais e computacionais, será utilizada a representação exemplificada pela Figura 45, e descrita na Seção 4.2.2.6. Considerando os efeitos de localização de correntes observadas na Fig. 44, a correlação com estas é facilmente observada na Fig. 45c, que apresenta a distribuição de corrente linearizada para $I=10$ A do conjunto II de vazões. A Fig. 45 é largamente representativa do comportamento observado para os demais conjuntos de vazão, à medida que os valores de corrente se aproximam da estequiometria estabelecida (ver Anexo A). Por outro lado, de maneira notável, as superfícies simuladas para altos valores de $I$ nos conjuntos III e IV diferem de maneira significativa, conforme apresentado e discutido abaixo.

De maneira análoga à análise realizada para as curvas de polarização, serão avaliados o 
Figura 44 - Superfícies de corrente experimentais (linha superior) e simuladas (linha inferior) para valores representativos de $I_{R}$ dos conjuntos I, II e III, indicados em cada coluna. As entradas de gases se dão pelo canto inferior esquerdo e direito para o cátodo e ânodo, respectivamente. As saídas se são no canto superior direito e esquerdo, para o cátodo e ânodo, respectivamente.

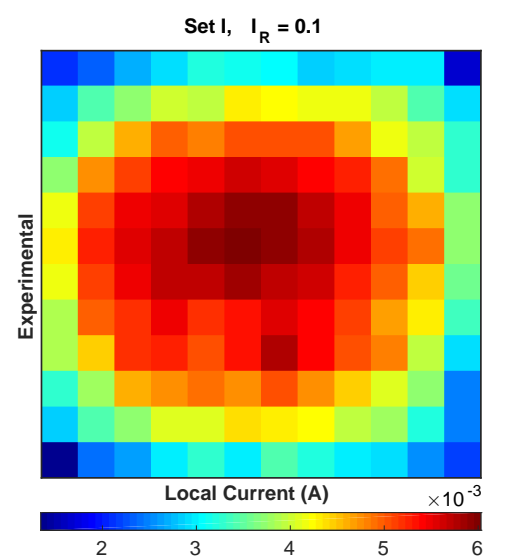

(a)

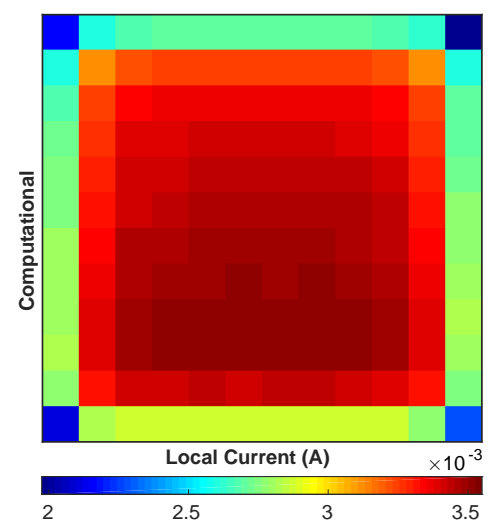

(d)

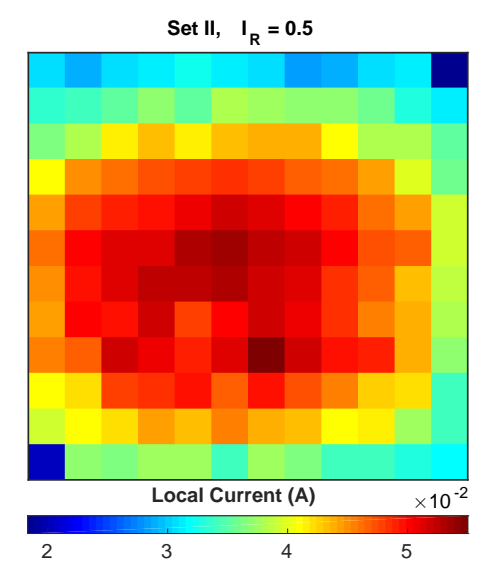

(b)

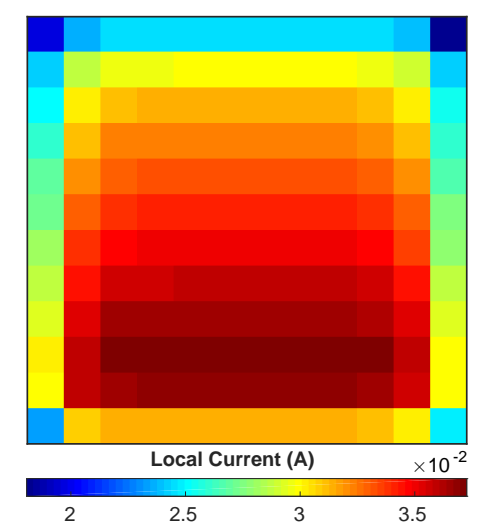

(e)

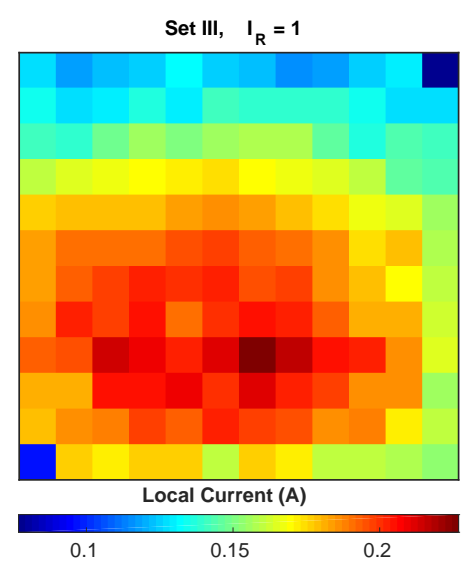

(c)

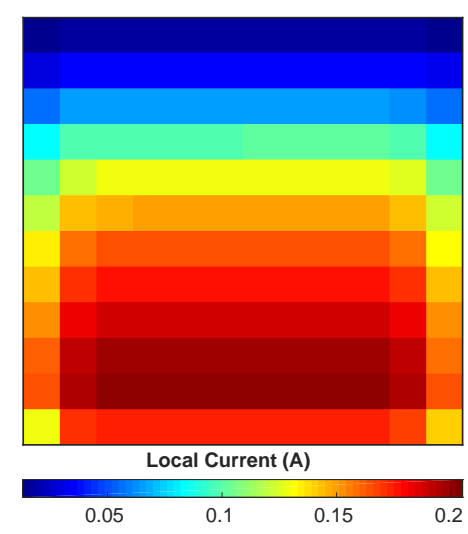

(f)

Fonte: Autoria própria.

ME, MAE, R e os resíduos. A Figura 46 apresenta os valores calculados de ME, MAE e R para cada distribuição linearizada de corrente em função da corrente total. Como pode ser observado na Fig. 46a, os valores de ME encontram-se muito próximos de 0 $\left(\approx 10^{-17}\right)$, enquanto os valores de MAE encontram-se largamente agrupados em $\approx 10^{-3}$. O motivo de tal discrepância é prontamente conjecturado, observando-se as distribuições na Fig. 45: o erro, ou resíduo, distribui-se quase igualmente ao redor de zero, para uma dada distribuição de corrente. Considerando apenas o valor de ME, isto é indicativo que o modelo é capaz de reproduzir de maneira geral os resultados experimentais. Por outro lado, os valores de MAE indicam certa consistência nos desvios entre os resultados computacionais e experimentais, sugerindo uma deficiência da formulação matemática ou uma parametrização inadequada. Por outro lado, a Fig. 46b apresenta valores de R relativamente baixos, se comparados aos valores obtidos para as curvas de polarização (Tab. 17). Os valores observados ainda indicam boa correlação linear entre os resultados 
Figura 45 - Distribuições de corrente linearizadas, para o conjunto de vazões II, experimentais $(\times)$ e computacionais $(\square)$, para as correntes a) $I=1$, b) 5 e c) 10 A. As barras de erro nos resultados experimentais representam um desvio em relação à média. A entrada de gases catódica se dá em altos valores da abscissa, enquanto a saída se dá para baixos valores.

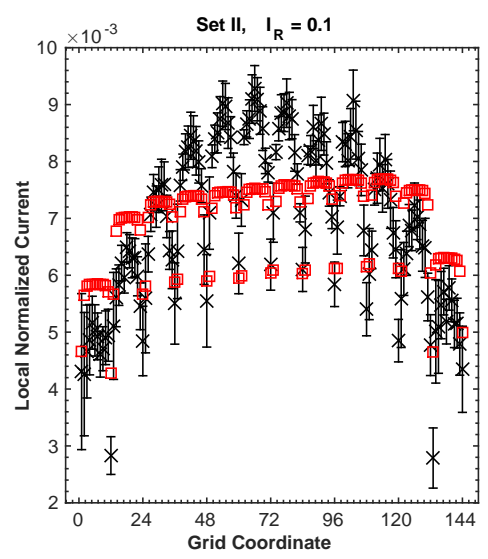

(a)

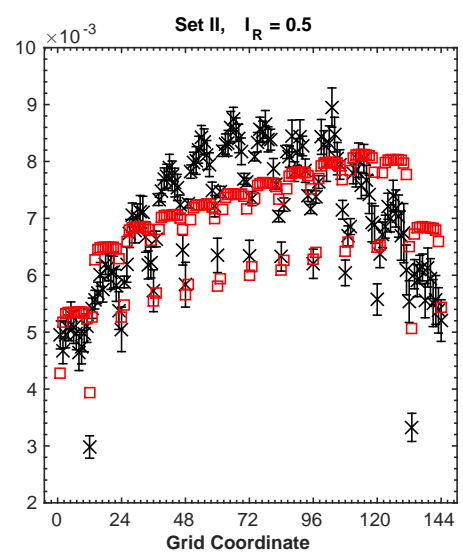

(b)

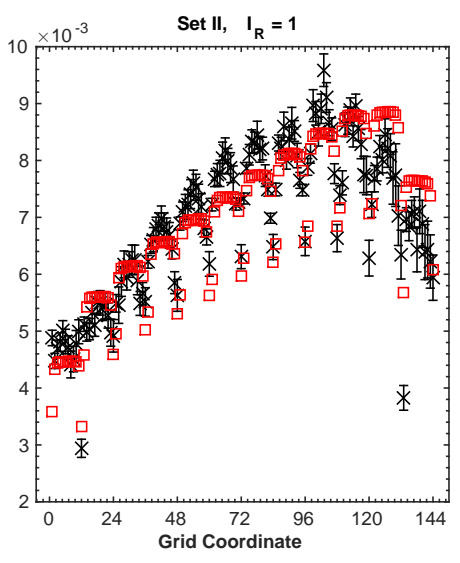

(c)

Fonte: Autoria própria.

computacionais e experimentais, sendo importante notar que o desvio não é levado em conta. Entretanto, nota-se que a região de polarização de queda ôhmica, basicamente os valores médios dos intervalos de corrente de cada conjunto, apresentam os menores valores de $\mathrm{R}$, sendo que é a região de melhor concordância no caso das curvas de polarização. Isto é observado na Fig. 45, onde observa-se que os resultados computacionais apresentam localização da corrente nas regiões próximas da entrada de gases já em valores de $I \geq 5 \mathrm{~A}$, enquanto que os resultados experimentais mostram melhor distribuição da corrente mesmo em $I=7$ A. Por outro lado, a região de polarização por transporte de massa, i.e. em altos valores de $I$, o valor de $\mathrm{R}$ torna a aumentar. Isso também é percebido na Fig. 45, em $I=10$ A, onde a localização de corrente é observada em ambas distribuições. Por outro lado, conforme notado acima, para os conjuntos III e IV, a correlação em altos valores de $I$ ainda são relativamente baixos, dado que as distribuições computacionais apresentam forte localização da corrente próxima à entrada de gases, enquanto que as distribuições experimentais apresentam melhor distribuição (ver Anexo A). Isto é verdade mesmo considerando valores normalizados de corrente, o que indica desvios particularmente graves do modelo em relação à realidade, neste caso.

Por fim, são analisados os resíduos relativos, $\Delta_{\text {res }} I$, das distribuições linearizadas de corrente. A Figura 47 apresenta os resíduos relativos para as distribuições apresentadas na Fig. 45, i.e. para o conjunto II de vazões. Os resíduos para os demais conjuntos de vazões são apresentados no Anexo A. A análise dos resíduos corrobora o sugerido acima, isto é, as distribuições de corrente simuladas pelo modelo mkII diferem marcadamente das experimentais. De fato, os resíduos encontram-se largamente fora do limite de convergência do modelo, e mostram forte tendência parabólica. Tal tendência também é observada no 
Figura 46 - a) Erro médio (ME, símbolos vazios) e erro absoluto médio (MEA, símbolos cheios) e b) coeficiente de correlação de Pearson (R), em função da corrente total aplicada, entre as distribuições linearizadas de corrente computacionais e experimentais: conjunto I (o), II ( $\square$ ), III $(\triangle)$, e IV $(\diamond)$. A linha sólida preta em a) representa erro nulo.

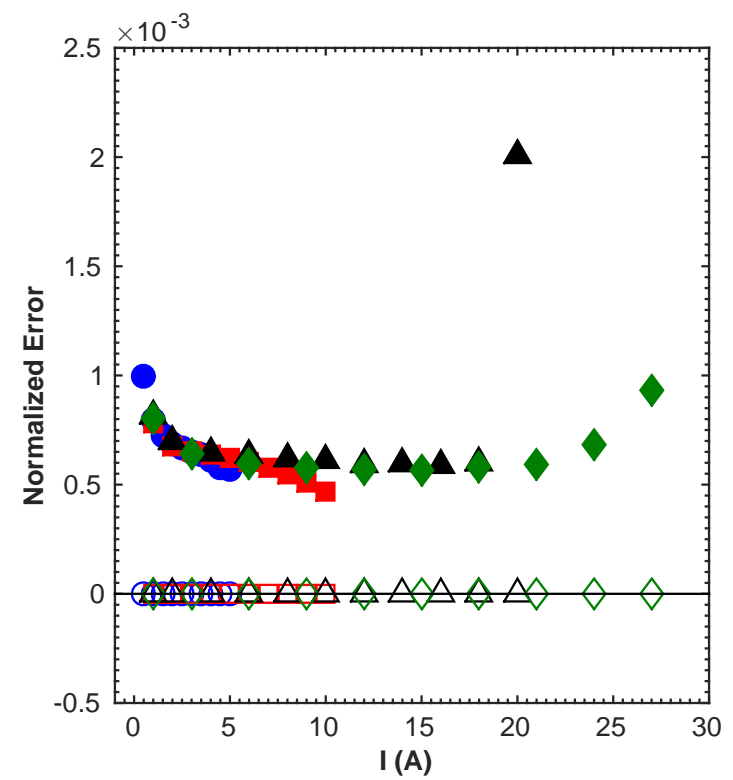

(a)

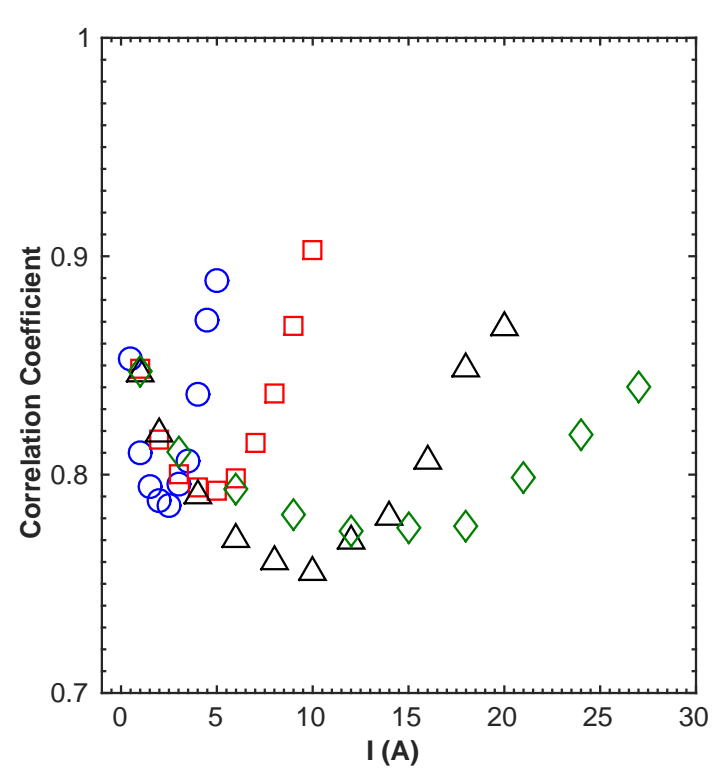

(b)

caso das curvas de polarização, porém de maneira menos marcante e, possivelmente, por motivos diferentes. Também observa-se que no caso de altas correntes, $I=10$ A neste caso, os resíduos mostram uma tendência significativa, além de se encontrarem largamente fora do limite de convergência do modelo; apesar do alto valor de $\mathrm{R}$ em comparação às demais (Fig. 46b). Isto corrobora a ideia que a redução de dimensionalidade pode super-simplificar o problema, e levar à interpretações erradas dos resultados.

Como ilustração de um caso particularmente grave de falha de previsão do modelo, será analisada a distribuição de corrente linearizada do conjunto III de vazões, em $I=20 \mathrm{~A}$. A Figura 48a apresenta as distribuições computacionais e simuladas, além do resíduo relativo entre estas. Em primeiro lugar, considere a concordância entre o potencial de eletrodo simulado e experimental para tal valor de corrente, sendo de 0,648 e 0,653 $0,014 \mathrm{~V}$, respectivamente. Os resultados são estatisticamente iguais, e com uma margem relativamente pequena, considerando que o desvio experimental em relação à média é de 2, $2 \%$. Por outro lado, a Fig. 48a mostra diferenças marcantes entre as distribuições de corrente simulada e experimental. É possível observar que a grande maioria dos pontos (115 de 144) são estatisticamente diferentes entre si, mantendo em mente que os desvios experimentais em relação à média são significativamente maiores que os observados para a curva de polarização (média $\approx 5 \%$, máximo $\approx 15 \%$ ). Por outro lado, dado o quão diferentes são as distribuições computacional e experimental em comportamento ao longo da posição no grid, é plausível sugerir que os pontos estatisticamente iguais o são por mera coincidência. Isto é corroborado, e explicitado, analisando a distribuição do resíduo 
Figura 47 - Resíduo relativo entre as distribuições de corrente linearizadas simuladas pelo modelo FC mkII e experimentais, usando o conjunto de vazões II: a) $I=1$, b) 5 e c) 10 A. A linha sólida preta indica $\Delta_{\text {res }} I=0$, enquanto as linhas tracejadas indicam o limite relativo de convergência do modelo, $10^{-2}$. As barras de erro são os desvios experimentais em relação à média, normalizados pelos respectivos valores simulados.

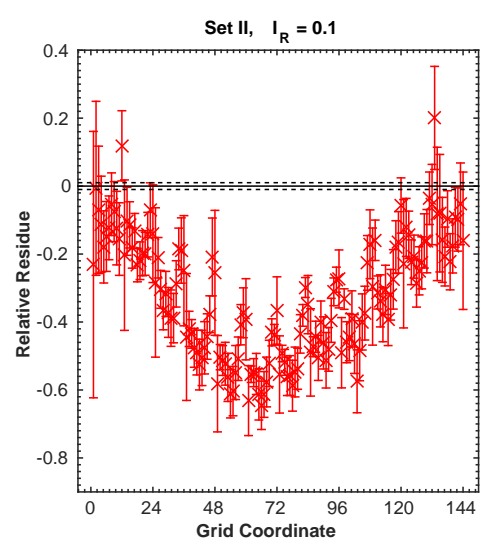

(a)

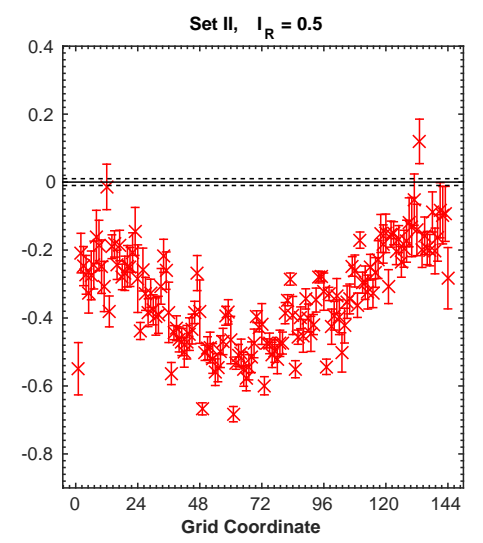

(b)

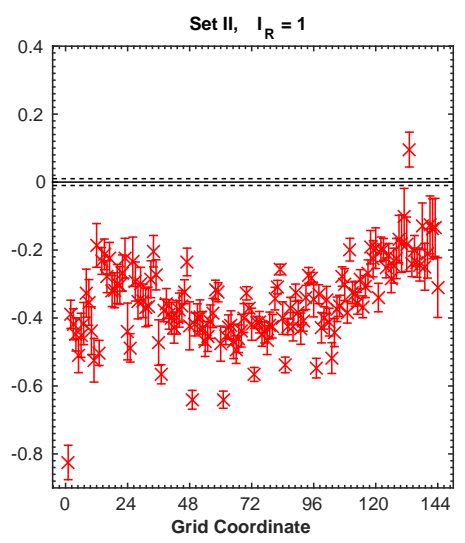

(c)

Fonte: Autoria própria.

relativo na Fig. 48b. Existe uma forte tendência na distribuição em torno de zero, sendo que os erros relativos são da ordem de $10^{0}$, marcadamente superiores aos observados para o conjunto II e a maioria das demais distribuições. Como mencionado anteriormente, algo similar é observado para o conjunto IV, em $I=27$ A (ver Anexo A), porém é notável que de maneira menos marcante, com resíduos relativos na ordem de $10^{-1}$.

A comparação dos aspectos elétricos entre os resultados computacionais do modelo FC mkII e experimentais evidencia a relativa facilidade em reproduzir aspectos globais de dispositivos experimentais, neste caso as curvas de polarização, quando considerado que o modelo mkII apresenta aproximações bem conhecidas e desconsidera efeitos tomados como importantes em tais dispositivos, e.g. a dinâmica da água na fase líquida. Por outro lado, quando considerada a distribuição espacial de corrente, um aspecto mais sensível aos efeitos locais, as previsões do modelo falham de maneira notável. Isto sugere que curvas de polarização são pouco restritivas na validação de modelos, tanto em relação à descrição dos efeitos físicos como para a parametrização. Ao mesmo tempo, evidencia-se o potencial de se utilizar distribuições de corrente para uma validação mais rigorosa de modelos computacionais. Deve-se apontar, ainda, que vários fenômenos físicos contribuem para estes resultados, portanto o uso de diversas variáveis, e a validação independente destas, é imprescindível para a obtenção de modelos capazes de reproduzir e prever corretamente o comportamento de dispositivos experimentais.

\subsubsection{Aspectos térmicos}

Considerados os aspectos elétricos disponíveis, volta-se agora para os aspectos térmicos. Em primeiro lugar, será considerada a temperatura dos compartimentos anódico e catódico 
Figura 48 - a) Distribuições de corrente linearizada simulada com o modelo FC mkII $(\triangle)$ e experimentais $(\times)$, e b) resíduo relativo entre as curvas de a). Conjunto de vazões III e corrente total $I=20 \mathrm{~A}$. As barras de erro em a) representam um desvio em relação à média, enquanto as barras de erro em b) são os desvios experimentais normalizados pelos respectivos valores simulados. A linha sólida preta indica $\Delta_{\text {res }} I=0$, enquanto as linhas tracejadas indicam o limite relativo de convergência do modelo, $10^{-2}$. As barras de erro são os desvios experimentais em relação à média, normalizados pelos respectivos valores simulados.

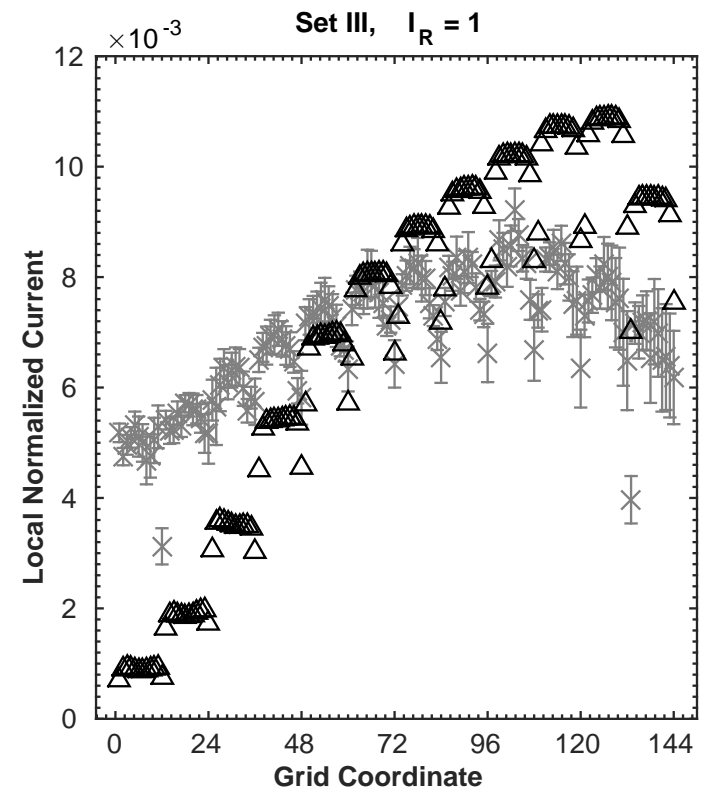

(a)

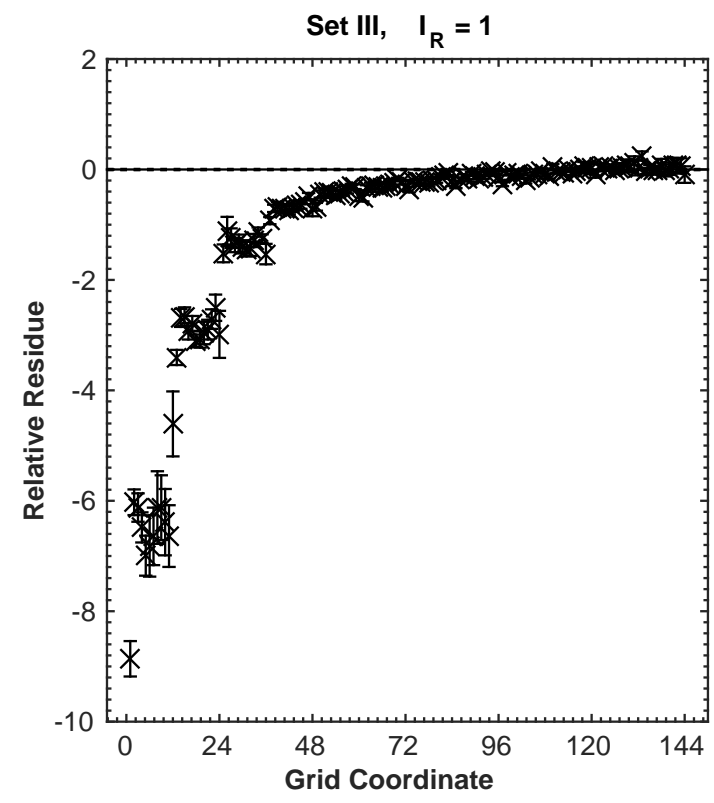

(b)

Fonte: Autoria própria.

ao longo da curva de polarização. As Figuras 49 e 50 apresenta as curvas de temperatura média anódica e catódica, respectivas, simuladas com o modelo FC mkII e experimentais. Em primeiro lugar, é possível observar que, para ambos os casos, as variações de temperatura ao longo da curva de polarização são relativamente pequenas, atingindo $\approx 1 \mathrm{~K}$ no caso da temperatura anódica para o conjunto IV. Apesar da pequena variação, observa-se nas Figs. 49a e 50a uma tendência de aumento da temperatura ao longo da curva de polarização, tanto nos resultados computacionais como experimentais, para os conjuntos de vazão II, III e IV. No caso do conjunto I, observa-se que, dentro do desvio experimental, a temperatura dos compartimentos anódico e catódico permanecem aproximadamente constantes, o que também é observado para os resultados computacionais.

Considere agora as curvas individuais de temperatura do compartimento anódico (Fig. 49b). Uma inspeção visual indica boa concordância entre os resultados computacionais e experimentais para todos os conjuntos, em particular para os conjuntos I e II. Os valores de ME, MAE e R são apresentados na Tabela 18, e suportam a boa concordância entre os resultados computacionais e experimentais. Os valores de ME e MAE encontram-se largamente dentro da precisão das medidas experimentais, $\sim 10^{-1} \mathrm{~K}$, enquanto que os valores de $\mathrm{R}$ são elevados, indicando forte correlação positiva entre os resultados. É 
Figura 49 - a) Curvas de temperatura do compartimento anódico obtidas ao longo da curva de polarização, computacionais e experimentais $(\times)$, para os conjuntos de vazão I (o), II ( $\square)$, III $(\triangle)$, e IV $(\diamond$. b) Comparação individual dos resultados simulados aos experimentais. O conjunto de vazões é indicado no título de cada subgráfico. As barras de erro nos resultados experimentais representam um desvio em relação à média.

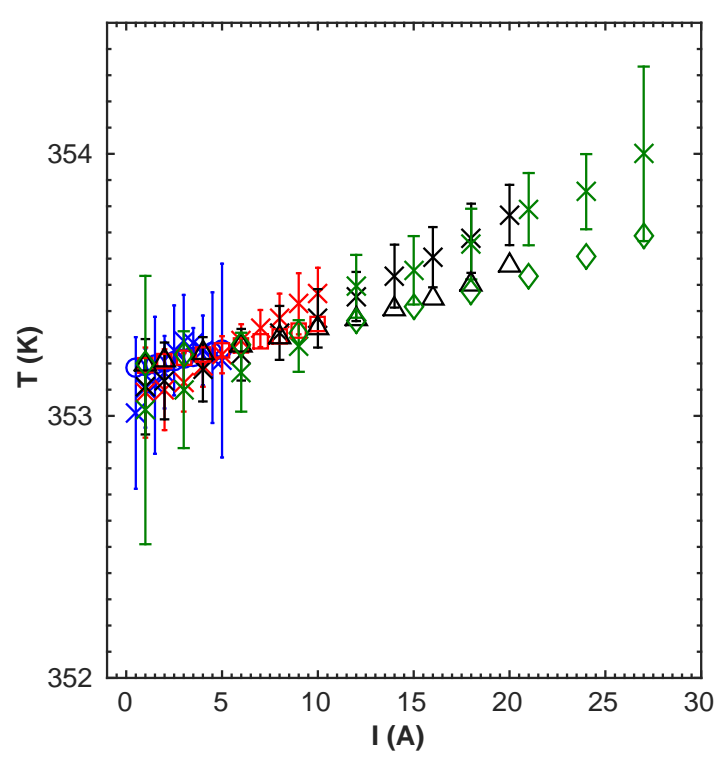

(a)
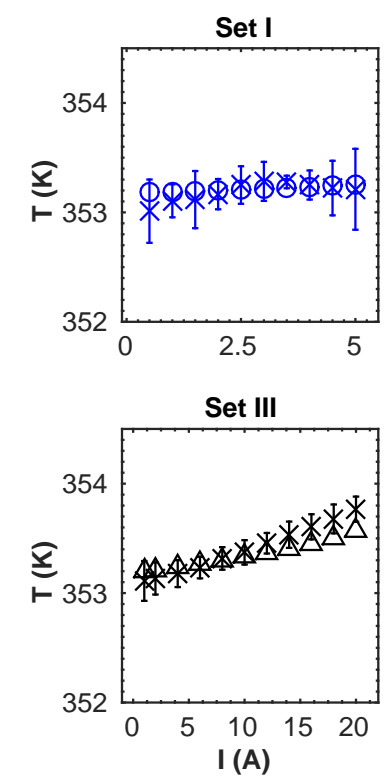

(b)

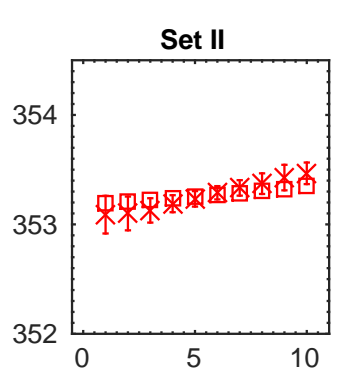

Set IV

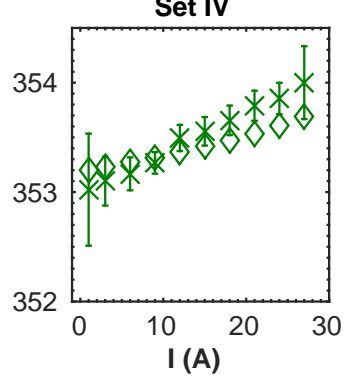

Fonte: Autoria própria.

notável, no entanto, o baixo valor de R obtido para o conjunto I. Isto se deve às flutuações do valor médio obtido para os resultados experimentais, levando a desvios em relação à média superiores aos demais conjuntos. Apesar do relativo baixo valor de $\mathrm{R}$, tais desvios asseguram que, dado o número de replicatas, os resultados experimentais são estatisticamente iguais aos computacionais.

Por fim considere as curvas individuais de temperatura do compartimento catódico (Fig. 50b). De maneira similar ao observado para as temperaturas anódicas, observa-se boa concordância entre os resultados computacionais e experimentais para os conjuntos I e II. Os resultados de ME, MEA e R (Tab. 18) corroboram tal observação, sendo que nota-se uma situação análoga à temperatura anódica para o conjunto I, i.e. um baixo valor de $\mathrm{R}$ mas concordância estatística entre os resultados. Por outro lado, para as curvas dos conjuntos III e IV, observa-se que os resultados computacionais superestimam a temperatura catódica em altos valores de corrente. Os valores de ME, MEA e $\mathrm{R}$ ainda sugerem boa concordância entre os resultados, porém o comportamento observado para os resultados computacionais é significativamente diferente dos experimentais. Isto difere do observado para as temperatura anódicas, onde apesar da sugestão de que os resultados computacionais subestimam os valores de temperatura, estes apresentam comportamentos muito similares aos experimentais.

Concluindo a análise das temperaturas, a Figura 51 apresenta os resíduos relativos, 
Figura 50 - a) Curvas de temperatura do compartimento catódico obtidas ao longo da curva de polarização, computacionais e experimentais $(\times)$, para os conjuntos de vazão I (०), II ( $\square)$, III $(\triangle)$, e IV $(\diamond$. b) Comparação individual dos resultados simulados aos experimentais. O conjunto de vazões é indicado no título de cada subgráfico. As barras de erro nos resultados experimentais representam um desvio em relação à média.

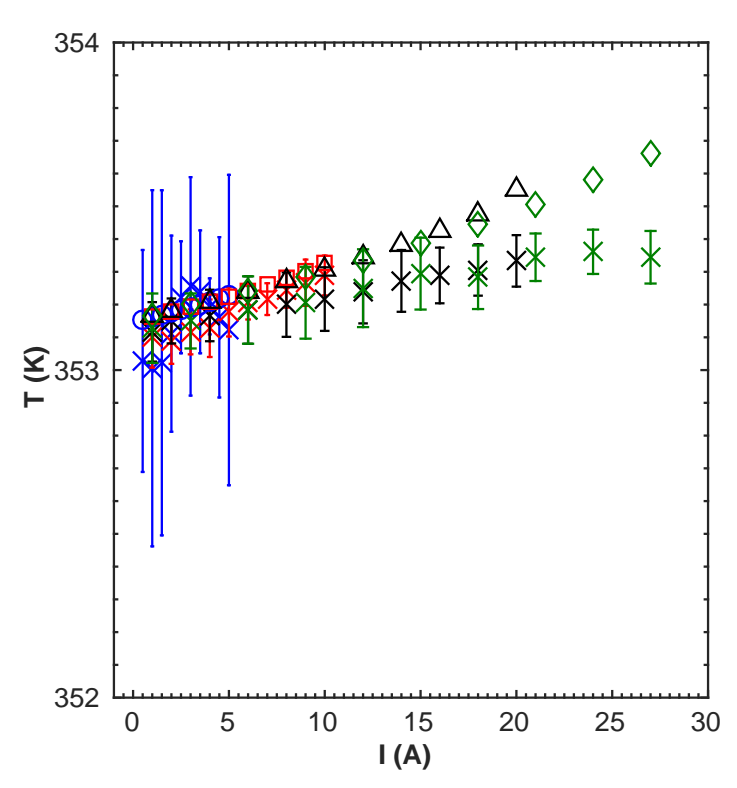

(a)

Fonte: Autoria própria.
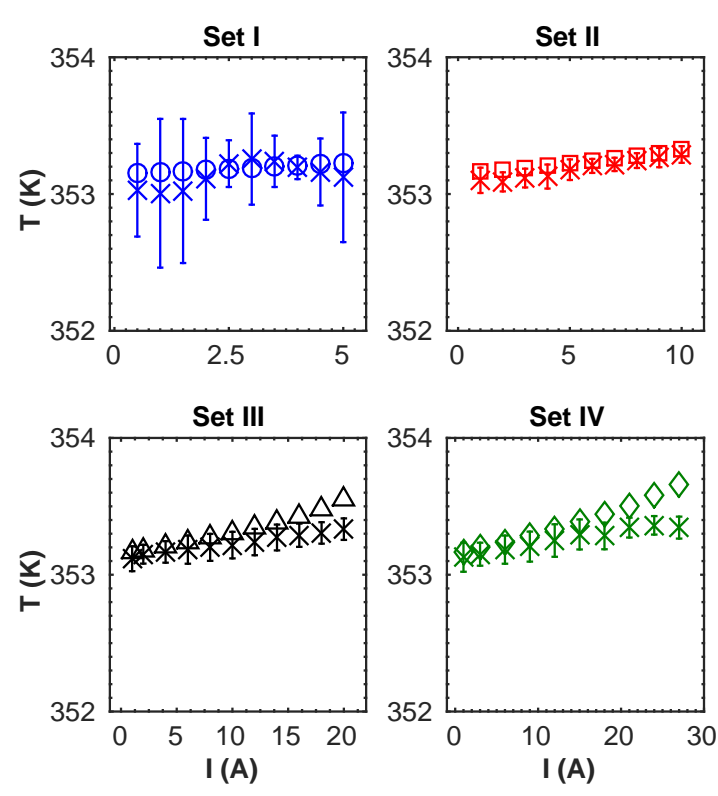

(b)

Tabela 18 - Grandezas analisadas para avaliação do desempenho do modelo FC mk2 em relação às curvas de temperaturas anódica e catódica.

\begin{tabular}{ccccccc}
\hline \multirow{2}{*}{ Conjunto } & ME (K) & Ânodo & MAE (K) & R & ME (K) & Cátodo \\
& MAE (K) & R \\
\hline I & 0,03 & 0,06 & 0,7111 & 0,05 & 0,08 & 0,5835 \\
II & 0,00 & 0,07 & 0,9951 & 0,05 & 0,05 & 0,9856 \\
III & $-0,05$ & 0,10 & 0,9956 & 0,10 & 0,10 & 0,9885 \\
IV & $-0,08$ & 0,17 & 0,9863 & 0,13 & 0,13 & 0,9560 \\
\hline
\end{tabular}

Fonte: Autoria própria.

$\Delta_{\text {res }} T$, para as temperaturas dos compartimentos anódico e catódico. Em ambos os casos, observa-se para o conjunto I uma distribuição ao redor de $\Delta_{\text {res }} T=0$, com os desvios normalizados cobrindo o valor nulo em todos os pontos. A distribuição não é exatamente uniforme ao redor de zero, o que sugere a existência de efeitos não considerados, porém os resíduos corroboram a boa concordância entre os resultados computacionais e experimentais. No caso dos conjuntos II, III e IV, para as temperaturas anódicas, observa-se que grande parte dos desvios normalizados cobrem o valor nulo, porém apresenta-se uma tendência mais pronunciada que para o conjunto I. Os mesmo acontece para as temperatura catódicas, porém com tendência diferentes, e menor abrangência da linha em $\Delta_{\text {res }} T=0$. Conforme sugerido pela análise acima, o modelo FC mkII subestima de maneira geral as temperaturas anódicas nos conjuntos II, III e IV, particularmente para altos valores de $I$. No caso das 
Figura 51 - Resíduo relativo entre curvas de temperaturas a) anódicas e b) catódicas, simuladas pelo modelo FC mkII e experimentais. Conjunto de vazão são indicados no título de cada subgráfico: I $(\times)$, II $(\times)$, III $(\times)$ e IV $(\times)$. A linha sólida preta indica $\Delta_{\text {res }} T=0$. As barras de erro são os desvios experimentais em relação à média, normalizados pelos respectivos valores simulados.
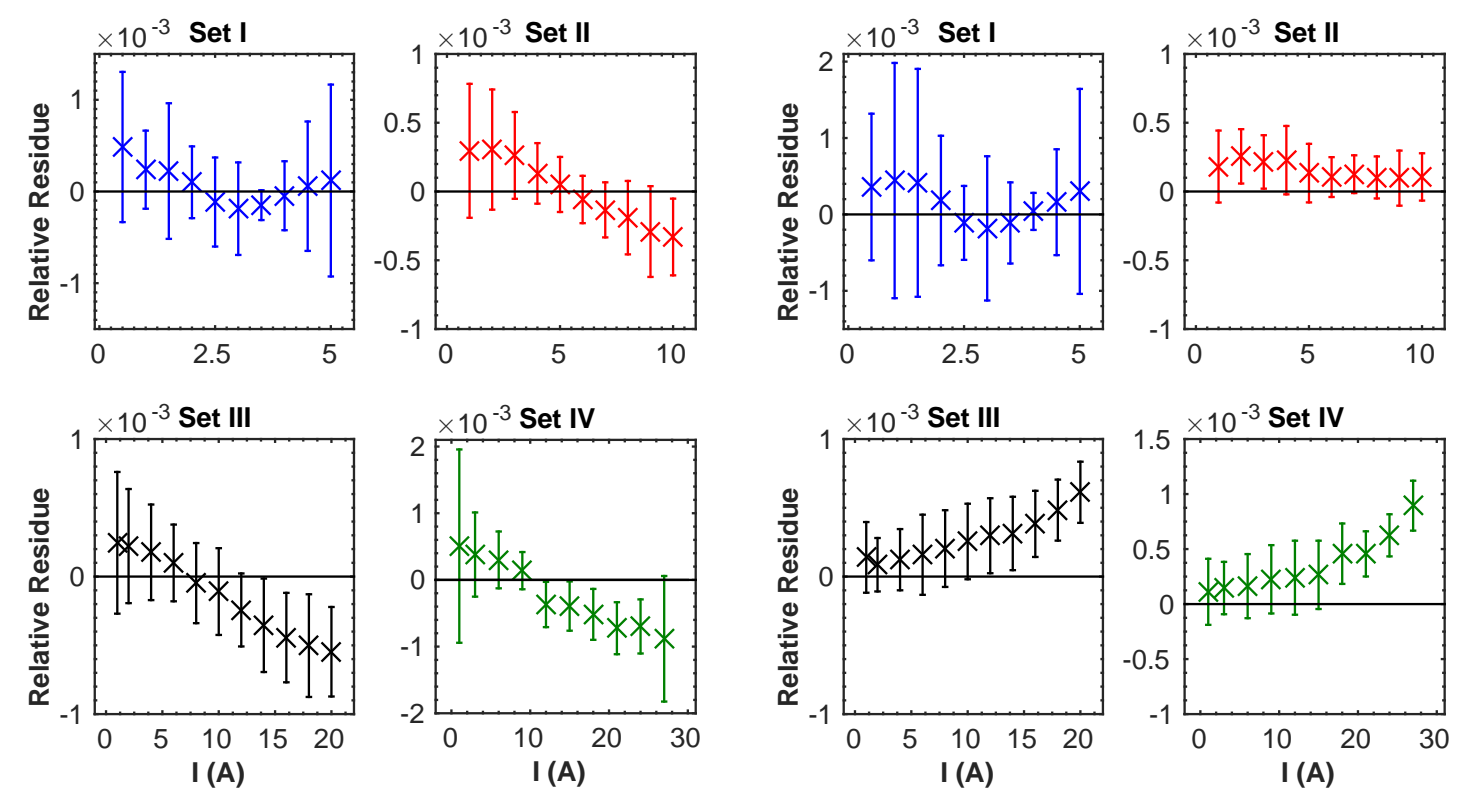

(a)

(b)

Fonte: Autoria própria.

temperaturas catódicas, o inverso é observado, o que sugere que efeitos diferentes estão sendo negligenciados em cada caso. Por fim, deve-se notar que todos os resíduos relativos encontram-se dentro da faixa de convergência do modelo numérico. Isto não significa que os resultados são considerados iguais, ou mesmo que as tendência observadas sejam artefatos, apenas que erros numéricos podem afetar a concordância entre os resultados computacionais e experimentais.

Voltando-se agora para as superfícies de temperatura, nota-se novamente que, como descrito na Seção 4.2.2.6, estas serão comparadas às superfícies experimentais após transformação para desvios de temperatura. Nota-se, ainda, conforme descrito no Apêndice $\mathrm{E}$, que foram utilizados dados experimentais para estabelecimento da escala de temperatura referente ao calor simulado, sendo que dois pontos podem ser levantados: i) as temperaturas catódicas simuladas (Fig. 50) são, em geral, maiores que as experimentais; e ii) os desvios de temperatura observados nas superfícies experimentais (Figs. 14 e 15 , considerando $\Delta \mathbf{T}_{\exp }=\mathbf{T}_{\exp }-T_{0}$ ) são significativamente maiores que as registradas para o compartimento catódico. Tais pontos sugerem fontes de erro na comparação entre as superfícies de calor transformadas e de temperatura, tornando completamente inviável uma comparação quantitativa. Espera-se, no entanto, uma correlação entre os resultados computacionais e experimentais, justificando assim uma comparação qualitativa entre as superfícies. 
Prosseguindo conforme a Seção 6.2.1.1, são comparadas, na Figura 52, as distribuições de desvio de temperatura computacionais e experimentais para os valores representativos de $I_{R}$ para os conjuntos I, II e III. De maneira similar às distribuições de correntes (Fig. 44), a distinção entre as superfícies experimentais e computacionais é nítida, assim como em relação à distribuição de valodes de temperatura (calor). Uma diferença digna de nota refere-se às regiões onde as temperaturas mais altas se encontram. No caso das superfícies experimentais, os valores encontram-se concentrados próximos à entrada de gases anódica em baixos valores de $I_{R}$, em seguida concentrando-se na região central do grid, em altos valores de $I_{R}$. Por outro lado, as superfícies computacionais apresentam uma distribuição relativamente homogênea em baixos valores de $I_{R}$, notando-se valores altos próximos à entrada de gases catódica, concentrando-se nas regiões inferiores à medida que ${ }_{R} I$ aumenta. Em relação ao intervalo de valores, a diferença entre os resultados experimentais e computacionais é marcante, chegando a duas ordens de grandeza. A determinação da escala de temperatura, como descrita no Apêndice E, provavelmente contribui para esta diferença, porém suspeita-se que a formulação do modelo é o principal contribuinte.

Para análise das distribuições de temperatura, também serão utilizadas os gráficos linearizados, similar ao apresentado para as superfícies de corrente. A Figura 53 apresenta as superfícies linearizadas de temperatura experimentais e computacionais, normalizadas pela respectiva soma sobre todos os índices do grid, para valores selecionados de $I$ do conjunto de vazões II. Exemplos para os demais conjuntos podem ser encontrados no Anexo B. Apesar das complicações na análise, a informação contida na Fig. 53 (e nas apresentadas no Anexo B) é particularmente marcante: o modelo FC mkII falha gravemente em reproduzir o comportamento observado nas superfícies de temperatura experimentais. Diferentemente das distribuições de corrente, onde tendências das superfícies em função de $I$ eram similares, apresentando relativa boa correlação entre os resultados; as distribuições de temperatura simuladas são incapazes de descrever virtualmente todos os aspectos das superfícies experimentais. É possível observar em alguns casos, como na Fig. 53a, uma completa inversão de comportamento, onde pontos do grid pertencentes à região central de uma mesma coluna (e.g. de 1 a 6 , ou 13 a 18) apresentam $\Delta T_{i j}<0$, sendo ainda significativamente menores que as posições extremas. Em outros casos no entanto, para altos valores de $I$, como na Fig. 53c, certa correlação pode ser visualizada. Uma inspeção cuidadosa revela correlação com as distribuições de corrente (Fig. 45c), tanto simulada como experimentais, em relação à um aumento da temperatura nas regiões próximas das entradas de gases. Porém, tal comportamento não é observado na maioria das distribuições de temperatura experimentais. É notável, no entanto, que para $I=27 \mathrm{~A}$ do conjunto IV (Fig. ??), os comportamento observados dentro de uma mesma coluna de posições são similares, quando comparada a região central do dispositivo. Isso não redime o modelo FC mkII, dado que as regiões próximas às entradas e saídas de gases ainda são 
Figura 52 - Superfícies de desvios de temperatura experimentais (linha superior) e simuladas (linha inferior) para valores representativos de $I_{R}$ dos conjuntos I, II e III, conforme indicado em cada superfície. As entradas de gases se dão pelo canto inferior esquerdo e direito para o cátodo e ânodo, respectivamente. As saída se dão no canto superior direito e esquerdo, para o cátodo e ânodo, respectivamente.

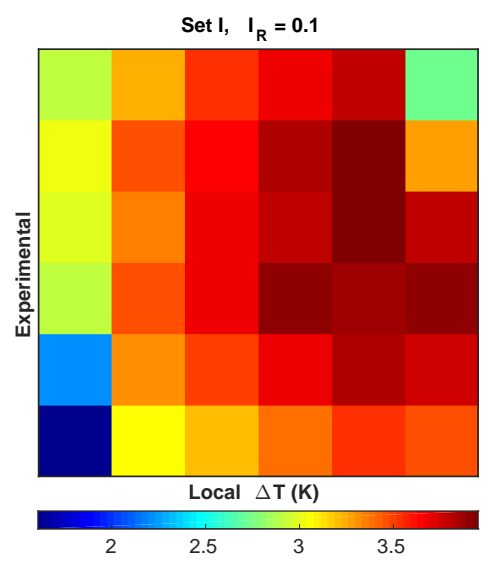

(a)

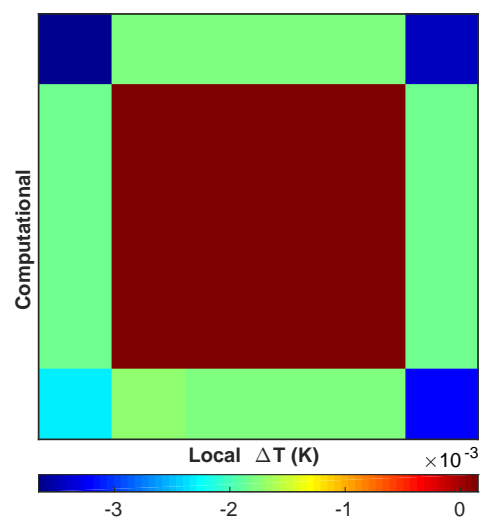

(d)

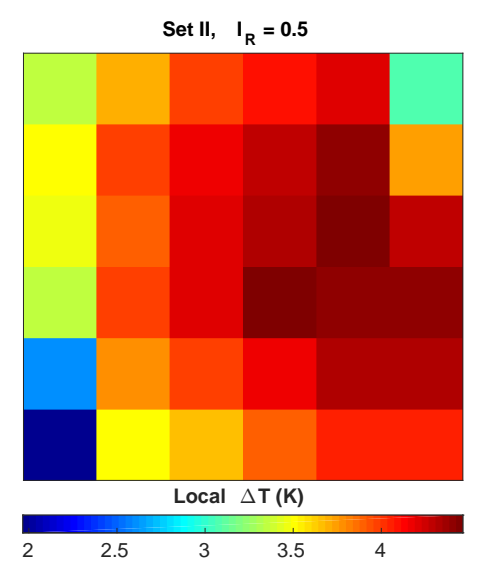

(b)

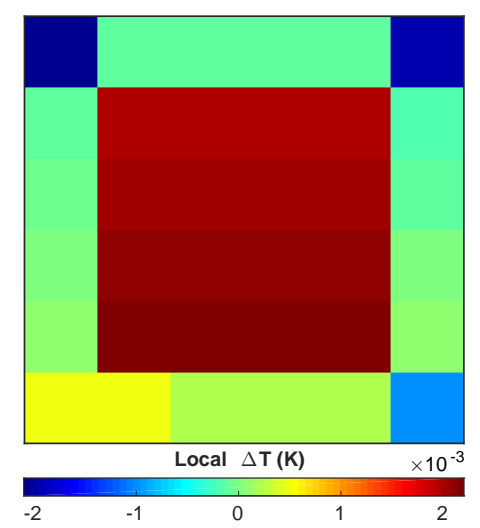

(e)

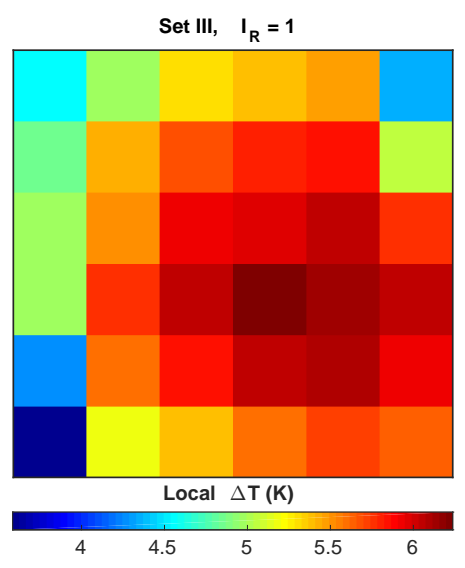

(c)

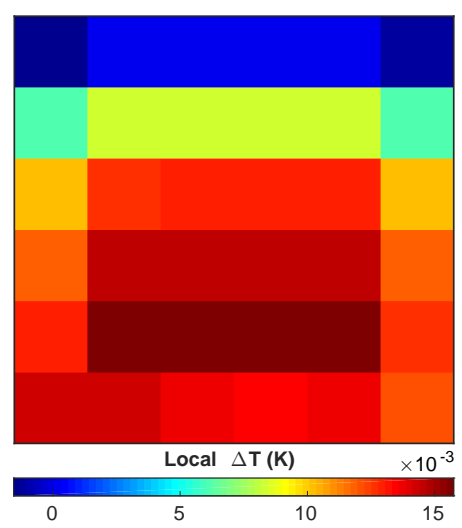

(f)

Fonte: Autoria própria.

significativamente diferentes dos resultados experimentais, também sendo observado o acúmulo de calor, mencionado acima, próximo às entradas de gases.

A título de completar a análise, são apresentados os valores de ME, MAE e R entre as distribuições linearizadas de temperatura computacionais e experimentais na Figura 54 . Em primeiro lugar, similarmente às distribuições de corrente, o ME das distribuições de temperatura encontram-se muito próximos de zero, sugerindo, dada a inspeção visual das distribuições e o observado para a distribuição de corrente, uma distribuição simétrica dos resíduos. O MAE, por outro lado, difere de maneira significativa do observado para as distribuições de corrente (Fig. 46a), sendo duas ordens de magnitude superiores. É notável, no entanto, a presença de um máximo de MAE, para todos os conjuntos de vazões, por volta de $I=3 \mathrm{~A}$, algo não observado para o ME (não visualizável na escala). Ainda mais marcante são os valores de R, apresentados na Fig. 54b, onde não só é observado correlação 
Figura 53 - Distribuições de desvios de temperatura linearizadas, para o conjunto de vazões II, experimentais $(\times)$ e computacionais $(\square)$, para as correntes a) $I=1, \mathbf{b}) 5$, d) 10 A. As barras de erro nos resultados experimentais representam um desvio em relação à média. A entrada de gases catódica se dá em altos valores da abcissa, enquanto a saída se dá para baixos valores.

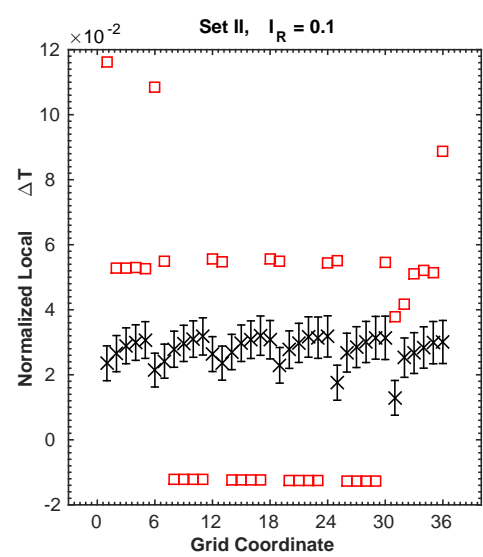

(a)

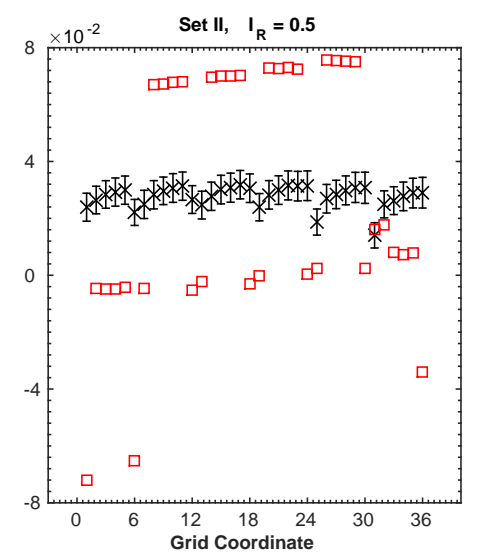

(b)

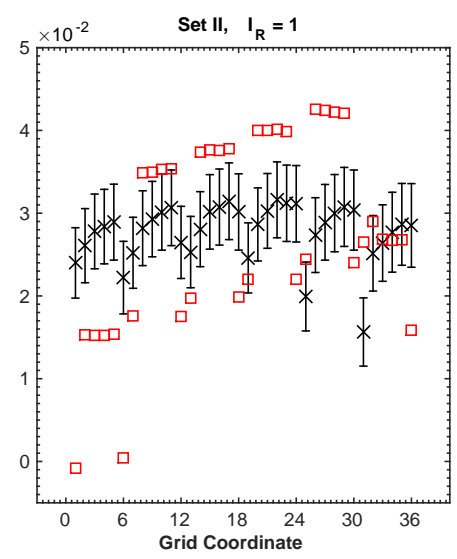

(c)

Fonte: Autoria própria.

negativa, mas também uma inversão da correlação também por volta de $I=3 \mathrm{~A}$. Como apontado acima, a correlação aumenta para altos valores de $I_{R}$ em um dado conjunto de vazões; porém, considerando os valores obtidos e a inspeção visual descrita acima, são tidos como forte evidência da incapacidade do modelo FC mkII de reproduzir os resultados experimentais, mesmo de maneira qualitativa.

A análise de resíduos é tomada como desnecessária, considerando o observado nas distribuições linearizadas de temperatura, e os resultados de ME, MAE e R apresentados acima. Porém, o máximo de MAE e inversão de correlação observados na Fig. 54 para valores de $I$ próximos a $3 \mathrm{~A}$ instigam uma inspeção mais cuidadosa. Como sugerido pelas distribuições apresentadas no Anexo B, foi observado que os pontos de máximo MAE e de inversão dos valores de $\mathrm{R}$ correspondem ao momento onde o calor gerado na região central do modelo torna-se maior que as perdas, levando assim ao aumento de temperatura dessa região. Tal mudança de comportamento não é observada nas curvas de temperatura do compartimento catódico (Fig. 50) ou nas distribuições de temperatura experimentais. Conforme apontado anteriormente, isto pode ser devido à diferença entre grandezas avaliada, e a uma subestimativa da escala de temperatura relacionada ao calor simulado. No entanto, a correlação entre as grandezas não foi como esperada, sendo que a Fig. 54b indica que tal correlação é frágil na melhor das situações. Assim, sugere-se que a formulação do modelo mkII como um todo, dado sua natureza altamente acoplada, é incapaz de reproduzir os processos físicos que levam à distribuição de temperatura (calor). 
Figura 54 - a) Erro médio (ME, símbolos vazios) e erro absoluto médio (MEA, símbolos cheios) e b) coeficiente de correlação de Pearson (R), em função da corrente total aplicada, entre as distribuições linearizadas de desvio de temperatura computacionais e experimentais: conjunto I $(\circ)$, II $(\square)$, III $(\triangle)$, e IV $(\diamond)$. A linha sólida preta indica erro nulo.

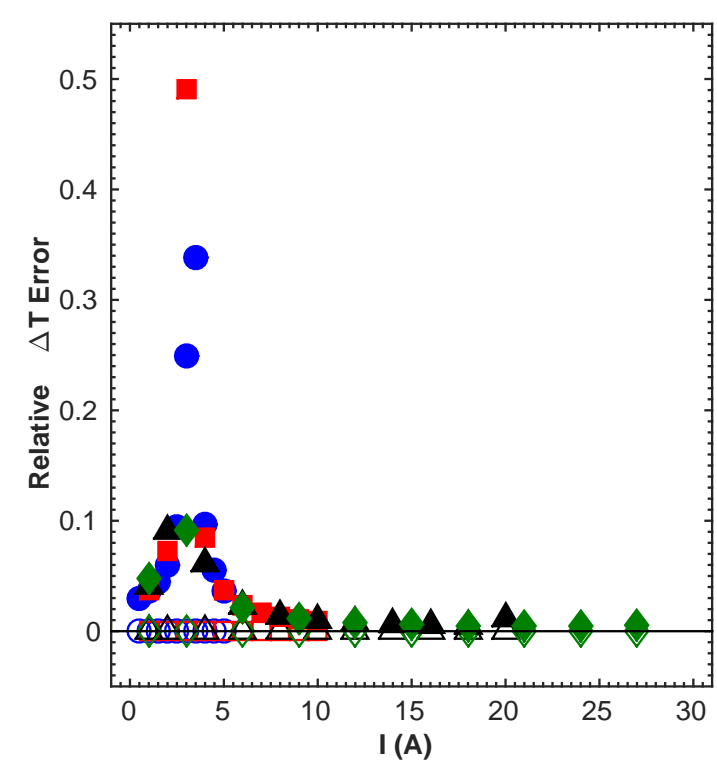

(a)

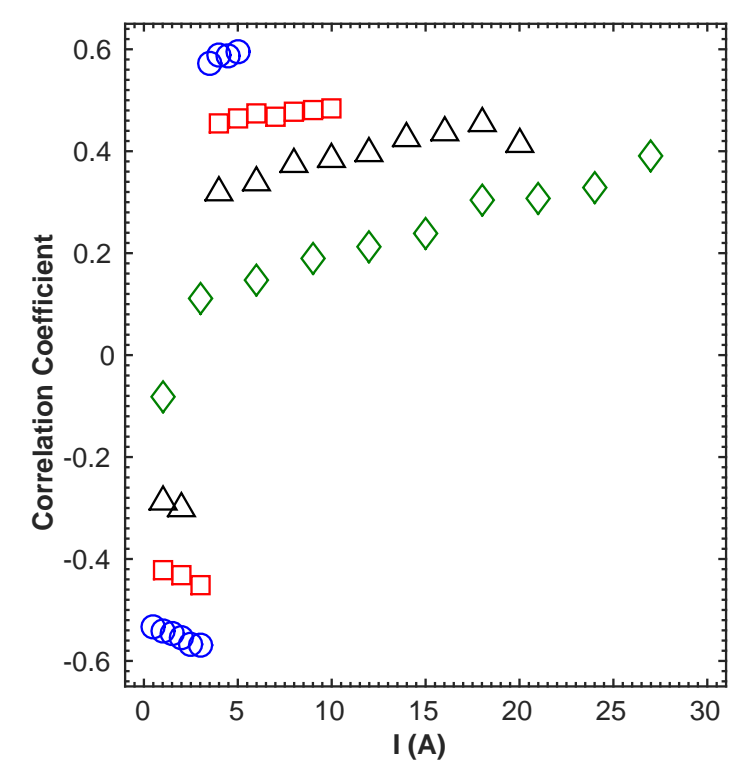

(b)

Fonte: Autoria própria.

\subsubsection{Discussões}

Dos resultados apresentados acima, e da breve discussão realizada em cada ponto levantado, a conclusão imediata é a de que o modelo FC mkII é incapaz de reproduzir os resultados experimentais disponíveis. Em essência, o sucesso não era esperado, mas sim a identificação dos pontos frágeis da formulação do modelo. Isto se deve devido à dificuldade de obtenção de informações rigorosas e inequívocas das propriedades dos materiais e condições operacionais utilizadas. Além disso, conforme já apontado anteriormente, o modelo mkII utiliza sabidamente aproximações para sua formulação. Por outro lado, modelos de PEMFC similares, mais ou menos complexos que o apresentado aqui, são facilmente encontrados na literatura (e.g. a impressionante lista de trabalhos compilada em (17)). Os pontos a serem levantados, portanto, são os motivos pelos quais o modelo FC mkII ter falhado, e qual a necessidade da contínua busca por modelos capazes de reproduzir resultados experimentais, dado a montante de modelos "bem-sucedidos" observada na literatura.

Será considerado inicialmente a validação do modelo FC mkII sob um ponto de vista geral. Conforme apresentado, quatro conjuntos de resultados foram comparados: i) curvas de polarização, ii) distribuições de corrente, iii) curvas de temperatura anódica e catódica, e iv) distribuições de temperatura catódica. Destes, i) e iii) são considerados aspectos globais do dispositivo, sendo que as curvas de polarização são largamente utilizadas para representação do desempenho dos mesmos e para a validação de modelos. São resultados 
facilmente obtidos, experimentalmente, e tendem a reduzir drasticamente a complexidade da análise, explicando assim, no caso das curvas de polarização, sua popularidade. Os demais, ii) e iv) representam aspectos locais, possibilitando uma análise mais cuidadosa, ainda que discutivelmente insuficiente, das contribuições dos diversos fenômenos físicos acoplados presentes nos dispositivos. Juntamente com isso, estas grandezas trazem consigo complicações na análise, devido ao caráter espacial, e também a necessidade de equipamentos especializados. Isto potencialmente explica a baixa popularidade no seu uso, mas também sugere grande valia para a obtenção de informações, seja para estudos experimentais ou a validação de modelos computacionais, conforme sublinhado em (17).

Desta maneira, e considerando os resultados apresentados anteriormente, pode-se dizer que o modelo FC mkII é capaz de reproduzir satisfatoriamente os aspectos globais do dispositivo estudado, considerando a resolução e os desvios apresentados pelos resultados experimentais. Por outro lado, os resíduos apresentam tendência, principalmente para as temperaturas anódica e catódica, sugerindo a necessidade de refino da formulação matemática e/ou da parametrização utilizada. Considerando que uma análise de sensitividade não foi feita com o modelo mkII, e que apenas uma parte da formulação matemática foi validada independentemente, torna-se difícil apontar de maneira precisa as contribuições para as diferenças observadas. Sugere-se, no entanto, a seguinte interpretação, baseada no comportamento dos resíduos. No caso das curvas de polarização, considerando como os resíduos contemplam a região de convergência do modelo em quase todos os casos, as tendências observadas, sendo similares, apontam para contribuição de fenômenos físicos não considerados no modelo mkII. O mesmo é sugerido no caso das curvas de temperatura anódica, onde a tendência observada é interpretada como o efeito de fenômenos não considerados no modelo. A temperatura catódica, por outro lado, apresenta um comportamento distinto, sendo, de maneira geral, consistentemente superestimada pelo modelo. Dado o comportamento da curva de temperatura anódica, sugere-se, adicionalmente à presença de efeitos adicionais negligenciados nos demais casos, à presença de água líquida. Apesar de ser aparentemente pouco relevante para o potencial elétrico e a temperatura anódica, é esperado que a água líquida tome papel importante no gerenciamento de calor, dado sua grande capacidade calorífica.

Em relação aos aspectos locais, o modelo mkII fracassa consideravelmente, especialmente em relação à distribuição de temperatura (calor). Em primeiro lugar, é importante relembrar que as comparações feitas aos resultados experimentais foram qualitativas, e que, desde o princípio, o modelo mkII não era capaz de providenciar comparações diretas. Isso se deve à diferença na corrente total das distribuições de corrente, e devido à natureza das grandezas, no caso das distribuições de temperatura. Mesmo desconsiderando tais pontos, como feito acima, o modelo mostrou-se incapaz de reproduzir de maneira satisfatória os resultados experimentais. No caso da distribuição de corrente, o modelo prevê uma distribuição mais homogênea de corrente, e deixa evidente efeitos de limitação 
de reagentes em virtualmente todo intervalo de $I$ estudado (concentração da corrente próximo às entradas de gases). Experimentalmente, o que se observa é uma concentração de corrente nas regiões centrais do dispositivo, enquanto que os sinais de limitação de reagentes tornam-se claros apenas em altos valores de $I$. O caso das distribuições de temperatura é ainda pior, apresentando correlações negativas e inversão de comportamento ao longo dos valores de $I$. Devido à maior complexidade da análise dos aspectos locais, é difícil sugerir possíveis origens para tais diferenças sem explorar diferentes modelos. Mas dado como as diferenças foram substanciais, sugere-se que a contribuição da formulação matemática deve ser significativa.

Voltando-se agora para a literatura, buscaram-se trabalhos relativos à validação de modelos de PEMFC, independente da formulação e método de resolução, utilizando as palavras-chave "model validation". Quatro revistas científicas foram escolhidas, Fuel Cells, J. Power Sources, Int. J. Hydrogen Energy e J. Electrochem. Soc.; considerando a comunidade atingida e o amplo espectro de disciplinas abordadas. No caso do $J$. Electrochem. Soc., apenas trabalhos abertos ao público foram considerados. A busca resultou em pouco mais de 400 trabalhos, sendo que 15 foram considerados relevantes e analisados em relação à formulação matemática e validação dos modelos descritos $(74,75$, $31,76,77,78,79,80,81,82,30,83,84,85,86)$. Destes trabalhos, apenas dois $(85,80)$ não avaliaram curvas de polarização, afirmando validação prévia. Entre os demais trabalhos, seis trabalhos $(74,76,78,79,80,84)$ apresentam distribuições de corrente, sendo que quatro(74, 76, 79, 78) são similares aos apresentados na Seção 6.2.1.1. Por outro lado, cinco trabalhos $(74,77,79,78,85)$ avaliam medidas de temperatura, sendo que três deles $(74,79,78)$ utilizam distribuições de temperatura similares ao apresentados na Seção 6.2.1.2. Um dos trabalhos(82) apresenta um modelo para espectroscopia de impedância eletroquímica (EIS), utilizando informações adicionais e pouco usuais para a validação do modelo descrito. É notável que apenas dois trabalhos $(76,85)$ apresentam replicatas e resultados estatísticos, possibilitando uma comparação adequada entre os resultados experimentais e computacionais.

Considerando primeiramente os aspectos elétricos, será dado foco aos trabalhos que apresentaram resultados de distribuição de corrente. Fink, Karpenko-Jereb e Ashton(74) apresentam um modelo 3D de CFD acoplado à um modelo de degradação da PEM, sendo comparado à resultados experimentais de curvas de polarização e distribuições de corrente e temperatura. Entre os pontos dignos de nota, o modelo considera transporte de espécies, momento, carga e calor, similarmente ao modelo FC mkII, porém considerando a possibilidade de escoamento bifásico e tratando as CLs como superfícies 2D. As condições de contorno não são bem descritas e a parametrização não possui referências, sendo que alguns parâmetros foram sabidamente ajustados. A comparação entre a curva de polarização computacional e experimental mostra boa concordância, porém não são apresentados intervalos de confiança ou resíduos; o que dificulta uma análise apropriada. Em relação às 
distribuições de corrente, obtidas para dois valores de corrente total, $I_{1}<I_{2}$ observam-se diferenças significativas em $I_{1}$, tanto quantitativas como qualitativas, enquanto que para $I_{2}$ estas são basicamente qualitativas. De qualquer maneira, as comparações não possibilitam uma análise rigorosa da capacidade do modelo de reproduzir os resultados experimentais, dado que não é apresentada a incerteza relativa aos resultados experimentais.

O trabalho de Carnes et al.(76) utiliza um modelo previamente reportado, não disponível, e o compara a distribuições de corrente experimentais. São propostos critérios para validação, essencialmente análises estatísticas semelhantes às apresentadas na Seção 6.2.1.1. O modelo, descrito brevemente, é similar ao descrito em (74), contemplando transporte de espécies, momento, carga e calor, além de considerar a possibilidade de transporte bifásico através de modelos de mistura. A parametrização não é referenciada neste trabalho, deixando aberta a possibilidade de ajustes. Em relação à validação, a curva de polarização experimental representa a média temporal da medida, com a incerteza caracterizando flutuações durante a operação. A concordância dos resultados simulados é boa, porém observa-se que estes estão fora dos limites de confiança apresentados em alguns pontos. As distribuições de corrente apresentam grandes diferenças qualitativas, mesmo considerando que os resultados experimentais foram processados para uma melhor comparação com os resultados computacionais. Foram avaliadas condições de umidade relativa $(\mathrm{RH})$ e temperatura diferentes, mas observa-se que o modelo utilizado é incapaz de reproduzir as superfícies de corrente em todos os casos.

Os outros dois trabalhos, de Robin et al.(79) e de Nandjou et al.(78), são aparentemente do mesmo grupo, e possuem similaridades, como por exemplo a técnica utilizada para a obtenção das distribuições de corrente e o fato que os resultados experimentais são referentes à módulos de células. Em (79) é descrito um modelo baseado na teoria de grafos de ligações (bond graph theory), contemplando transporte de espécies, momento, carga e calor, e considerando o transporte de água líquida. É notável, no entanto, que os FCs são negligenciados, considerando apenas perdas de carga e pressões parciais de reagentes como parâmetros de entrada. Em (78), por outro lado, um modelo similar ao FC mkII é apresentado, contemplando transporte de espécies, momento, carga e calor, sendo que a presença de água líquida é apenas inferida em um processamento pós-cálculo. Em ambos os casos, são ajustados parâmetros com base em um sistema de referência. Quanto à validação, Robin et al. comparam curvas de polarização em quatro condições diferentes, obtendo boa concordância, porém consistentemente subestimando o valor do potencial elétrico. Nandjou et al. comparam apenas uma curva de validação, obtendo aparentemente excelente concordância, apesar do pequeno número de pontos simulados. No entanto, a falta de análise estatística torna a comparação frágil, impossibilitando qualquer avaliação rigorosa dos modelos. Quanto às distribuições de corrente, os resultados experimentais apresentam ótima resolução espacial, particularmente em (78), porém os resultados computacionais são incapazes de prever o comportamento experimental, 
especialmente em (79). Em baixos valores de $I$, os resultados de Nandjou e colaboradores apresentam certa correlação aos experimentais, entretanto a boa resolução espacial e a falta de replicatas sugerem que tal correlação pode ser devido à flutuações experimentais. Por outro lado, os resultados experimentais de Robin e colaboradores diferem de maneira tão significativa dos computacionais, e do comportamento esperado tendo em vista os resultados apresentados nas Seções 6.2.1.1 e nos demais trabalhos, que sugere-se alguma dificuldade nas medidas.

Os demais trabalhos diferem significativamente em relação ao sucesso dos modelos. As formulações são, de modo geral, muito parecidas às do modelo mkII, e da sugerida em (17), com diferentes graus de ajustes e fontes em relação à parametrização. De modo geral, observa-se boa concordância entre curvas de polarização experimentais e computacionais, especialmente em modelos 3D ou com parâmetros ajustados. Porém a falta de uma estimativa da variância experimental deixa dois pontos em aberto: i) até que ponto as diferenças observadas são estatisticamente significativas e ii) qual a facilidade de se obter resultados que são estatisticamente iguais aos experimentais. Neste ponto, os resultados utilizados para validação do modelo mkII possuem incertezas relativamente baixas, e a capacidade do modelo de reproduzir as curvas de polarização de maneira satisfatória são evidências seguras de que, ao menos globalmente, a formulação do modelo é condizente com a realidade. Quanto aos resultados espacialmente resolvidos, além dos analisados acima, observa-se, de maneira geral, certa concordância, porém com diferenças claras e significativas, apesar da falta de resultados estatisticamente válidos. Neste ponto, o modelo FC mkII é similar aos demais, apresentando superfícies reproduzidas de maneira bem sucedida, porém com falhas claras. Deve-se apontar, no entanto, que o modelo FC mkII não possui parâmetros ajustados, e o conjunto de dados experimentais utilizados em sua validação é significativamente maior que os apresentados nos trabalhos mencionados. Espera-se que isso possibilite, com a continuidade dos trabalhos, a identificação de fenômenos físicos relevantes e o refino do modelo, de modo a aprimorar resposta do mesmo em relação aos resultados experimentais.

Em relação aos aspectos térmicos, os modelos descritos em $(74,79,78)$ já foram descritos. No caso de Fink, Karpenko-Jereb e Ashton(74), as distribuições de temperatura simuladas são significativamente distintas das experimentais, apresentando valores de temperatura consistentemente inferiores às experimentais, no caso de $I_{1}$, e com um comportamento distinto, apesar de valores próximos, no caso de $I_{2}$. Robin et al.(79) apresentam superfícies simuladas com certa correlação com as experimentais, em relação às regiões de acúmulo de calor, no entanto o modelo prevê um máximo global de temperatura nas regiões centrais, enquanto que os resultados experimentais não apresentam um máximo global tão distinto. No caso de Nandjou e colaboradores(78), os resultados experimentais são muito próximos aos apresentados em (79), sendo que os resultados simulados apresentam ótima correlação com estes, especialmente em altas correntes. Deve-se apontar novamente que o modelo 
descrito em (78) não considera explicitamente o transporte de água líquida, e que no caso da distribuição de temperatura, estas são corrigidas com o calor de vaporização e condensação da água. Isto torna menos evidente o motivo para o fracasso marcante do modelo FC mkII, dado que é de se esperar que a presença de água líquida seja particularmente importante no gerenciamento de calor de PEMFCs. Por outro lado, a compensação descrita em (78) pode ser o motivo da boa concordância observada entre resultados experimentais e computacionais.

Da análise realizada acima, e do sugerido em (17), pode-se concluir que dentro da amostragem realizada, apesar de grandes avanços na simulação de PEMFCs, modelos de interesse prático e de certa complexidade ainda são incapazes de reproduzir de maneira satisfatória resultados experimentais. É importante notar, no entanto, que os motivos não pesam unicamente sobre os modelos. Apesar de não mencionado, os trabalhos discutidos apresentam uma variabilidade impressionante de condições operacionais, desenhos de dispositivos e materiais utilizados. Somando-se com a falta de rigor na obtenção e descrição de resultados experimentais, e com a falta de prática com métodos estatísticos robustos (inclusive este trabalho), o que se observa é um campo de pesquisa largamente desnorteado. Sugere-se, aqui, que é necessário um envolvimento significativo entre pesquisadores experimentais e computacionais, de modo a elaborar experimentos e modelos que possam, de fato, prover informações sobre os fenômenos físicos e propriedades de materiais presentes em dispositivos bem caracterizados e, possivelmente, padronizados. Não é perdida a noção de que o mesmo pode ser dito do modelo FC mkII, mas sublinha-se que tal percepção também é fruto do desenvolvimento do modelo. Trabalhos futuros no desenvolvimento e validação de modelos computacionais, e discutivelmente também no estudo de dispositivos reais, devem levar em conta a necessidade de interação entre pesquisadores experimentais e computacionais.

\subsubsection{Estudo do Transporte Convectivo}

Sendo comparado o modelo FC mkII com os resultados experimentais disponíveis, será realizado o estudo da formulação e contribuição do transporte convectivo no dispositivo simulado. Inicialmente será avaliada a formulação do transporte de momento, similarmente ao realizado na Seção 6.1.1, porém utilizando as mesmas variáveis descrita na Seção 6.2.1, acima. Em seguida será avaliado a contribuição do transporte convectivo nas camadas porosas, sendo analisadas as mesmas variáveis descritas abaixo.

\subsubsection{Efeitos da formulação do transporte de momento}

Seguindo a ordem e simbologia utilizada na comparação aos resultados experimentais, serão primeiramente avaliados os aspectos elétricos, sendo que os resultados experimentais serão mantidos como referência. Desta maneira, o primeiro ponto de comparação é dado 
Figura 55 - Curvas de polarização simuladas com o modelo FC mkII, usando as formulações DB (símbolos vazios) e SD (símbolos cheios), para os conjuntos de vazão a) I (o) e II ( $\square$ ), e b) III ( $\triangle$ ) e IV $(\diamond)$, conforme indicados no título de cada subgráfico. Os resultados experimentais $(\times)$ são incluídos como referência. As barras de erro nos resultados experimentais representam um desvio em relação à média.
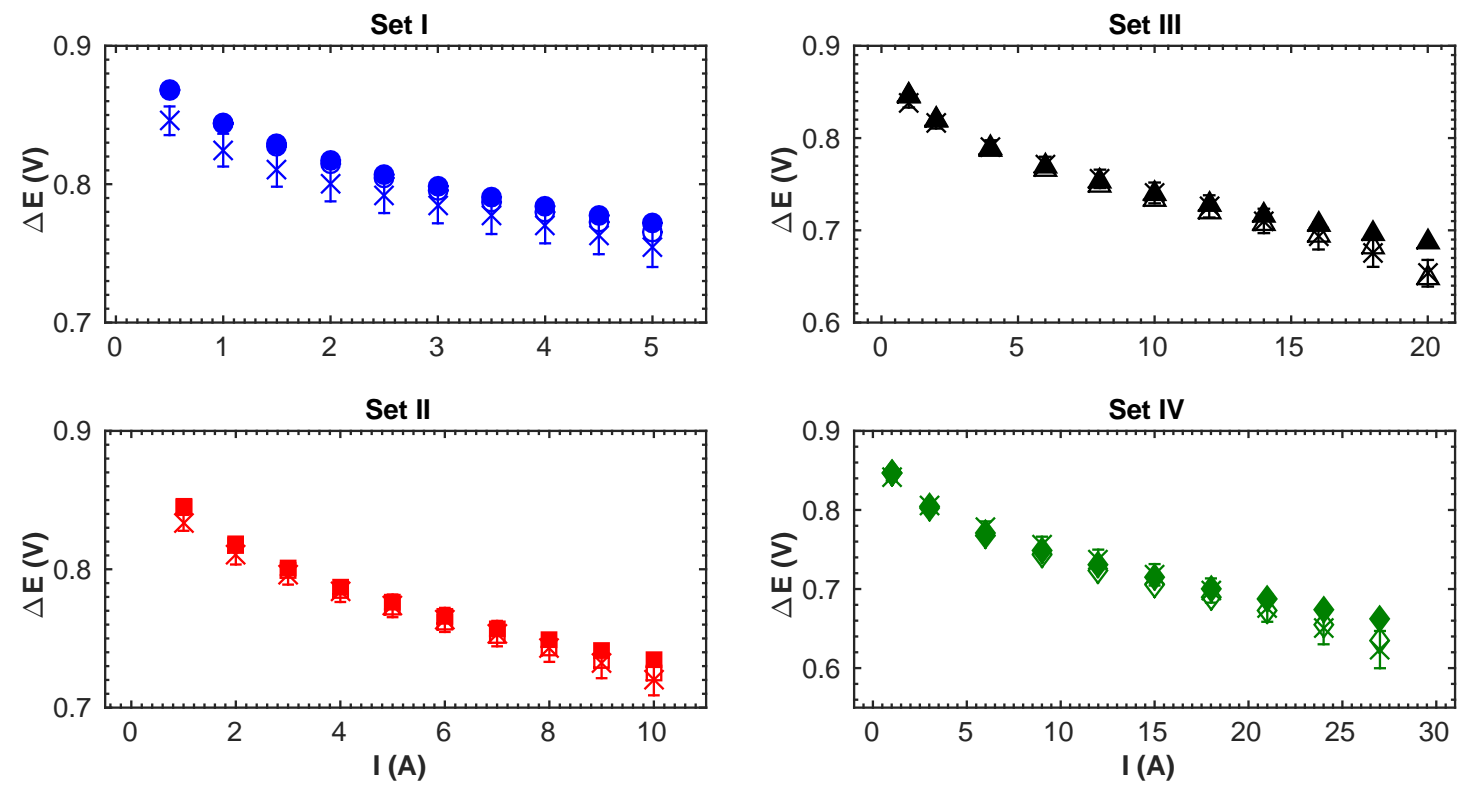

(a)

(b)

Fonte: Autoria própria.

pelas curvas de polarização para os quatro conjuntos de vazões, apresentadas na Figura 55. De maneira geral, o efeito observado se dá na região de polarização por transporte de massa, sendo que a formulação Stokes-Darcy (SD) prevê valores de $E$ maiores que os dados pela formulação Darcy-Brinkman (DB). Isto é particularmente notável para maiores valores de vazão (Fig. 55b), onde não é observado limitação por transporte de massa para a formulação SD, no intervalo de $I$ analisado, diferentemente da formulação DB e dos resultados experimentais. Considerando que a parametrização utilizada foi a mesma para ambas formulações, observa-se que os resultados da formulação SD são estatisticamente distinto dos experimentais nas regiões de altos valores de $I$ em todos os conjuntos de vazões.

São comparados também os valores de $E(I=0)$ e $R_{\Omega}$, sendo replicados os valores da Tab. 17 para a formulação DB e resultados experimentais. Como pode ser observado, os valores de $E(I=0)$ são idênticos entre as formulações, considerando o intervalo de convergência relativo do modelo, $10^{-2}$. Por outro lado, os valores de $R_{\Omega}$ apresentam diferenças entre as formulações, com os valores obtidos para a formulação SD sendo estatisticamente inferiores aos da DB em todos os casos, com exceção do conjunto II. Em comparação aos valores experimentais, os valores de $R_{\Omega}$ da formulação SD para os conjuntos I e II são mais próximos à média experimental que os da DB; estando ambas, no entanto, dentro do erro experimental. Para os conjuntos III e IV, por outro lado, a 
formulação DB apresenta valores mais próximos aos experimentais que os obtidos com a $\mathrm{SD}$, sendo estatisticamente igual no caso do conjunto IV.

Tabela 19 - Grandezas analisadas para comparação entre as formulações de transporte de momento usadas no modelo $\mathrm{FC}$ mk2, em relação às curvas de polarização.

\begin{tabular}{ccccc}
\hline \multirow{2}{*}{ Grandeza } & \multirow{2}{*}{ Conjunto } & \multicolumn{2}{c}{ Computacional } & \multirow{2}{*}{ Experimental } \\
& & DB & SD & \\
\hline \multirow{2}{*}{$E(I=0)(\mathrm{mV})$} & I & 915 & 915 & $914 \pm 17$ \\
& II & 916 & 916 & $920 \pm 16$ \\
& III & 916 & 917 & $923 \pm 16$ \\
& IV & 917 & 918 & $927 \pm 16$ \\
& & & & \\
$R_{\Omega}(\mathrm{m} \Omega)$ & I & $16,3 \pm 0,6$ & $14,9 \pm 0,6$ & $15,0 \pm 1,6$ \\
& II & $11,1 \pm 0,5$ & $10,3 \pm 0,5$ & $10,5 \pm 0,5$ \\
& III & $6,73 \pm 0,13$ & $5,86 \pm 0,18$ & $7,71 \pm 0,61$ \\
& IV & $5,85 \pm 0,13$ & $4,37 \pm 0,19$ & $6,57 \pm 0,65$ \\
\hline
\end{tabular}

Nota: Desvios indicados representam erros da regressão linear, no caso de resultados computacionais, e desvio em relação à média, no caso de resultados experimentais.

Fonte: Autoria própria.

Para análise das distribuições de corrente, apenas as superfícies linearizadas serão consideradas, dado que as formulações DB e SD resultam em superfícies qualitativamente similares. Adicionalmente, serão analisadas as regiões de limitação por transporte de massa, dado que foram observadas maiores distinções entre as formulações nesta região das curvas de polarização. A Figura 56 apresenta as distribuições linearizadas para o maior valor do intervalo de $I$ em cada conjunto de vazões. Como é possível observar, em todos os casos, a formulação SD prevê uma distribuição mais homogênea que a DB, sendo particularmente distintas no caso do conjunto III (Fig. 56c). Quando comparada aos resultados experimentais, a formulação SD se aproxima destes, qualitativamente, nos conjuntos III e IV, em forte contraste à formulação DB. Por outro lado, para os conjuntos I e II, a formulação SD prevê melhor distribuição de corrente do que observado experimentalmente, e previsto pela formulação DB.

Os resultados observados nas Figs. 55 e 56 estão de acordo com as conclusões tiradas da validação do modelo Alfa (Seção 6.1.1.3), i.e. que a formulação SD prevê maiores valores de pressão parcial de reagentes que a DB. No caso do modelo FC mkII, isso se dá pelos maiores valores de $E$ (Fig. 55) relativos à formulação DB e, consequentemente, também aos resultados experimentais; assim como pela maior homogeneidade das distribuições de corrente, o que também sugere maior pressão parcial dos reagentes que o dado pela formulação DB. Apesar da melhor concordância da formulação SD com as superfícies linearizadas dos conjuntos III e IV, estas ainda encontram-se largamente fora do intervalo de confiança dos resultados experimentais, ponto também observado para as curvas de polarização destes conjuntos. 
Figura 56 - Distribuições de corrente linearizadas simuladas com o modelo FC mkII, com as formulações DB (símbolos vazios) e SD (símbolos cheios), para os conjuntos de vazões a) I (o), b) II ( $\square$ ), c) III $(\triangle)$ e d) IV $(\diamond)$. Resultados experimentais $(\times$ e $\times)$ são incluídos como referência. As barras de erro nos resultados experimentais representam um desvio em relação à média.

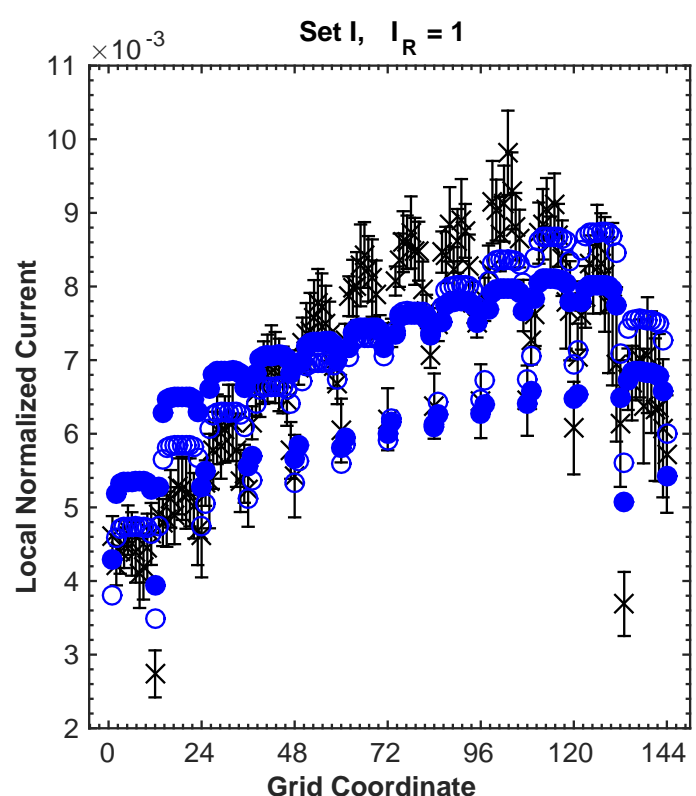

(a)

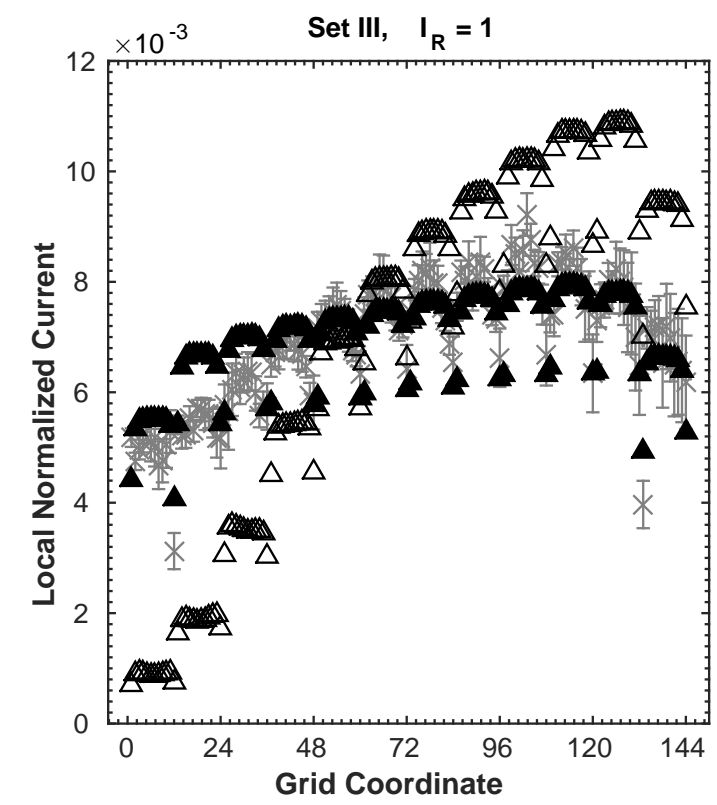

(c)

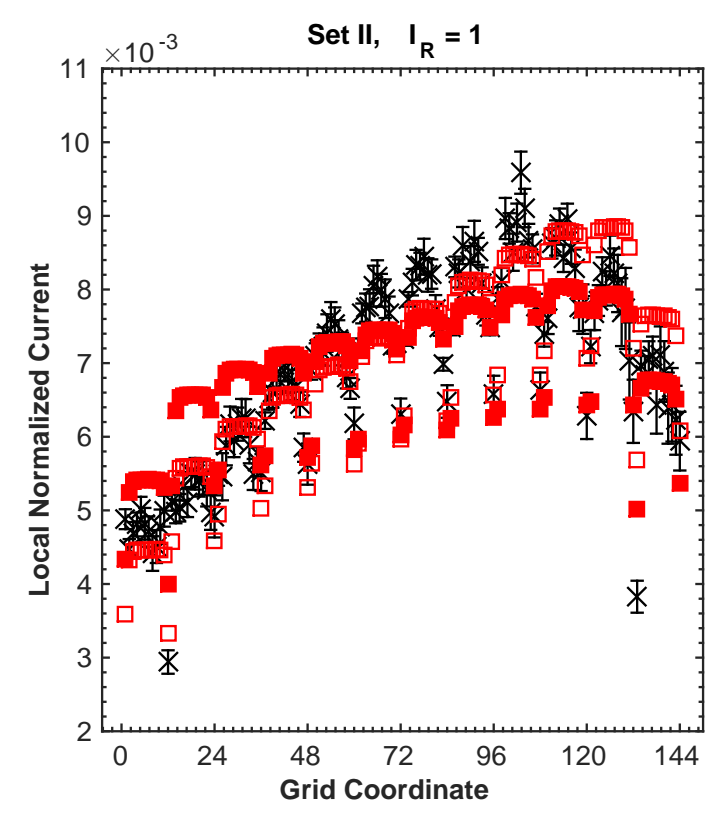

(b)

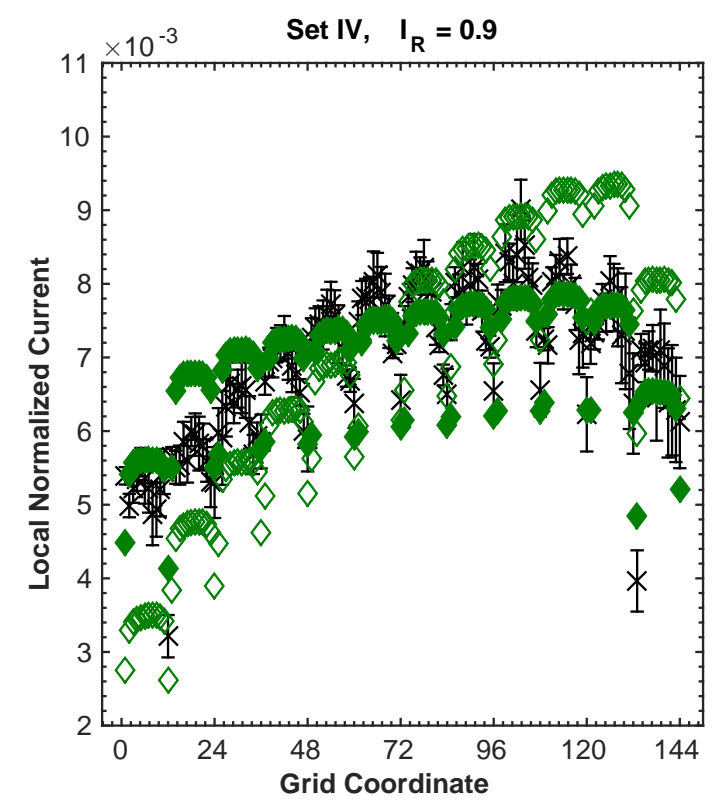

(d)

Fonte: Autoria própria. 
Figura 57 - Curvas de temperatura dos compartimentos a) anódico e b) catódico, obtidas ao longo da curva de polarização, para as formulações DB (símbolos vazios) e SD (símbolos cheios). Os conjuntos de vazão são indicados no título de cada subgráfico: I ( ○), II ( $\square)$, III $(\triangle)$, e IV ( $\diamond$. Os resultados experimentais são incluídos como referência. As barras de erro nos resultados experimentais representam um desvio em relação à média.
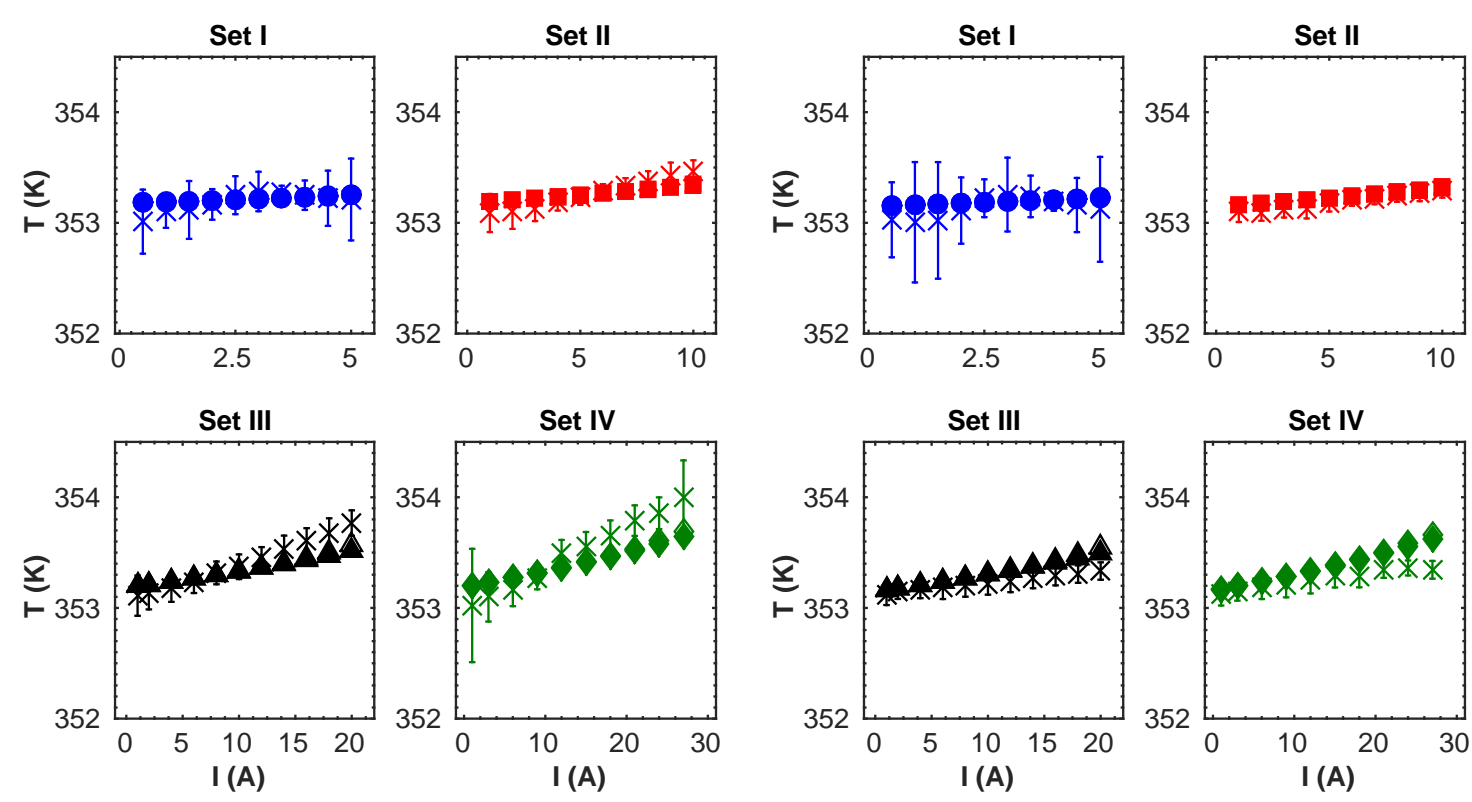

(a)

(b)

Fonte: Autoria própria.

Em relação aos aspectos térmicos, o primeiro conjunto de dados a ser comparado é dado pelas temperaturas dos compartimentos anódico e catódico. A Figura 57 apresenta as curvas de temperaturas em função da corrente total $I$. Similarmente às curvas de polarização, observam-se diferenças na região de altos valores de $I$, neste caso sendo observadas menores temperaturas previstas pela formulação SD que a DB em todos os casos. Usando os resultados experimentais como referência, no caso da temperatura do compartimento anódico, menores temperaturas resultam em pior concordância, dado que a formulação DB subestima consistentemente tal temperatura. Por outro lado, no caso do compartimento catódico, menores temperaturas melhoram a concordância com os dados experimentais. Entretanto, a situação das duas formulações é muito similar, dada a pequena diferença entre suas previsões, superestimando de maneira significativa a temperatura catódica no caso dos conjuntos III e IV.

Em relação às distribuições de temperatura (calor), estas não serão comparadas às experimentais, sendo utilizadas apenas as distribuições de calor integrado gerados pelas duas formulações. Similarmente ao apresentado para as distribuições de corrente, a Figura 58 apresenta as distribuições linearizadas de calor para os maiores valores dos intervalos de I investigados para cada conjunto de vazões. Como observado na Fig. 57 para as curvas de temperatura, a formulação SD subestima de maneira geral o calor trocado através das BPs, sendo particularmente notável no caso dos conjuntos III e IV. As diferenças observadas 
Figura 58 - Distribuições de calor linearizadas simuladas com o modelo FC mkII, com as formulações DB (símbolos vazios) e SD (símbolos cheios), para os conjuntos de vazões a) I (o), b) II ( $\square$ ), c) III $(\triangle)$ e d) IV $(\diamond)$.
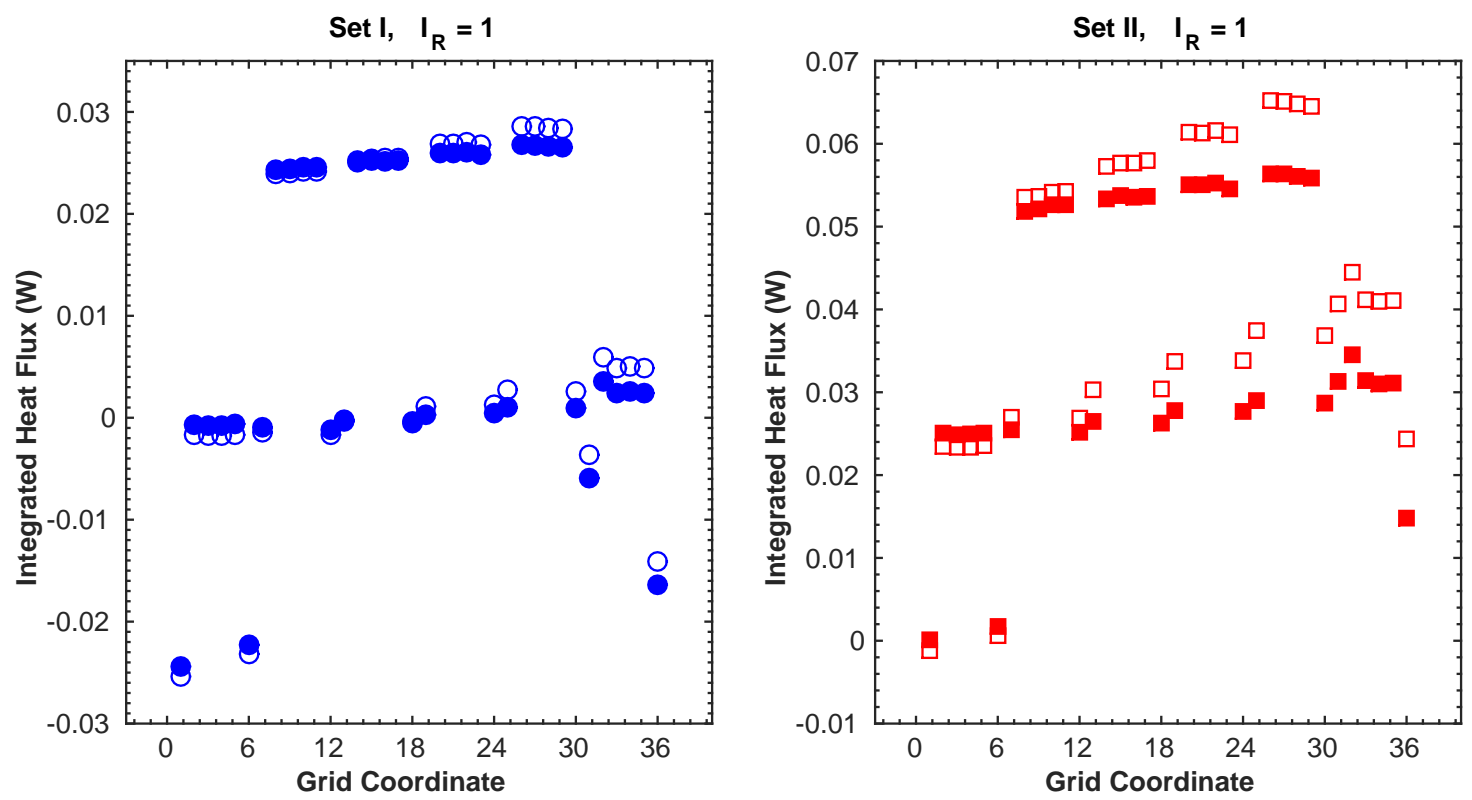

(a)

(b)
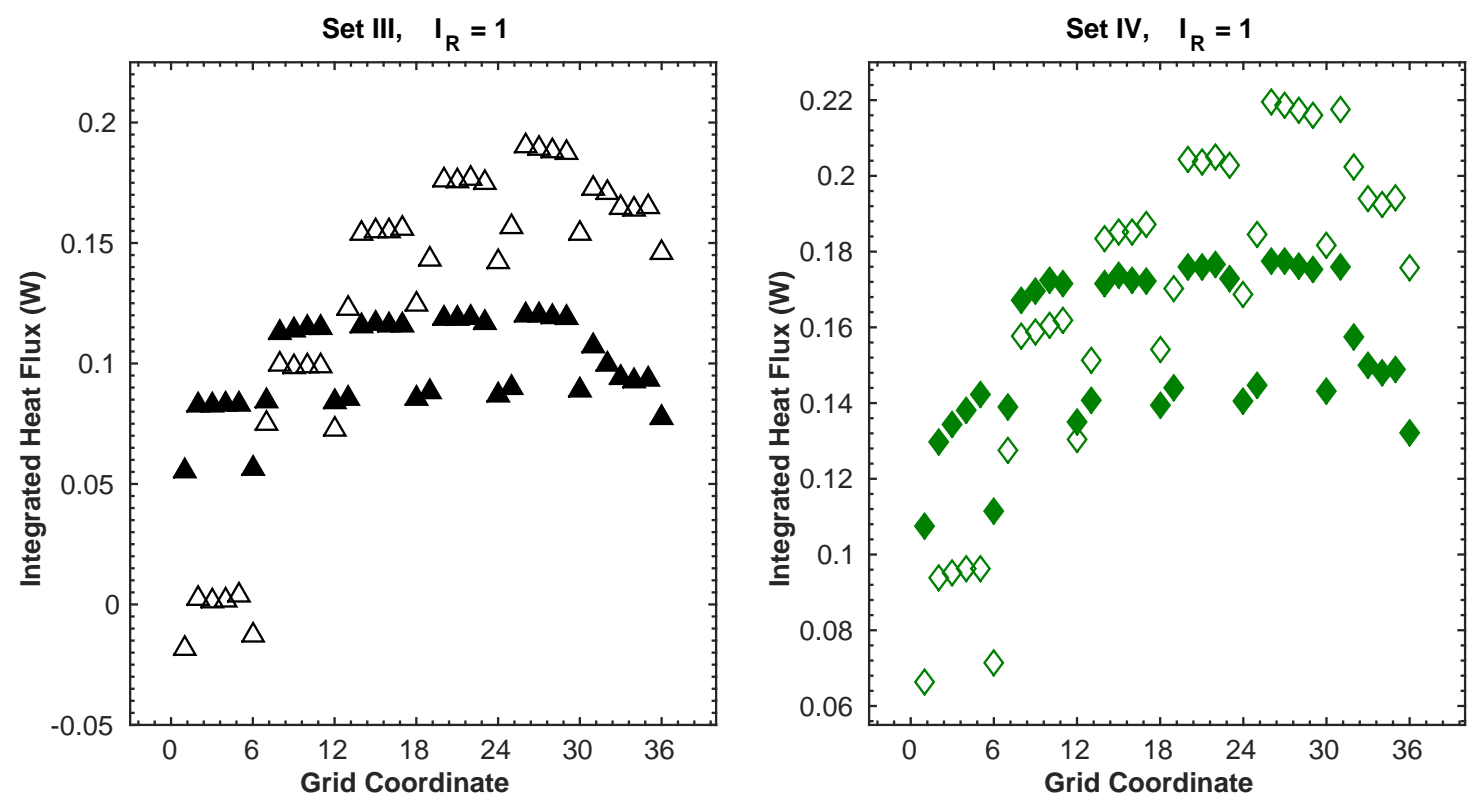

(c)

(d)

Fonte: Autoria própria.

correlacionam com as diferenças observadas na Fig. 56 para as distribuições linearizadas de corrente. Isto sugere que as diferenças nos aspectos térmicos apenas refletem a diferença de distribuição e pressão parcial dadas pela formulação SD em relação à DB.

As conclusões tiradas da comparação entre as formulações do transporte de momento no modelo FC mkII são as mesmas apontadas anteriormente, para o modelo Alfa e o protótipo de célula. Assumindo uma mesma parametrização, e a falta de parâmetros 
ajustáveis, a formulação SD (como implementada neste caso) superestima a performance do dispositivo, prevendo maiores potenciais elétricos e melhor distribuição espacial de corrente, devido à maior pressão parcial e distribuição dos reagentes. Esta análise estende o intervalo de vazões avaliados para o modelo Alfa, $200 \leq Q \leq 450 \mathrm{~cm}^{3} \mathrm{~min}^{-1}$, para $42 \leq Q \leq 995 \mathrm{~cm}^{3} \mathrm{~min}^{-1}$, se considerados os valores de vazão anódica e catódica. Apesar de não ter sido feita uma validação independente neste intervalo de vazões, como realizado para o modelo Alfa, nota-se que os efeitos são consistentes com os observados na Seção 6.1.1. Em particular, foi sugerido o impacto das formulações através de "curvas de polarização" utilizando uma corrente da decomposição do ozônio, $I_{\mathrm{O}_{3}}$, e um sobrepotencial de concentração médio, $\eta_{C}$, indicando que a formulação SD subestima os valores de $\eta_{C}$. Isto é sugerido no caso do modelo FC mkII pelas curvas de polarização (Fig. 55) na região de limitação por transporte de massa. Para verificar a previsão do modelo Alfa, foram obtidas curvas de sobrepotencial de concentração médio de $\mathrm{H}_{2}$ e $\mathrm{O}_{2}$, conforme descrito na Seção 4.2.3. A Figura 59 compara os sobrepotenciais anódico e catódico simulados com as formulações DB e SD, para os conjuntos de vazões avaliados. Corroborando a inspeção das curvas de polarização, a formulação SD subestima significativamente tanto $\eta_{\mathrm{H}_{2}}$ como $\eta_{\mathrm{O}_{2}}$. É notável, no entanto, que os valores de $\eta_{\mathrm{H}_{2}}$ são mais negativos que os de $\eta_{\mathrm{O}_{2}}$ em todos os conjuntos de vazões, sugerindo que, neste caso, o $\mathrm{H}_{2}$ pode ser o reagente limitante. As curvas de sobrepotencial de concentração sumarizam o efeito que o uso da formulação SD tem na performance do dispositivo simulado, que é uma superestimativa significativa da distribuição e pressão parcial de reagentes.

\subsubsection{Contribuição do transporte convectivo}

Mais uma vez, conforme a ordem estabelecida acima, são avaliados os aspectos elétricos do dispositivo, a começar pelas curvas de polarização. A Figura 60 apresenta tais curvas para os conjuntos de vazões estudados, comparando os resultados do modelo FC mkII e mkII-mod. Os resultados experimentais são mantidos como referência. Similarmente ao observado acima, para as formulações de transporte de momento, e conforme esperado, as diferenças se tornam visíveis na região de polarização por transporte de massa. O efeito da remoção do transporte convectivo nos meios porosos é de diminuição de $E$ para um dado valor de $I$, sendo mais apreciável em altos valores de $I$ para os conjuntos III e IV (Fig. 60b). É notável, no entanto, que as curvas para o modelo mkII-mod encontram-se largamente dentro do erro experimental, com exceção de poucos pontos, de maneira similar às curvas do modelo mkII completo.

Os valores de $E(I=0)$ e $R_{\Omega}$ não serão avaliados, dado que a inspeção visual da Fig. 60 deixa claro que os valores serão muito semelhantes, ainda mais que no caso das formulações DB e SD (Fig. 55). Observa-se, no caso mais drástico, um leve aumento de $R_{\Omega}$ para o modelo mkII-mod, que pode ser largamente atribuído à rotina de regressão e à contribuição dos menores valores de $E$ em altos valores de $I$. 
Figura 59 - Sobrepotenciais médios a) anódico e b) catódico para as formulações DB (símbolos vazios) e SD (símbolos cheios). Os conjuntos de vazões são indicados no título de cada subgráfico: I $(\circ)$, II $(\square)$, III $(\triangle)$ e IV $(\diamond)$.
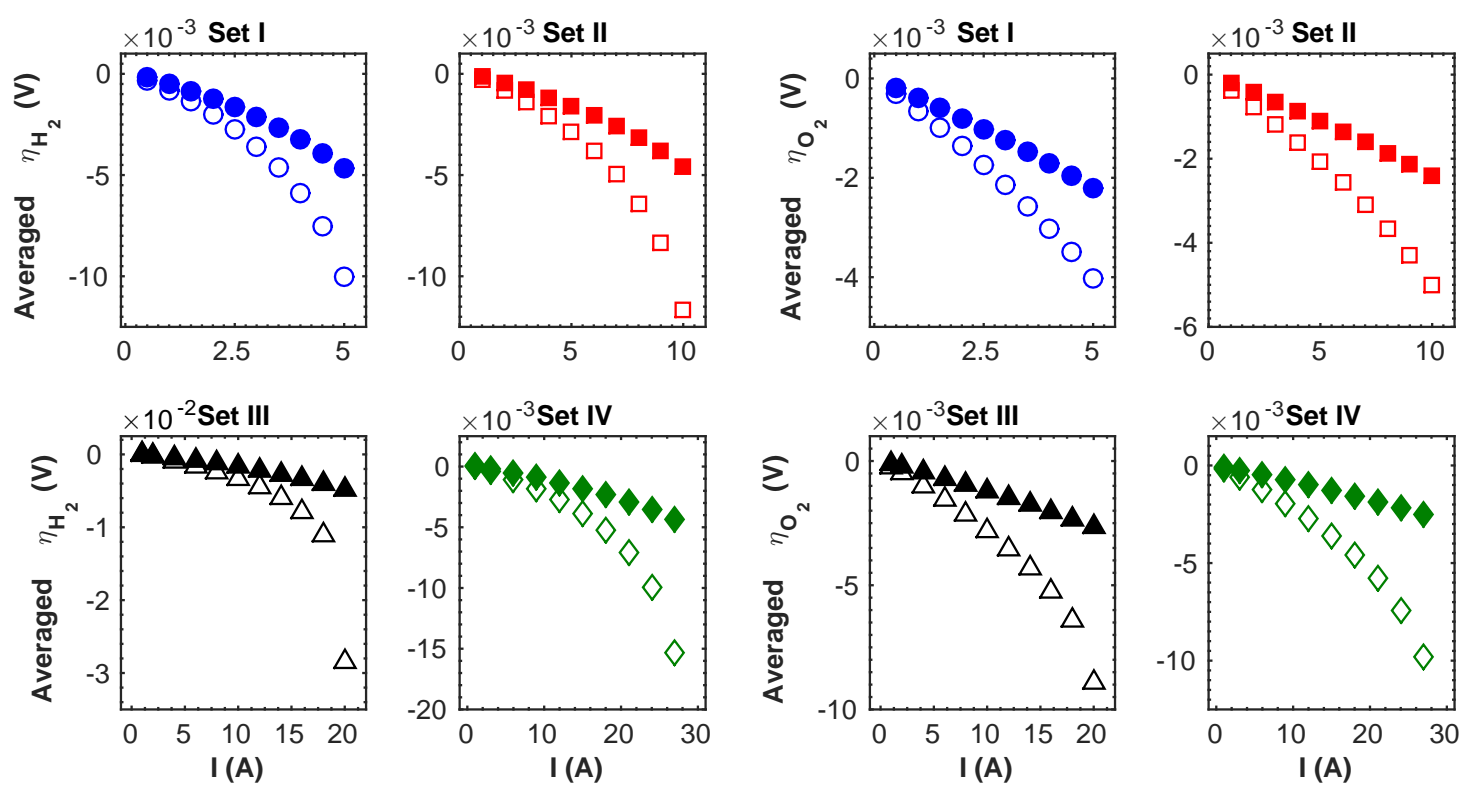

(a)

(b)

Fonte: Autoria própria.

Figura 60 - Curvas de polarização simuladas com o modelos FC mkII (símbolos vazios) e mkII-mod (símbolos cheios), para os conjuntos de vazão a) I (o) e II ( $\square$ ), e b) III $(\triangle)$ e IV ( $\diamond)$, conforme indicados no título de cada subgráfico. Os resultados experimentais $(\times)$ são incluídos como referência. As barras de erro nos resultados experimentais representam um desvio em relação à média.
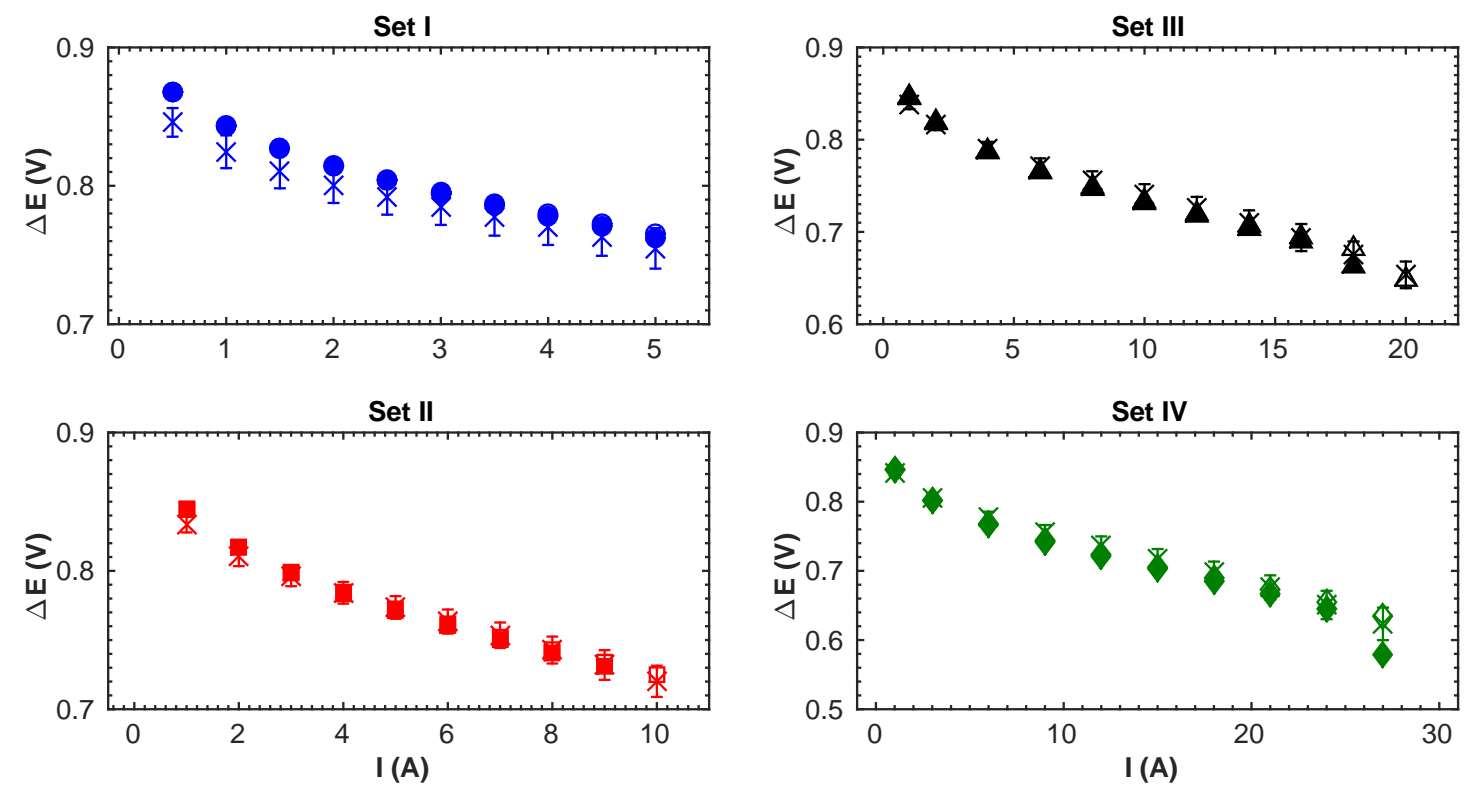

(a)

(b)

Fonte: Autoria própria. 
Seguindo em frente, as distribuições de corrente linearizadas são apresentadas na Figura 61, para os maiores valores de $I$ para cada conjunto de vazões. Conforme observados para as curvas de polarização, as distribuições de corrente para os conjuntos I e II, Figs. $61 \mathrm{a}$ e $61 \mathrm{~b}$ respectivamente, são similares entre os modelos mkII e mkII-mod. Também observa-se uma maior localização da corrente para o modelo mkII-mod, conforme esperado pelos menores valores de $E$ apresentados na região de polarização por transporte de massa nas curvas de polarização (Fig. 60a). Para os conjuntos III e IV, Figs. 61c e 61d respectivamente, observam-se diferenças significativas entre os resultados computacionais, sendo que o modelo mkII-mod prevê forte localização da corrente próximo às entradas de gases, especialmente para altas correntes no conjunto IV. Tais distribuições de corrente também são esperadas dados os valores de $E$ observados nas curvas de polarização (Fig. $60 \mathrm{~b})$.

Neste ponto é conveniente elaborar brevemente sobre os efeitos de localização da distribuição de corrente e dos valores de $E$ observados nas curvas de polarização. Apesar de observado e mencionado em vários pontos anteriormente, tal correlação foi tomada como óbvia, e seus motivos foram deixados implícitos. Como já mencionado, a região de altos valores de $I$ em uma dada curva de polarização, caracterizada pela não-linearidade e súbita queda de $E$, é dita controlada por transporte de massa. Dois efeitos contribuem de maneira significativa nesta região: i) o consumo de reagentes se aproxima do fluxo molar à CL, e ii) o encharcamento do cátodo, i.e. o acúmulo de água na fase líquida na CL catódica; em ambos os casos diminuindo a pressão parcial de reagentes e consequentemente aumentando significativamente o sobrepotencial de concentração $\eta_{i}$, conforme a Eq. 4.137. A definição de $\eta_{i}$ explica a diminuição de $E$ nas curvas de polarização, mas não deixa claro o motivo para a concentração de carga nas regiões próximas à entrada de gases. Isso se dá pelo motivo i), acima: dado que o consumo de reagentes exigido pelo valor de $I$ se aproxima do fluxo molar de entrada estabelecido pela estequiometria $\lambda_{i}$ (Eq. 3.1), o maior tempo de residência devido aos meios porosos faz com que a maior parte dos reagentes seja consumida logo na região de entrada dos gases. Tal efeito resulta na localização de corrente observada nas superfícies de corrente apresentadas anteriormente, explicando os efeitos observados, tanto para a comparação entre as formulações do transporte de momento, como para o modelo mkII-mod. Não significa, no entanto, que o mesmo pode ser dito do dispositivo experimental. Sabe-se que a presença de água líquida neste é provável, além disso o modelo FC mkII, em qualquer formulação, não reproduz adequadamente a totalidade dos resultados experimentais apresentados anteriormente.

Sendo esclarecido este ponto, serão utilizadas as curvas de sobrepotencial de concentração para quantificar o quanto o transporte convectivo, nos meios porosos, contribui para estes efeitos em uma PEMFC. A Figura 62 apresentas as curvas de $\eta_{\mathrm{H}_{2}}$ e $\eta_{\mathrm{O}_{2}}$ para os modelos mkII e mkII-mod. Como esperado, em ambos os casos o modelo mkII-mod apresenta valores de $\eta_{i}$ significativamente menores que os do modelo mkII, especialmente 
166

Capítulo 6. Resultados Computacionais

Figura 61 - Distribuições de corrente linearizadas simuladas com o modelos FC mkII (símbolos vazios) e mkII-mod (símbolos cheios), para os conjuntos de vazões a) I (o), b) II ( $\square$ ), c) III ( $\triangle$ ) e d) IV $(\diamond)$. Resultados experimentais $(\times \mathrm{e} \times)$ são incluídos como referência. As barras de erro nos resultados experimentais representam um desvio em relação à média.
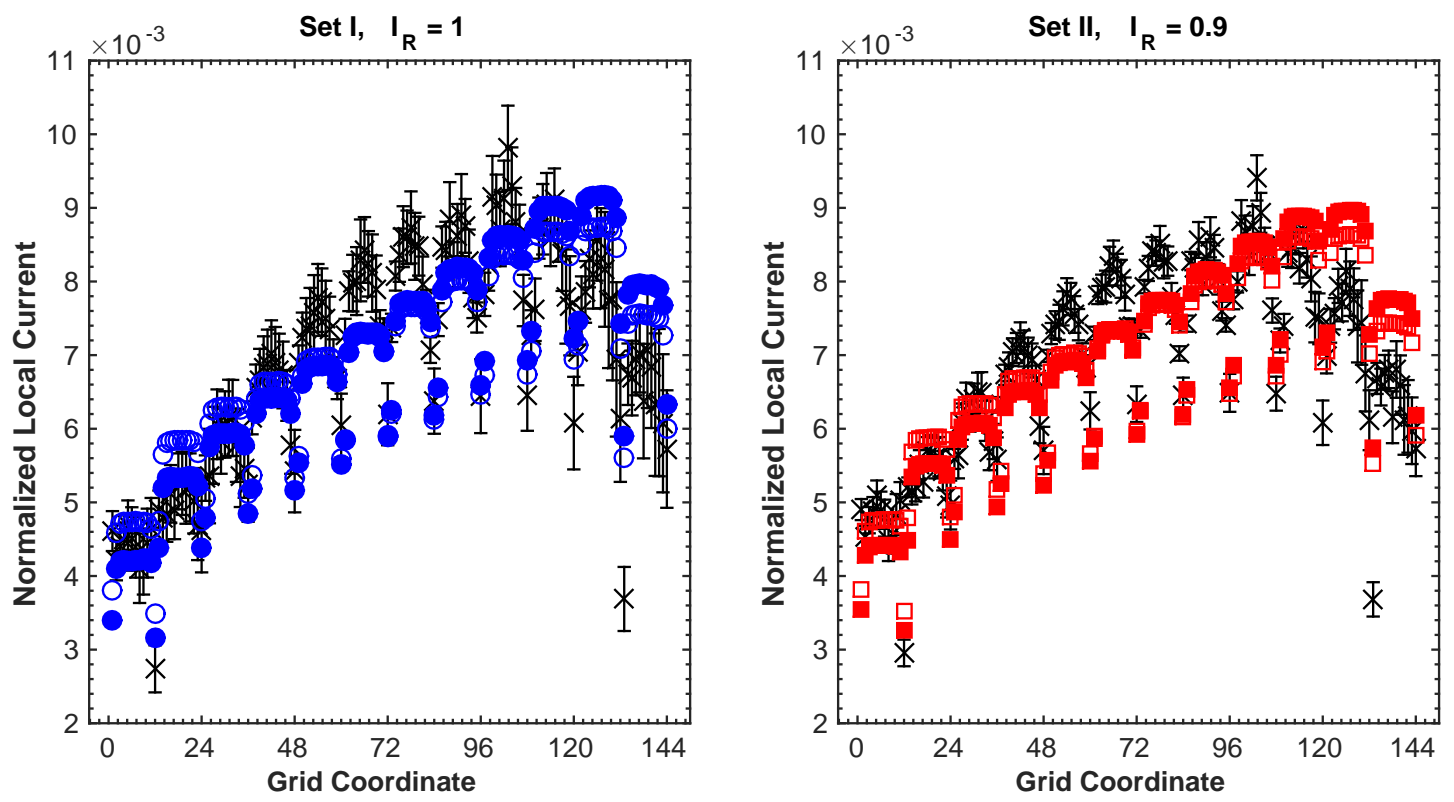

(a)

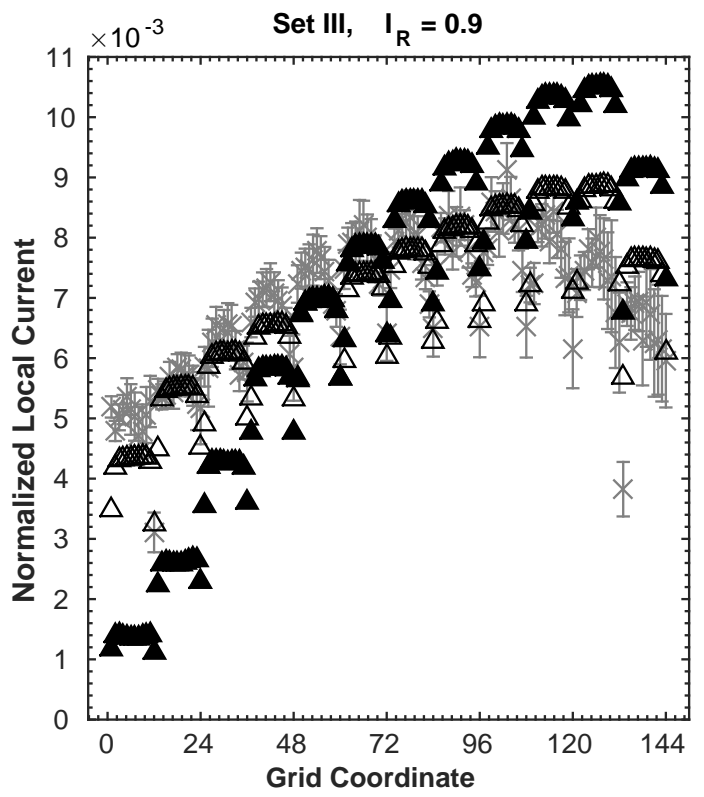

(c) (b)

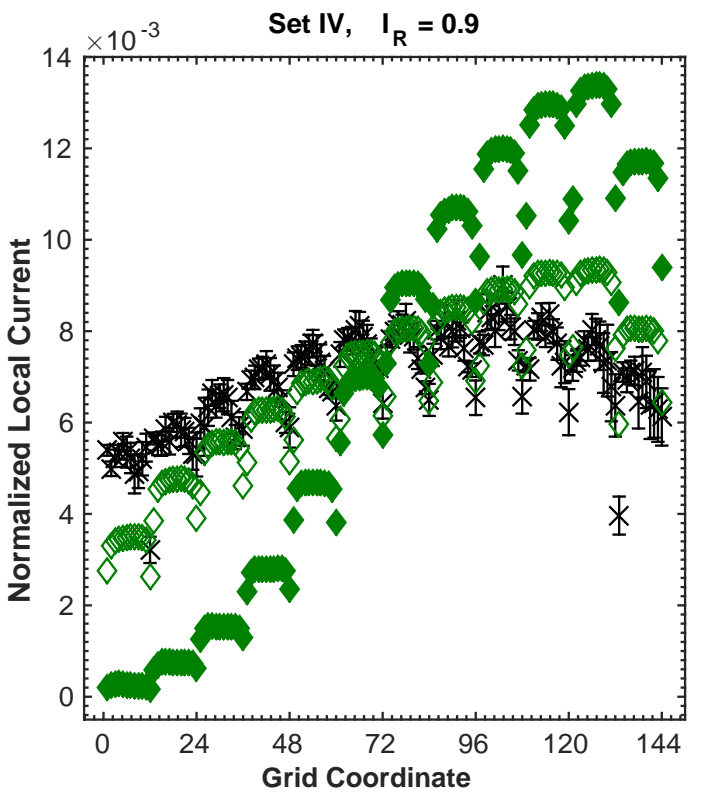

(d)

Fonte: Autoria própria. 
Figura 62 - Sobrepotenciais médios a) anódico e b) catódico para os modelos FC mkII (símbolos vazios) e mkII-mod (símbolos cheios). Os conjuntos de vazões são indicados no título de cada subgráfico: I (०), II $(\square)$, III $(\triangle)$ e IV $(\diamond)$.
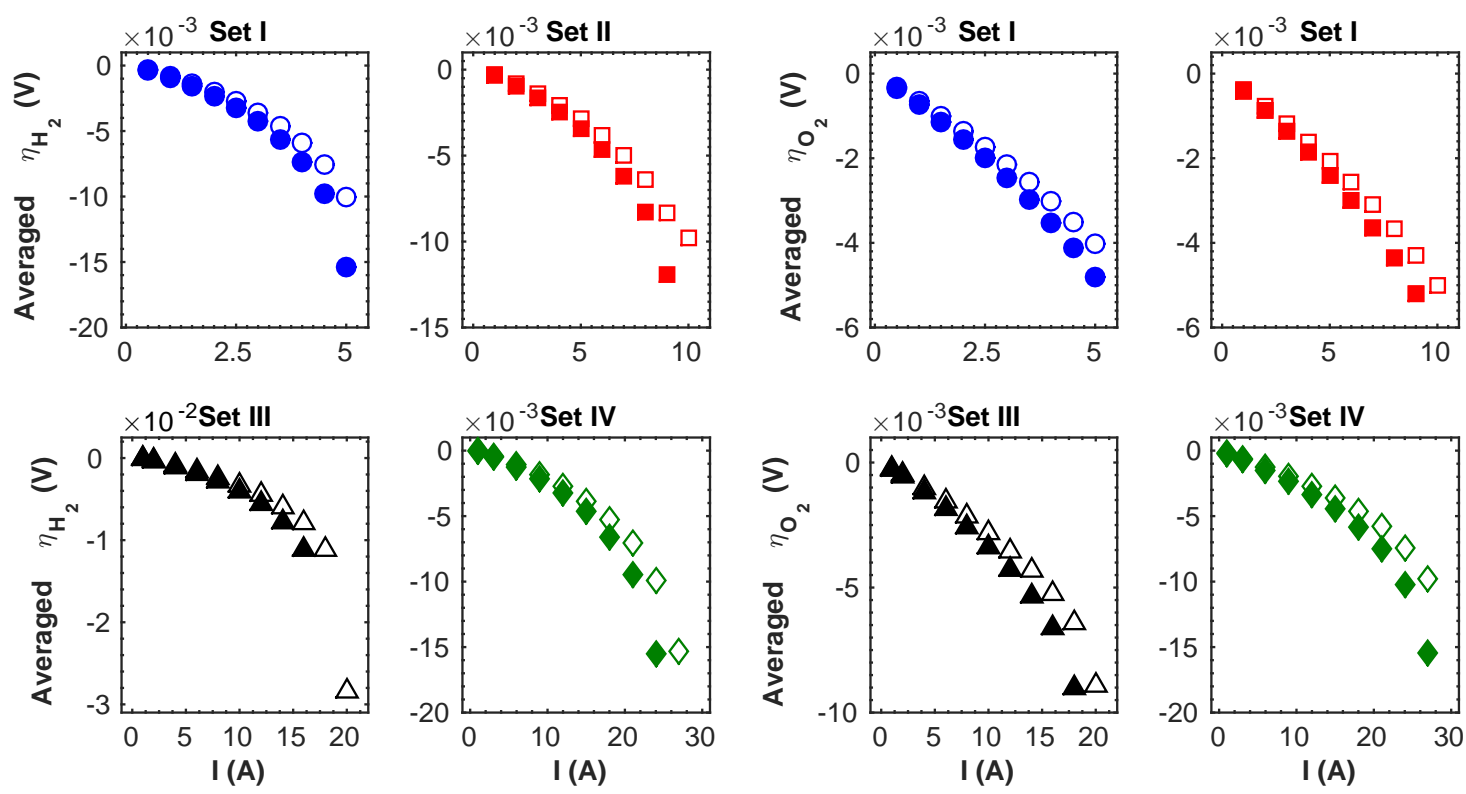

(a)

(b)

Fonte: Autoria própria.

para $\eta_{\mathrm{H}_{2}}$. Também é notável que, em altos valores de $I, \eta_{\mathrm{H}_{2}}$ diverge, como por exemplo no caso do conjunto III, devido à valores de $P_{\mathrm{H}_{2}}$ próximos a zero. Em relação à contribuição do transporte convectivo nos meios porosos, a Tabela 20 compila os intervalos de valores observados para a razão $\eta_{i}^{\text {full }} / \eta_{i}^{\text {mod }}$. Como é possível observar, de modo geral, o transporte convectivo nos meios porosos contribui, no mínimo, em $\approx 13 \%$ no sobrepotencial de concentração, dentro do intervalo previsto com o modelo Alfa (21\% - 3\%, Seção 6.1.2.2). Em altos valores de $I$, no entanto, esta contribuição pode ser de até $54 \%$ para o $\mathrm{H}_{2}$ e $37 \%$ para o $\mathrm{O}_{2}$, no caso do conjunto IV. Isto extende a análise feita com o modelo Alfa, de maneira análoga ao observado na Seção 6.2.2.1, considerando que o mesmo comportamento é observado entre os modelos FC mkII e mkII-mod, i.e. um aumento da contribuição do transporte convectivo nos meios porosos proporcional ao aumento de $Q$.

Tabela 20 - Razão entre os sobrepotenciais médios, anódico e catódico, dos modelos mkII e mkII-mod.

\begin{tabular}{ccc}
\hline \multirow{2}{*}{ Conjunto } & $\begin{array}{c}\text { Razão } \\
\text { Anódico }\end{array}$ & Caull $/ \eta_{i}^{\text {mod }}$ \\
& Catódico \\
\hline I & $0,65-0,87$ & $0,84-0,88$ \\
II & $0,70-0,86$ & $0,83-0,86$ \\
III & $0,71-0,86$ & $0,71-0,86$ \\
IV & $0,46-0,87$ & $0,63-0,86$ \\
\hline
\end{tabular}

Fonte: Autoria própria. 
Figura 63 - Curvas de temperatura dos compartimentos a) anódico e b) catódico, obtidas ao longo da curva de polarização, para os modelos FC mkII (símbolos vazios) e mkII-mod (símbolos cheios). Os conjuntos de vazão são indicados no título de cada subgráfico: I (o), II ( $\square)$, III $(\triangle)$, e IV $(\diamond)$. Os resultados experimentais são incluídos como referência. As barras de erro nos resultados experimentais representam um desvio em relação à média.
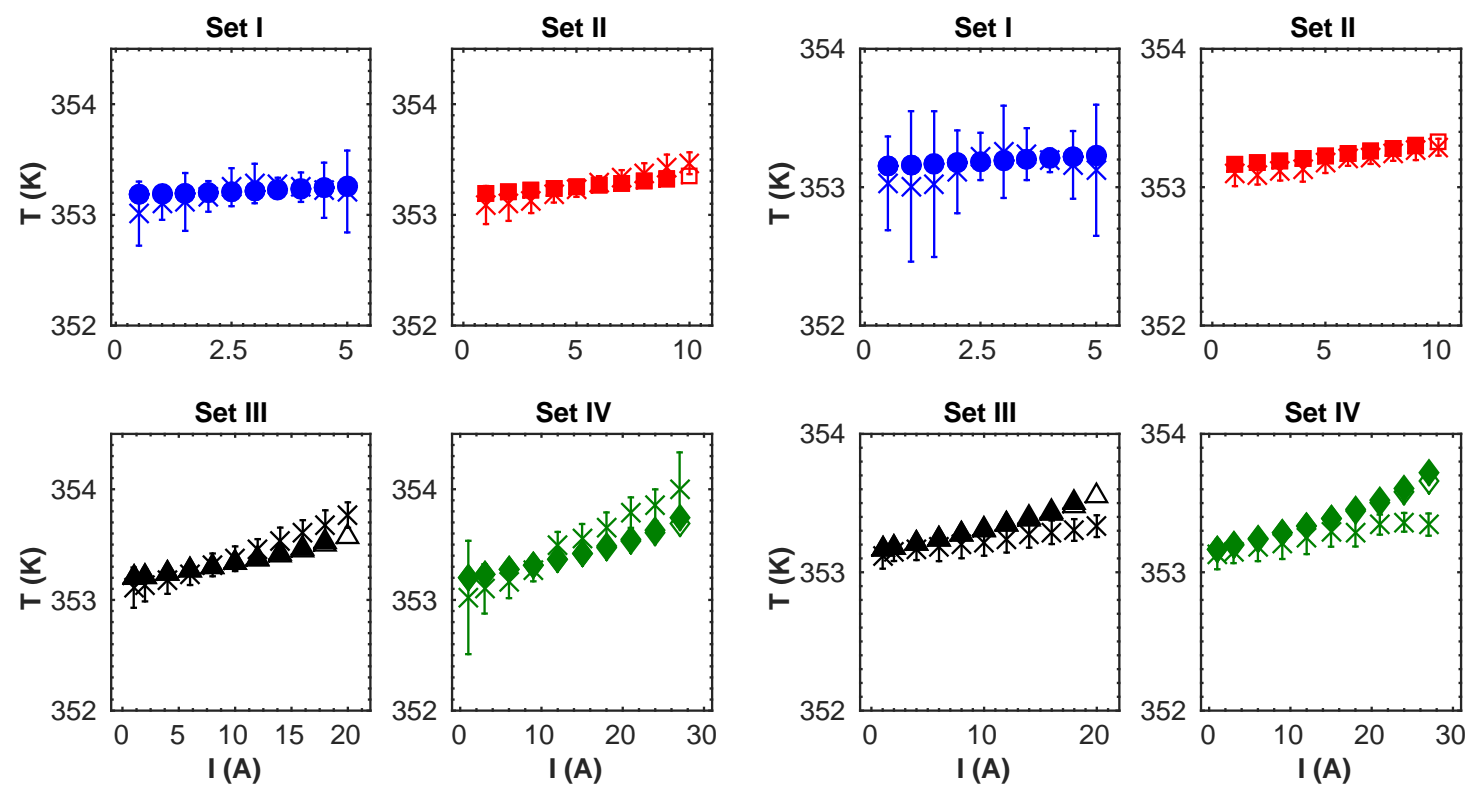

(a)

(b)

Fonte: Autoria própria.

Voltando-se para os aspectos térmicos, a Figura 63 apresenta as curvas de temperatura média dos compartimentos anódico e catódico. Como é possível observar, as diferenças entre os modelos são pequenas, sendo outra vez mais significativas em altos valores de I em cada conjunto de vazões. É notável, no entanto, que as diferenças são de ordem similar, ou até maiores, que as observadas entre as formulações DB e SD (Fig. 57). Porém, contrário ao caso mencionado, o modelo mkII-mod apresenta valores médio de temperatura levemente superiores aos do modelo mkII, em especial para o compartimento catódico, nos conjuntos III e IV. Considerando que o transporte de calor ainda é acoplado ao transporte convectivo, tal informação sugere que a localização de carga observada nas distribuições de corrente, acima, leva a um aumento da temperatura média. Apesar de esperado pelo efeito Joule, onde a potência de calor é dada por $P_{Q} \propto I^{2}$, é notável que a contribuição da convecção no transporte de espécies seja visível em situações relativamente brandas. No entanto, nenhuma variação qualitativa é observada nas curvas de temperatura, o que deixa o modelo mkII-mod na mesma situação que o modelo mkII, não sendo possível diferenciá-los dada a precisão atual dos resultados experimentais.

Quanto às distribuições de calor, a Figura 64 apresenta exemplos para os maiores valores de $I$ de cada conjunto de vazões, onde mais uma vez são esperadas diferenças significativas. Conforme sugerido pelas curvas de temperatura e distribuições de corrente, observa-se que o modelo mkII-mod prevê valores maiores de calor, especialmente próximo 
à entrada de gases. Atualizando a observação acima, é notável que as diferenças entre os modelos são superiores às diferenças entre as formulações DB e SD (Fig. 58). Também é digno de nota que as diferenças apresentam um perfil diferente do observado entre as formulações, neste caso sendo principalmente localizados próximo à entrada de gases, como mencionado, enquanto naquele caso as diferenças eram observadas ao longo de toda a superfície, em maior ou menor escala, dados os efeitos da formulação SD. Apesar da validação da formulação DB, e de ser reconhecido que transporte convectivo existe nos meios porosos independente da magnitude, é importante notar estas diferenças qualitativas, de modo a possibilitar a identificação de maneira inequívoca a origem dos processos físicos existentes no dispositivo real.

\subsubsection{Discussões}

Uma análise conjunta dos resultados apresentados nas Seções 6.2.2.1 e 6.2.2.2 traz luz a pontos levantados anteriormente, na Seção 6.2.1.3, e permite também estabelecer conclusões importante acerca do trabalho como um todo.

Em primeiro lugar, a análise acima mostra que as previsões dadas por modelos diferentes, seja em formulação matemática ou conceitualmente, resultam em resultados globais largamente semelhantes. Qualitativamente, considerando os resultados e incertezas experimentais, as previsões são virtualmente idênticas. Quantitativamente, as incertezas atualmente presentes nos resultados experimentais impossibilitam identificar qual modelo melhor representa a realidade. É claro que relativamente pouco foi avaliado neste trabalho, em relação aos modelos. No entanto, ao menos em relação ao transporte convectivo, sugere-se que foi o suficiente para responder parte da questão levantada na Seção 6.2.1.3: qual a necessidade de novos modelos sendo que modelos bem-sucedidos são observados na literatura. Ao que cabe os resultados e discussões apresentados neste trabalho, deve-se ao fato que os resultados experimentais reproduzidos pela grande maioria dos modelos reportados na literatura são, no mínimo, pouco significativos em relação à fundamentação teórica destes dispositivos. No mínimo, devido ao fato que estes, em sua maioria, não apresentam qualquer garantia de serem se quer reprodutíveis, muito menos de serem capazes de prover informações à respeito dos processos físicos por trás dos resultados observáveis.

Em segundo lugar as variáveis locais, por outro lado, revelam diferenças significativas entre os modelos, não tanto quantitativas mas qualitativas, que podem ser comparadas aos resultados experimentais fornecendo informações sobre a capacidade de um modelo de reproduzi-los. No entanto, ainda são relativamente raro os trabalhos que as usam, onde sugere-se que tratam-se de medidas especializadas, de difícil manipulação e comparação direta dos resultados, limitando o seu uso. Por outro lado, não se pode ignorar o fato de que muitos grupos de pesquisa não estudam o dispositivo, mas sim apenas o utilizam e buscam algum sucesso comercial. Também suspeita-se de que o simples fato de que tais 
Figura 64 - Distribuições de calor linearizadas simuladas com os modelos FC mkII (símbolos vazios) e mkII-mod (símbolos cheios), para os conjuntos de vazões a) I (o), b) II ( $\square)$, c) III $(\triangle)$ e d) IV $(\diamond)$.
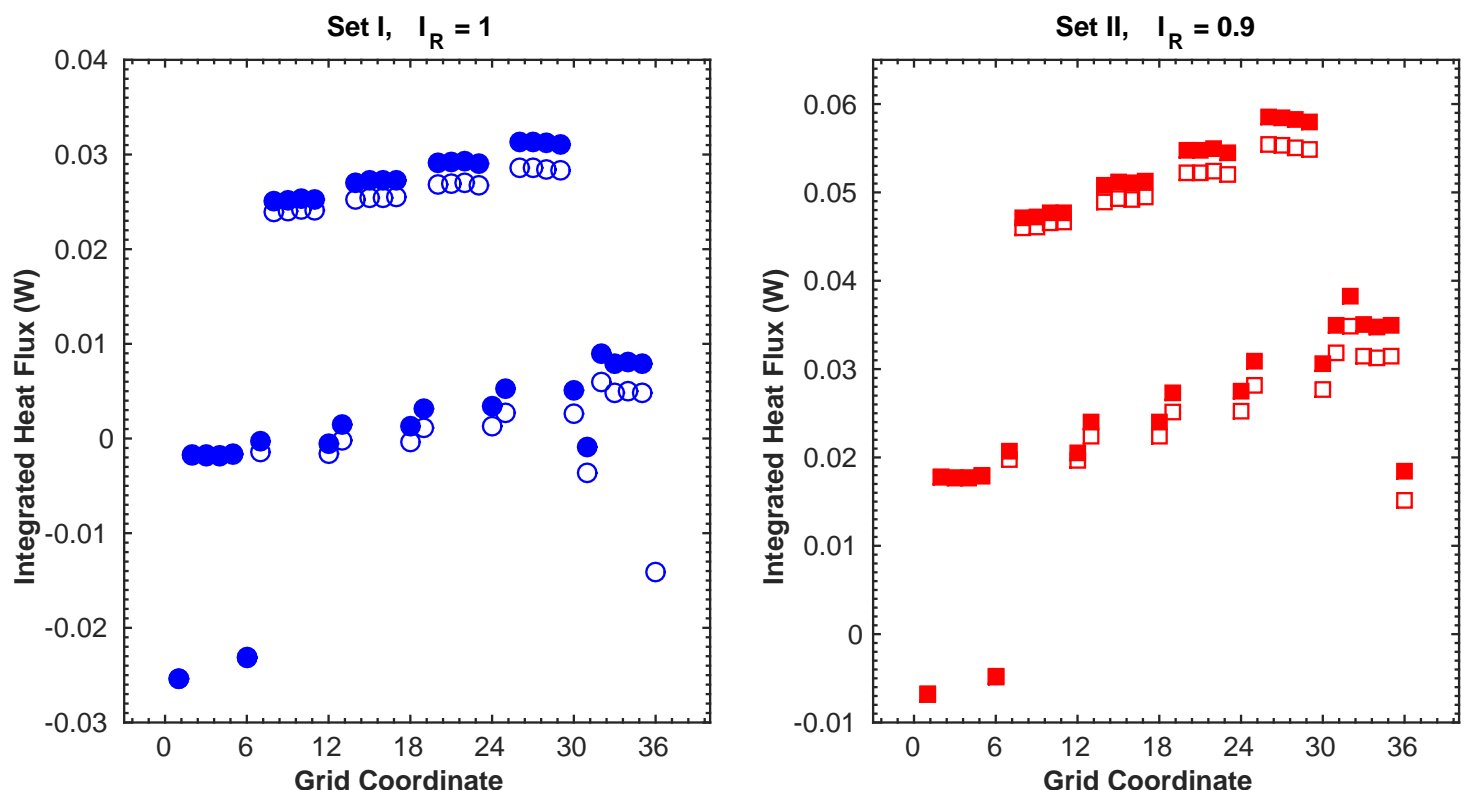

(a)

(b)
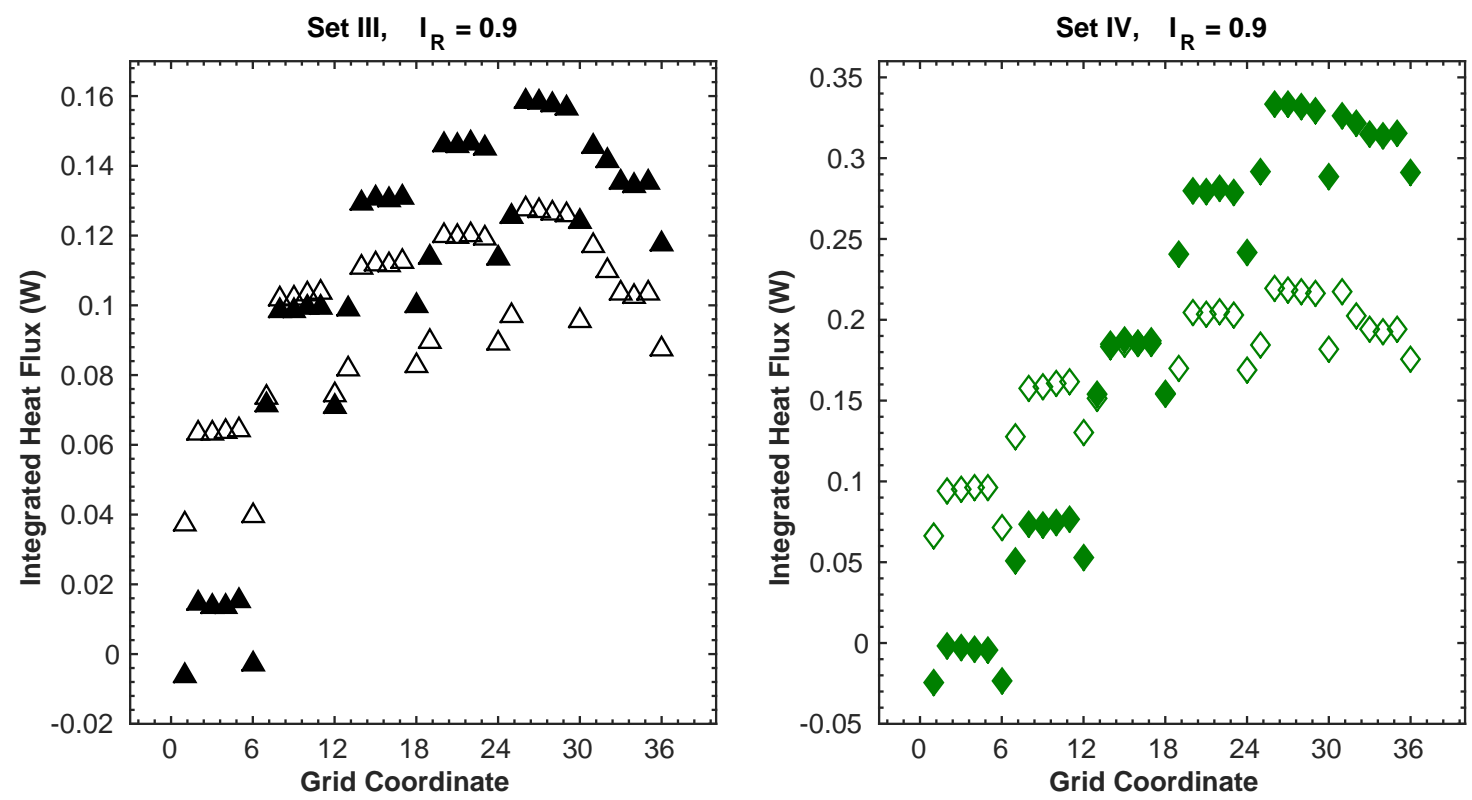

(c)

(d)

Fonte: Autoria própria. 
resultados apontam a insuficiência dos modelos mais utilizados atualmente, seja motivo suficiente para que estes sejam "indisponíveis". O compartilhamento, entre pesquisadores, de resultados experimentais e computacionais de forma padronizada poderia suprir uma lacuna particularmente grande neste campo.

Em relação a pontos específicos dos resultados apresentados na Seção 6.2.2, alguns pontos adicionais podem ser levantados. Em relação à formulação do transporte de momento, um ponto digno de ser ressaltado é a superestimativa da performance do dispositivo prevista pela formulação SD. Isto sugere que, para modelos que apresentem parâmetros ajustáveis, estes estão sujeitos a subestimar a qualidade de materiais ou mesmo as condições ótimas de operação para um sistema, por exemplo as vazões de entrada. Existem subjetividades em relação às formulações $\mathrm{DB}$ e SD, como discutido para o modelo Alfa na Seção 6.1.1.3. Porém vários trabalhos reportados, relativamente recentes, utilizam a formulação SD ou variantes sem o devido cuidado quanto às condições de contorno e paramétricas, potencialmente propagando um erro significativo (exemplos podem ser encontrados em (13) e, de maneira mais notável, em (17) e (87)).

Quanto ao transporte convectivo, conforme notado brevemente durante os estudos com o modelo Alfa (Seção 6.1.2), este representa um ponto largamente inexplorado em PEMFCs; a notar pela breve referência a respeito de convecção na revisão de Weber e Newman(13) sobre modelagem de fenômenos de transporte em PEMFCs. Isto também se reflete pela aparente pouca importância dada à formulação utilizada, como descrito acima. No entanto, trabalhos mais recentes têm se preocupado com o papel do transporte convectivo, apesar que usualmente focados na manutenção da água líquida nos canais de escoamento a nível micro- ou mesoscópico, e.g. $(88,89)$. Ainda assim, os resultados da Seção 6.2.2.2 demonstram a importância, e o potencial, do estudo do transporte convectivo a nível macroscópico mesmo na ausência de escoamento bifásico.

O tratamento, ou não, de escoamento bifásico merece um breve comentário. Muita atenção é dada para o tratamento da manutenção da fase líquida em PEMFCs de baixa temperatura $(<373 \mathrm{~K})$, dada sua importância na distribuição de reagentes e temperatura e manutenção da integridade da PEM. Em particular, é notável a correlação usualmente assumida entre o encharcamento do cátodo e o aumento do sobrepotencial de concentração nas região de limitação por transporte de massa em curvas de polarização, conforme apontado anteriormente. No entanto, como observado na Seção 6.2.1.1, o modelo FC mkII foi capaz de reproduzir a região de polarização por transporte de massa das curvas de polarização nos quatro conjuntos de vazões estudados, apesar de não considerar de maneira nenhuma a existência de fase líquida. Além disso, apesar do fracasso em reproduzir os aspectos locais do dispositivo experimental, observou-se boa concordância entre as distribuições de corrente experimentais e computacionais nesta mesma região. A validação independente da formulação do transporte de momento reforça a significância destes resultados, dado que fora demonstrado a capacidade deste de reproduzir adequadamente 
os resultados experimentais em um sistema onde a presença de água líquida pode ser completamente negligenciada. Não nega-se, é claro, que o tratamento de água líquida é necessário para a correta descrição do sistema. Sublinha-se, no entanto, a possibilidade de efeitos mais importantes que o tratamento da fase líquida dependendo das condições operacionais do dispositivo, mesmo em baixas temperaturas.

Seguindo a linha de raciocínio de que certos pontos tendem a ser exagerados, a análise dos sobrepotenciais de concentração anódico e catódico (Fig. 62 e a Tab. 20) revelou algo usualmente negligenciado em relação à polarização por transporte de massa. Conforme mencionado, um dos efeitos que contribuem para o aumento de $\eta_{i}$ é o consumo de reagentes se aproximar do fluxo molar de espécies à CL. No entanto, assume-se usualmente que o maior limitante é o $\mathrm{O}_{2}$, principalmente devido ao possível encharcamento do cátodo. Porém, como apontado anteriormente para a Fig. 59, e reforçado aqui, observa-se uma predominância de valores $\eta_{\mathrm{H}_{2}}<\eta_{\mathrm{O}_{2}}$ para os conjuntos de vazões estudados. Isto traz algumas implicações sobre o funcionamento de uma PEMFC e sobre o modelo FC mkII. Em primeiro lugar, uma primeira abordagem sugere que uma estequiometria de $\lambda_{\mathrm{H}_{2}}=1,2$ não é adequada para garantir um suprimento de $\mathrm{H}_{2}$ para os valores de $I$ indicados. Por outro lado, deve-se lembrar que tanto dispositivo experimental como o modelo mkII não foram pressurizados, enquanto que os valores de $\lambda_{i}$ sugeridos em (41) são acompanhados da imposição de 25 psi sobre o sistema. Caso tais condições sejam suficientes para evitar altos $\eta_{\mathrm{H}_{2}}$, e que portanto os resultados aqui apresentados são artefatos, sugere-se maior rigor quando na determinação das condições experimentais. A gravidade é devido ao fato que os valores de $Q$ que acompanham os valores de $I$ e $\lambda_{i}$ são facilmente calculados usando aproximações grosseiras e condições padrão para os fluxos molares anódico e catódico. A precisão recai, portanto, à calibração e experiência prévia de usuários, experimentais ou computacionais, para adequar o sistema às condições recomendadas. Levando isto em conta, não é de se espantar a significativa discrepância entre resultados de grupos de pesquisa diferentes, como apontado na Seção 6.2.1.3, e uma falta aparente de replicatas em trabalhos experimentais.

Em relação ao modelo FC mkII, desconsiderando o apontado acima para as condições experimentais, o ponto mais evidente é uma má retratação do sistema, em particular para o ânodo. Entre os pontos passíveis de contribuir significativamente para tal discrepância, podem ser citados i) a fração mássica de entrada de $\mathrm{H}_{2}$, que é desconhecida; ii) as condições padrão da entrada de fluido; iii) a cinética eletroquímica da oxidação de $\mathrm{H}_{2}$; e de modo mais geral, iv) a descrição dos materiais envolvidos no dispositivo. Como mencionado na Seção 4.2, o modelo mkII é um modelo base, considerado consistente, porém de maneira nenhuma completo. O aprimoramento da formulação matemática, e o refino contínuo dos parâmetros e condições de contorno utilizadas, utilizando tais discrepâncias com os resultados experimentais, e outras apontadas anteriormente, são importantes para o progresso nos estudos computacionais desenvolvidos aqui. Igualmente importante é 
a diminuição da incerteza experimental, e a obtenção de maiores informações sobre o dispositivo e suas componentes, de modo a possibilitar testes mais rigorosos dos modelos futuramente desenvolvidos. 



\section{CONSIDERAÇÕES FINAIS}

Em resumo, foram apresentados estudos computacionais referentes à PEMFCs, tanto para um protótipo como um dispositivo real. Os modelos computacionais apresentados foram comparados à resultados experimentais, quando possível, permitindo avaliar a exatidão dos modelos. Uma breve análise dos resultados experimentais mostrou a importância de replicatas, e também a magnitude da incerteza decorrente de particularidades do sistema. Nos estudos computacionais foi dado foco na dinâmica de fluidos e o impacto desta nos demais processos observados nos dispositivos experimentais, sendo utilizado o protótipo de célula para validar a abordagem utilizada. Foi possível avaliar a contribuição do transporte convectivo na distribuição de espécies e demais variáveis relevantes em cada dispositivo. Mais significativamente, a análise da dinâmica de fluidos na protocélula permitiu propor a melhor geometria de canais para uma dada estequiometria, considerando a distribuição espacial de espécies. Por outro lado, para o dispositivo real, foi possível reproduzir as curvas de polarização através de um modelo sem parâmetros ajustáveis, ao mesmo tempo em que a distribuição espacial de corrente é marcadamente diferente do observado experimentalmente.

Mais especificamente, em relação aos resultados experimentais, foi observado que os resultados obtidos com um MEA são estatisticamente diferentes dos obtidos com outro. Tal constatação levanta dúvidas gerais sobre a validade de resultados sem replicatas, mas no caso específico deste trabalho, contribui para a incerteza da validação dos modelos computacionais. Por outro lado, foi apresentado um grande conjunto de dados que é facilmente obtido experimental e computacionalmente, contribuindo para demonstrar que a visão dada por Weber e colaboradores(17), a respeito da validação de modelos computacionais, é factível.

Quanto aos resultados computacionais, a começar pelos modelos Alfa e Beta, foi validada a formulação matemática da dinâmica de fluidos em meios livre e poroso, além de se estudar as contribuição do transporte convectivo nos meios porosos de uma PEMFC. Foi demonstrado que a formulação de Stokes-Darcy, largamente utilizada em modelos de PEMFCs, é incapaz de reproduzir adequadamente a dinâmica de fluidos de um protótipo de PEMFC. Por outro lado, a formulação de Darcy-Brinkman foi capaz de reproduzir, dentro das incertezas experimentais, o comportamento observado no dispositivo real. $\mathrm{O}$ modelo Alfa foi então utilizado para demonstrar que o transporte convectivo tem papel fundamental, mesmo nos meios porosos, para explicar o desempenho de uma PEMFC. Foi observado que escoamentos secundários presentes nos canais de escoamento são essenciais para descrever corretamente a distribuição espacial de espécies na camada catalítica. A contribuição de tais escoamentos, e de fato do transporte convectivo como um todo, foram calculados como sendo de 0,29 a 0,58 do transporte total de espécies à CL, dentro do intervalo estudado de $200 \leq Q \leq 450 \mathrm{~cm}^{3} \mathrm{~min}^{-1}$. 
Refinando o modelo Alfa, foi obtido um modelo capaz de concordar quantitativamente, dentro das incertezas, com os resultados experimentais disponíveis. Dentre as mudanças no modelo, foi incorporada a deformação do substrato macroporoso em resposta da compressão dos meios porosos. Apesar de não ter sido possível reproduzir as dispersões observadas nas superfícies de pressão parcial experimentais, foi possível mostrar que as deformações do MPS sobre o FC são essenciais para reproduzir corretamente os resultados experimentais de maneira quantitativa. Tal resultado aponta para a necessidade de se incorporar efeitos de deformação mecânica explicitamente em modelos de PEMFCs. Em retrospecto, no entanto, tal necessidade é de longa data, considerando a configuração da PEMFC utilizada neste trabalho. Por fim, com o modelo Beta, foi explorada a dinâmica de fluido em quatro outras geometrias de FC comumente utilizadas. Foi quantificada a contribuição do transporte convectivo em cada caso, culminando na proposição de uma medida de mérito para classificação da melhor geometria, neste caso a minimização do sobrepotencial de concentração em função da estequiometria utilizada. No caso dos valores recomendados para PEMFCs(41), observou-se que os melhores desenhos de FC são serpentina-1 e serpentina-2 ou 3, para o cátodo (considerando ar, $\lambda_{\mathrm{O}_{2}}=2$ ) e ânodo $\left(\lambda_{\mathrm{H}_{2}}=1,2\right)$, respectivamente.

Em relação aos estudos sobre a PEMFC, foi possível obter boa concordância entre os aspectos elétricos globais do modelo FC mkII e do dispositivo real. As curvas de polarização simuladas encontram-se, em grande parte do intervalo de corrente total, dentro das incertezas experimentais, para cada conjunto de vazões estudado. Os efeitos de polarização por ativação e queda ôhmica também são bem descritos em todos os casos, o que é digno de nota considerando as aproximações do modelo e a falta de parâmetros ajustáveis. Por outro lado, os demais pontos de comparação entre computacional e experimental tiveram, no melhor dos casos, pouco êxito. As curvas de temperatura média dos compartimentos anódico e catódico, ao longo das curvas, apresentaram em geral boa concordância qualitativa, apresentando, no entanto, valores consistentemente inferiores, no caso do ânodo, e superiores, no caso do cátodo. Os aspectos locais, por outro lado, falharam de maneira significativa em reproduzir o comportamento experimental, em especial para a distribuição de temperatura (calor). Enquanto que a tendência geral ao longo da curva de polarização foi similar, o comportamento espacial simulado difere do experimental em quase todos os casos. Dado que os aspectos globais apresentaram boa concordância, suspeita-se que a parametrização é satisfatória, apesar que compensação de erros não pode ser descartada. Dada a formulação do modelo mkII, sugere-se que há efeitos desconsiderados por este que são cruciais na correta reprodução do dispositivo experimental.

Apesar do fracasso em reproduzir os aspectos locais do dispositivo experimental, o modelo mkII utiliza da formulação matemática validada através dos modelos Alfa e Beta. Com isso, foi possível quantificar o erro relacionado ao uso da formulação Stokes-Darcy no 
modelo de uma PEMFC real, sendo observado que esta superestima de maneira significativa o desempenho do dispositivo. No caso do conjunto de dados disponível, é notável que a formulação SD é um modelo pior que a formulação DB, em especial em valores de corrente próximos à estequiometria nominal. Isto corrobora o observado ao se estudar o protótipo de célula e os modelos Alfa e Beta, dando maior validade à plataforma proposta por Lopes e colaboradores(33). Por outro lado, tais resultados também sugerem que modelos que utilizem a formulação SD em condições próximas à estequiometria estão compensando de alguma maneira os resultados computacionais obtidos, muitas vezes apresentados como concordando com resultados experimentais. A contribuição do transporte convectivo também foi quantificada, estendendo a análise feita para a protocélula. Foi observado que a contribuição da convecção nas camadas porosas é significativa, reduzindo em até $54 \%$ e 37\% o sobrepotencial anódico e catódico, respectivamente, para os maiores valores de vazão estudados. Em particular, foi observado que a redução do sobrepotencial devido ao transporte convectivo de $\mathrm{O}_{2}$ nas camadas porosas é de $16 \%$ a $47 \%$, para um intervalo de $166 \leq Q_{\text {cat }} \leq 995 \mathrm{~cm}^{3} \mathrm{~min}^{-1}$. Tal resultado é condizente com a contribuição sugerida pelo modelo Alfa, corroborando mais uma vez os estudos realizados com a protocélula.

Conclui-se, assim, que a obtenção de resultados experimentais para a validação, tanto global como local, de modelos computacionais é passível de ser realizada de maneira adequada. Tendo em mãos tais resultados, foi demonstrado a obtenção de modelos capazes de descrever tais dispositivos corretamente, mas também a necessidade do aprimoramento contínuo dos mesmos. Paralelamente, é necessário o refino dos conjuntos de dados, e a busca por novas medidas capazes de providenciar informações sob aspectos previamente inacessíveis. Os resultados são, potencialmente, o entendimento dos fenômenos que existem nestes sistemas, e a possibilidade de auxiliar no desenvolvimento tecnológico dos mesmos. 



\section{PERSPECTIVAS}

Considerando o que foi desenvolvido no trabalho e o que já é conhecido na literatura, alguns pontos podem ser sugeridos para direcionar futuros trabalhos, tanto computacionais como experimentais. Em termos gerais, conforme já apontado durante o desenvolvimento deste documento, há a necessidade de incorporar aspectos sabidamente negligenciados nos modelos Beta e FC mkII, e a busca de mais dados empíricos para a validação contínua dos modelos computacionais. Especificamente, no aspecto computacional, os pontos imediatos a serem trabalhados, em relação à protocélula, podem ser tomados como:

- Incorporação de interação entre espécies e tratamento explícito dos componentes do ar, i.e. tratamento de misturas concentradas;

- Desenvolvimento da cinética de degradação do ozônio, buscando, ou calculando, a constante de velocidade; e incorporando o tratamento de reações heterogêneas.

- Aprimoramento da descrição mecânica dos materiais e do processo de compressão dos meios porosos.

Futuramente, também é de interesse a incorporação de escoamento bifásico e transporte de calor, de modo a possibilitar uma plataforma mais semelhante à PEMFCs reais. Adicionalmente, pretende-se estudar a medida de mérito proposta para a otimização de geometrias de canais de escoamento, e posterior validação experimental. Com o refino do modelo, espera-se obter uma melhor representação do sistema através do sobrepotencial de concentração, e também a proposição de outras medidas de mérito para demais variáveis de interesse.

Em relação à PEMFCs, os seguintes pontos são de interesse imediato:

- Desenvolvimento da cinética eletródica, através do detalhamento das etapas elementares das reações anódica e catódica, assim como pelo aprimoramento do modelo de eletrodo poroso utilizado.

- Aprimoramento das condições do transporte de calor, como por exemplo condições de aquecimento da célula, perda de calor ao ambiente e fontes e sorvedouros de calor.

- Incorporação da mecânica dos sólidos presentes no dispositivo, e a descrição da influência da distribuição não-uniforme de tensão mecânica na compressão dos elementos do MEA.

- Descrição do transporte de água através da PEM, de modo a incorporar efeitos de fluxo eletro-osmótico e da dependência da condutividade local com a hidratação da mesma, ao mesmo tempo estabelecendo a base para a incorporação de escoamento bifásico. 
Tais pontos representam vulnerabilidades no modelo FC mkII, portanto são imperativos de serem explorados. Futuramente, a incorporação do escoamento bifásico e a busca por uma descrição universal das espécies presentes no dispositivo são, também, de interesse.

No aspecto experimental, o primeiro passo é a identificação de possíveis erros sistemáticos presentes na aquisição de dados, seguida do contínuo acúmulo de dados de modo a minimizar erros aleatórios passíveis de existir. Também é de interesse imediato a obtenção de informações a respeito dos materiais em uso no dispositivo sob estudo, minimizando o problema de diversidade de materiais e desenhos de PEMFCs. Futuramente, é de interesse a busca por novas técnicas, ou a implementação de técnicas já conhecidas, para a obtenção de informações atualmente inacessíveis nos dispositivos em estudo, como por exemplo a distribuição de água líquida nos canais de escoamento e MEA, através de técnicas espectroscópicas ou de espalhamento; ou ainda a estrutura tridimensional do MEA e sua propriedades de transporte, através de técnicas de tomografia. 


\section{REFERÊNCIAS}

1 YANG, Y.-B.; SUFIAN, R. S.; ALEXANDRU, A.; DRAPER, T.; GLATZMAIER, M. J.; LIU, K.-F.; ZHAO, Y. Glue spin and helicity in the proton from lattice QCD.

Physical Review Letters, v. 118, p. 102001, 2017.

2 CASTELVECCHI, D. Taxi-sharing in cities follow universal maths law. 2017. Disponível em: 〈http://www.nature.com/news/ taxi-sharing-in-cities-follows-universal-maths-law-1.21586 $\rangle$. Acesso em: 04 abr. 2017.

3 SNOW, J. Computers learn to cooperate better than humans. 2017. Disponível em: 〈http://www.sciencemag.org/news/2017/03/ computers-learn-cooperate-better-humans $\rangle$. Acesso em: 04 abr. 2017.

4 HUTSON, M. Beware emotional robots: giving feelings to artificial beings could backfire, study suggests. 2017. Disponível em: 〈http://www.sciencemag.org/news/2017/03/ beware-emotional-robots-giving-feelings-artificial-beings-could-backfire-study-suggests $\rangle$. Acesso em: 04 abr. 2017.

5 MASSONNET, F.; BELlPRAT, O.; GUEMAS, V.; DOBLAS-REYES, F. J. Using climate models to estimate the quality of global observational data sets. Science, v. 354, p. $452-455,2016$.

6 CHAND, S. S.; TORY, K. J.; YE, H.; WALSH, K. J. E. Projected increase in El Niño-driven tropical cyclone frequency in the Pacific. Nature Climate Change, v. 7, p. 123-127, 2017.

7 BAKKER, P.; ClARK, P. U.; GOLlEDGE, N. R.; SCHMITTNER, A.; WEBER, M. E. Centennial-scale Holocene climate variations amplified by Antarctic ice sheet discharge. Nature, v. 541, p. 72-76, 2017.

8 ABBOTT, B. P. Observation of gravitational waves from a binary black hole merger. Physical Review Letters, v. 116, p. 061102, 2016.

9 ABBOTT, B. P. GW151226: observation of gravitational waves from a 22-solar-mass binary black hole coalescence. Physical Review Letters, v. 116, p. 241103, 2016.

10 BLOCK, D. L.; BOURNAUD, F.; COMBES, F.; GROESS, R.; BARMBY, P.; ASHBY, M. L. N.; FAZIO, G. G.; PAHRE, M. A.; WILLNER, S. P. An almost head-on collision as the origin of two off-centre rings in the Andromeda galaxy. Nature, v. 443, p. 832-834, 2006.

11 MAYER, L.; KAZANTZIDIS, S.; ESCALA, A.; CALLEGARI, S. Direct formation of supermassive black holes via multi-scale gas inflows in galaxy mergers. Nature, v. 466, p. 1082-1084, 2010.

12 Alimi, J.-M.; BOUILLOT, V.; REVERDY, V.; CORASANITI, P.-S.; BALMES, I.; REQUENA, S.; DELARUELLE, X.; RICHET, J.-N. DEUS full observable $\Lambda$ CDM universe simulation: the numerical challenge. arXiv, 2012. Disponível em: 〈https://arxiv.org/abs/1206.2838〉. Acesso em: 22 maio 2017. 
13 WEBER, A. Z.; NEWMAN, J. Modeling transport in polymer-electrolyte fuel cells. Chemical Reviews, v. 104, p. 4679-4726, 2004.

14 KREUER, K.-D.; PADDISON, S. J.; SPOHR, E.; SCHUSTER, M. Transport in proton conductors for fuel-cell applications: simulations, elementary reactions and phenomenology. Chemical Reviews, v. 104, p. 4673-4678, 2004.

15 BAVARIAN, M.; SOROUSH, M.; KEVREKIDIS, I. G.; BENZIGER, J. B.

Mathematical modeling, steady-state and dynamic behavior, and control of fuel cells: a review. Industrial \& Engineering Chemistry Research, v. 49, p. 7922-7950, 2010.

16 BARBIR, F. PEM fuel cells: theory and practice. 2a ${ }^{\mathrm{a}}$ ed. San Diego: Academic Press, 2013. 518 p.

17 WEBER, A. Z.; BORUP, R. L.; DARLING, R. M.; DAS, P. K.; DURSCH, T. J.; GU, W.; HARVEY, D.; KUSOGLU, A.; LITSTER, S.; MENCH, M. M.; MUKUNDAN, R.; OWEJAN, J. P.; PHAROAH, J. G.; SECANELL, M.; ZENYUK, I. V. A critical review of modeling transport phenomena in polymer-electrolyte fuel cells. Journal of the Electrochemical Society, v. 161, p. F1254-F1299, 2014.

18 PANTEA, D.; DARMSTADT, H.; KALIAGUINE, S.; ROY, C. Electrical conductivity of conductive carbon blacks: influence of surface chemistry and topology. Applied Surface Science, v. 217, p. 181-193, 2003.

19 WILliAMS, M. V.; BEGG, E.; BONVILLE, L.; KUNZ, H. R.; FENTON, J. M. Characterization of gas diffusion layers for pemfc. Journal of the Electrochemical Society, v. 151, p. A1173-A1180, 2004.

20 KHANDELWAL, M.; MENCH, M. M. Direct measurement of through-plane thermal conductivity and contact resistance in fuel cell materials. Journal of Power Sources, v. 161, p. 1106-1115, 2006.

21 GURAU, V.; BLUEmLE, M. J.; CASTRO, E. S. D.; TSOU, Y.-M.; JR., T. A. Z.; JR., J. A. M. Characterization of transport properties in gas diffusion layers for proton exchange membrane fuel cells 2. absolute permeability. Journal of Power Sources, v. 165, p. 793-802, 2007.

22 FISHMAN, Z; BAZYLAK, A. Heterogeneous through-plane distributions of tortuosity, effective diffusivity, and permeability for pemfe gdls. Journal of the Electrochemical Society, v. 158, p. B247-B252, 2011.

23 LOBATO, J.; nIZARES, P. C.; RODRIGO, M. A.; PINAR, F. J.; ÚBEDA, D. Study of flow channel geometry using current distribution measurement in a hight temperature polymer electrolyte membrane fuel cell. Journal of Power Sources, v. 196, p. 4209-4217, 2011.

24 PARK, S.; LEE, J.-W.; POPOV, B. N. A review of gas diffusion layer in pem fuel cells: Materials and designs. International Journal of Hydrogen Energy, v. 37, p. 5850-5865, 2012.

25 WANG, C.-Y. Fundamental models for fuel cell engineering. Chemical Reviews, v. 104, p. 4727-4766, 2004. 
26 HAJIMOLANA, S. A.; HUSSAIN, M. A.; DAUD, W. M. A. W.; SOROUSH, M.; SHAMIRI, A. Mathematical modeling of solid oxide fuel cells: a review. Renewable and Sustainable Energy Reviews, v. 15, p. 1893-1917, 2011.

27 PRESS, W. H.; TEUKOLSKY, S. A.; VETTERLING, W. T.; FLANNERY, B. P. Numerical recipes in $\mathrm{C}$ : the art of scientific computing. $2^{\text {a }}$. ed. Cambridge: Cambridge University, 1992. 994 p.

28 SUN, P. Modeling studies and efficient numerical methods for proton exchange membrane fuel cell. Computer Methods in Applied Mechanics and Engineering, v. 200, p. 3324-3340, 2011.

29 FORTUNA, A. O. Técnicas computacionais para dinâmica dos fluidos. $2^{\mathrm{a}}$. ed. São Paulo: Editora da Universidade de São Paulo, 2012. 547 p.

30 SOUSA, T.; MAMLOUK, M.; SCOTT, K.; RANGEL, C. M. Three dimensional model of a high temperature PEMFC. study of the flow field effect on performance. Fuel Cells, v. 12, p. 566-576, 2012.

31 PAUlinO, A. L. R.; CUNHA, E. F.; ROBAlinhO, E.; LINARDI, M.; KORKISCHKO, I.; I., S. E. CFD analysis of PEMFC flow channel cross sections. Fuel Cells, v. 17, p. 27-36, 2017.

32 BARD, A. J.; FAULKNER, L. R. Electrochemical methods: fundamentals and applications. 2 ${ }^{\text {a }}$. ed. New York: John Wiley, 2001. 833 p.

33 LOPES, T.; HO, M.; KAKATI, B. K.; KUCERNAK, A. R. J. Assessing the performance of reactant transport layers and flow fields towards oxygen transport: A new imaging method based on chemiluminescence. Journal of Power Sources, v. 274, p. 382-392, 2015.

34 PAULING, L. General chemistry. 3ª ed. New York: Dover, 1970. 959 p.

35 MESSIAH, A. Quantum mechanics. New York: Dover, 1999. 1136 p.

36 SALINAS, S. R. A. Introdução à física estatística. $2^{a}$. ed. São Paulo: Editora da Universidade de São Paulo, 2005. 464 p.

37 JACOBI, C. G. J. Über ein leichtes verfahren die in der theorie der säcularstörungen vorkommenden gleichungen numerisch aufzulösen. Crelle's Journal, v. 30, p. 51-94, 1846 .

38 HARTREE, D. R. The wave mechanics of an atom with a non-Coulomb central field. Part I. Theory and methods. Mathematical Proceedings of the Cambridge Philosophical Society, v. 24, p. 89-110, 1928.

39 JACQUEMIN, D.; DUCHEMIN, I.; BLASE, X. Is the Bethe-Salpeter formalism accurate for excitation energies? Comparisons with TD-DFT, CASPT2 and EOM-CCS. The Journal of Physical Chemistry Letters, v. 8, p. 1524-1529, 2017.

40 YAKHOT, V.; ORSZAG, S. A. Renormalization group analysis of turbulence. I. Basic theory. Journal of Scientific Computing, v. 1, p. 3-51, 1986. 
41 UNITED STATES FUEL CELL COUNCIL. Single cell test protocol. Washington, 2006, 26 p.

42 BARS, M. L.; WORSTER, M. G. Interfacial conditions between pure fluid and a porous medium: implications for binary alloy solidification. Journal of Fluid Mechanics, v. 550, p. 149-173, 2006.

43 ONO, R.; ODA, T. Spatial distribution of ozone density in pulsed corona discharges observed by two-dimensional laser absorption method. Journal of Physics D: Applied Physics, v. 37, p. 730-735, 2004.

44 MASSMAN, W. J. A review of the molecular diffusivities of $\mathrm{H}_{2} \mathrm{O}, \mathrm{CO}_{2}, \mathrm{CH}_{4}, \mathrm{CO}, \mathrm{O}_{3}$, $\mathrm{SO}_{2}, \mathrm{NH}_{3}, \mathrm{~N}_{2} \mathrm{O}$, NO and $\mathrm{NO}_{2}$ in air, $\mathrm{O}_{2}$ and $\mathrm{N}_{2}$ near STP. Atmospheric Environment, v. 32, p. 1111-1127, 1998.

45 FiSHMAN, Z.; HiNEBAUGH, J.; BAZYLAK, A. Microscale tomography investigations of heterogeneous porosity distributions of pemfc gdls. Journal of the Electrochemical Society, v. 157, p. B1643-B1650, 2010.

46 SCHENK, O.; GäRTNER, K. Parallel Sparse Direcr Solver PARDISO - User Guide. Versão 5.0.0. [S.l.], 2014, 66 p. Disponível em:〈http://pardiso-project.org/〉. Acesso em: 30 ago. 2017.

47 MILlingtON, R. J.; QUIRK, J. P. Permeability of porous solids. Transactions of the Faraday Society, v. 57, p. 1200-1207, 1961.

48 BECKER, J.; FLüCKIGER, R.; REUM, M.; BüCHI, F. N.; MARONE, F.; STAMPANONI, M. Determination of material properties of gas diffusion layers: experiments and simulations using phase contrast tomographic microscopy. Journal of the Electrochemical Society, v. 156, p. B1175-B1181, 2009.

49 SAAD, Y.; SCHULTZ, M. H. GMRES: A generalized minimal residual algorithm for solving nonsymmetric linear systems. SIAM Journal on Scientific and Statistical Computing, v. 7, p. 856-869, 1986.

50 COMSOL. Structural mechanics module user's guide. Versão 5.2a. Los Angeles, 2016, 430 p.

51 KLEEMANN, J.; FINSTERWALDER, F.; TILLMETZ, W. Characterisation of mechanical behaviour and coupled electrical properties of polymer electrolyte membrane fuel cell gas diffusion layers. Journal of Power Sources, v. 190, p. 92-102, 2009.

52 EL-KHAROUF, A.; MASON T. J. ND BRETT, D. J. L.; POLLET, B. G. Ex-situ characterisation of gas diffusion layers for proton exchange membrane fuel cells. Journal of Power Sources, v. 218, p. 393-404, 2012.

53 KENDALL, J.; MONROE, K. P. The viscosity of liquids. ii. the viscosity-composition curve for ideal liquid mixtures. Journal of the American Chemical Society, v. 39, p. 1787-1802, 1917.

54 LEMMOM, E. W.; MCLINDEM, M. O.; FRIEND, D. G. Thermophysical properties of fluid systems. In: LINSTROM, P. J.; MALLARD, W. G. (Ed.). NIST chemistry webbook, NIST standard Reference Database Number 69. 
Gaithersburg: National Institute of Standards and Technology, 2016. Disponível em: 〈http://webbook.nist.gov/chemistry/fluid/〉. Acesso em: 22 maio 2017.

55 HUBER, M. L.; HARVEY, A. H. Diffusion in gases. In: HAYNES, W. M. (Ed.). CRC handbook of chemistry and physics. 95 ${ }^{\mathrm{a}}$ ed. Boca Raton: CRC, 2015. cap. 6, p. 259-260.

56 MARRERO, T. R.; MASON, E. A. Gaseous diffusion coefficients. Journal of Physical and Chemical Reference Data, v. 1, p. 3-118, 1972.

57 SCHUNK IBÉRICA. Placas bipolares de Schunk para pilas de combustible. Madrid, 2007. Disponível em: 〈http://www.schunk.pt/PT/catalogos/Placas_bipolares_ Schunk_para_pilhas_de_combustivel.pdf $\rangle$. Acesso em: 24 abr. 2017.

58 ZOLTEK CORPORATION. Panex ${ }^{\circledR} 30$ thermal management solutions. St. Louis, MO, 2017. Disponível em:〈https://zoltek.com/wp-content/uploads/2011/06/ Sales-Sheet-Panex-30.pdf $\rangle$. Acesso em: 24 abr. 2017.

59 DEAN, J. A. Properties of atoms, radicals and bonds. In: of chemistry. $15^{\mathrm{a}}$. ed. New York: McGraw-Hill, 1999. cap. 4, p. 1-84.

Lange's handbook

60 BRADLEY, P. E.; RADEBAUGH, R. Heat capacity of selected solids. In: HAYNES, W. M. (Ed.). CRC handbook of chemistry and physics. 95a . ed. Boca Raton: CRC, 2015. cap. 12 , p. 215.

61 ZOLTEK CORPORATION. Panex ${ }^{\circledR} \mathbf{3 0}$ fabric technical datasheet. St. Louis, MO, 2017. Disponível em:〈http://zoltek.com/products/panex-30/〉. Acesso em: 24 abr. 2017.

62 CABOT CORPORATION. VULCAN ${ }^{\circledR}$ XC72 conductive black. Billerica, MA, 2017. Disponível em: 〈http://www.cabotcorp.com/solutions/products-plus/ specialty-carbon-blacks/conductive〉. Acesso em: 24 abr. 2017.

63 FUELCELLSETC. Nafion membrane comparison table. College Station, TX, 2017. Disponível em: 〈http://fuelcellsetc.com/helpful-tools/ nafion-membrane-comparison-table/ $\rangle$. Acesso em: 24 abr. 2017.

64 ZOLTEK CORPORATION. Panex ${ }^{\circledR} 35$ commercial carbon fiber. St. Louis, MO, 2017. Disponível em:〈http://zoltek.com/products/panex-35/〉. Acesso em: 24 abr. 2017.

65 NEYERLIN, K. C.; GU, W.; JORNE, J.; GASTEIGER, H. A. Study of the exchange current density for the hydrogen oxidation and evolution reactions. Journal of the Electrochemical Society, v. 154, p. B631-B635, 2007.

66 VANýSEK, P. Electrochemical series. In: HAYNES, W. M. (Ed.). CRC handbook of chemistry and physics. $97^{\mathrm{a}}$. ed. Boca Raton: CRC, 2017. cap. 5, p. 78-84.

67 PEREZ, J.; GONZALEZ, E. R.; TICIANELLI, E. A. Impedance studies of the oxygen reduction on thin porous coating rotating platinum electrodes. Journal of the Electrochemical Society, v. 145, p. 2307-2313, 1998.

68 KEHIAIAN, H. V. Mean free path and related properties of gases. In: HAYNES, W. M. (Ed.). CRC handbook of chemistry and physics. 95 ${ }^{\mathrm{a}}$. ed. Boca Raton: CRC, 2015. cap. 6, p. 65. 
69 COMSOL. COMSOL multiphysics reference manual. Versão 5.2a. Los Angeles, 2016, 1380 p.

70 COMSOL. Batteries \& fuel cells module user's guide. Versão 5.2a. Los Angeles, 2016, 374 p.

71 WHITAKER, S. Flow in porous media I: A theoretical derivation of Darcy's law. Transport in Porous Media, v. 1, p. 3-25, 1986.

72 OCHOA-TAPIA, J. A.; WHITAKER, S. Momentum transfer at the boundary between a porous medium and a homogeneous fluid-I. Theoretical development. International Journal of Heat and Mass Transfer, v. 38, p. 2635-2646, 1995.

73 KALYVAS, C.; KUCERNAK, A.; BRETT, D.; HINDS, G.; ATKINS, S.; BRANDON, N. Spatially resolved diagnostic methods for polymer electrolyte fuel cells: a review.

WIREs Energy and Environment, v. 3, p. 254-275, 2014.

74 FINK, C.; KARPERNKO-JEREB, L.; ASHTON, S. Advanced CFD analysis of an air-cooled PEM fuel cell stack predicting the loss of performance with time. Fuel Cells, v. 16, p. 490-503, 2016.

75 LABACH, I.; RALLIèRES, O.; TURPIN, C. Steady-state semi-empirical model of a single proton exchange membrane fuel cell (PEMFC) at varying operating conditions. Fuel Cells, 2017. No prelo. doi:10.1002/fuce.201600074.

76 CARNES, B.; SPERJNAK, D.; LUO, G.; HAO, L.; CHEN, K. S.; WANG, C.-Y.; MUKUNDAN, R.; BORUP, R. L. Validation of a two-phase multidimensional polymer electrolyte membrane fuel cell computational model using current distribution measurements. Journal of Power Sources, v. 236, p. 126-137, 2013.

77 SALVA, J. A.; IRANZO, A.; ROSA, F.; TAPIA, E. Experimental validation of the polarization curve and the temperature distribution in a PEMFC stack using a one dimensional analytical model. International Journal of Hydrogen Energy, v. 41, p. 20615-20632, 2016.

78 NANDJOU, F.; POIROT-CROUVEZIER, J.-P.; CHANDESRIS, M.; BULTEL, Y. A pseudo-3D model to investigate heat and water transport in large area PEM fuel cells - Part 1: model development and validation. International Journal of Hydrogen Energy, v. 41, p. 15545-15561, 2016.

79 ROBIN, C.; GERAR, M.; D'ARBIGNY, J.; SCHOTT, P.; JABBOUR, L.;

BULTEL, Y. Development and experimental validation of a PEM fuel cell 2D-model to study heterogeneities effects along large-area cell surface. International Journal of Hydrogen Energy, v. 40, p. 10211-10230, 2015.

80 LUM, K. W.; MCGUIRK, J. J. Three-dimensional model of a complete polymer electrolyte membrane fuel cell - model formulation, validation and parametric studies. Journal of Power Sources, v. 143, p. 103-124, 2005.

81 IRANZO, A.; MUñOZ, M.; ROSA, F.; PINO, J. Numerical model for the performance prediction of a PEM fuel cell. model results and experimental validation. International Journal of Hydrogen Energy, v. 35, p. 11533-11550, 2010. 
82 SETZLER, B. P.; FULLER, T. F. A physics-based impedance model of proton exchange membrane fuel cells exhibiting low-frequency inductive loops. Journal of the Electrochemical Society, v. 162, p. F519-F530, 2015.

83 SUI, P. C.; KUMAR, S.; DJILALI, N. Advanced computational tools for PEM fuel cell design Part 1. development and base case simulations. Journal of Power Sources, v. 180 , p. $410-422,2008$.

84 SUI, P. C.; KUMAR, S.; DJILALI, N. Advanced computational tools for PEM fuel cell design Part 2. detailed experimental validation and parametric study. Journal of Power Sources, v. 180, p. 423-432, 2008.

85 MATIAN, M.; MARQUIS, A. J.; BRANDON, N. P. Application of thermal imaging to validate a heat transfer model for polymer electrolyte fuel cells. International Journal of Hydrogen Energy, v. 35, p. 12308-12316, 2010.

86 FALCãO, D. S.; GOMES, P. J.; OLIVEIRA, V. B.; PINHO, C.; PINTO, A. M. F. R. 1D and 3D numerical simulations in PEM fuel cells. International Journal of Hydrogen Energy, v. 36, p. 12486-12498, 2011.

87 BEDNAREK, T.; TSOTRIDIS, G. Issues associated with modelling of proton exchange membrane fuel cells by computational fluid dynamics. Journal of Power Sources, v. 343, p. 550-563, 2017.

88 PARK, J.; MATSUBARA, M.; LI, X. Application of lattice Boltzmann method to a micro-scale flow simulation in the porous electrode of a PEM fuel cell. Journal of Power Sources, v. 173, p. 404-414, 2007.

89 PARK, J.; LI, X. Multi-phase micro-scale flow simulation in the electrodes of a PEM fuel cell by lattice Boltzmann method. Journal of Power Sources, v. 178, p. 248-257, 2008. 



\section{APÊNDICE A - PROPRIEDADES DE TRANSPORTE DA CL NO MODELO ALFA}

Devido à particularidade da CL utilizada no trabalho de Lopes et al.(33), virtualmente nenhum dado foi encontrado em relação às propriedades de transporte de uma camada porosa composta de partículas micrométricas de sílica gel. Na tentativa de obter tais dados, essenciais ao modelo Alfa, uma simulação de um experimento de descarga sobre um leito poroso bidimensional foi realizada. O uso de um modelo bidimensional assume isotropia das propriedades de transporte do material.

A geometria do modelo, um exemplo sendo apresentado na Figura 65, consiste de três domínios: o domínio central representa um leito poroso, composto de partículas esféricas de diâmetros uniformemente distribuídos dentro de um certo intervalo, com largura de $1 \mathrm{~mm}$, e altura equivalente à da CL (Tabela 2); e os domínios laterais, para a entrada e saída de fluido, com largura equivalente à espessura da CL, e altura equivalente a $1 / 5$ da largura. As dimensões dos domínios laterais são completamente arbitrárias. O intervalo de diâmetro de partícula foi baseado em dados fornecidos pelo fabricante da sílica gel (Sigma Aldrich), sendo de 6, 0 a 9,0 0 m. A distribuição das mesmas foi feita de maneira aleatória, utilizando uma implementação em linguagem $\mathrm{C}$ do algoritmo descrito a seguir. O código é reproduzido no Apêndice B.

Inicialmente, um intervalo de diâmetro de partículas é fornecido, e então o intervalo do raio das partículas é estabelecido. Em seguida, o intervalo de coordenadas em $x$ e $y$ é fornecido, e um fator de compressão das partículas pode ser definido (sendo zero nesse caso). Utilizando o menor raio do intervalo, o inteiro resultante da razão entre a área da região definida e a área de uma partícula com tal raio é definido como um limite superior do número de partículas, para fins de alocação de memória. Como semente para os números aleatórios, três inteiros aleatórios deve ser fornecidos.

A geração das coordenadas cartesianas e do raio de cada partícula é feito através da

\footnotetext{
Figura 65 - Exemplo de geometria utilizada na simulação do experimento de descarga, sendo indicados a entrada e saída de fluido.
}

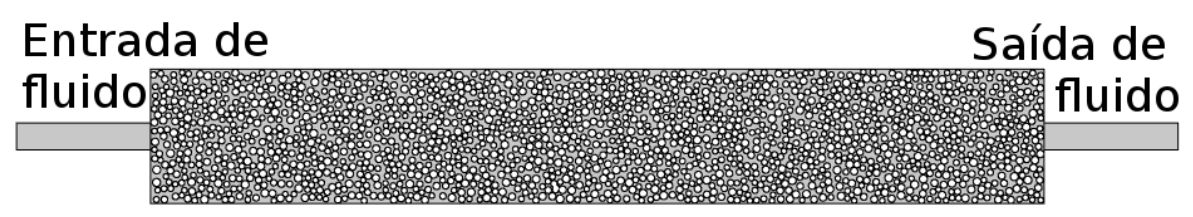

Fonte: Autoria própria. 
geração de três números aleatórios uniformes dentro dos respectivos intervalos definidos previamente. Cada partícula gerada é avaliada quanto à possibilidade de sua existência: a superfície da partícula, i.e. as coordenadas do centro somadas ao raio, deve estar dentro da região definida; e a distância entre o centro da partícula e o de cada outra partícula existente deve ser maior que a soma dos raios do par. Caso contrário, uma nova partícula é gerada. O algoritmo suspende a geração de coordenadas após $10^{6}$ rejeições. O gerador de números aleatórios utilizado é baseado na implementação em linguagem $\mathrm{C}$ do gerador de L'Ecuyer, denominado ran2, conforme descrito na Seção 7.1 de (27).

Finalmente, o código imprime as coordenadas e os raios de cada partícula em um arquivo do tipo .dxf, usando um arquivo de referência para obter o restante do arquivo, pronto para ser importado no software COMSOL Multiphysics ${ }^{\circledR}$.

\section{A.1 Metodologia computacional}

A simulação do experimento de descarga foi realizada utilizando a formulação compressível das equações de Navier-Stokes:

$$
\rho(\mathbf{u} \cdot \nabla) \mathbf{u}=\nabla \cdot\left[-P \mathbf{I}+\mu\left(\nabla \mathbf{u}+(\nabla \mathbf{u})^{\mathrm{T}}\right)-\frac{2}{3} \mu(\nabla \cdot \mathbf{u}) \mathbf{I}\right]
$$

com densidade $\rho$ e viscosidade dinâmica $\mu$ representando as propriedades de ar seco, dadas por:

$$
\begin{aligned}
\rho_{\mathrm{ar}}(P, T)= & \frac{P}{R_{\mathrm{ar}} T} \\
\mu_{\mathrm{ar}}(T)= & -8,38278 \times 10^{-7}+8,35717 \times 10^{-8} T-7,69430 \times 10^{-11} T^{2} \\
& +4,64373 \times 10^{-14} T^{3}-1,06586 \times 10^{-17} T^{4}
\end{aligned}
$$

onde $R_{\mathrm{ar}}=287,0 \mathrm{~J} \mathrm{~kg}^{-1} \mathrm{~K}^{-1}$, e $T=298 \mathrm{~K}$. O sistema deve respeitar a equação da continuidade:

$$
\nabla \cdot(\rho \mathbf{u})=0
$$

Todos os cálculo foram sujeitos a um pressão de referência $P_{\text {ref }}=1,027 \times 10^{5} \mathrm{~Pa}$.

A condição de entrada é dada pela equação:

$$
\mathbf{u} \cdot \mathbf{n}=\frac{\mu \operatorname{Re}}{\rho L}
$$

onde $L$ é o comprimento característico do escoamento, nesse caso pela altura do domínio da entrada; e Re é o número de Reynolds, variado de 0,1 a 1 . A saída é definida por uma pressão, dada pela equação:

$$
\left[-P \mathbf{I}+\mu\left(\nabla \mathbf{u}+(\nabla \mathbf{u})^{\mathrm{T}}\right)-\frac{2}{3} \mu(\nabla \cdot \mathbf{u}) \mathbf{I}\right] \mathbf{n}=0
$$


A malha utilizada é gerada automaticamente pelo software, com tamanho de elemento pré-definido como fine, com o número total de elementos variando de acordo com a distribuição de partículas. O solver utilizado também foi o padrão gerado pelo software, composto de um único passo utilizando a implementação do solver PARDISO.

Para obter as propriedades de transporte do leito, foi utilizada a Lei de DarcyForchheimer(21):

$$
\nabla P=-\frac{\mu}{\kappa} q-\frac{\rho}{\kappa_{I}} q^{2}
$$

onde $q$ é o fluxo no leito, i.e. vazão por unidade de área da seção transversal do domínio do leito, e $\kappa_{I}$ a permeabilidade inercial. O gradiente de pressão foi tomado como linear, portanto $\nabla P=\Delta P / l$, onde $l$ é o comprimento do leito. A perda de carga $\Delta P$ foi obtida pela diferença entre a pressão na saída e na entrada do domínio do leito, e $q$ foi obtido pela vazão, $Q$, na saída de gases, dividida pela área da seção transversal do leito, tomada como $A=1,5 \times 10^{-7} \mathrm{~m}^{2}$. O modelo utilizado foi, portanto:

$$
\Delta P=-\frac{\mu}{\kappa} l q-\frac{\rho}{\kappa_{I}} l q^{2}
$$

O software MATLAB ${ }^{\circledR}$ foi utilizado para realizar as regressões, através da rotina NonLinearModel.fit, usando a Equação A.8, com valores iniciais de $10^{-10}$ para ambos os parâmetros. A porosidade, $\epsilon$, foi obtida pela fração de espaço livre no domínio do leito, calculado pelo software COMSOL Multiphysics ${ }^{\circledR}$.

As simulações foram realizadas um total de 10 vezes, com distribuições de partículas diferentes em cada iteração. Os valores de $\kappa_{C L}$ e $\epsilon_{C L}$ apresentados na Tabela 3 representam a média obtida sobre todos os valores resultantes das simulações. 



\section{APÊNDICE B - CÓDIGO PARA DISTRIBUIÇÃO ALEATÓRIA DE PARTÍCULAS}

É apresentado a seguir o código completo da implementação em linguagem C do algoritmo descrito no Apêndice A. Infelizmente, por motivos de licenciamento, a implementação do gerador de números aleatórios ran2 não deve ser providenciada. Detalhes, nesse caso, devem ser buscados na Seção 7.1 de (27).

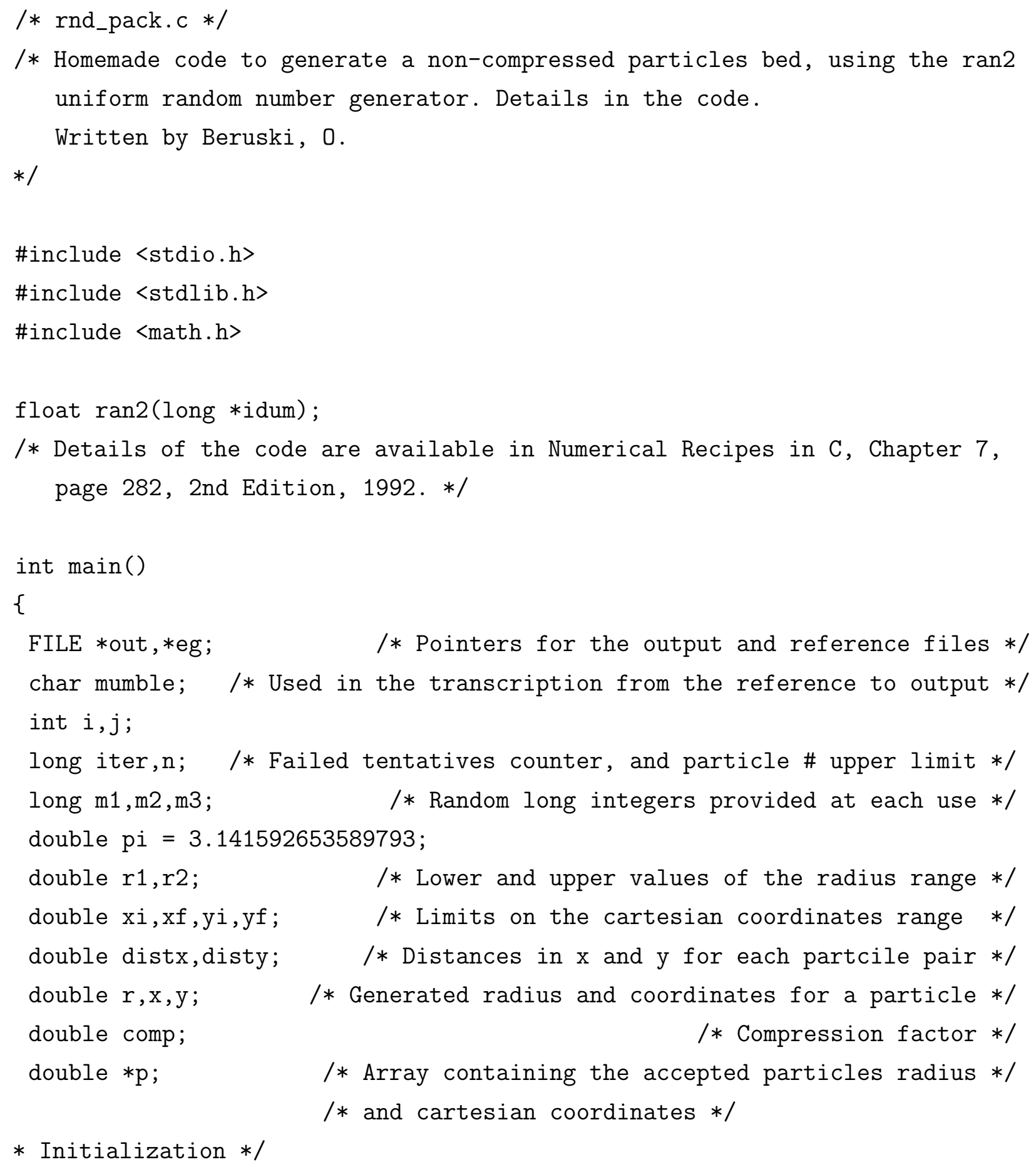




$$
\begin{aligned}
& \mathrm{n}=0 ; \\
& \text { iter }=0 ; \\
& \mathrm{m} 1=0 ; \\
& \mathrm{m} 2=0 ; \\
& \mathrm{m} 3=0 ; \\
& \mathrm{r} 1=0.0 ; \\
& \mathrm{r} 2=0.0 ; \\
& \mathrm{xi}=0.0 ; \\
& \mathrm{xf}=0.0 ; \\
& \mathrm{y} i=0.0 ; \\
& \mathrm{yf}=0.0 ; \\
& \mathrm{r}=0.0 ; \\
& \mathrm{x}=0.0 ; \\
& \mathrm{y}=0.0 ; \\
& \text { comp }=0.0 ; \\
& \text { distx }=0.0 ; \\
& \text { disty }=0.0 ;
\end{aligned}
$$

\section{/* Input Requisition */}

/* Code is designed to provide a clean input requisition for the user */ printf(" \n Please provide the range of particle sizes ( $r 1<=r 2): \backslash n "$ "); scanf (" \%lf $\%$ lf", \&r1, \&r2);

$$
\begin{aligned}
& r 1=r 1 / 2.0 ; \\
& r 2=r 2 / 2.0 ;
\end{aligned}
$$

printf("\n Assuming the particles are spherical, the particle radius"); printf("\n is between \%3.2E and \%3.2E m.",r1,r2);

printf("\n\n Now please provide the boundaries in the $\mathrm{x}$ dimension: \n "); scanf ("\%lf $\% l f ", \& x i, \& x f)$;

printf("\n And the boundaries in the y dimension: \n "); scanf ("\%lf \%lf",\&yi, \&yf);

printf("\n Please choose a compaction factor $(0<=c<1): \backslash n$ "); $\operatorname{scanf}(" \% l f "$, \&comp); 


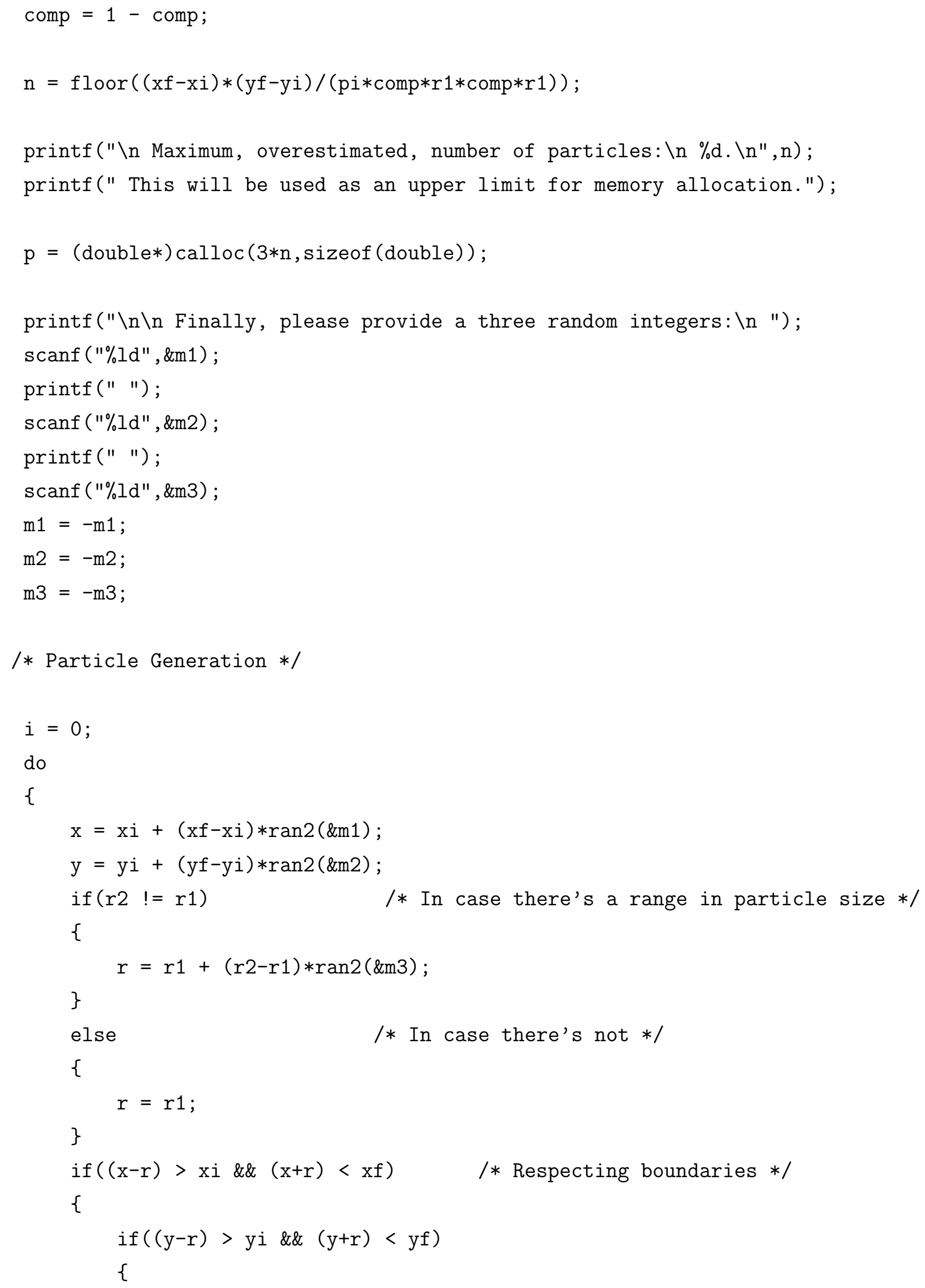




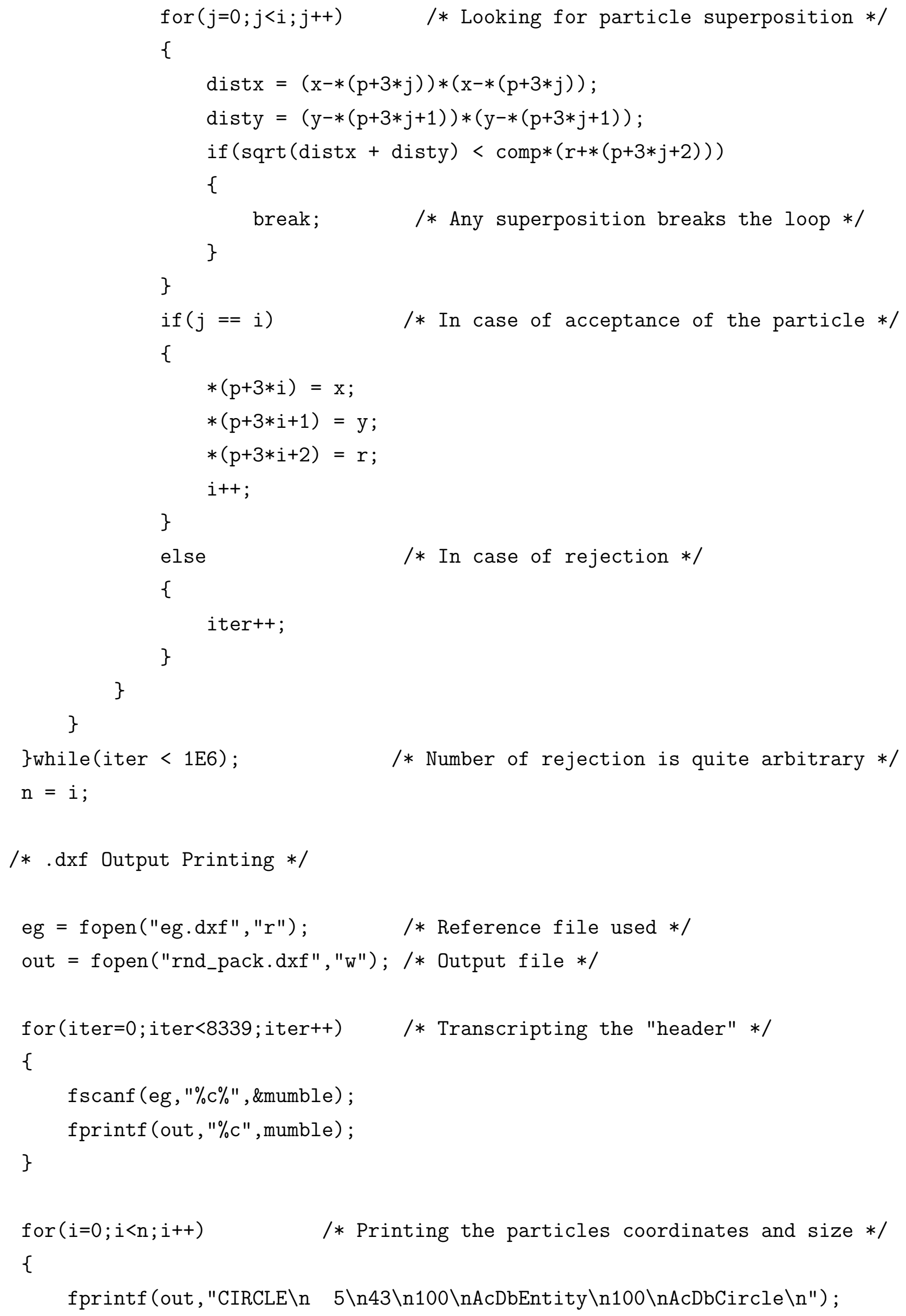




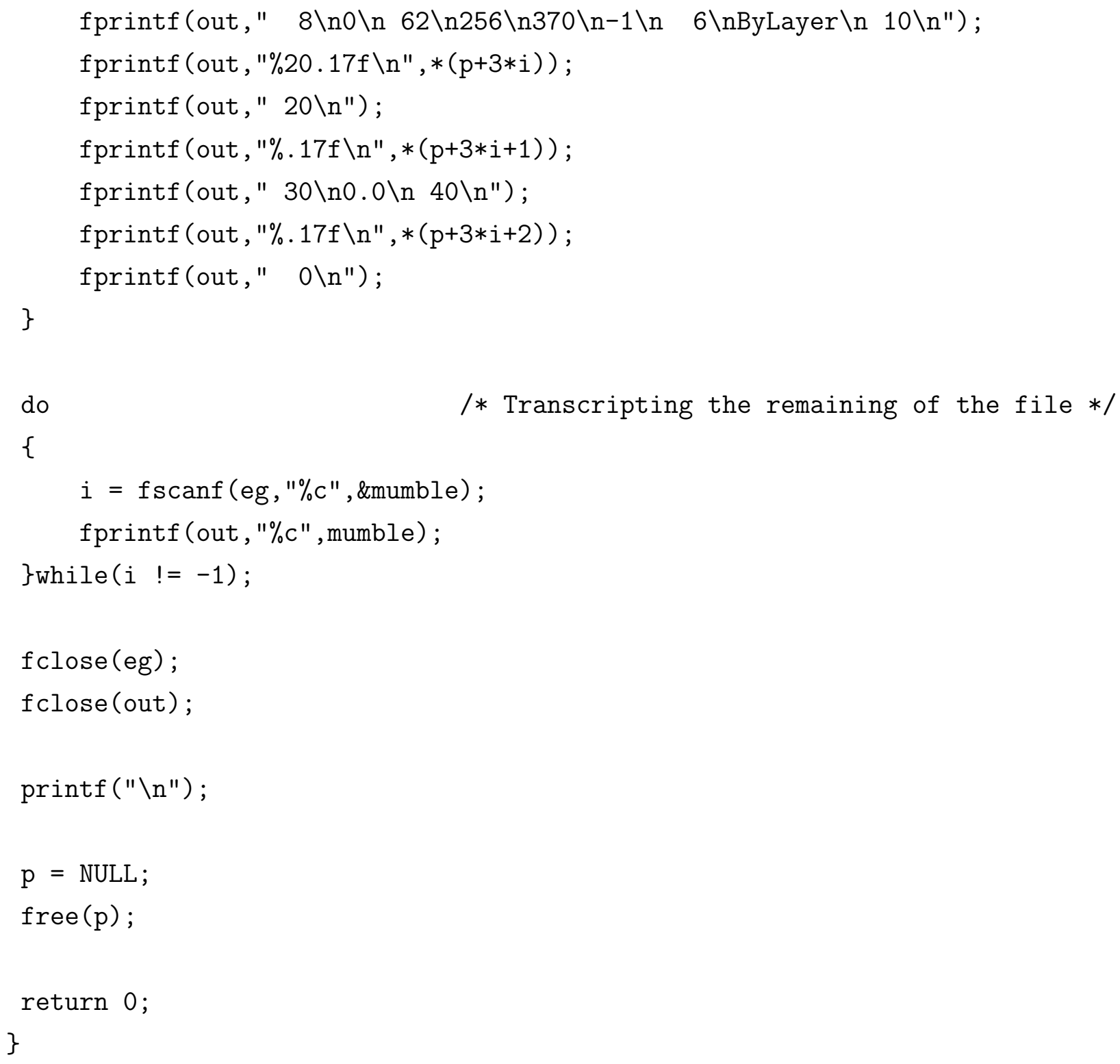





\section{APÊNDICE C - ANÁLISE DA QUALIDADE DE MALHA USADA NO MODELO ALFA}

De modo a avaliar a influência da qualidade da malha utilizada nas simulações realizadas com o modelo Alfa, quatro malhas diferentes foram utilizadas, e a convergência dos resultados foi analisada. As malhas foram geradas pelo software, utilizando diferentes definições de tamanho dos elementos de fronteira e de domínio, porém mantendo a inclusão de três elementos de "camada limite".

\section{C.1 Metodologia Computacional}

A malha I consiste em elementos de fronteira e domínio com especificações do tipo "normal" e "coarser", respectivamente; a malha II consiste em elementos com especificações do tipo "fine" e "coarse"; a malha III utiliza especificações do tipo "finer" e "normal"; e a malha IV utiliza tipos "extra fine" e "fine". A Figura 66 apresenta a visão lateral da geometria do modelo, exemplificando a diferenças entre as malhas. A Tabela 21 apresenta os parâmetros de tamanho de elemento para cada malha e o número total aproximado de elementos de domínio resultantes. O intervalo de tamanho dos elementos é dada em razão de uma escala de comprimento representativa para o domínio do canal de escoamento, sendo escolhido $L=10^{-3} \mathrm{~m}$. Nota-se que a malha utilizada para a validação do modelo Alfa encontra-se próxima da malha III (ver Seção 4.1.2).

Tabela 21 - Parâmetros utilizados nas malhas analisadas para o modelo Alfa.

\begin{tabular}{|c|c|c|c|c|c|c|}
\hline Malha & $\begin{array}{c}\text { Total } \\
\text { aproximado } \\
\text { de elementos }\end{array}$ & $\begin{array}{c}\text { Tipo } \\
\text { de } \\
\text { elemento }\end{array}$ & $\begin{array}{c}\text { Intervalo } \\
\text { de tamanho } \\
\text { relativo }\end{array}$ & $\begin{array}{c}\text { Taxa de } \\
\text { crescimento } \\
\text { máxima }\end{array}$ & $\begin{array}{c}\text { Fator } \\
\text { de } \\
\text { curvatura }\end{array}$ & $\begin{array}{l}\text { Resolução } \\
\text { em regiões } \\
\text { estreitas }\end{array}$ \\
\hline \multirow{2}{*}{ I } & \multirow{2}{*}{$5,15 \times 10^{5}$} & Fronteira & $0,15-0,51$ & 1,15 & 0,6 & 0,7 \\
\hline & & Domínio & $0.31-0,99$ & 1,25 & 0,8 & 0,6 \\
\hline \multirow{2}{*}{ II } & \multirow{2}{*}{$1,07 \times 10^{6}$} & Fronteira & $0,076-0,40$ & 1,13 & 0,5 & 0,8 \\
\hline & & Domínio & $0,23-0,76$ & 1,2 & 0,7 & 0,6 \\
\hline \multirow{2}{*}{ III } & \multirow{2}{*}{$1,99 \times 10^{6}$} & Fronteira & $0,031-0,28$ & 1,1 & 0,4 & 0,9 \\
\hline & & Domínio & $0,15-0,51$ & 1,15 & 0,6 & 0,7 \\
\hline \multirow{2}{*}{ IV } & \multirow{2}{*}{$5,14 \times 10^{6}$} & Fronteira & $0,012-0,18$ & 1,08 & 0,3 & 0,95 \\
\hline & & Domínio & $0,076-0,40$ & 1,13 & 0,5 & 0,8 \\
\hline
\end{tabular}

Fonte: Autoria própria.

A resolução do sistema prosseguiu da mesma maneira com todas as malhas, utilizando o esquema padrão do software, i.e. um solver segregado de duas etapas, variáveis de escoamento e concentração, com tolerância relativa de $10^{-3}$. Cada passo foi resolvido com a implementação do solver iterativo GMRES, sendo que o número de níveis multigrid foi fixado em 2 para as variáveis de escoamento. Todas as variáveis possuem discretização linear, e a escala das mesmas foi escolhida de acordo com o valor inicial. Um solver 
Figura 66 - Vista lateral da geometria do modelo Alfa, evidenciando as diferentes malhas descritas na Tab. 21: a) I, b) II, c) III e d) IV.

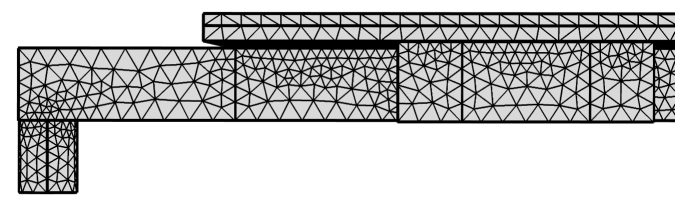

(a)

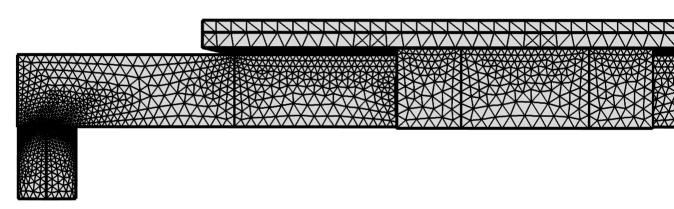

(c)

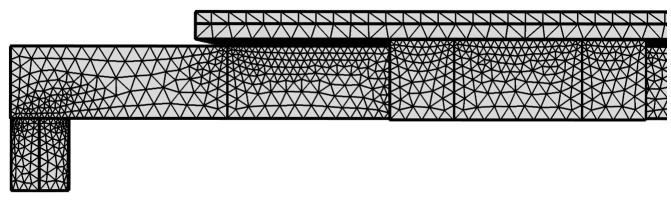

(b)

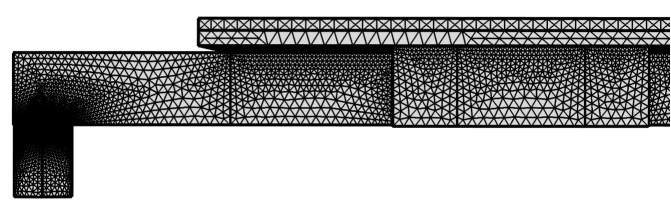

(d)

paramétrico foi utilizado para os valores de vazão $Q$, variando em um intervalo de 200 a $450 \mathrm{~cm}^{3} \mathrm{~min}^{-1}$. Os parâmetros são os mesmos utilizados para a validação do modelo Alfa (ver Seção 4.1.2, com $k=250 \mathrm{~s}^{-1}$ ).

Os resultados analisados para convergência foram os mesmos avaliados para a validação do modelo (ver Seção 4.1.2), e incluem as superfícies de pressão parcial, perda de carga e consumo total de ozônio. Adicionalmente, foram avaliados o ME, MaxE, MEA e desvio padrão (STD) das superfícies de pressão parcial relativos à malha anterior, e a variação do $\mathrm{R}$ entre as malhas e os valores experimentais de consumo de ozônio.

\section{C.2 Resultados}

A Figura 67a apresenta a perda de carga em função da vazão de entrada para as malhas analisadas. Os valores experimentais foram incluídos a título de referência. Observa-se que os resultados não apresentaram a convergência esperada com o aumento da resolução da malha. No entanto, nota-se que, independente da malha utilizada, os resultados de perda de carga encontram-se próximos dos valores experimentais e dentro da incerteza da medida. Isso é evidenciado na Figura 67b, onde é apresentado a diferença relativa da perda de carga entre malhas. Como já notado, não observa-se convergência para as malhas utilizadas. No entanto, a incerteza experimental relativa à perda de carga medida é maior que a variação entre malhas.

O mesmo é apresentado na Figura 68 para o consumo total de ozônio. Observa-se na Figura 68a uma certa convergência entre as malhas I - III, porém uma grande discrepância 
Figura 67 - a) Perda de carga em função da vazão de entrada para as diferentes malhas utilizadas com o modelo Alfa: I ( $\square)$, II ( $\square$ ), III ( $\square$ ), e IV $(\square)$. Os valores experimentais (o) foram incluídos como referência. b) Perda de carga relativa em função da vazão de entrada: II - I ( $\square$ ), III - II ( $\square$ ), IV - III ( $\square)$. A diferença é relativa à malha anterior. Os resultados experimentais (o) representam a incerteza das medidas relativas à magnitude.

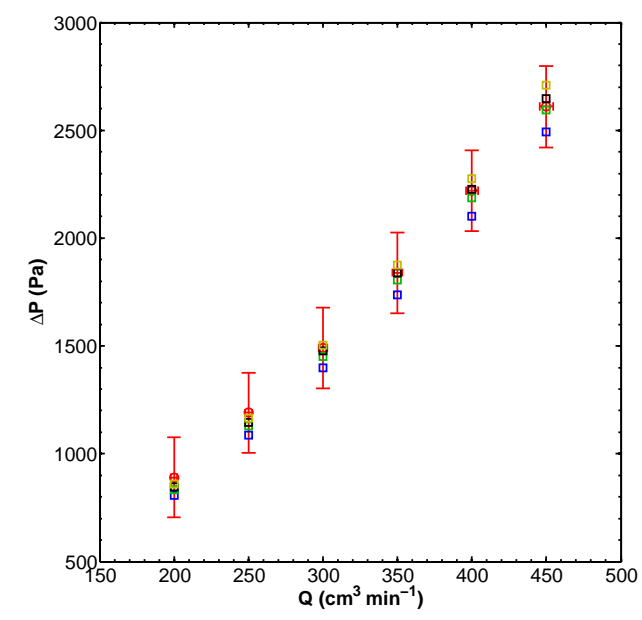

(a)

Fonte: Autoria própria.

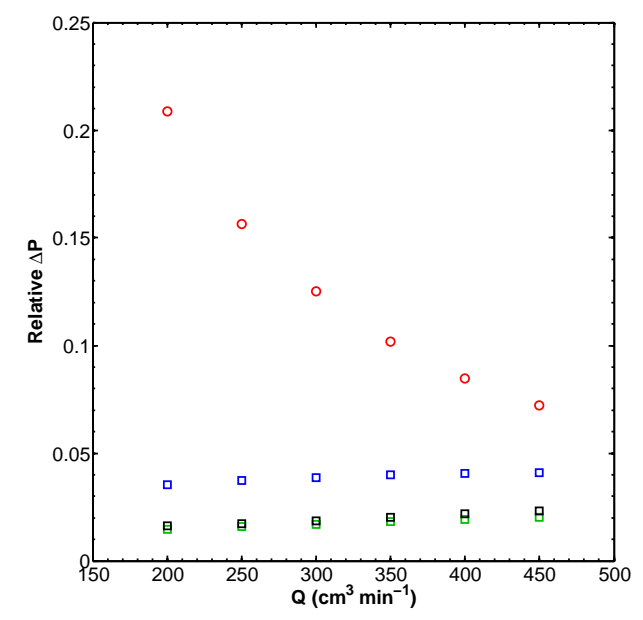

(b)

entre as malhas III e IV. A diferença relativa, neste caso absoluta, entre as malhas mostra o mesmo comportamento, como observado na Figura 68b. Entretanto, a diferença relativa entre as malhas III e IV encontram-se acima do desvio relativo dos valores experimentais.

Apesar da discrepância entre as malhas III e IV, é tentador assumir que o uso da malha IV é necessário, dado os resultados da Fig. 68a. No entanto, deve-se notar que esta análise é qualitativa, como discutido na Seção 6.1.1. Assim, deve-se analisar a variação do coeficiente de correlação $R$ das simulações aos resultados experimentais. O coeficiente de correlação assume os valores $R=[0,9853 ; 0,9848 ; 0,9810 ; 0,9803]$ para a malha de I a IV. Apesar da diferença aparentemente pequena, nota-se uma relação inversa ao aumento da qualidade da malha, dificultando a análise de convergência.

Por fim, são analisadas as superfícies de pressão parcial de ozônio na CL. A Figura 69 apresenta os histogramas da diferença relativa entre malhas, separados em 100 colunas. Superposto a cada histograma, é indicado o erro médio (ME), erro máximo (MAE), erro médio absoluto (MEA) e o intervalo de um desvio padrão (STD), com os respectivos valores indicados na caixa de texto. É possível notar, mais uma vez, pela comparação dos histogramas e os momentos estatísticos, que não foi observado convergência para as malhas. Em particular, a transição até a malha III apresenta o comportamento antecipado, i.e. a diminuição do erro, entretanto a transição para a malha IV apresenta um aumento do erro, além de um maior desvio padrão. 
Figura 68 - a) Consumo de ozônio em função da vazão de entrada para as diferentes malhas utilizadas com o modelo Alfa: I ( $\square$ ), II ( $\square)$, III ( $\square)$, e IV ( $\square$ ). Os valores experimentais (o) foram incluídos como referência. b) Consumo de ozônio relativo, absoluto, em função da vazão de entrada: II - I ( $\square)$, III - II ( $\square$ ), IV - III ( $\square$ ). A diferença é relativa à malha anterior. Os resultados experimentais (o) representam o desvio padrão das medidas relativas à magnitude.

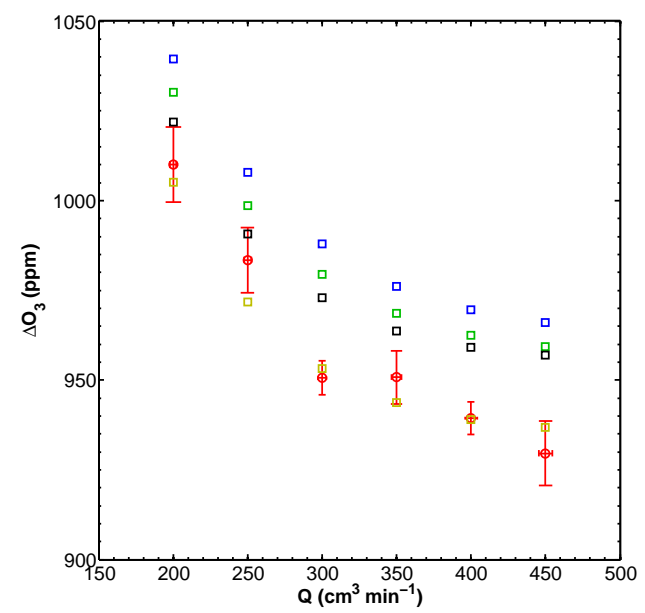

(a)

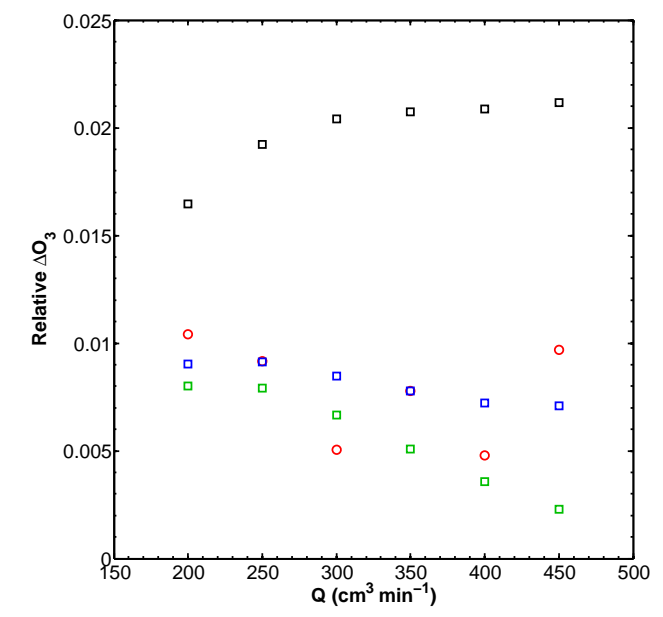

(b)

Fonte: Autoria própria.

Figura 69 - Histogramas da diferença relativa de pressão parcial de ozônio entre pares de malhas: a) II - I; b) III - II; e c) IV - III. As linhas tracejadas representam o erro médio (ME), erro máximo (MAE), erro médio absoluto (MEA) e um intervalo de desvio padrão (STD). Os histograma foram criados a partir de matrizes $536 \times 500$, sendo os valores organizados em 100 colunas.

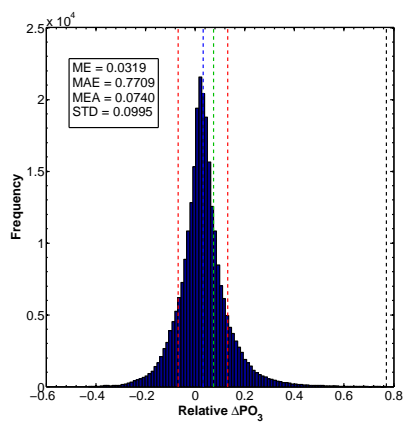

(a)

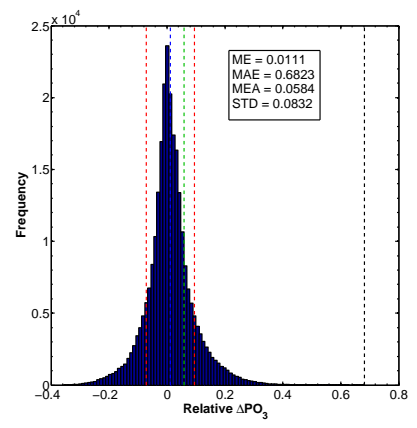

(b)

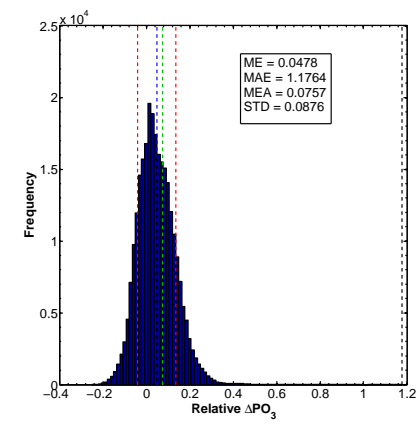

(c) 
Dada a análise acima, conclui-se que não fora observado um comportamento convergente em relação à melhoria da qualidade da malha utilizada no modelo Alfa. Porém, se for ignorado os resultados da malha IV, pode-se dizer que o comportamento segue o esperado, e que a malha III é adequada, apresentando variações relativas à malha II menores que as incertezas experimentais. 



\section{APÊNDICE D - ANÁLISE DA CONDIÇÃO DE ENTRADA USADA NO MODELO ALFA}

Após a aquisição do módulo de CFD, foi possível o uso da condição de entrada de fluido de vazão mássica (MF). Em princípio, tal condição reproduz de maneira mais adequada o perfil de velocidade na fronteira correspondente à entrada de fluidos do que um valor de velocidade constante $(\mathrm{CV})$. Para avaliar tal mudança, ambas as condições foram comparadas, assim como a convergência em função da qualidade da malha.

\section{D.1 Metodologia Computacional}

O modelo segue o descrito na Seção 4.1.1, onde é utilizada a condição de velocidade constante:

$$
\mathbf{u} \cdot \mathbf{n}=Q / A_{\text {in }}
$$

onde $\mathbf{n}$ é o vetor normal à fronteira correspondente, $Q$ é a vazão volumétrica e $A_{i} n$ é a área da fronteira. A condição de vazão mássica é dada por:

$$
-\int_{\partial \Omega} \frac{\rho}{\rho_{\mathrm{std}}}(\mathbf{u} \cdot \mathbf{n}) \mathrm{d} S=Q
$$

onde $\rho_{\text {std }}$ é a densidade padrão, neste caso sendo dada pela Eq. 4.14 para $P_{\text {std }}=1$ atm e $T_{\text {std }}=273 \mathrm{~K}$. O subescrito $\partial \Omega$ indica a integração sobre a fronteira apropriada.

As malhas e o procedimento de resolução foram os mesmos detalhados no Apêndice C, com a mudança de uso de atualização automática para o fator de relaxamento do passo 2 , referente à concentração. Os resultados das simulações foram avaliados da mesma maneira. Nota-se que a qualidade da malha utilizada em 4.1.5 se aproximada da malha III, descrita em C.

\section{D.2 Resultados}

Inicialmente são apresentados, na Figura 70, os perfis de velocidade para cada condição de entrada, em função dos eixos $x$ e $z$ na região de entrada do domínio do canal de escoamento. Como esperado, observa-se para a condição MF um perfil de velocidade, ao longo da seção transversal do escoamento (Fig. 70a), mais condizente com um escoamento do tipo Haagen-Poiseuille(29). Por outro lado, a condição CV resulta em um perfil mais comportado, ao longo do eixo z (Fig. 70b), na transição entre as seções circular e retangular da entrada do canal de escoamento. Isso pode levar à uma maior estabilidade numérica 
Figura 70 - Perfis da magnitude da velocidade de escoamento ao longo dos eixos a) $x$ e b) $z$, na região de entrada do domínio do canal de escoamento, para as condições CV e MF. A linha tracejada em b) indica a interface entre as seções cílindrica e retangular do canal de escoamento.

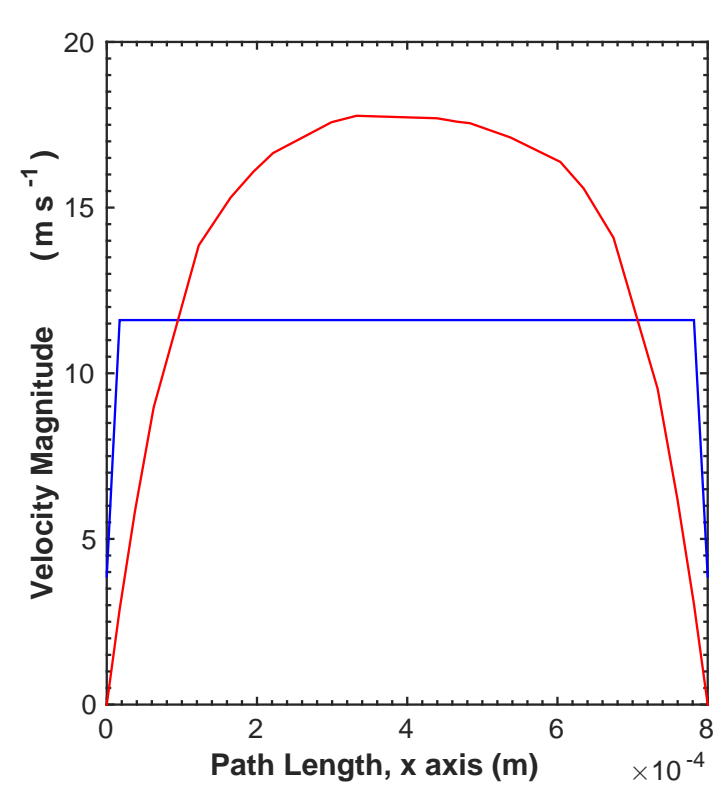

(a)

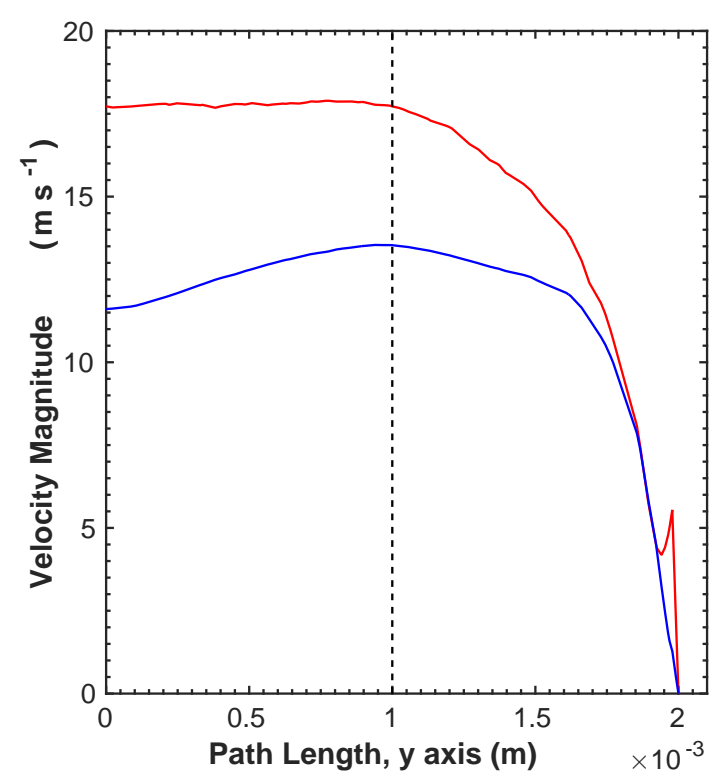

(b)

durante a resolução do modelo, porém sob a pena de representar inadequadamente o perfil na seção transversal ao escoamento.

A Figura 71a apresenta a perda de carga em função da vazão de entrada para as diferentes malhas e ambas as condições de entrada utilizadas. É possível observar que a condição de MF reproduz os resultados experimentais, da mesma maneira que a condição de CV. Por outro lado, nota-se que a condição de MF apresenta menor dispersão em relação à qualidade da malha, quando comparado à CV. Tal fato é evidenciado na Figura 71b, onde também observa-se que a diferença relativa com a condição CV aproxima-se de zero para a malha IV, sendo menor que a incerteza experimental a partir da malha II.

O consumo de ozônio é apresentado na Figura 72a. Nota-se uma convergência dos valores referentes à condição de MF, com valores próximos aos da condição de CV até a malha III. Tais pontos são melhor observados na Figura 72b, onde observa-se a convergência dos valores referentes à condição MF em relação às malhas III e IV. Os coeficientes de correlação quando usadas as condições MF e CV, em relação aos valores experimentais, são 0,9789 e 0,9803, respectivamente. Considerando unicamente tal ponto, o uso da condição CV seria mais adequado, entretanto a convergência dos valores em relação à malha, e a justificativa física, tornam o uso da condição MF mais atrativa.

Para as superfícies de pressão parcial de ozônio, inicialmente é feita a comparação entre as condições de entrada. Os histogramas de diferença relativa são apresentados na Figura 73. Pode-se notar que todos os momentos estatísticos avaliados diminuem com o aumenta da qualidade da malha, e em todos os casos os valores são considerados pequenos, mesmo 
Figura 71 - a) Perda de carga em função da vazão, para as condições de entrada MF $(\triangle)$ e CV $(\square)$, usando diferentes malhas no modelo Alfa: I $(\triangle)$, II $(\triangle)$, III $(\triangle)$, e IV $(\triangle)$. Os valores experimentais $(\circ)$ foram inclú́dos como referência. b) Perda de carga relativa em função da vazão. Diferença relativa entre condições MF e CV, para as malhas: I $(\square)$, II $(\square)$, III $(\square)$, e IV $(\square)$. Diferença relativa entre pares de malhas para a condição MF: II - I $(\triangle)$, III - II $(\triangle)$, IV - III $(\triangle)$. A diferença é relativa à malha anterior. Os resultados experimentais $(\circ)$ representam a incerteza das medidas relativas à magnitude.

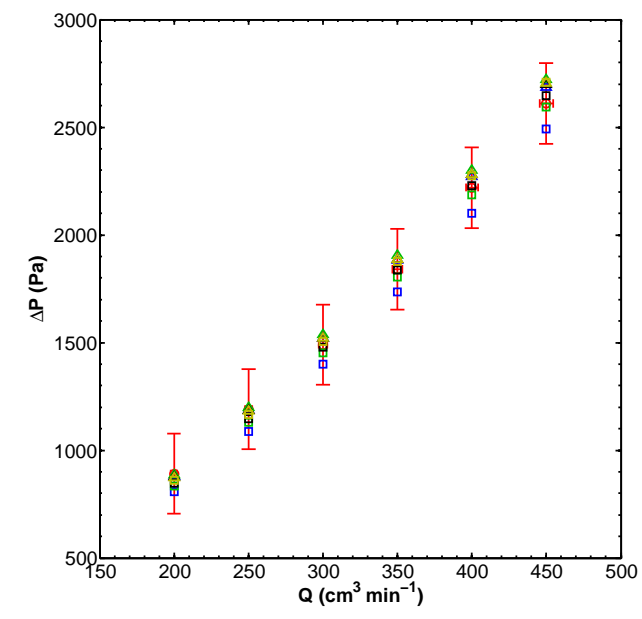

(a)

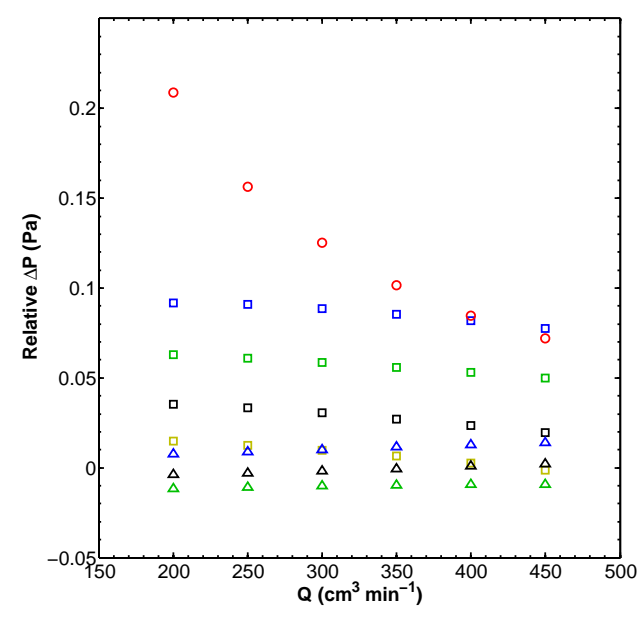

(b)

Fonte: Autoria própria.

para o erro máximo, chegando a $\approx 0,06$ no caso da malha IV. Isto indica que os resultados obtidos com a condição MF são condizentes com os resultados validados da condição CV. Por outro lado, esta tendência também indica que a condição MF, diferente das demais variáveis analisadas, não apresenta o comportamento esperado para a pressão parcial de ozônio na CL em função da qualidade de malha. Os histogramas não são mostrado, porém os momentos estatísticos confirmam tal comportamento.

Dados os resultados apresentados acima, considera-se que a mudança de condição de entrada de velocidade constante, dada pela Eq. D.1, para a condição de vazão mássica, dada pela Eq. D.2, não altera de maneira significativa os resultados obtidos com o modelo Alfa. Por outro lado, julga-se que esta é em realidade mais adequada, tanto pelo justificativa física como pela obtenção de convergência dos resultados de perda de carga e consumo de ozônio em relação à malha utilizada. 
Figura 72 - a) Consumo de ozônio em função da vazão, para as condições de entrada $\operatorname{MF}(\triangle)$ e CV $(\square)$, usando diferentes malhas no modelo Alfa: I $(\triangle)$, II $(\triangle)$, III $(\triangle)$, e IV $(\triangle)$. Os valores experimentais $(\circ)$ foram incluídos como referência. b) Consumo de ozônio relativo em função da vazão. Diferença relativa entre condições MF e CV, para as malhas: I $(\square)$, II $(\square)$, III $(\square)$, e IV $(\square)$. Diferença relativa entre pares de malhas para a condição MF: II - I $(\triangle)$, III - II $(\triangle)$, IV - III $(\triangle)$. A diferença é relativa à malha anterior. Os resultados experimentais (०) representam a incerteza das medidas relativas à magnitude.

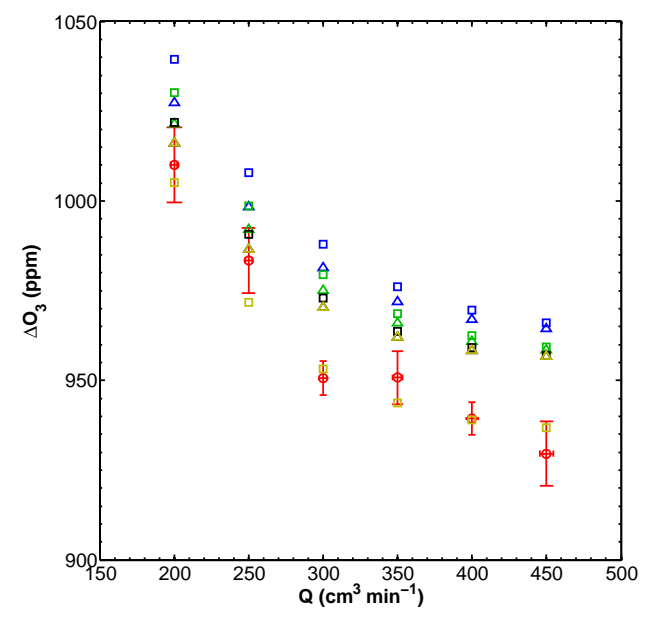

(a)

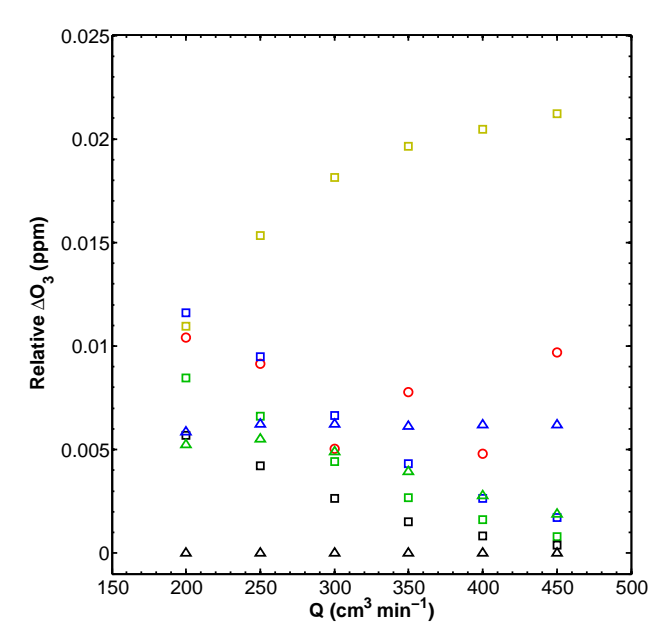

(b)

Fonte: Autoria própria. 
Figura 73 - Histogramas da diferença relativa de pressão parcial de ozônio entre condições de entrada MF e CV, para as malhas: a) I, b) II, c) III, e d) IV. As linhas representam o erro médio (ME), erro máximo (MAE), erro médio absoluto (MEA) e um intervalo de desvio padrão (STD). Os histograma foram criados a partir de matrizes $536 \times 500$, sendo os valores organizados em 100 colunas.

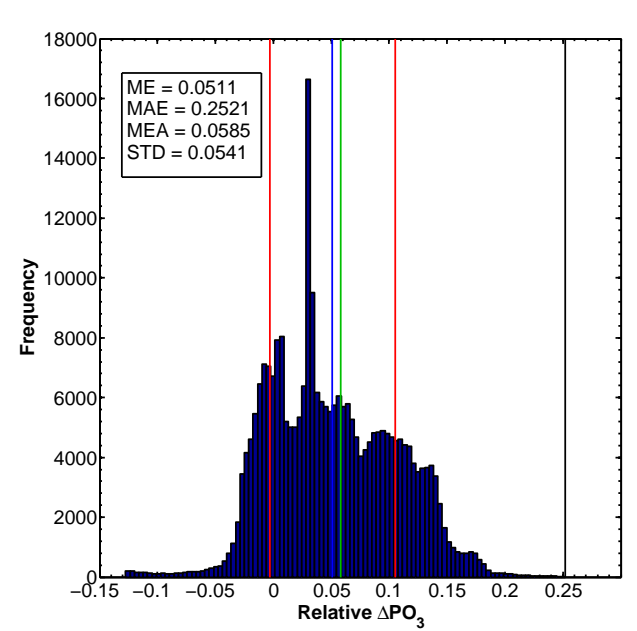

(a)

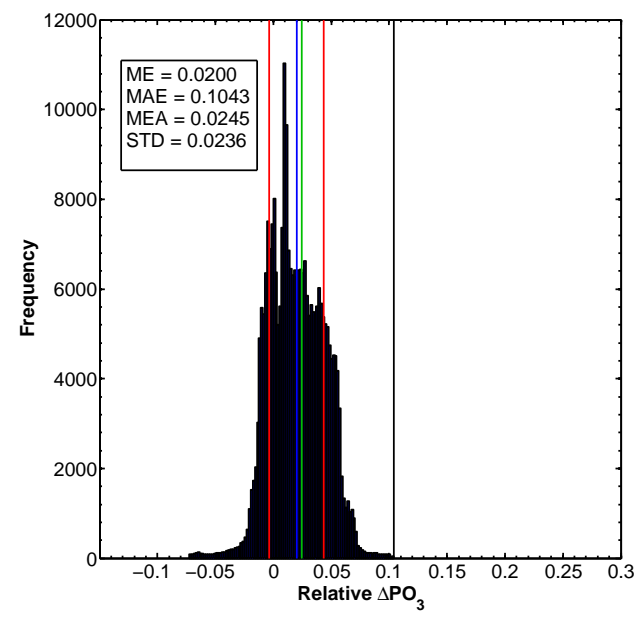

(c)

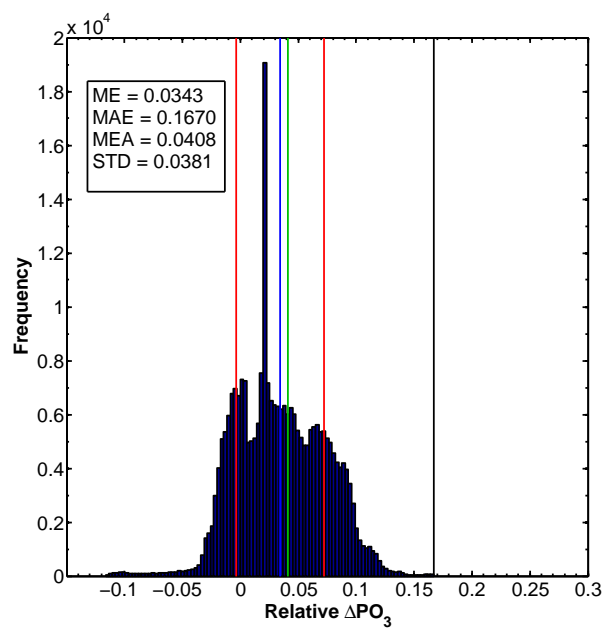

(b)

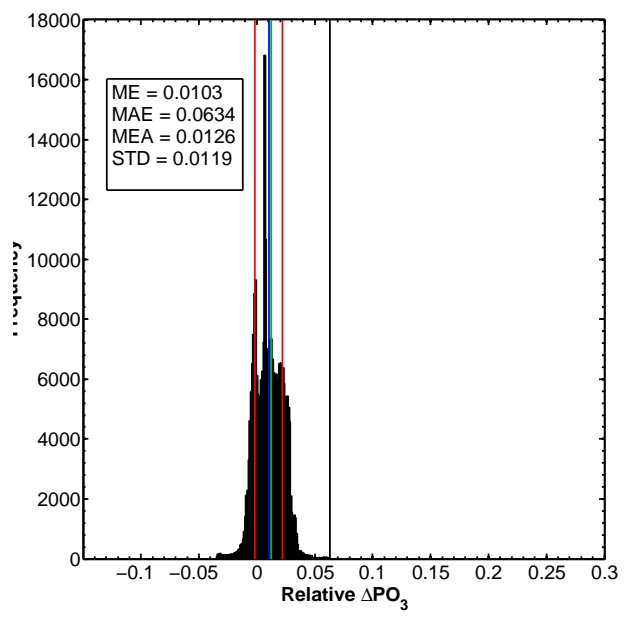

(d) 



\section{APÊNDICE E - DETERMINAÇÃO DA ESCALA DO FLUXO DE CALOR SIMULADO}

Devido às características do modelo FC mkII (e mkIII), não é possível obter superfícies de temperatura análogas às experimentais, dificultando a validação de uma aspecto importante do modelo. De modo a permitir uma comparação, mesmo que qualitativa, voltou-se para a análise do fluxo de calor simulado, esperando-se uma correlação entre as superfícies. Ainda assim, sendo grandezas diferentes, a comparação entre as superfícies de temperatura e de fluxo de calor integrado não é direta, principalmente devido ao fato que o fluxo de calor admite valores negativos, i.e. calor é tomado pelo sistema. Para transpor tal dificuldade, utilizaram-se os dados de temperatura do compartimento catódico experimentais para determinar uma escala de temperatura associado ao fluxo de calor total simulado, permitindo uma comparação direta com as superfícies de temperatura experimentais.

\section{E.1 Metodologia Computacional}

As superfícies de fluxo de calor integrado, $\mathbf{Q}_{\mathrm{xc}}$, foram obtidas conforme descrito na Seção 4.2.2.6, sendo que neste caso foram utilizados o fluxo de calor total:

$$
Q_{\mathrm{xc}}=\sum_{i, j} Q_{\mathrm{xc}_{i j}}
$$

para um dado valor de corrente total $I$. Os resultados experimentais utilizados foram as temperaturas do compartimento catódico, obtidos ao longo da curva de polarização (ver Seção 6.2.1.2), subtraída a temperatura imposta no dispositivo, $T_{0}=353 \mathrm{~K}$, resultando nos desvios de temperatura:

$$
\Delta T_{\text {cat }}=T_{\text {cat }}-T_{0}
$$

Para o ajuste entre as grandezas Delta $T_{\text {cat }}$ e $Q_{\mathrm{xc}}$, foram utilizados três modelos minimalistas, com perfis sigmoidais. O motivo de tal escolha se baseia, além do aspecto das curvas de temperatura, nas seguintes suposições: i) o desvio de temperatura é simétrico em relação à origem, i.e. $\Delta T_{\text {cat }}\left(-Q_{\mathrm{xc}}\right)=-\Delta T_{\text {cat }}\left(Q_{\mathrm{xc}}\right)$; e ii) o resfriamento do dispositivo é dado por difusão e convecção de calor, sendo que cada processo domina em regiões distintas de $\Delta T_{\text {cat }}\left(Q_{\text {xc }}\right)$. Portanto, no intervalo de $I$ e $Q_{\text {xc }}$ analisados, propõem-se uma variação inicial da temperatura devido à troca de calor com o ambiente devido à difusão. Em seguida a convecção natural emergente da diferença de temperatura, para maiores valores de $Q_{\mathrm{xc}}$, tende a manter a temperatura aproximadamente constante, trocando calor com o ambiente de maneira mais eficiente. Deve-se notar que, seguindo tal raciocínio, um 
novo aumento de $\left|\Delta T_{\text {cat }}\right|$ deve ser observado para valores mais altos de $\left|Q_{\text {xc }}\right|$. Tal efeito não é capturado nos modelos descritos a seguir, mas pode ser incorporado futuramente se necessário.

Os modelos utilizados contém dois parâmetros, $a$ e $b$, com unidades de $\mathrm{K} \mathrm{e} \mathrm{W}^{-1}$, respectivamente, e são dados por:

$$
\begin{aligned}
& \Delta T_{\mathrm{cat}}^{(1)}=a^{(1)} \operatorname{erf}\left(b^{(1)} Q_{\mathrm{xc}}\right) \\
& \Delta T_{\mathrm{cat}}^{(2)}=a^{(2)} \operatorname{atan}\left(b^{(2)} Q_{\mathrm{xc}}\right) \\
& \Delta T_{\mathrm{cat}}^{(3)}=a^{(3)} \tanh \left(b^{(3)} Q_{\mathrm{xc}}\right)
\end{aligned}
$$

onde erf, atan e tanh são as funções erro, arco tangente e tangente hiperbólica, respectivamente. As regressões foram realizadas utilizando a rotina NonLinearModel.fit, com valores iniciais de $0,2 \mathrm{~K}$ e $1 \mathrm{~W}^{-1}$ para $a$ e $b$ respectivamente.

\section{E.2 Resultados}

A Figura 74 apresenta os dados experimentais de $\Delta T_{\text {cat }}$ em função dos valores de $Q_{\mathrm{xc}}$ simulados, juntamente com as curvas resultantes das regressões não-lineares utilizando os modelos descritos acima, e os resíduos para cada modelos. A Tabela 22 apresenta os resultados das regressões. Como é possível observar na Fig. 74, os três modelos reproduzem adequadamente o comportamento ao longo de toda a curva, incluindo os resultados para $\Delta T_{\text {cat }}$ e $Q_{\text {xc }}$ menores que zero. Isso é ressaltado nos resíduos, que apresentam uma distribuição aparentemente uniforme em torno de zero, sendo que, em todos os casos, o desvio em relação à média dos resultados experimentais contempla o valor nulo de resíduo. Considerando os resultados estatísticos, nota-se que os valores de ME são relativamente baixos, na ordem de $6 \times 10^{-2}$ da média dos valores experimentais, enquanto os valores de MAE são relativamente altos, na ordem de $44 \times 10^{-2}$. Os valores de $R$ são relativamente altos, considerando a dispersão nas regiões próximas da origem, e indicam boa correlação linear entre o modelo e resultados experimentais. A escolha do melhor modelo recai à incerteza nos coeficientes, dado que os valores de ME e MEA estão dentro da incerteza experimental, $10^{-2} \mathrm{~K}$, e os valores de $\mathrm{R}$ são muito próximos entre os modelos. Pelos valores dados na Tab. 22, o modelo da Eq. E.3 possui a menor incerteza nos coeficientes, sendo de $10,76 \%$ e $21,37 \%$ para $a$ e $b$ respectivamente.

De maneira a assegurar-se da escolha, e da boa robustez dos modelos, uma nova análise foi feita removendo-se os dados do conjunto de vazões I, que contempla a região próxima da origem, e apresenta grandes incertezas nos valores de $\Delta T_{\text {cat }}$. A Figura 75 apresenta as curvas de $\Delta T_{\text {cat }}\left(Q_{\mathrm{xc}}\right)$ e os resíduos para este novo conjunto de dados, enquanto a Tab. 22 apresenta os resultados das regressões não-lineares. A concordância mantém-se adequada, reproduzindo todas as regiões da curvas de maneira apropriada. Os valores de ME apresentaram pouca diferença, mantendo-se na ordem de $10^{-2}$ dos valores experimentais, 
Figura 74 - Desvio de temperatura catódica em relação à $T_{0}(\times)$ em função do fluxo total de calor

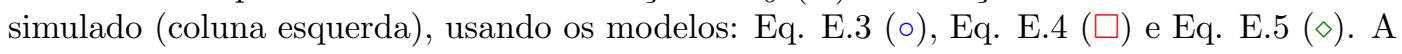
coluna direita apresenta os resíduos dos respectivos modelos, sendo que a linha sólida preta indica resíduo igual a zero. As barras de erro representam um desvio em relação à média experimental.

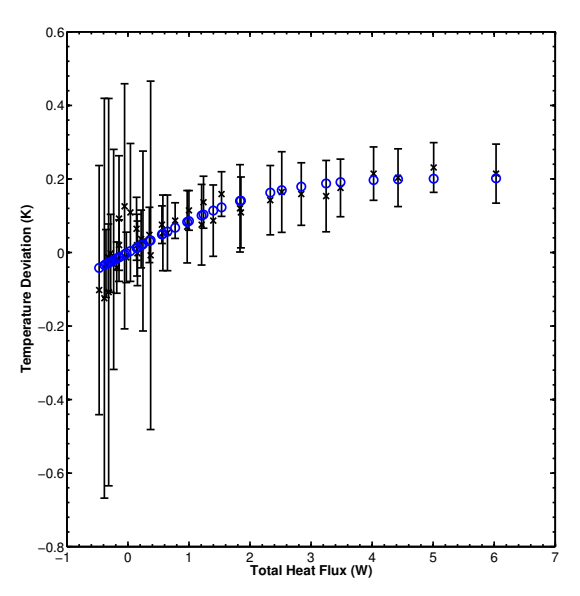

(a)

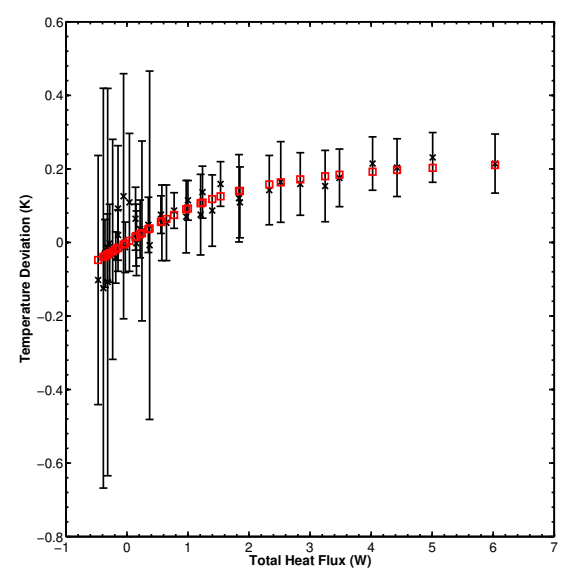

(c)

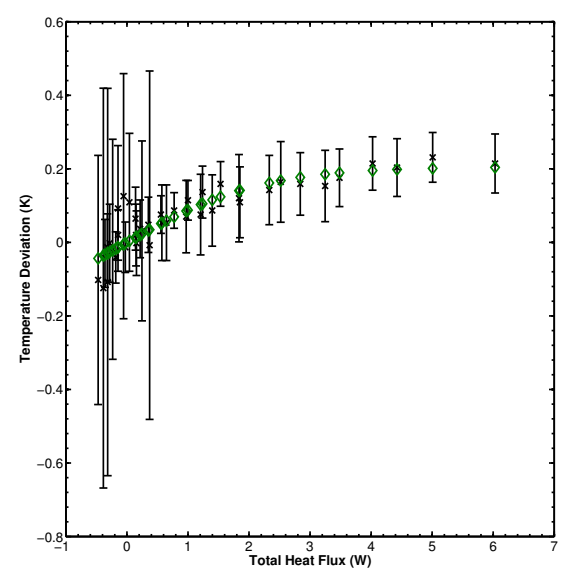

(e)

Fonte: Autoria própria.

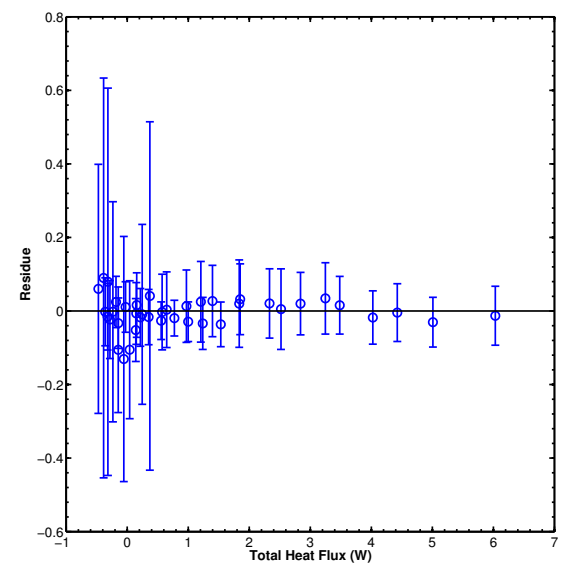

(b)

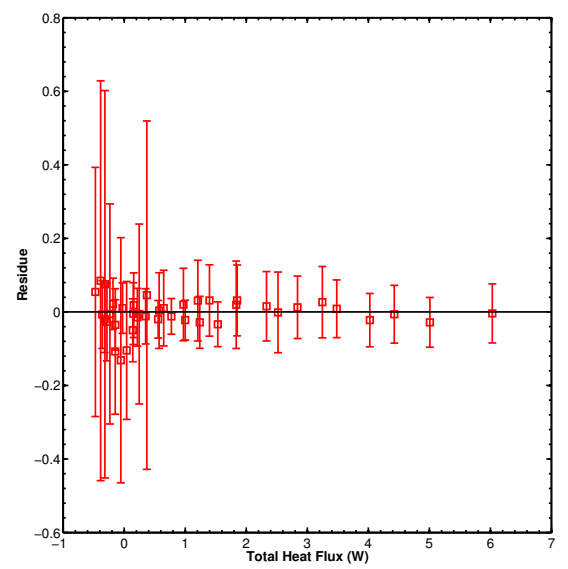

(d)

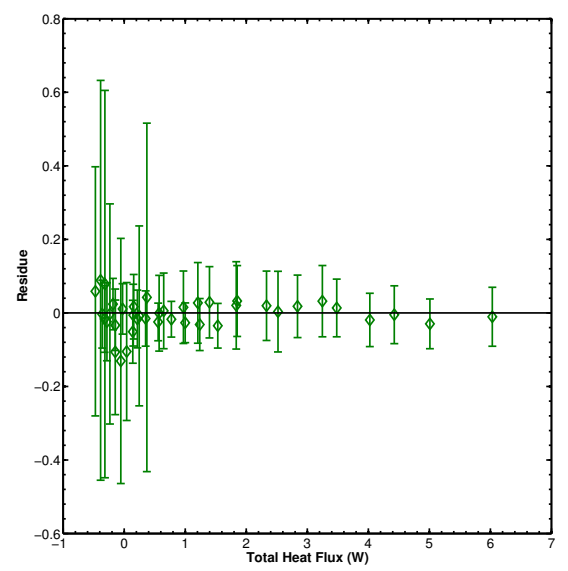

(f) 
Tabela 22 - Coeficientes e resultados estatísticos das regressões não-lineares da variação da temperatura catódica experimental em função do fluxo total de calor simulado.

\begin{tabular}{cccccc}
\hline \multirow{2}{*}{ Modelo } & \multicolumn{2}{c}{ Coeficientes } & \multirow{2}{*}{ ME $(\mathrm{mK})$} & \multirow{2}{*}{ MAE $(\mathrm{mK})$} & \multirow{2}{*}{$\mathbf{R}$} \\
\hline Eq. E.3 & $0,2018 \pm 0,02172$ & $0,3945 \pm 0,08429$ & $-4,7$ & 31,0 & 0,8746 \\
Eq. E.4 & $0,1591 \pm 0,02271$ & $0,6553 \pm 0,1941$ & $-4,4$ & 29,8 & 0,8796 \\
Eq. E.5 & $0,2056 \pm 0,02355$ & $0,4549 \pm 0,1054$ & $-4,5$ & 30,6 & 0,8762 \\
& & & & & \\
\hline & & & & & \\
Eq. E.3 & $0,2086 \pm 0,01232$ & $0,3524 \pm 0,04008$ & $-3,8$ & 18,0 & 0,9640 \\
Eq. E.4 & $0,1697 \pm 0,01321$ & $0,5507 \pm 0,08514$ & $-3,0$ & 17,2 & 0,9675 \\
Eq. E.5 & $0,2138 \pm 0,01340$ & $0,4018 \pm 0,04929$ & $-3,5$ & 17,7 & 0,9652 \\
\hline
\end{tabular}

Nota: A segunda seção refere-se à regressão excluindo-se o conjunto I.

Fonte: Autoria própria.

enquanto os valores de MAE apresentaram uma diminuição significativa, para $\approx 25 \times 10^{-2}$. Os valores de $\mathrm{R}$ apresentam um aumento também significativo, para $>0,96$, porém mantendo a boa concordância entre os modelos. Assim, mais uma vez, a escolha do melhor modelo para reproduzir os resultados de $\Delta T_{\text {cat }}$ recai sobre os coeficientes. Em primeiro lugar, nota-se que os valores pouco mudaram entre os dois conjuntos, o que sugere certa robustez para a forma escolhida para os modelos. Em segundo lugar, nota-se uma redução da incerteza relativa para ambos coeficientes, em particular para $b$, em um fator de $\approx 2$. Analisando a incerteza relativa, o melhor modelo, segundo este critério, permanece sendo o modelo da Eq. E.3:

$$
\Delta T_{\text {cat }}\left(Q_{\mathrm{xc}}\right)=0,2086 \times \operatorname{erf}\left(0,3524 \times Q_{\mathrm{xc}}\right)
$$

com incertezas relativas nos coeficientes $a$ e $b$ de $5,91 \%$ e $11,4 \%$, respectivamente. 
Figura 75 - Desvio de temperatura catódica em relação à $T_{0}(\times)$ em função do fluxo total de calor

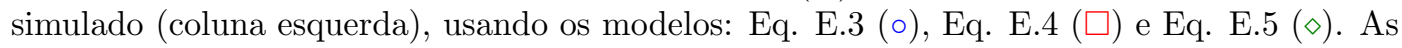
regressões foram realizadas desconsiderando os valores de $\Delta T_{\text {cat }}$ do conjunto de vazões I. A coluna direita apresenta os resíduos dos respectivos modelos, sendo que a linha sólida preta indica resíduo igual a zero. As barras de erro representam um desvio em relação à média experimental.

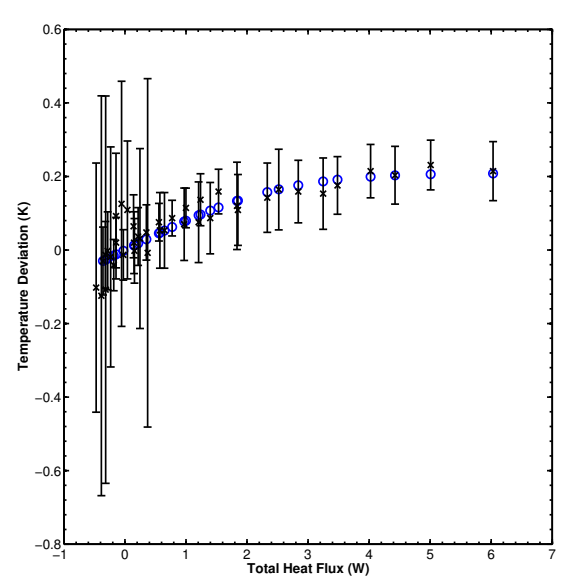

(a)

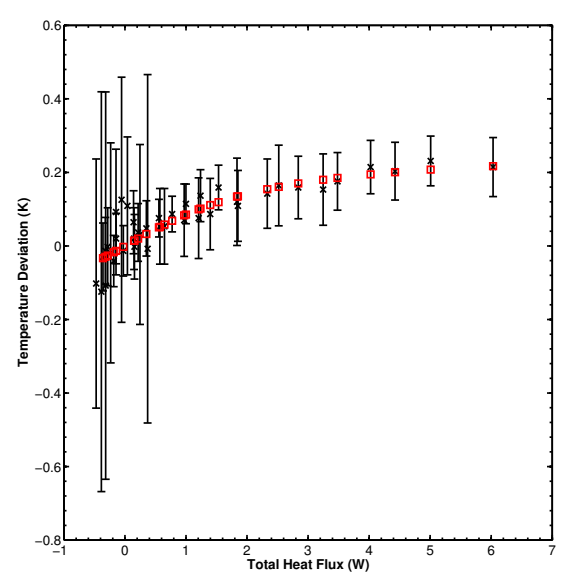

(c)

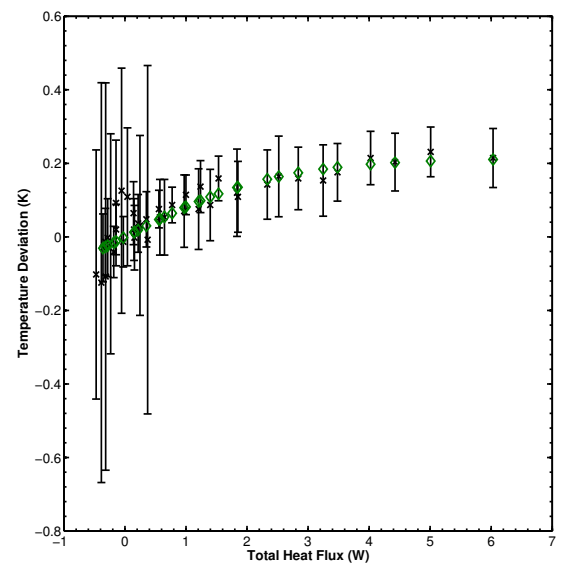

(e)

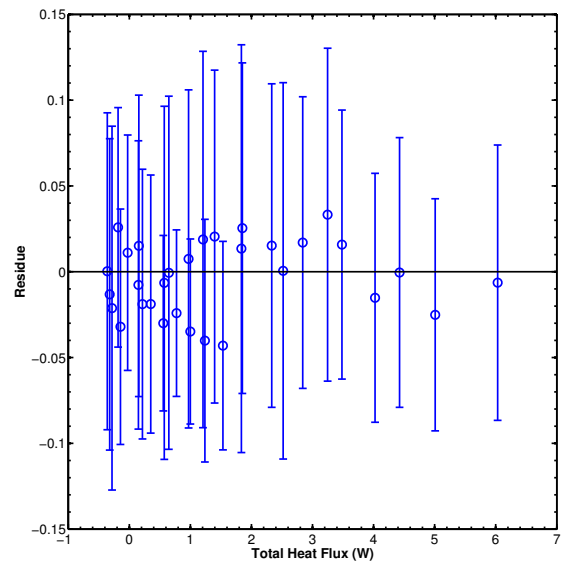

(b)

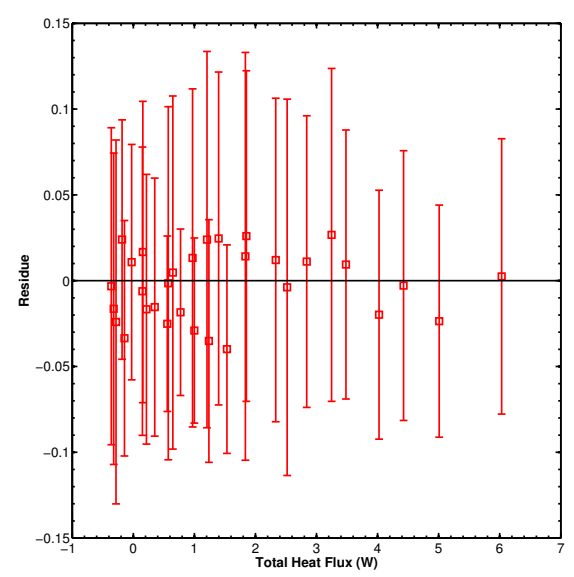

(d)

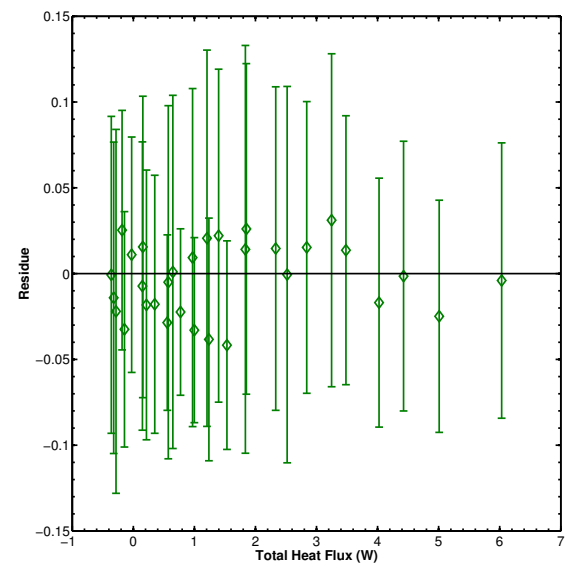

(f)

Fonte: Autoria própria. 



\section{ANEXO A - DISTRIBUIÇÕES DE CORRENTE LINEARIZADAS}


Figura 76 - Distribuições de corrente linearizadas computacionais, para os conjunto de vazões I (o), II $(\square)$, III $(\triangle)$ e IV $(\diamond)$; e os respectivos valores experimentais $(\times \mathrm{e} \times)$. Os valores de corrente relativa são dados no título de cada gráfico. As barras de erro nos resultados experimentais representam um desvio em relação à média.
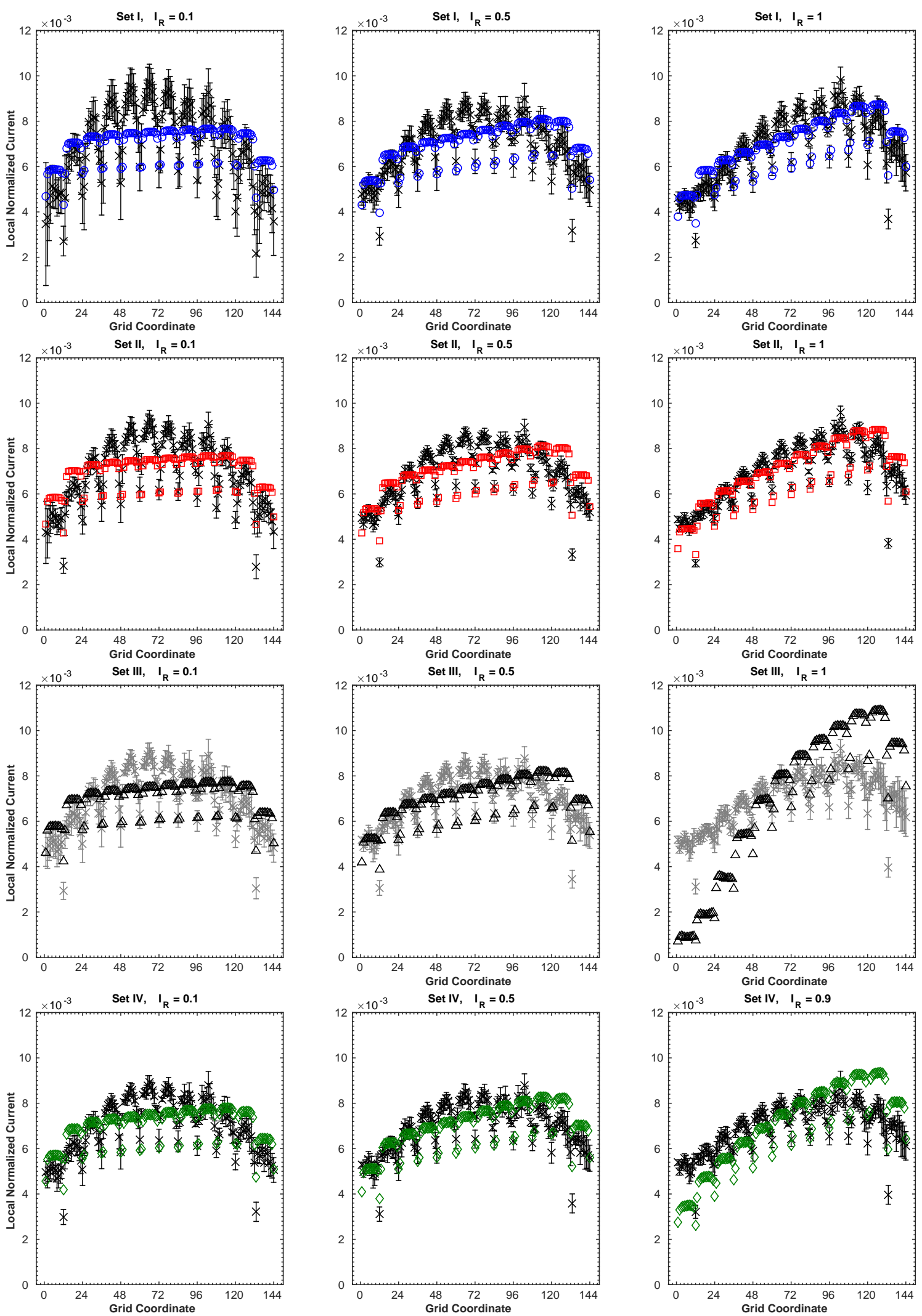

Fonte: Autoria própria. 
Figura 77 - Resíduo normalizado para distribuições de corrente, para os conjunto de vazões I $(\times)$, II $(\times)$, III $(\times)$ e IV $(\times)$. Os valores de corrente relativa são dados no título de cada gráfico. As barras de erro representam um desvio experimental, normalizados pelo respectivo valor simulado. A linha contínua preta indica $\Delta_{\text {res }} I=0$, enquanto as linhas tracejadas indicam o limite relativo de convergência do modelo, $10^{-2}$.
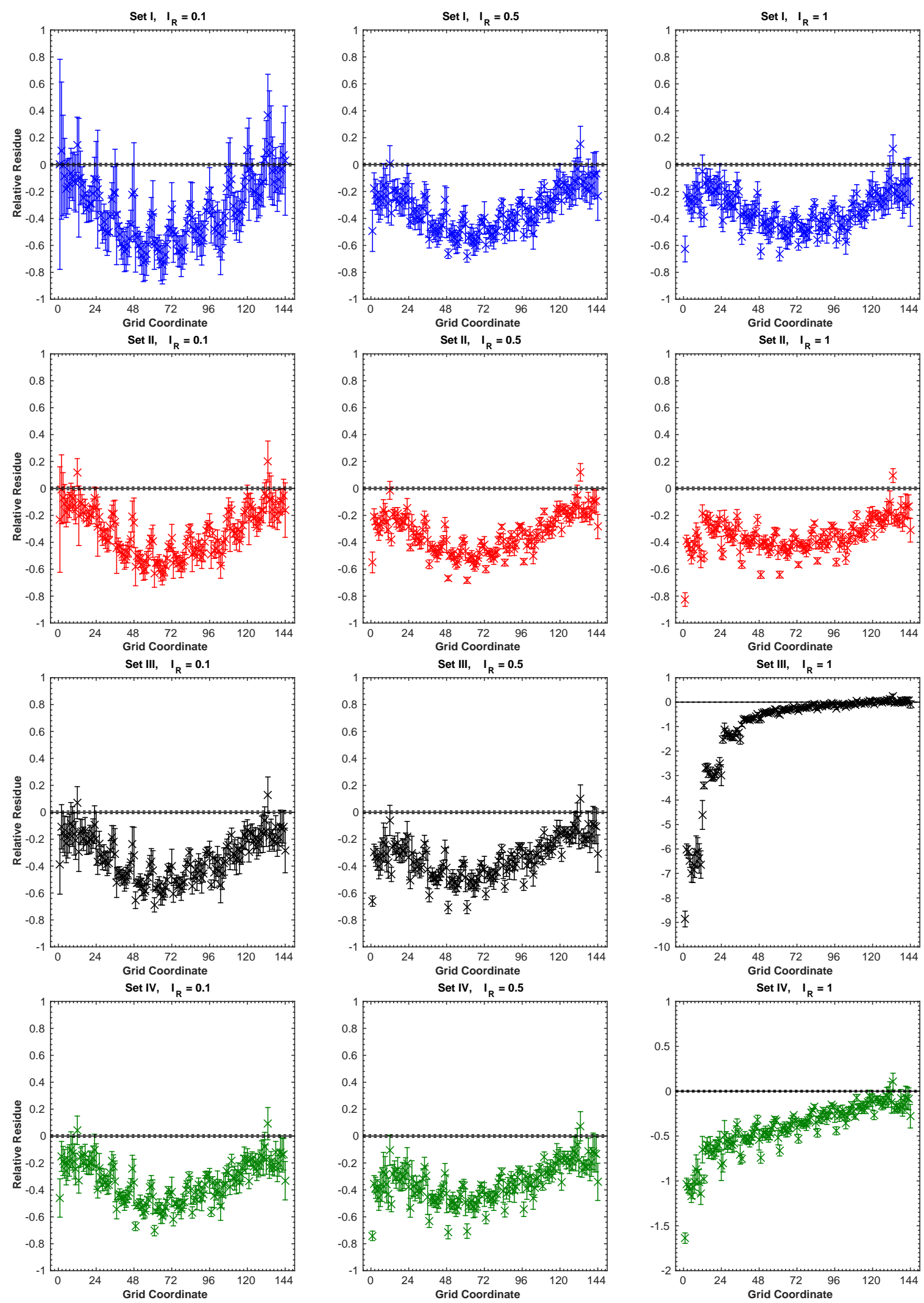

Fonte: Autoria própria. 



\section{ANEXO B - DISTRIBUIÇÕES DE TEMPERATURA LINEARIZADAS}


Figura 78 - Distribuições de desvios de temperatura linearizadas computacionais, para os conjunto de vazões I $(\circ)$, II $(\square)$, III $(\triangle)$ e IV $(\diamond)$; e os respectivos valores experimentais $(\times$ e $\times)$. Os valores de corrente relativa são dados no título de cada gráfico. As barras de erro nos resultados experimentais representam um desvio em relação à média.
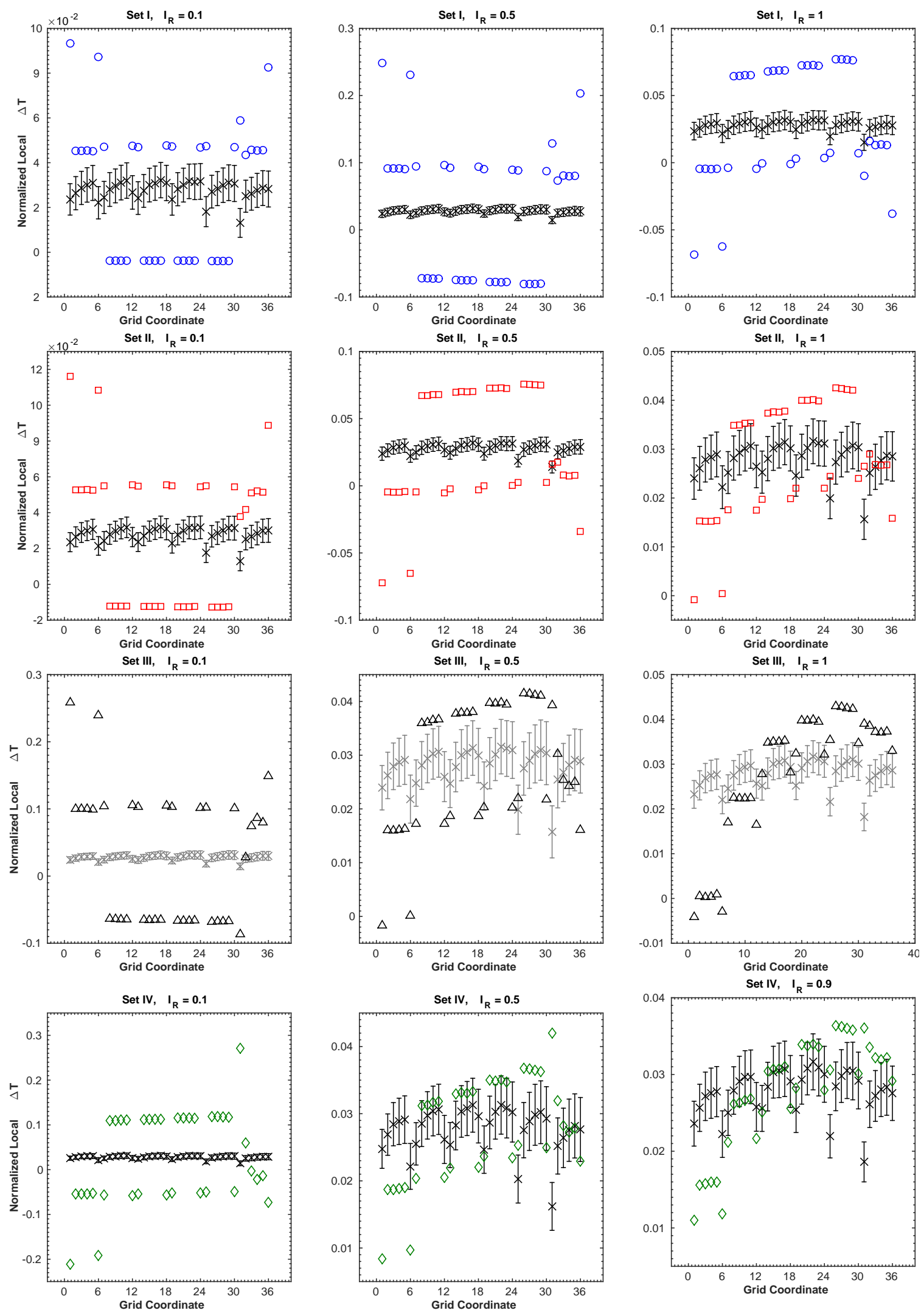

Fonte: Autoria própria. 